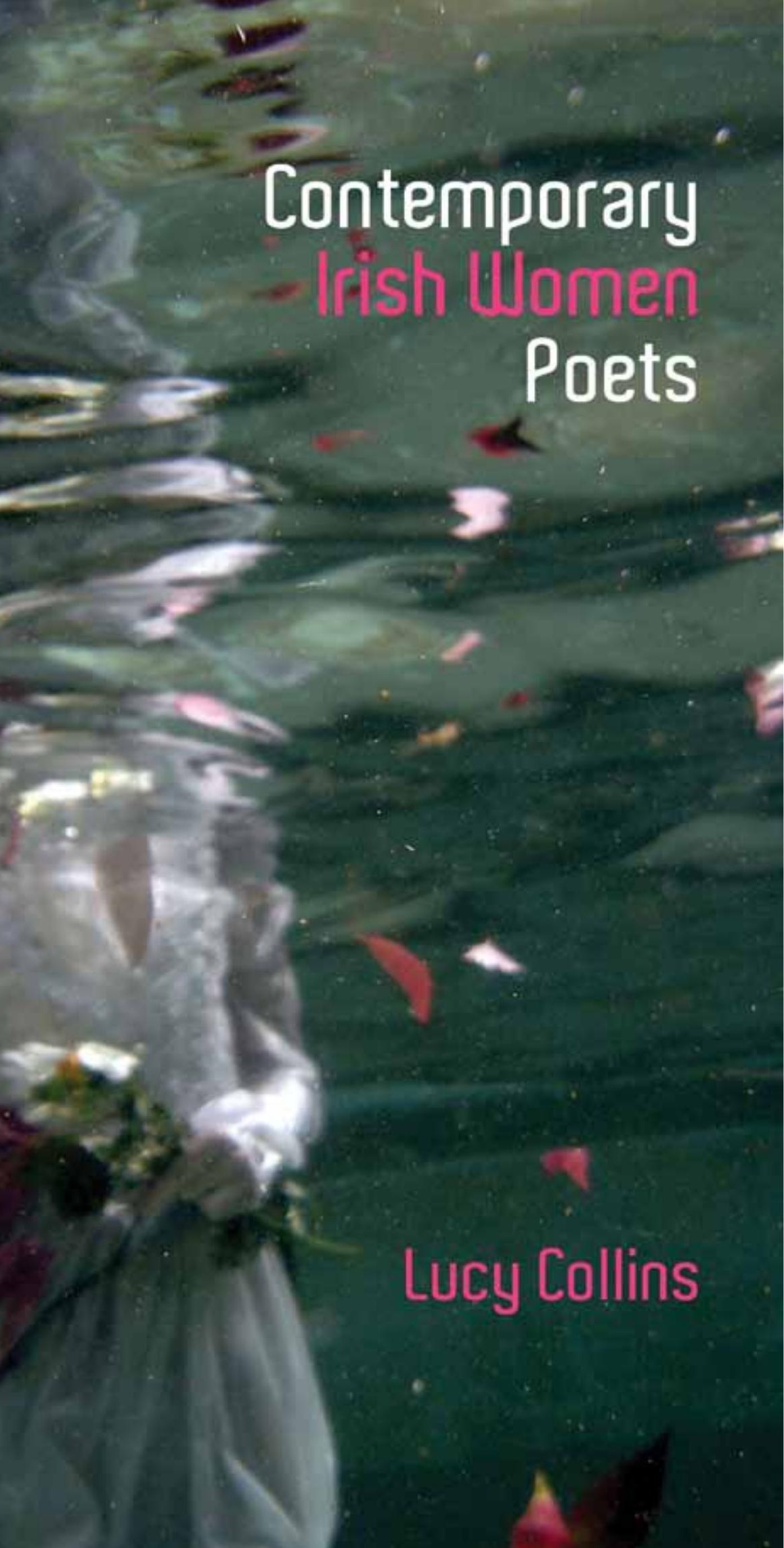





\title{
CONTEMPORARY IRISH WOMEN POETS
}

MEMORY AND ESTRANGEMENT

\author{
LUCY COLLINS
}


First published 2015 by

Liverpool University Press

4 Cambridge Street

Liverpool

L69 7ZU

Copyright (C 2015 Lucy Collins

The right of Lucy Collins to be identified as the author of this work has been asserted by her in accordance with the Copyright, Designs and Patents Act 1988.

All rights reserved. No part of this book may be reproduced, stored in a retrieval system, or transmitted, in any form or by any means, electronic, mechanical, photocopying, recording, or otherwise, without the prior written permission of the publisher.

British Library Cataloguing-in-Publication data

A British Library CIP record is available

print ISBN 978-1-78138-187-8 cased

epdf ISBN 978-1-78138-469-5

Typeset by Carnegie Book Production, Lancaster

Printed and bound by CPI Group (UK) Ltd, Croydon CR0 4YY 
For Andrew 



\section{Contents}

Acknowledgements $\quad$ ix

Abbreviations $\quad$ xi

Introduction: Memory, Estrangement and the Poetic Text I

\section{Concepts}

Chapter I Lost Lands: The Creation of Memory in the Poetry of Eavan Boland

Chapter 2 Between Here and There: Migrant Identities and the Contemporary Irish Woman Poet

Chapter 3 Private Memory and the Construction of Subjectivity in Contemporary Irish Women's Poetry

\section{Achievements}

Chapter 4 Eiléan Ní Chuilleanáin's Spaces of Memory

Chapter 5 Medbh McGuckian's Radical Temporalities

Chapter 6 Catherine Walsh: A Poetics of Flux

Chapter 7 Vona Groarke: Memory and Materiality

Conclusion: Memories of the Future

Bibliography

Index 



\section{Acknowledgements}

This book has been the product of a long period of reading and thinking about contemporary women poets and I would like to thank those who have supported this project. I am grateful to the following libraries for access to materials: the British Library, the National Library of Ireland, Trinity College Library and University College Dublin Library. Thanks to my colleagues at University College Dublin for their comradeship and encouragement, especially John Brannigan, Danielle Clarke, Sharae Deckard, Fionnuala Dillane, Anne Fogarty, Jane Grogan, Margaret Kelleher, Gerardine Meaney and Tony Roche. Emilie Pine's work in the field of Irish Memory Studies has been an inspiration and this book has benefited greatly from her initiatives. To Catriona Clutterbuck I owe a particular debt of gratitude for her interest in all things poetic and for her generosity. Other friends and colleagues both in Ireland and abroad have spurred me on: Rebecca Barr, Matthew Campbell, Patricia Coughlan, Alex Davis, Gerald Dawe, Eric Falci, Borbála Faragó, Luz Mar González-Arias, Neil Hegarty, Peter Kuch, Lucy McDiarmid, Jody Allen Randolph, Hedwig Schwall, Moynagh Sullivan and James Woolley. I am grateful to colleagues at UCD Library and Special Collections for their work with the Poetry@UCD initiative, especially Ursula Byrne, Evelyn Flanagan and Eugene Roche. My students, past and present, test my ideas on poetry. I would like particularly to thank recent and current graduate students Jaclyn Allen, Amanda Bell, Paola Benchi, Colleen English, Ken Keating, Aoife Lynch and Jacqui Meisel for their enthusiasm and conversation. At Liverpool University Press, Anthony Cond and his team have been very supportive of the project and the readers of the initial manuscript offered many insights and suggestions from which the book has benefited. Thanks to Rachel Adamson and Lucy Frontani at Carnegie Book Production for their attention to production and design; I'm especially grateful to Irene Barry for permission to use her work on the cover of this book. My greatest 
debts are to my family - to my father and my sisters for their interest and support, as well as their patience. Andrew Carpenter has, as usual, worked harder than anyone to bring my scholarly planets into alignment. This book is dedicated to him.

Earlier versions of some sections in this book have appeared as: 'A Way of Going Back: Memory and Estrangement in the Poetry of Paula Meehan', An Sionnach: A Journal of Literature, Culture and the Arts 5.I-2 (Spring/Fall 2009), pp. I27-39; 'Joyful Mysteries: Language and Spirituality in Medbh McGuckian's Recent Poetry', in Elke d'Hoker, Raphaël Ingelbien and Hedwig Schwall (eds), Irish Women's Writing (Berne: Peter Lang, 2010), pp. 4I-56; 'What She Lost and How: Eavan Boland's London Childhood', in Thomas Herron (ed.), Irish Writing London, vol. 2, Post-War to the Present (London: Continuum, 2012), pp. 33-46; and 'Being in Span: The Space of the Subject in Catherine Walsh's City West', Journal of British and Irish Innovative Poetry 5.2 (20I4), pp. 3I-46.

For permission to quote the work of these poets, thanks are due to the following publishers: Carcanet Press for permission to quote from the work of Eavan Boland, Paula Meehan, Sinéad Morrissey and Mary O'Malley. Dedalus Press for permission to quote from the work of Eva Bourke. Gallery Press for permission to quote from the work of Sara Berkeley, Eiléan Ní Chuilleanáin, Vona Groake, Medbh McGuckian and Paula Meehan. Pan Macmillan for permission to quote from the work of Colette Bryce. Random House for permission to quote from the work of Leontia Flynn. Invisible Books and Shearsman Press for permission to quote from the work of Catherine Walsh. Wild Honey Press, Publishing Genius and Miami University Press for permission to quote from the work of Mairéad Byrne. W. W. Norton and Company for permission to quote from the work of Eavan Boland. 


\section{Abbreviations}

BA Medbh McGuckian, The Book of the Angel (Oldcastle, Co. Meath: Gallery Press, 2004)

BH Mary O'Malley, The Boning Hall: New and Selected Poems (Manchester: Carcanet, 2002)

BHT Sinéad Morrissey, Between Here and There (Manchester:

Carcanet, 2002)

BLH Mairéad Byrne, The Best of (What's Left of) Heaven

(Baltimore, MD: Publishing Genius, 20IO)

CL Medbh McGuckian, Captain Lavender (Oldcastle, Co.

Meath: Gallery Press, I995)

CW Catherine Walsh, City West (Exeter: Shearsman, 2005)

$D \quad$ Paula Meehan, Dharmakaya (Manchester: Carcanet, 2000)

$D R \quad$ Leontia Flynn, Drives (London: Jonathan Cape, 2008)

F Vona Groarke, Flight (Oldcastle, Co. Meath: Gallery Press, 2002)

FE Medbh McGuckian, The Face of the Earth (Oldcastle, Co. Meath: Gallery Press, 2002)

FM Medbh McGuckian, The Flower Master (Oxford: Oxford University Press, I982; Oldcastle, Co. Meath: Gallery Press, I993)

FRT Colette Bryce, The Full Indian Rope Trick (London: Picador, 2005)

$H B$ Colette Bryce, The Heel of Bernadette (London: Picador, 2000)

HTL Medbh McGuckian, Had I a Thousand Lives (Oldcastle, Co. Meath: Gallery Press, 2002)

IEMT Catherine Walsh, Idir Eatortha and Making Tents (London: Invisible Books, 1996) 
J Eavan Boland, The Journey and Other Poems (Galway: Arlen House, 1986; Manchester: Carcanet, 1987)

JS Vona Groarke, Juniper Street (Oldcastle, Co. Meath: Gallery Press, 2006)

KW Mary O'Malley, The Knife on the Wave (Galway: Salmon Press, 1997)

MMW Paula Meehan, The Man Who Was Marked by Winter

(Oldcastle, Co. Meath: Gallery Press, I99I)

MR Leanne O'Sullivan, The Mining Road (Tarset,

Northumberland: Bloodaxe Books, 2013)

MSCM Mary Dorcey, Moving into the Space Cleared by Our Mothers (Galway: Salmon Press, 199I)

NHB Mairéad Byrne, Nelson and the Huruburu Bird (Bray, Co. Wicklow: Wild Honey Press, 2003)

OPH Vona Groarke, Other People's Houses (Oldcastle, Co. Meath: Gallery Press, 1999)

$P \quad$ Eva Bourke, Piano (Dublin: Dedalus Press, 20II)

PR Paula Meehan, Painting Rain (Manchester: Carcanet, 20I2)

PT Paula Meehan, Pillow Talk (Oldcastle, Co. Meath: Gallery Press, 1994)

PX Sinéad Morrissey, Parallax (Manchester: Carcanet, 2013)

$S \quad$ Medbh McGuckian, Shelmalier (Oldcastle, Co. Meath: Gallery Press, 1998)

SD Vona Groarke, Spindrift (Oldcastle, Co. Meath: Gallery Press, 2009)

SH Vona Groarke, Shale (Oldcastle, Co. Meath: Gallery Press, 1994)

SPD Colette Bryce, Self-Portrait in the Dark (London: Picador, 2008)

ST Sara Berkeley, Strawberry Thief (Oldcastle, Co. Meath: Gallery Press, 2005)

SV Eiléan Ní Chuilleanáin, The Second Voyage (Dublin: Gallery Press, 1986)

TFV Sinéad Morrissey, There was Fire in Vancouver (Manchester: Carcanet, 1996)

TG Eva Bourke, Travels with Gandolpho (Dublin: Dedalus Press, 2000)

TP Mairéad Byrne, Talk Poetry (Oxford, OH: Miami University Press, 2007) 
TV Eavan Boland, In a Time of Violence (Manchester: Carcanet, 1994)

$V \quad$ Mary O'Malley, Valparaiso (Manchester: Carcanet, 20I2)

VH Sara Berkeley, The View from Here (Oldcastle, Co. Meath: Gallery Press, 2010)

VR Medbh McGuckian, Venus and the Rain (Oxford: Oxford University Press, 1984; Oldcastle, Co. Meath: Gallery Press, 1994)

VWE Paddy Bushe (ed.), Voices at the World's Edge: Irish Poets on Skellig Michael (Dublin: Dedalus Press, 20IO)

WRU Colette Bryce, The Whole and Rain-domed Universe (London: Picador, 20I4)

$X \quad$ Vona Groarke, $X$ (Oldcastle, Co. Meath: Gallery Press, 20I4) 



\title{
Introduction
}

\author{
Memory, Estrangement \\ and the Poetic Text
}

For Irish women poets, past and present exist in thematic and aesthetic alignment, making their treatment of memory of enduring importance to readers. Since the process of remembrance reveals as much about present needs as it does about past events, its conceptualization in the work of women poets reflects contemporary critical debate, as well as issues around the formation of Irish poetic traditions. In this way, to remember is to engage with a process of cultural evolution, perhaps even more than with calculated political change: 'Images of the past change or remain the same [...] to the degree that they fit into a changing or stable culture, a process that calls our attention away from cynical manipulations to an analysis of culture sui generis.' ${ }^{1}$ This study of contemporary women poets explores the function of memory in their work, examining the impact that both individual and cultural memory has on their creative processes. Their handling of poetic temporalities is of fundamental importance in exploring, whether obliquely or directly, their place in the tradition. All these women acknowledge poetic precursors and their work engages with earlier poems - their own and the work of others - in ways that constitute acts of textual memory. In this sense the book also considers the broader temporal framework within which the poetry must be read, in both political and aesthetic terms. Literary memory prompts exploration of the relationship between poet and reader, as well as of the larger critical contexts that support and impede the production of creative work. This study is concerned with issues of tradition and innovation as well as with the negotiation of public and private roles for these poets. 
From these binary states emerge questions of belonging and estrangement which continue to shape women's perceptions of their relationship to Ireland's culture and its languages. The generation of Irish women who began to publish in the 1960s were the first to attract a wide readership both in Ireland and abroad yet their work remains alert to marginal states, to the silences at the edge of tradition. In their poetry the relationship between self and other is frequently interrogated, highlighting not only the place of the poetic subject but the process by which subjectivity itself is expressed in language. Julia Kristeva sees art, religion and psychoanalysis as the three main ways in which we try to understand our encounter with the other, but poetry is another important form through which ideas of the strange can be explored. ${ }^{2}$ By challenging unitary perspectives, many of these poets confront their readers with an experience of estrangement that simultaneously probes cultural exclusion and emphasizes the incongruity of language itself. In this way, the dynamics of private and public remains at the heart of the poetry explored here.

The development of memory studies in the Irish context has drawn attention to the relationship between individual and shared versions of the past, and this difference has significance for the ways in which literary tradition is perceived, especially by groups who have not had an established role to play in these debates. Increasingly we come to view our engagement with the past through the lens of memory. For Barbara Misztal, since the end of the cold war there has been:

a newly important politics of identity, which proclaims memory as the basis of the collective identity of a community and sees memory as a resource for the construction and defence of cultural identities. Memory is used strategically: not merely to explain the group past but also to transform it into a reliable identity source for the group present. ${ }^{3}$

From an academic perspective, Memory Studies has brought the disciplines of history, politics, literature, art history and sociology into close proximity, as well as interrogating the relationship between scholarly approaches in the sciences and humanities. More recently, scholars of Irish history and culture have found this field to offer useful ways of engaging with the continued importance of the past in contemporary Irish cultural and political life. The Irish Memory Studies Network, founded by Emilie Pine, has fostered debate in the field among Irish and international scholars and arts practitioners. Memory Ireland, a four-volume collection of essays edited by Oona Frawley, also 
demonstrates the broad spectrum of scholarly interest in this area, as well as highlighting the significance of key historical moments in the formation of modern Irish memory. ${ }^{4}$

This study of contemporary Irish women poets does not posit the direct intervention of poets in these debates. Instead, it explores their continuous engagement with the processes of remembering, both individually and collectively, in their work. Their attention to the moral, political and aesthetic dimensions of past, present and future overtly and implicitly critiques received versions of history as well as problematizing simplified acts of remembrance. As Charles Maier has recently argued, the current interest in memory studies is not evidence of historical confidence but rather of a retreat from transformative politics, a concern to mediate the present through reflection on the past. ${ }^{5}$ For contemporary women poets this means that the role of memory acquires political significance, given the uneasy relationship between women's place in Irish history and their current position in literary culture. The period from 1980 has seen a significant rise in the publication and reading of poetry by women and a corresponding evolution of styles and themes in their work. Although the most important sources for the study of cultural memory have historically been letters and diaries, literary texts offer specific insights into the how cultural memory is produced and understood. ${ }^{6}$ In light of the evolving role for women in Irish culture, their poetic mediation of the past is of considerable significance. It has also deepened our scrutiny of the relationship between the politics of writing and its forms.

The concept of memory has come to indicate a wide range of applications - as Geoffrey Cubitt notes, "Memory" may be mental or physical, natural or artificial, conscious or unconscious, individual or social: it may be embodied in animal instinct, or in cultural programming, or in electronic systems.' ${ }^{7}$ Mieke Bal has gone on to define memory as a 'travelling concept', one that moves between disciplines and periods as well as between geographical locations; definitions of memory are further extended by these different applications. ${ }^{8}$ This breadth of inference can create critical problems: in this book the application of memory acknowledges its relevance for the individual as well as the group and considers its function in contexts beyond the island of Ireland. Yet the treatment of memory here remains firmly grounded in its relevance to literary production, as well as its specific potential to extend our engagement with and understanding of poetic texts. The first part of this study explores some of the key ways in which poetry's relationship to the past has been mediated by women poets. Eavan 
Boland is a key figure in this respect and the opening chapter is devoted to an exploration of the dynamics of personal and cultural memory in her work. Her interrogation of the place of the woman poet in the Irish literary tradition has set the terms for these debates in recent decades and has proved foundational to the study of gender and Irish poetry. These issues of identity and tradition are also relevant to the study of migrant poets, whose mobility challenges our sense of a unified literary tradition. Women poets born in Ireland but living abroad, together with those who have moved to the country from elsewhere, have extended our sense of the poetic past in important ways. Their work, explored in Chapter 2 of this book, raises key questions concerning the unifying function of memory. Next the role of private memory in constructing subjectivity, and in changing the relationship between self and other, is explored. For many poets the traumatic past is shown to link personal and collective experience in key ways, so the debates in this chapter have an important resonance for the study as a whole. In the second part of the book, four individual poets are explored in detail. Here there is a growing emphasis on the relationship between memory and aesthetic judgment in the works of these poets, and the extent to which the textual past shapes their current practice is of central importance. This trajectory demonstrates the necessity for examining individual responses to memory and estrangement, as well as considering the shared dynamics that these writers exhibit. The study as a whole confirms the importance of sustained close reading in exploring the unique and considered engagement of each poet with private and public pasts.

\section{Remembering Place}

In any study defined by concepts of a national tradition, attention is immediately drawn to the role of place and belonging in how identities are formed. The experience of space may be our first entry into temporality and, some have argued, our predominant means of remembering the world. 9 Both Maurice Halbwachs and Pierre Nora have signalled the importance of spatiality in the shaping of collective memory, and, for the individual too, place may prove inspiring or inhibiting to creative expression. Engagement with both public and private spaces is an important characteristic of work by contemporary Irish women poets. Some are explicitly identified with particular locations: Paula Meehan with Dublin; Mary O'Malley with Galway; Sinéad Morrissey with Belfast. Some draw creative sustenance from other cultures as does 
Eiléan Ní Chuilleanáin from Italy. These complex interrelationships indicate the importance both of imaginative freedom and of creative and critical space for the production of original work. The space of the Irish tradition has not always been hospitable to women and this feeling of estrangement has been recorded by many of those who feature in this book. ${ }^{10}$ Under these conditions, women found it difficult to be easily assimilated into groups or movements within the larger poetic tradition, leading them to emphasize their individuality, rather than their feeling of belonging. Even poets who identify with specific group identities can never be seen as simply representative but rather as individuals working within the compass of their own experience to explore more public roles.

Eavan Boland is the first poet of the older generation to draw repeated attention to the important relationship between place and writing. She uses memories of growing up in London and later New York as the experiential foundation for an enquiry into the concept of belonging, both personally and culturally, to a particular place. Boland's interrogation of the role of the woman poet in the Irish tradition is directly related to her engagement with the processes of memory and to her deepening awareness of the exclusions practised within Irish literary culture. Boland understands her experiences outside Ireland to be formative of her later stance on this issue; in other instances, too, the diaspora has clearly influenced the kinds of literature, in both form and theme, which have been - and continue to be - produced by Irish writers. For diasporic women writers the dynamics of exclusion are formative. The crossing of boundaries that bilingual poets and immigrant poets must enact fundamentally questions the relationship between self and other. Poets are confronted with the notion of the stranger within - with the extent to which their own creative self encompasses opposing perspectives.

Identity debates are also shaped, at least in part, by those who live or have lived - outside Ireland. Justin Quinn has noted the importance of childhood to these writers and problematizes the role of memory in retaining a connection to that earlier self. ${ }^{11}$ Women poets featured in this study respond to this issue through the evolution of their craft: Dublin-born Mairéad Byrne has lived in the USA for most of her adult life; for her the geographical move offered opportunities to extend her poetic practice beyond the lyrical into performance and electronic modes. Other poets have spent shorter periods abroad but their work has been shaped in important ways by the experience: Vona Groarke, Sinéad Morrissey and Catherine Walsh are just three poets whose work explores personal memories of other countries as well as the larger 
implications of this boundary-crossing for their creative process. All reflect on the heightened relationship between self and other that such experiences generate - Groarke and Morrissey by deploying different forms of poetic sequence to record the experience; Walsh by extending the inclusive shape of her experimental texts to facilitate a movement between geographical locations. All these poets reflect deeply on the relationship between individual and shared pasts and on the ways in which different cultures and new experiences may suggest familiarity as well as estrangement.

For other women the space of the past is shaped by the language question. Poets who have travelled to Britain or to America experience no linguistic barrier. However, for those spending time in non-Englishspeaking countries (such as Sinéad Morrissey in Japan), the journey is not only geographical but also linguistic. Likewise, poets born outside Ireland but making their home there must choose their creative language. Eva Bourke, for example, publishes originally in English though she carries with her the rich heritage of her upbringing in Germany. Though they are not the specific focus of examination here, Irish-language poets such as Nuala Ní Dhomhnaill and Celia de Fréine must also consider the past in relation to its linguistic expression. For these and other writers in Irish the importance of that language tradition in shaping the relationship between past and present draws attention to the role of folklore and myth in the Irish tradition. Cultural memory, then, is deeply implicated in the language in which the remembering is done.

\section{Memory and History}

The relationship between memory and history is a significant one and is often conceived in oppositional terms: a historiographical process entails a systematic examination of evidence in the pursuit of understanding, while memory remains subjective and loosely formed. The contrast can also be imagined in temporal terms - as material passes from living memory it becomes subject to archival process and historical study. Yet this transition is not an unproblematic one. Pierre Nora has argued that the archive is associated not with remembering but with forgetting: once the material has been deposited it can be eliminated from personal memory. ${ }^{12}$ In the same way, once the sites of memory become history, rather than part of living commemorative experience, they cease to be fully meaningful. For marginalized groups, such as women, this process 
is a significant one since it affirms the important role of intervention in the processes of cultural formation. ${ }^{13}$ It also marks a specific disjunction between the material of everyday life and that of narrative history - a division more profound in the experience of women than of men.

The complex relationship between remembering and forgetting reminds us of the contingent nature of memory practices. The importance of forgetting can also be demonstrated in the larger cultural arena, especially where the handling of traumatic political pasts is involved:

Every act of remembrance, whether individual or collective, necessarily involves selective, partial, or otherwise biased forms of forgetting [...] The problem which is posed does not take the form of a clear choice for either remembering or forgetting. Instead, we are faced with concrete choices about when, how and which events of the traumatic or guilty past will eventually be recalled and faced by individuals, community and state. ${ }^{14}$

In the Irish context there are a number of historical events that have been subject to this difficult dynamic of memory and forgetting. The Northern Irish Troubles is among the most recent, and prominent, of these. Much research has been done in this area - since it is within living memory there is ample opportunity for oral testimony as well as detailed documentation of events. This memory-work has been influenced by other models, such as South Africa's Truth and Reconciliation Commission, and takes account of the important role of individual as well as of collective memory. The important ways in which these two are intertwined is reflected in the work of poets who had direct experience of the Troubles, such as Medbh McGuckian, Sinéad Morrissey and Colette Bryce. Yet their poetry also demonstrates that the violence in the province did not affect everyone in the same way, or for the same duration. Each of these three women responds to the events in strikingly different ways, from McGuckian's explicit commemoration of earlier revolutionaries to Bryce's memories of childhood encounters with members of the British Army. Even when expressing states of collective consciousness, the poets acknowledge the importance of private perspectives on events of enduring historical importance.

The versions of the past that emerge from such situations of violence and trauma may be closely linked to the formation of the nation state and to its cultures of memory. Eberhard Bort has commented thus on the multi-layered purpose of the practices of remembrance: 'Commemorations may serve competing goals - to pay tribute to the dead, to console the bereaved, and to incorporate mourners' individual 
memories into a larger political discourse.'15 The last of these aims has been the most contentious, especially in its tendency to reduce the significance of individual experiences that may not serve this larger narrative. Women poets are especially attuned to the effects of exclusion from commemoration and, conversely, to the powerful impact that recognition - however belated - may have. ${ }^{16}$ Seamus Deane was a prescient critic of the commodification of Irish history ${ }^{17}$ while more recent work by Guy Beiner has explored the problematic intersection between contemporary political discourse and the public commemoration of Ireland's past. ${ }^{18}$ From the end of the nineteenth century the rise in nationalism demanded an increased emphasis on the concept of a shared history, including the deliberate elision of elements that would prove disruptive to idealized unity. The practice of popular commemoration was designed to enhance this development. ${ }^{19}$ As Eric Hobsbawm and Terence Ranger have argued, the legitimization of existing class structures in the face of a rising proletariat necessitated the invention of traditions that would emphasize a shared history. ${ }^{20}$ While Ian McBride has problematized any simplistic reading of this tendency, it helps to situate Irish state formation in a larger political context, and to see the place of women in this dynamic as historically determined, at least in part. ${ }^{21}$ It also sheds light on how the discipline of history intersects with the process of cultural formation, confirming Ernest Renan's contention that historical study poses a threat to nationality by revealing differences between shared memories and actual events. ${ }^{22}$

For women this process of elision has had serious consequences. As well as confronting the same difficulties as other citizens of the newly independent nation state, women faced a form of cultural marginalization that quickly became an integral part of Irish identity-in-process: 'Womanhood and Irishness are metaphors for one another', Eavan Boland would later declare, 'there are resonances of humiliation, oppression and silence in both of them'. ${ }^{23}$ Yet the relationship between political challenge and a politically engaged poetics is not a straightforward one. As Guinn Batten has pointed out, an emphasis on representation of the revolutionary spirit may prevent the actuality of revolution. ${ }^{24}$ For this reason there is little direct correlation between a feminist aesthetic and specific activism.

Boland's insistent return to the concept, as well as to the material, of history, signals its importance for the construction of female subjectivity among Ireland's writers. Boland detects a moral difference between the male-determined histories and the kind of history that women will 
write. Women, as they move from being objects within poems to being authors of poems themselves, raise questions of poetic motive and ethical direction. ${ }^{25}$ Gerardine Meaney takes this issue further:

Anxiety about one's fitness for a (masculine) role of authority, deriving from a history of defeat or helplessness, is assuaged by the assumption of sexual dominance.

Women in these conditions become guarantors of their men's status, bearers of national honour and the scapegoats of national identity. They are not merely transformed into symbols of the nation. They become the territory over which power is exercised. ${ }^{26}$

As this comment reveals, the woman writer must renegotiate her position within the national imaginary with care. Perhaps for this reason Boland's poetry is more responsive than her prose to the ambiguities of this dialogue. As her poem 'Outside History' suggests, the process of connecting with something beyond the self is crucial, even though this connection may deepen the subject's awareness of the significance of individual perspectives. This testing of association has important implications for the exploration of shared memory and for the creation of imaginative worlds that will be open to a wide range of readers. The biases of history are inevitable results of the subjectivity of all narrative acts, yet the imbalances are clearly not confined to gender issues: racial identity and class affiliation also influence representation crucially. Many women poets address these issues directly in their work both in their rewriting of historical material and in their recognition that their encounter with the past is often through texts which, by their very nature, must cause women to question their relationship to tradition. This is especially true for Irish-language poets and for migrant writers.

It is important to recognize that memory is historically embedded and is shaped by the expectations of its own time and place. In this way, memory can tell us as much about the conditions for those remembering as it can about the past. Women poets writing in Ireland since 1980 have witnessed the most far-reaching changes in the lives of women in this century. The significance of Ireland's modernization - its movement away from the conservative Catholic past towards a liberal European future - is an important part of this transition. The generations of women considered in this book, from those who paved the way, such as Eavan Boland and Eiléan Ní Chuilleanáin, to younger poets including Colette Bryce and Leanne O'Sullivan, reveal the remarkable transition in the role and the expectation for women both in Ireland and abroad. 


\section{Cultural Memory and the Irish Woman Poet}

'Memory is more than the act of recollection by recollecting persons', writes Edward Shils, 'memory leaves an objective deposit in tradition'.27 It is this continuing role for memory within the dialectic of past and present that is most significant in the study of contemporary poetry in Ireland. Halbwachs's views on the transformation of social memory within a group confirms that this memory is always in danger of erosion, whether by the loss of members or by conflict amongst them. He argues that past events and people are not forgotten due to indifference but because the group remembering them fade away. ${ }^{28}$ This notion of shared or collective memory, while foundational to modern memory studies, is also controversial. Critics have argued that Halbwach's concept of collective memory limits the role for the remembering self - a significant limitation when reading poems that, for the most part, present complex individual responses. Wulf Kansteiner is among those who have suggested other ways of understanding the relationship between the individual and the group here: he distinguishes between 'collective memory' and 'collected memories' - the former are shared communications, the latter 'an aggregate of individual memories which behaves and develops just like its individual composites'. ${ }^{29}$ This dynamic permits us to address productively the complex relationship between the individual poet and the term 'Irish women poets'. This study does not attempt to create a unified sense of this term, nor does it argue that all the women whose work is explored here prioritize gender as a shaping force on their work. What it does suggest, though, is that all these poets write with some awareness of the Irish tradition - and of the woman poet's place within it - and in this way are implicitly in dialogue with writers and readers on these terms. Some of the figures explored here are conscious of the implications of writing out of a shared context for women's experience: Eiléan Ní Chuilleanáin explores the relationship between individual and community especially in a religious context; Catherine Walsh's innovative poetics challenge our perception of the boundaries between self and other. Even poets from the younger generation are concerned with the networks of belonging that shed new light on contemporary individualism.

Eavan Boland is perhaps the most outspoken of contemporary poets in dealing with the role of the woman poet in Irish society. She drives the inquiry away from broad social issues towards more exclusively artistic ones but in doing so highlights the role of creative individuals in giving 
expression to political, as well as to personal, positions. A Kind of Scar (1989) - her pamphlet on the role of the woman in the Irish poetic tradition - blends poetry, personal anecdote and critical reflection; here she acknowledges the vexed role of memory early: 'Memory is treacherous. It confers meanings which are not apparent at the time'. ${ }^{30}$ The past, then, is another country, yet one that cannot easily be removed from contemporary maps. Boland's continuing engagement with the representation of women from the past emphasizes the connected nature of women's lives across time. Boland is acutely aware that - as Jacques Derrida has argued - gender, race and class determine those who are allowed to write and those whose work is preserved in archives. ${ }^{31}$ Our access to memory is profoundly shaped by social factors and Boland wishes to draw specific parallels between the exclusion of women in the past and conditions faced by women today. Her poem 'The Famine Road' is one example of shifting historical perspectives that operate in subtle and original ways. In combining a narrative concerning the building of famine roads with the story of a woman learning that she is unable to bear children, the poem itself represents the intersection of historical and personal, public and private worlds. This imagery links directly to the evocation of famine through the figure of the starving woman and child: in folklore, as Patricia Lysaght has commented, 'this is often tempered by the parallel image of the generous woman who comes to their assistance'. ${ }^{32}$ Here Boland creates a poem that simultaneously speaks to the contemporary reader and examines a familiar folk image, marking the combined intellectual and emotional power of her work. ${ }^{33}$

The role of folklore in extending the range of cultural memory is a significant one, not only for Irish language writers - who have, historically, the closest connections to the folk tradition - but for all modern poets who enquire into the representation of the past. ${ }^{34} \mathrm{~A}$ number of women poets explore the past by means of folklore. Nuala Ní Dhomhnaill is renowned for her engagement with a folk past that is full of vigour and energy - breaking with tradition to create strong and outspoken female characters. Mary O'Malley also draws on the folk materials of the western seaboard to explore the dynamics of land and sea and of belonging and estrangement in such poems as 'The Maighdean Mhara' and 'Song of the Wise Woman' (BH 70, 92). In a similar way, much of Boland's poetry presents, though it does not constitute, an improvisatory practice that ventures into areas of the past from which no definitive readings can be produced. Boland returns to this theme again and again, most memorably perhaps in 'Lava Cameo' from her 1994 collection In a 
Time of Violence, where the story 'is not a story, / more a rumour or a folk memory, / something thrown out once in a random conversation' $(T V$ 35). The distinction she draws here between story and folk memory is significant in that she claims both less certainty and more significance for her poems of family pasts. Many scholars have drawn attention to the specific role of folklore in the reclamation of the past. Cormac Ó Gráda has questioned its value in exploring 'what really happened', suggesting instead that it reveals much about people's attitude and feelings. ${ }^{35}$ Guy Beiner has also drawn attention to the problems inherent in wholesale dismissal of folk material by historians:

Though useful in putting insular misconceptions into perspective, such realist iconoclasm, which is founded on a sweeping dismissal of popular beliefs as 'harmful mythology,' proves to be of limited value for studies of mentalité that seek to decode conflicts sustained by intransigent mindsets. ${ }^{36}$

The need to consider not only what can be known about the past but also how its practices can be decoded is an important part of the contribution of poetry to memory debates.

\section{The Body and Traumatic Memory}

The importance of experience in the formation of memory is especially prominent in the context of contemporary poetry, and the extent to which this experience might involve the recollection of traumatic events is significant. This form of memory has a very different relationship to thought than do other modes; in this case, as David Farrell Krell has argued, memory is both the source of the malady and the therapy it requires. ${ }^{37}$ This doubleness is also expressed in the recurrent nature of the experience itself, as Cathy Caruth writes:

trauma is not locatable in the simple violent or original event in an individual's past, but rather in the way that its very unassimilated nature the way in which it was precisely not known in the first instance - returns to haunt the survivor later on. ${ }^{38}$

The necessity of continuous engagement has important cultural ramifications too. Dominick LaCapra emphasizes this dimension of historical trauma, in which 'the hauntingly possessive ghosts' of traumatic events affect not just individuals but society at large. ${ }^{39}$ While acknowledging the importance of truth claims to this process, LaCapra argues that these must be 'cogently related to other dimensions of historiography, including empathic, responsive understanding and performative, dialogical uses of 
language'. ${ }^{40}$ The latter observation leads him later to indicate the value of literary texts in providing insight into the emotional response to trauma. ${ }^{41}$ In this respect, poetry plays an important role in the exploring of traumatic conditions, since it facilitates the representation of complex and changing emotional states, as well as interpretative positions.

For some women the personal past is a difficult space; while not experiencing specific trauma these women might register their childhood or earlier adulthood as troubled or deprived. This experience may have a larger cultural or existential resonance - writers such as Paula Meehan and Mary O'Malley are aware of the power of this darkness to both inspire and overwhelm creative achievement. The importance of the body in the mediation of traumatic states is one of the reasons why it has been an area of representational difficulty for women writers who struggle at once to present and to re-think the symbolic reading of the female body in Irish myth and history. Suffering is expressed in these poems in both occluded and explicit ways: sometimes the expression of taboo subjects at once confirms and breaks the silence of oppression. Eithne Strong, an important precursor for women in this volume, speaks of the prohibitive attitudes towards bodily pleasure that overshadowed her upbringing in the Ireland of the I930s. This control was felt by some poets of the first generation explored in this study. Mary Dorcey, one of Ireland's most prominent lesbian writers, has written about the trauma of repressed sexuality on her work; though her use of language and form is often comparatively conventional, many of her poems use repeated lines and syntax to emphasize the relentless nature of the conditions she describes. Since political and moral restraints on the body have been a significant feature of Irish social development, writing about the body is an important way for Irish women poets to initiate new forms of self-representation. The body expresses not only lived experience but an influential range of symbolic readings and is a way of investigating the links between actual experience and metaphorical understanding. For many women poets the body provides a useful axis in considering both biological and cultural identities, as well as in articulating important tensions between past and present.

As the bearer of experience, the body itself - through the revealing of wounds or scars - may be the means by which the trauma is expressed. In the words of Maud Ellmann: 'Pain without marks is like speech without writing, doomed to pass into oblivion.' ${ }^{42}$ The representation of the disfigured self alerts us to the process of change at the same time as it refuses to allow such change to obscure the moment of suffering. 
Violence against the body also disrupts the normal dynamics of private and public, revealing what is normally hidden from view. 43 The representation of pain is itself a process burdened by problems; it is difficult to express pain adequately in language and almost impossible for another to understand fully the impact of that experience. In many ways, pain reflects the disintegration of language and exposes its inherent limitations. The rendering of pain in poetic form, therefore, not only pushes poetry to the limits of its aesthetic capabilities, it also bridges that important gap between private and public realms, between past and present, between the body and the imagination, between nature and culture.

Physical illness also has accompanying psychic and bodily wounds and presents a particularly interesting case, since it represents the body in rebellion, the part threatening the life of the whole. While the relationship between actual and metaphorical readings is suggestive, ${ }^{44}$ the representations of illness to be found among contemporary women are usually bound closely to personal experience. What Kerry Hardie calls the 'ancient practice' of sickness has exerted a shaping force on her body of work as a whole, which often catalogues the slow process of overcoming debilitating illness. The exact knowledge, brought about by the slowness of time and of death, allows the pain and diminution to remain in the private realm yet imbues it with a significance that exceeds a purely personal connection.

The importance of experience is central to many of the debates on the definition of the woman poet. Ironically, critical views here at once particularize experience and highlight its shared nature. The drawing together of the act of writing and that of experience is a notable one, permitting experience to become not just the inspiration for the poem but the poem itself. As Boland had commented, 'for somebody like me, who thinks of herself as a lyric poet, writing is not an expression, it is an experience' ${ }^{45}$ It is a position that restricts the development of form in key ways; however:

the feminist poetry that has been institutionalized within women's studies programs and teaching anthologies can be restrictively organized around a normative concept of 'experience' that renders all but the most tentative formal innovation by women inadmissible and anathematizes theoretical reflection on poetic practice. 46

These limitations highlight the tendency to attribute to women experiential rather than textual memories and therefore to confine them to a relationship with the past which is stripped of its cultural significance. 


\section{Memory and Poetic Practice}

In spite of the pre-eminence of experience in the critical framework applied to women's poetry, the extent to which these poets remember through the agency of poetic texts is considerable. Writing itself is an act of memory as well as one of interpretation:

All texts participate, repeat, and constitute acts of memory; all are products of their distancing and surpassing of precursor texts. In addition to manifest traces of other texts and obvious forms of transformation, all contain cryptic elements. All texts are stamped by the doubling of manifest and latent, whether consciously or unconsciously. ${ }^{47}$

Many of the women whose work is explored here are in dialogue with earlier texts, whether with major Irish figures such as W. B. Yeats, Louis MacNeice or Thomas Kinsella or international artists - John Berryman, Elizabeth Bishop, Sylvia Plath. Yet in spite of the stimulus provided by these texts, some Irish women poets specifically register a lack of literary foremothers. Their sense of working creatively without the sustenance which earlier female achievement would bring can emphasize their estrangement from literary tradition. Anne Ulry Colman argues that these precursors can easily be found, especially among women writing during the nineteenth century: 'Contemporary women poets may be writing out of silence, but it is the silence of ignorance, brought about through the time's neglect of their maternal literary heritage.' 48 Thus Boland's contention that women writing today have little sense of their own precursors is at once a limited view on the question of influence and an accurate presentation on the perception of writers working in the field. This dynamic is not only confined to women, though; it has contributed to a division between generations in terms of the operation of memory, as Paul Connerton has observed:

Across generations, different sets of memories, frequently in the shape of implicit background narratives, will encounter each other; so that, although physically present to one another in a particular setting, the different generations may remain mentally and emotionally insulated, the memories of one generation locked irretrievably, as it were, in the brains and bodies of that generation. ${ }^{49}$

This necessary work of reclamation constitutes an important part of any study of women in literature, not only in shaping critical perceptions but also in altering the individual poet's sense of their relationship to others, past and present. 
The state of women's history in Ireland has been undergoing progressive change. This, in turn, demands a re-evaluation of women's relationship both to their personal past and to the narratives of the past that persist in their psyche, as well as to their creative work. As Renate Lachmann points out, 'Literature becomes the bearer of actual, and the transmitter of historical, knowledge and it construes intertextual bonds between literary and non-literary texts.'50 Thus any re-evaluation needs to take account of the intertextual nature of the relationship between past and present, and of the ways in which women have interpreted the literary models open to them. It is often in more experimental works that the relationship between private and public realms is most obviously problematized. Clair Wills argues that experimental poetry by women often reveals:

not the absence of a sphere of privacy but the ways in which that private or intimate realm of experience is constructed 'through' the public, and therefore elements of 'expressivity', though radically divorced from notions of authenticity, are present. ${ }^{51}$

This uncoupling of 'expressivity' from authenticity is an important one for women and a decisive step in freeing them to participate in more innovative creative practices. In this study the integration of lyrical and avant-garde poets, as well as the inclusion of poets from different generations, seeks to overcome the unproductive categorization of women poets. This strategy also emphasizes the aesthetic choices made by these women as formative of their response to the past and their perception of its larger political ramifications.

The craft of poetry is foremost in the elucidation of memory in the work of contemporary Irish women poets. Marked by a wide variety of techniques and influences, these texts negotiate the relationship between past and present in unique ways, revealing the vital importance of the moment of writing and the changing dynamics that shape all creative processes.

\section{Notes}

I Jeffrey K. Olick, The Politics of Regret: On Collective Memory and Historical Responsibility (London: Routledge, 2007), p. 8.

2 Julia Kristeva's work on estrangement underpins this investigation. Richard Kearney's Strangers, Gods and Monsters: Interpreting Otherness (London: Routledge, 2002) situates the philosophical dimensions of estrangement in ways that illuminate the work of Jacques Derrida, Emmanuel Levinas, Immanuel Kant and Kristeva herself. All these thinkers form an important basis for the discussions here. 
3 Barbara A. Misztal, 'Memory and History', in Oona Frawley (ed.), Memory Ireland, vol. I, History and Modernity (Syracuse, NY: Syracuse University Press, 20II), p. 3.

4 Memory Ireland covers a wide range of material, from conceptual considerations of postcolonial memory to explorations of the impact of the Great Famine, the War of Independence, the Troubles and institutional child abuse on national identity. Key essays by Guy Beiner, Oona Frawley, Elmer Kennedy-Andrews, Emilie Pine, David Lloyd and Barbara Misztal are referenced here.

5 Charles Maier, 'A Surfeit of Memory: Reflections on History, Melancholy and Denial', History and Memory 5.2 (1993), pp. 136-52.

6 Ann Rigney stresses the vital role that literature plays in the production of cultural memory. See Rigney, 'Plenitude, Scarcity and the Circulation of Cultural Memory', Journal of European Studies 35.I/2 (2005), pp. 209-26.

7 Geoffrey Cubitt, History and Memory (Manchester: Manchester University Press, 198I), loc. 198 [Kindle edition].

8 Mieke Bal, Travelling Concepts in the Humanities (Toronto: University of Toronto, 2002), p. 24.

9 See Elizabeth Grubgeld 'Topography, Memory, and John Montague's “The Rough Field”, Canadian Journal of Irish Studies I4.2 (January 1989), p. 26.

Io The publication of the three-volume Field Day Anthology of Irish Writing (Derry: Field Day Publications, I99I) revealed how marginal women writers remained within the Irish tradition, even to recuperative projects such as this one. The limited number of texts by women in these volumes caused a protracted critical debate which resulted in the production of a further two volumes devoted to Irish women's writing and traditions.

II Justin Quinn, 'Introduction', Metre 3 (Autumn 1997) - 'Irish Poetry and the Diaspora'.

I2 Anne Whitehead, Memory (London: Routledge, 2009), loc. 243I [Kindle edition].

I3 Eavan Boland's choice of a cyclical structure for her book, Object Lessons: The Life of the Woman and the Poet in Our Time (London: Vintage, 1996) builds on this necessity for repetition and continuous engagement.

I4 Aleida Assmann and Linda Shortt, 'Memory and Political Change: Introduction' in Aleida Assmann and Linda Shortt (eds), Memory and Political Change (Basingstoke: Palgrave Macmillan, 20I2), p. 5.

Is Eberhard Bort (ed.), Commemorating Ireland: History, Politics, Culture (Dublin: Irish Academic Press, 2004), p. 2.

I6 In February 2013, the Taoiseach, Enda Kenny, made a public apology to the women who had suffered abuse in Ireland's Magdalene Laundries. Mr Kenny had been criticized by survivors for his initial failure to make an adequate response to the McAleese Report, which investigated state involvement with the laundries. This apology, together with the announcement of a compensation scheme, was welcomed by those who had fought for acknowledgment of the state's responsibility in these events. The official nature of the apology significantly increased its impact.

I7 Seamus Deane, 'Wherever Green is Read', in Máirín Ní Dhonnchadha and Theo Dorgan (eds), Revising the Rising (Derry: Field Day, I99I).

I8 See Guy Beiner, 'Commemorative Heritage and the Dialectics of Memory', in Mark McCarthy (ed.), Ireland's Heritages: Critical Perspectives on Memory and Identity (London: Ashgate, 2005), pp. 55-69; 'Between Trauma and Triumphalism: The Easter Rising, the Somme, and the Crux of Deep Memory in Modern Ireland', 
Journal of British Studies 46.2 (April 2007), pp. 366-89; also 'Modes of Memory: Remembering and Forgetting the Irish Rebellion of 1798', in Oona Frawley (ed.), Memory Ireland, vol. I, pp. 66-82.

I9 Anne Whitehead, Memory (London and New York: Routledge, 2009), pp. 63-5. Some writers of the early years of the twentieth century, including George Bernard Shaw, were particularly critical of the urge to memorialize, judging it to be at the expense of principled attention to present and future.

20 Eric Hobsbawm and Terence Ranger (eds), The Invention of Tradition (Cambridge: Cambridge University Press, I983), pp. I-I4.

2I Ian McBride, 'Memory and National Identity in Modern Ireland', in Ian McBride (ed.), History and Memory in Modern Ireland (Cambridge: Cambridge University Press, 200I), p. 8.

22 See ibid., p. I.

23 Eavan Boland, in Gillean Somerville-Arjat and Rebecca E. Wilson (eds), Sleeping with Monsters: Conversations with Scottish and Irish Women Poets (Dublin: Wolfhound Press, 1990), p. 84.

24 Guinn Batten, 'Boland, McGuckian, Ní Chuilleanáin and the Body of the Nation', in Matthew Campbell (ed.), The Cambridge Companion to Contemporary Irish Poetry (Cambridge: Cambridge University Press, 2003), p. I70.

25 Eavan Boland, A Kind of Scar: The Woman Poet in a National Tradition (Dublin: Attic Press, 1989), p. 6.

26 Gerardine Meaney (Un)like Subjects: Women, Theory, Fiction (London: Routledge, 1993), p. 233.

27 Edward Shils, Tradition (Chicago: Chicago University Press, I98I), p. I67.

28 Maurice Halbwachs, The Collective Memory, trans. Francis J. Ditter and Vida Yazdi Ditter (New York: Harper Colophon Books, 1980), p. 82.

29 Wulf Kansteiner, 'Finding Meaning in Memory: A Methodological Critique of Collective Memory Studies', History and Theory 4I.2 (December 2002), p. I86. Different modes of conceptualizing shared memory are outlined in Whitehead, Memory, loc. 2103-600 [Kindle edition].

30 Boland, $A$ Kind of Scar, p. 74.

3I See Jacques Derrida, Archive Fever: A Freudian Impression (Chicago: University of Chicago Press, 1998).

32 Patricia Lysaght, 'Perspectives on Women during the Great Irish Famine', Bealoideas 64/5 (1996-7), p. 76.

33 For further exploration of the role of famine memory, see David Lloyd, 'The Indigent Sublime: Specters of Irish Hunger' and Margaret Kelleher, 'Commemorating the Great Irish Famine: I840s-1990s', both in Oona Frawley (eds), Memory Ireland, vol. 3, The Famine and the Troubles (Syracuse, NY: Syracuse University Press, 20I4), pp. 17-58; 9I-I2O.

34 Niall Ó Ciosáin's essay on famine memory explains the ambiguities that are central to the Folklore Commission itself: 'on the one hand, the Folklore Commission and its archive were established precisely as a repository of national memory, manifest in the oral tradition, and can itself be considered a form of institutionalized public memory. On the other hand, the work of the Commission in practice conceived of memory as personal recollection'. Niall Ó Ciosáin, 'Famine Memory and the Popular Representation of Scarcity', in Ian McBride (ed.), History and Memory in Modern Ireland (Cambridge: Cambridge University Press, 200I), pp. 95-II7. 


\section{INTRODUCTION}

35 Cited in Ó Ciosáin, 'Famine Memory', p. 99.

36 Beiner, 'Between Trauma', p. 369.

37 David Farrell Krell, Of Memory, Reminiscence, and Writing: On the Verge (Bloomington, IN: Indiana University Press, 1990), p. I06.

38 Cathy Caruth, Unclaimed Experience: Trauma, Narrative and History (Baltimore, MD: Johns Hopkins University Press, 1996), p. 4.

39 Dominick LaCapra, Writing History, Writing Trauma (Baltimore, MD and London: Johns Hopkins University Press, 200I), loc. 52 [Kindle edition].

40 Ibid., loc. 74 [Kindle edition].

4I Ibid., loc. 278 [Kindle edition].

42 Maud Ellmann, The Hunger Artists: Starving, Writing and Imprisonment (London: Virago Press, 1992), p. 85.

43 For further discussion of the implications of this transition between private and public, see Elaine Scarry, The Body in Pain: The Making and Unmaking of the World (Oxford: Oxford University Press, 1987).

44 These analogies have been explored by Susan Sontag in Illness as Metaphor (New York: Farrar, Straus and Giroux, 1978) and AIDS and its Metaphors (New York: Farrar, Straus and Giroux, 1989).

45 Eavan Boland, in Somerville-Arjat and Wilson, Sleeping with Monsters, p. 82.

46 Lynn Keller and Cristanne Miller (eds), Feminist Measures: Soundings in Poetry and Theory (Ann Arbor, MI: University of Michigan Press, 1994), p. I.

47 Renate Lachmann, 'Mnemonic and Intertextual Aspects of Literature', in Astrid Erll and Ansgar Nünning (eds), Cultural Memory Studies: An International and Interdisciplinary Handbook (New York and Berlin: Walter de Gruyter, 2008), p. 304. 48 Anne Ulry Colman, 'Far from Silent: Nineteenth-Century Irish Women Writers', in Margaret Kelleher and James H. Murphy (eds), Gender Perspectives in NineteenthCentury Ireland: Public and Private Spheres (Dublin: Irish Academic Press, 1997), p. 203.

49 Paul Connerton, How Societies Remember (Cambridge: Cambridge University Press, I989), loc. I2I [Kindle edition]

50 Lachmann, 'Mnemonic and Intertexual Aspects', p. 306.

5I Clair Wills, 'Contemporary Women's Poetry: Experimentalism and the Expressive Voice', Critical Quarterly 36.3 (September 1994), p. 4I. 

I

Concepts 



\section{Lost Lands}

\section{The Creation of Memory in the Poetry of Eavan Boland}

The importance of a specifically Irish identity is central both to the critical trajectory Eavan Boland has traced for herself as a poet and to the way in which her work has been received and read. Boland's earliest investigations of the process of identity formation are shaped by her awareness of the concept of nation as foundational to her sense of self. An important facet of these explorations is Boland's perception of the exclusion of Irish women from the political and the cultural history of their nation. Her work registers the desire to draw attention to this act of exclusion and to the sense of loss it has created for later generations of women. Estranged from the national narrative of the past, women create alternative ways of articulating their relationship to history, both individually and collectively. Implicated in this project is Boland's presentation of her own experience as an Irish woman, and more specifically as an Irish woman writer. In her writing the relationship between creativity and literary tradition assumes an enduring importance. ${ }^{1}$

The concept of memory has been crucial to Boland's developing political thought for many years; it is with reference to memory that the interwoven states of private and public in her work must be problematized. This dynamic highlights the importance of gender to larger debates on memory, as Marianne Hirsch and Valerie Smith have indicated: 'What a culture remembers and what it chooses to forget are intricately bound up with issues of power and hegemony, and thus with gender.'2 As well as providing inspiration for Boland's work, the process of memory is reflected upon directly: as Catherine Kilcoyne has suggested, her oeuvre constitutes 'a critique of memory as poetic, 
linguistic device'. 3 As this chapter will argue, Boland first privileges the personal significance of memory before placing remembrance and memorialization at the centre of a larger debate on the limits of a national tradition. This progression is not a naturally evolving one, however, but rather a strategic reinforcement of the validity of lived experience as a foundation for cultural authority; it is Boland's early estrangement that legitimizes her continued identification with a marginalized position in spite of her creative and critical reputation. As a young child Boland was brought to live in London, and was educated there and later in New York before returning to Dublin to complete her school and university education. These London years, though representing a brief period in Boland's biography, are portrayed as formative of the child's sense of self and therefore significant for Boland's developing identity as a poet. This early experience of difference is linked to the poet's later preoccupation with cultural estrangement, and her determination to explore it in her work. The complex relationship between personal memory and intellectual exploration shapes this discussion of the poetry.

\section{The Spaces of Memory: Creating Childhood}

The urban environment as both historical entity and life experience has exerted an important influence on the writing of poetry in the modern period. The city is a space of acknowledged heterogeneity, and London, at the time that Boland experienced it, presented a geographically extensive and historically rich environment. It was also a city in a state of profound transition, owing to the period of reconstruction that followed the end of the Second World War. ${ }^{4}$ Though the damage left parts of London derelict, these were years of high employment and comparative prosperity. The large-scale immigration that was a feature of the post-war decade was beginning, yet the child of Boland's prose and poetry remains remote from these contexts, seeing the experience in deeply personal terms. ${ }^{5}$ Living at the Irish Embassy, Boland was at once sheltered from the normal life of the post-war capital and continually reminded of the significance of its political relationships. The cultural differences that she senses have a striking effect on her both at the time and later. Indeed, her memories of London are shaped by the feeling of strangeness, of otherness, that permeated her childhood as a whole; this is understood by Boland primarily in linguistic terms - 'I had moved around as a child. I had lived in other cities. I had learned no dialect of belonging; I knew no idiom of attachment to place or its purpose.' ${ }^{6}$ 
Such disengagement from the living environment can create obstacles to the formation of normal human bonds, but it can prompt more positive processes too, including a reflective, observant position. For James Conlon, 'the bountiful confusion of reality' that the city condenses into one place leads the mind to rethink its assumptions, to philosophize. ${ }^{7}$ So it may be that the confusion that Boland experiences as a child - this lack of an adequate 'dialect' or 'idiom' - is as much a feature of the life of the city itself as it is a circumstance of her sudden uprooting from her birthplace. That memory rewrites the text of the past to produce a form of representation that can be 'read' suggests that it offers an essential ordering process for the adult poet, who can use her formal skill to retain disorder within her method. ${ }^{8}$ The function of memory as representation reinforces both its conceptual richness and its strategic purpose for the poet. It permits her not only to reflect on the processes of identity formation but to change them at will. For this reason Boland's use of personal memories in her writing helps to consolidate her critical identity at the same time as it permits her to remain in a productively marginal position in relation to Ireland's poetic tradition. ${ }^{9}$

A crucial aspect in the literary construction of London for Boland is her use of the dynamics of place as a way of debating ideas of inclusion and exclusion. By invoking both the physical spaces of the city and the interior of the house in which she lived during her time in the British capital, Boland gives visible contours to the process of identity formation:

My childhood, certainly in the London years, wasn't happy. That isn't to say it wasn't a privileged childhood, because it was. But it was fictional and desolate in an odd way ... there was this huge, compartmentalised house. And I felt thoroughly displaced in it. I never believed I belonged there. I never felt it was my home. Some of the feelings I recognise as having migrated into themes I keep going back to - exile, types of estrangement, a relation to objects - began there.10

Since concepts of home, in particular of the unified family, have been central to the construction of an Irish national imaginary, it is noteworthy that Boland expresses her unease through the metaphor of the compartmentalized house. Her sense of displacement is double: the family of the diplomat is identifiably Irish, yet always at a distance from Ireland, and within this complex dynamic Boland is further displaced by the lack of permanence and intimacy of this life. To call her childhood 'fictional' is to draw attention to its creative potential; rather than these memories 'migrating' into her poetry, therefore, they are formed by her adult preoccupations. Although English experiences and education have 
had an impact on the poet - and are seen to shape the day-to-day lives of her child protagonists - they are used in her work to confirm the sense of cultural difference that lies at the core of the perceiving self, and that later validates Boland's persistent, yet questioning, location of herself in an Irish cultural tradition. Though recapturing the instinctive experiences of childhood and youth, these processes of remembering form part of a body of work with distinct aesthetic and political aims.

The city space remains a significant dimension of Boland's handling of these ideas. Roland Barthes figures it as the place where we come face to face with difference: 'The city, essentially and semantically, is the place of our meeting with the other.'11 This 'other' is both conceptual and individual, encompassing the notion of difference as well as the living being that embodies these characteristics, a combined identity that will later prove important to the poet in her use of particularized female experience to interrogate larger political positions. The city provides a locus for the arriving stranger, historically and metaphorically, creating an environment in which the other can be accommodated without either forced assimilation or an exaggerated sense of difference. The inclusive dimension of this experience is reinforced by Boland's diplomatic background; in personal terms, though, the transition is far from seamless. 'Hospitality means the right of a stranger not to be treated in a hostile manner by another upon his arrival on the other's territory', writes Kant, ${ }^{12}$ yet if, as Derrida argues, crossing the threshold is always a transgressive step, then both visitor and guest experience this sense of transgression when moving into a space in which they do not (yet) belong. ${ }^{13}$ Such a contravention may have been liberating for Boland, at least in retrospect, offering her new ways of construing the poetic subject. It also forms the basis of the ethical turn in her work: her use of these memories suggests an enduring concern with otherness and exclusion that contextualizes her later interrogation of the place of women within the Irish literary tradition:

Writing about the lost, the voiceless, the silent. And exploring my relation to them. And - more dangerous still - feeling my way into the powerlessness of an experience through the power of expressing it. This wasn't an area of artistic experiment. It was an area of ethical imagination, where you had to be sure, every step of the way - every word and every line - that it was good faith and good poetry. ${ }^{14}$

In contrast to Emmanuel Levinas, for whom the ethical challenge is presented to the spontaneous, free subject, ${ }^{15}$ Boland's moral questioning 
is part of a continuous process, one that is designed to broaden the intellectual and historical contexts of her work as well as to refine her ideas through evolving forms of reflection and representation. Boland's repeated return to key memories and themes in both her poetry and her prose works reveals the deliberate nature of her construction of ethical and political questions.

This questioning has its roots in an emotional response to place, however, and the continuing importance of spatial metaphor in Boland's work draws attention to the problematic dynamic of incorporation and expulsion that is closely linked to the issue of hospitality. ${ }^{16}$ For Levinas, the ethics of proximity invoke the interpersonal dimension of hospitality, the need for it to exist on an experiential rather than a conceptual level, and in Boland's case the state of difference invoked by her London childhood creates a productive tension not only for her personal creativity but also for her understanding of ideas of community and belonging. In this way, Boland's repeated return to these scenes of childhood insists on the all-encompassing character of this dynamic for ethical debates in both gendered and post-colonial settings. This form of memory reflects the prevailing power structures, and Boland's concern for the exclusion of women from cultural and political history in Ireland reveals her awareness of the effect this exclusion has on all acts of representation: it is thus 'neither marginal nor specialist' but 'concerns all of poetry, all that leads into it in the past and everywhere it is going in the future.' ${ }^{17}$ As identity is shaped both by individual experience and by a web of social and behavioural expectations, so public narratives reveal the texture of private experience. The importance of both personal and collective identities in the formation of memory is demonstrated in the subtle ways in which Boland investigates the relationship between subjective perception and shared understanding, as well as in her contemplation of the lives of earlier generations.

The yearning for origins is also the yearning for self-knowledge. As the child grows and questions, so she increasingly turns to the past, in search of a crucial dimension of her identity which remains occluded in her present life. This need to construct the self, not from an ongoing series of life experiences but from a barely reclaimable past, and from the personal histories of one's parents and grandparents, is itself a source of challenging inspiration for Boland. Especially important is her formation of the female continuum that will later provide her with a personally and politically sustaining narrative. She begins her autobiographical work, Object Lessons: The Life of the Woman and the Poet in Our Time 
(1996), not with the story of her own experiences, but instead those of her grandmother, acknowledging the complex temporality of identity formation, especially in contexts of hardship and dramatic social change. While the urge to form a unified self - and the political significance of this urge - appears to motivate much of Boland's writing, it is always overshadowed by doubts; doubts that reflect both the impossibility of the coherent subject and the limited perspectives that the attempt to construct it might perpetuate. This dynamic is important to an understanding of Boland's conviction that her writing should connect with the lives of other women, of both past and future generations. The presence of these women - who are at once 'other' to Boland's sense of selfhood and indicative of the importance of relational understanding becomes a central part of the poet's own narrative, with an ambiguity suggestive of Julia Kristeva's exploration of the foreign:

With the Freudian notion of the unconscious the involution of the strange in the psyche loses its pathological aspect and integrates within the assumed unity of human beings an otherness that is both biological and symbolic and becomes an integral part of the same. ... Uncanny, foreignness is within us: we are our own foreigners, we are divided. ${ }^{18}$

The incorporation of otherness within the self testifies to the permeability of the subject and to the resultant complexity of the singular being. Boland's interest in the hidden lives of her female relatives, and the composite nature of women's identity more generally, is matched by a growing awareness of the self-division that is an inevitable part of this identity. In this way, her representation of childhood instincts prefigures her later interrogation of gendered positions. Boland's mother, however, chose to distance herself from her past:

Unlike most people, she treated the past as an opportunity for forgetfulness rather than a source of definition. She had no photographs, not one, of herself as a child. No copybooks from school. No pantomime tickets. She talked of her childhood rarely and without sentiment. Almost, it seemed, without interest ... Childhood was a place of unreadable signposts and overgrown roads. The language could not be retrieved. ${ }^{19}$

By contrast, Boland's own early experiences of estrangement must be both expressed and interiorized in order that they can be transformed into conscious political thought. London plays an important role in the psychic development of the biographical and, indeed, fictional self for Boland in the way that it propels the speaker towards identification with her Irish past yet impedes her from embracing this past without 
equivocation. We know that the process of childhood identification with Ireland has been substituted by the poet's actual adult life in Dublin, and that Boland's relationship to London is shaped by the temporary nature of her time there. The brevity of this experience is at odds with its creative significance in expressing the personal condition of estrangement that, for Boland, provides the foundation for her investigation of the marginalization of women in modern Irish culture. For the attentive reader of Boland's work the repeated tropes of her London childhood will become more resonant as the poet's parallel exploration of the fate of women in Irish history proceeds.

\section{Remembering the Self: Text and Image}

In chronological terms, the first consideration of Boland's childhood outside Ireland occurs in the poem 'After a Childhood away from Ireland' in the 'Domestic Interiors' sequence from Night Feed (1982). In The Journey and Other Poems (1986) these experiences begin to exert an important shaping force: 'I Remember' is the first poem in this collection and gives an important indication of how the space of the volume will be defined. Light is an immediate consideration here and it will become a significant compositional technique for Boland, both at this stage and later. In this poem light is used to aestheticize the past, extending the imagery of painting outwards from the mother's easel to encompass the entire scene. This scheme reveals not only the resonance of childhood memories but also their susceptibility to conscious manipulation. The influence of life beyond the windows - 'the iron railings and the ruined evenings of / bombed-out, post-war London' ( $\left.J_{9}\right)$ - is slight, though its mood is crucial to the heightened sensual awareness of the anxious girl. Boland has often referred to the significance of her mother's artistic practice to her, both as a child and as a young writer, and here this world of making creates alternative energies to the post-war city in which it takes place. ${ }^{20}$ Identity is under construction in this poem: the face on the canvas is only a partial representation of the sitter who arrived and left, and its 'scattered fractions' testify not only to the fact that the representation is incomplete but to the conviction that selfhood is inherently fragmented. This fragmentation is further realized in the alienation of the child:

$$
\text { and I remember, I remember }
$$

I was the interloper who knows both love and fear, who comes near and draws back, who feels nothing 
beyond the need to touch, to handle, to dismantle it, the mystery; and how in the morning when I came down -

a nine-year-old in high, fawn socks -

the room had been shocked into a glacier

of cotton sheets thrown over the almond

and vanilla silk of the French Empire chairs. ${ }^{21}$

The 'I' of this poem, as in so many poems by Boland, is a layered and complex position. In the present, the ' $\mathrm{I}$ ' is the adult recalling the past, so that the act is not just one of remembering but of creating out of that past - an imagined synthesis of the present consciousness of the speaker and her earlier experiencing self. In the process the contexts of feeling become unclear: 'I was the interloper who knows' the 'voice' of the poem asserts. It is not the child who feels the need to dismantle the mystery, however, but the adult, the poet: yet both are caught between the need to live with ambiguities and the equal need to expose and understand them. At the moment of writing it seems that Boland uncovers a fruitful trope for the collision of cultural and personal divisions: the Irish girl in London, privileged yet excluded; one country recovering from the trauma of war and another building its identity independent of this harrowing experience. In this opening poem the focus is on the room - the locus of creativity where the making of meaning is central, both in the London of the poet's childhood and in the memory of that place. This containment facilitates not only the impression of separation from the culture in which the family now lives but also the distillation of the image: the self-conscious transformation of life into art. These moments of stillness become touchstones in Boland's art, beside which the broader experiences of childhood are situated with care.

Both at that time and today London differs from Dublin in key political and aesthetic respects: it is large enough for the act of defamiliarization to take place, and is often termed the 'strange city' in Boland's work. Despite its familiarity over the creative span of Boland's career, it retains this strangeness and the child's experiences there are intense, at once alienating and formative. They are resonant because they are 'other' to her Irish identity, but they are carefully particularized and recurring memories that mark moments of self-realization, even symbolic meaning. In 'The Source', the initial search for where a river rises yields instead an altogether different starting point: the image of a mirror in which a kneeling child is shown discovering a coil of her mother's hair, 
saved carefully in a box. For the poet this image is both inescapable and compelling: it marks a surprising release of the past, freighted with private meaning and with suggestions of lost youth and beauty. Yet in conjuring up this image the poet also contemplates the gap between it and the real circumstances of the life it reveals, and considers the impossibility of rendering existence in simplified forms:

As the light goes,

I hold in my hand the coarse weight and

hopeless safe-keeping

and there comes back to me

the adult language for mystery:

Maybe. Nearly. It could almost be.

This 'hopeless safe-keeping' speaks of the pointlessness of holding on to the past, when its meanings remain so elusive.22 Yet it may also suggest that the attentiveness of the discovering imagination is capable of raising to significance the least promising of objects or narratives. It is this capability that convinces Boland of the importance of retrieving the lost narratives of women of preceding generations, and her return to the life and memories of her mother is a testament to her sense of herself as facilitating this important act of witness - what Boland would call 'that shining I. That obdurate and central witness of the poet'.23

In spite, or perhaps because, of the complexity of the child's response to her early displacement, London itself would be a site of awakening for Boland, though not always consciously so. 'The Briar Rose' evokes a child on the brink of knowledge. The link that is made here - and repeated in the poem 'The Women' which follows it - is between the flower and the crêpe-de-Chine of sophisticated underwear. It is the presence of the roses in a Dublin garden that evokes sudden and vivid memory within the speaker:

I could be

the child I was, opening

a bedroom door

on Irish whiskey, lipstick,

an empty glass,

oyster crepe-de-Chine

and closing it without knowing why. 
These are suggestive details, yet the child is not consciously aware of the sexual intimacy that they imply, but rather of the sense of a private space into which she has strayed. In this case the child's innocence includes unconscious impressions, which are vital in testing the boundaries not only of childhood and adult experience but also of innocence and sophistication, tradition and modernity. Even the speaker's continuity with her own past is conditional - 'I could be / the child I was' (my italics); she acknowledges the past as the matter of both memory and invention. While subjective experience is significant here (only the child glimpses the scene, though the adult reader interprets it) there is always the sense in Boland's work of larger currents just beneath the surface of the text. The deliberate simplicity of the poem - its short lines, two balanced sentences, its refusal to complicate the moment of discovery - maintains the directness of the child's observation and openness to experience. Yet it also displays its own artifice: the isolation of the phrase 'I could be' tantalizes the reader and its 'oyster crepe-de-Chine' is too painterly for this naive form.

The negotiation between the desire to record loss and estrangement, and the level of poetic self-possession required to express it, has always been a delicate process for Boland. In her London poems the layering of adult and child selves and the repetition of key images and experiences from childhood are vital to the realization of the child's experience, while permitting the synthesizing consciousness of the adult poet a significant presence. This is important, not only in drawing attention to the sophisticated framing of experience that is so central to the relationship between Boland's work in poetry and prose, but in emphasizing the temporal nature of this understanding. Temporality is an important aspect of Boland's construction of herself as a poet: she positions herself as at once part of a continuum (of carefully documented experiences) and excluded from one (the continuum of valid poetic tradition). So the passage of time exerts a significant force not only on how the individual poet situates herself but also on how these very problematic traditions are constructed and reconstructed in contemporaneous critical narratives. It is possible to construe questions of belonging and estrangement, of hospitality and exclusion, in these terms too, as Clive Barnett writes:

what is most at issue in the encounter between Levinas and Derrida is the temporality of intersubjective relations. Figures of temporality - of memory, inheritance, anticipation and surprise - are central to the alternative, non-hierarchical evaluation of the value of proximity and distance that emerges in this line of thought. ${ }^{24}$ 
The complex relationship between self and other in Boland's work emphasizes at once the sameness and the difference that the singular subject, located in time, can encompass. It also creates an important sense of proximity to past generations and a commitment to understand and represent them with care. The past and history have a complex relationship with one another, as Boland herself points out, and the divergence of lived experience from the narrative that records it is a significant preoccupation for the poet. Maurice Halbwachs draws attention to the break in continuity 'between the society reading this history and the group in the past who acted in or witnessed the events', and it is this break that Boland seeks to address. ${ }^{25}$ Her reclamation of individual figures from the past suggests that proximity to key experiences alters the ethics of self-expression: the memory of participants is an important way in which an alternative understanding of events may be reached. Memory is inevitably selective, where history attempts coherent analysis: 'memory is by nature multiple and yet specific; collective, plural, and yet individual', writes Pierre Nora, 'history belongs to everyone and to no one'. ${ }^{26}$ For Boland, history belongs more specifically to those with continued political agency. ${ }^{27}$ Her earliest realization of this occurs at the interface of British and Irish histories, where the narrative of empire predominates. Later, it is the foundation of the Irish state and its shaping of social values that is the focus of her attention. Both the complexity and the fragility of personal recollection offers a counterbalance to the certainties of a male-dominated republic, and a poetics of reflection emerges in place of fixed narratives of national identity.

If the city is a bearer of history, and a showcase for the achievements of a culture, it is unsurprising that London should express the contrast between Britain and Ireland in pronounced ways. Boland - as the daughter of a diplomat - is an invited guest, not an unexpected visitor, so her presence does not threaten to destabilize the self-possession that renders Britain capable of hospitable action. The historical relationship between the two islands is a vexed one, however, and these tensions underpin Boland's growing determination to bring to light the limited perspectives that certain historical representations encode. Maps hold a particular fascination for Boland in this respect. They are pictorial references to the historical terms in which the world is seen yet they give only a partial view and a static one, refuting the dynamic nature of the world and its relationships. The linen map that features at the opening of 'In Which the Ancient History I Learn is Not My Own' has this air of permanence, yet seems newly fragile - it is 'cracked in 
places' and suspended by knotted cotton ( $T V$ 28). The colours of empire are faded out, indicative both of the length of time these assumptions of power have been in circulation and of the fact that they may now be diminishing - a view supported by intervening events which have helped to shape the vantage point of the poet. The temporal aspect of the relationships on the map is marked by the speaker's own conviction that Ireland is 'farther away every year', as its significance in her life is overtaken by her English education and her absorption of English history. That 'God's grace' should shape history suggests that a divine wish determines the acquisition of power, and that a moral imperative underpins the fate of nations. Ireland's ancient history cannot take the place of Classical narrative and thus it cannot be reclaimed: no Oracle exists to validate its meanings and the fatedness of its events. The Roman Empire is described as the greatest 'until our time of course', noting the satisfaction of British confidence, though the date named in the poem, 1952, reveals just how precarious that self-confidence is. The child's need to repeat the place names of her own country, to use language to bring this experience to reality and to locate her home with its sensory identity - the flight of steps to the door and the scented lilac tree - is noteworthy. But this yearning for what is almost lost is challenged by the final mention of the Oracle, and the ambiguity of its messages to those who travelled far to consult it. Even as Boland draws out the emotional intensity of lost experiences, she doubts the certainties that such emotions may suggest, both for the child-subject and for her readers. By leaving the interpretation of these elements open, she avoids over-determining the interpretation of the past, while continuing to affirm the importance of the act of remembering itself.

The inevitable entanglement between emotional states and political realities, and the tensions inherent in this relationship, will be an enduring concern for Boland. Her contemplation of subjectivity is always inflected by an awareness of the complex cultural forces shaping the self, and by a sense of the contingent nature of self-realization. In this respect the intersection of spatial and temporal concerns help to shape both the experiencing and the writing self. This is especially evident in 'The Game' from Outside History (1990). The perspective on the world outside is important in drawing attention to the forces brought to bear on the child. Important too is the need to stress cultural particularity - the English spring that by inference is so different from the Irish one. The poem begins as the fog is clearing, and the vision of the speaker asserts itself, and with this, her ability to see herself and to locate herself in a 
sensory world: 'I was a child in a north-facing bedroom in / a strange country' $(\mathrm{OH} \mathrm{I} 6)^{28}{ }^{28}$ The observations of the child are acute, yet her vision is doubly limited by circumstance - when the fog has cleared, the railings become visible, both containing the child and protecting her. At night what she hears is 'quarrelling and taffeta creaking and the clattering / of queens and aces on the inlaid card table': tensions made manifest in discord, in the strain of social fabric and the anxieties of risk-taking. These sounds, like the visual image of the late winter fog, are strangely timeless: it is as though the child is trapped, not just in a place, but also in a time not her own. These effects combine to create an atmosphere of foreboding; a stillness that heightens the child's feeling of entrapment. The illusion of flight that the wakeful child conjures up is her way of escaping these fears, yet she has to return from this clear created space, stimulating to the senses and without imaginative boundaries; she must go back to the sharply delineated world of her London home, full of edges and surfaces, with the cards of chance scattered. This is a life of hierarchy and social order: the King is prayed for in chapel, a king notably missing from the pack of cards that provides a recurring trope in the poem. Likewise the sculpted archangels are part of the structure of the church, at once transcendent and trapped in space and time. Yet this is a poem that shows the will and imagination that are necessary for the child herself to transcend circumstance, and to gain perspective on the life she is living. And its impulse matches the collection from which it is taken: Outside History explores the exclusion of women from recorded history, while at the same time suggesting both the imaginative freedom that this exclusion might take and the freshness of perspective open to a poet such as Boland who is free from some of the weight of established narrative.

Boland herself notes the difficulties in her writing process in the early I990s. In spite of increasing metrical skill on her part, she 'lost command' of her working methods and began to work in circular ways, endlessly rewriting poems. ${ }^{29}$ Yet this creative disturbance may have been the direct result of a newly emerging voice in her poetry and a growing confidence in her formal powers: 'I was always a hand-tomouth technician and command of the line was never exactly mine'; without such command, 'I don't think you have confidence that you can put together the poem you want in the voice you want'. ${ }^{30}$ Her sense of speaking clearly, as though for the first time, emerges decisively in the decades that followed as does her awareness that those women who did live and write before her have their own distinct understanding of 
these creative challenges. The subjectivity that we encounter in Boland's poems through the nineties is an increasingly complex one, and its relationship to its 'others' is deliberately unfixed. Though much of the material of Boland's work from Night Feed (1982) onward can be linked to biographical detail, there is no transparent connection between the life of the poet and the position of the speaker in her poems. Anne Fogarty has problematized 'the assumption that the voice of the lyric poem is coterminous with the poet's all-informing subjectivity', arguing instead that Boland's speakers combine aspects of both subject and object. ${ }^{31}$ In this scheme the voice bridges the gap between self and other: it 'renders audible, but never pretends to embody or comprehensively envision' the experience of another. ${ }^{32}$ Earlier, Catriona Clutterbuck had noted that Boland's 'ideology of estrangement is paradoxically present in the very language of "solidarity" that is used by the poem's politically capable speakers', ${ }^{33}$ so that an underlying detachment persists, and is cultivated in sophisticated ways, even when the broad thrust of the work affirms strong female connection. ${ }^{34}$

Many exiles, as Derrida argues, see language as 'their ultimate homeland', 35 but for Boland this position is complicated. The language with which she identifies is Hiberno-English, expressive of her own experience and noticeably different from the language of her London years:

Language. At first this was what I lacked. Not just the historic speech of the country. I lacked that too, but so did others. This was a deeper loss; I returned to find that my vocabulary of belonging was missing. The street names, the meeting places - it was not just that I did not know them. It was something more. I had never known them. I had lost not only a place but the past that goes with it and, with it, the clues from which to construct my present self.36

Yet the loss of language is not a personal one only: language itself is already compromised by a history that records the decline of Irish and its superimposition by English. The loss that Boland experiences as a child, therefore, is recognized by her adult self as indicative of the larger losses of the Irish, and more specifically of the Irish woman, in history. The third section of the volume The Journey and Other Poems (1986) contains two poems on school experiences in London, modelled closely on material that Boland recalls ten years later in Object Lessons (1996). One locates itself clearly as 'An Irish Childhood in England: 195I'. Language is the first consideration in this poem, and it will be the last. It begins with the 'bickering of vowels' heard on London 
buses, the important auditory shift that the child's relocation from Dublin to London occasions. It is part of a strange sensory landscape - the glimpse of the navy-skirted ticket collector, the taste of the 'ration-book pudding', the sound of English songs. The child's awareness of difference is limited, however; she suffers from 'some malaise / of love for what I'd never known I had' ( 50$)$. The temporary nature of human perception becomes important here. The moment of recollection extends to encompass the present - the child becomes the mother, caught in a passing reverie. 'We are what we have chosen' marks the power of individual decision-making, yet it remains a question, and the powerlessness of the child's perspective re-emerges. The elliptical structure of the poem is important here. The digression prompted by memory is reprised in another return to the conditions of the poet's London childhood:

Did I choose to? -

[...]

let the world I knew become the space between the words that I had by heart and all the other speech that always was becoming the language of the country that I came to in nineteen-fifty-one

The relationship between remembered experience and its representation in language is addressed here in complex terms, deliberately made convoluted by the turn of the line, the passage of poetic time, and the variable interpretations it generates. The poem addresses the varieties of representation itself - the difference between words known 'by heart' and the practical evolution of lived language. In doing so it hints too at the historical loss of the Irish language and traditions in favour of English, the language of modernization, of commerce, and of international literary representation. Yet the lost world of the speaker's Irish childhood is also 'the space / between the words' - what is ultimately incapable of representation. England becomes no more than a record of loss, in a poetic move that makes the 'freckled six-year-old' indicative of a culture that must see its neighbour as a corrective to its own limitations. This corrective is placed finally in the mouth of the teacher, rectifying the speaker's grammar, so a Hibernicism becomes wrong, and the need to abandon the language of the Irish past is emphasized.

Without the language of the past, how can its experiences be rendered with honesty and exactness? Much of Boland's developing 
style as a poet, and as an essayist and memoirist, reveals the inevitable self-consciousness of language use, the extent to which language cannot 'match' the world it interprets but creates a unique world, a world of the imagination that shares characteristics with the lived past but is not the same as it. 'Fond Memory' inhabits some of this same territory. Again it begins in the past, in a setting of styleless uniformity, 'a school where all the children wore darned worsted' $(J$ 52). Though the speaker is part of this anonymous scene, she is separated, in thought and syntax, from the rest: she too 'ate rationed food' and 'played English games', a description setting her apart from the rest, and one that echoes the old distinctions of cultural nationalism. History, it seems, is slanted in favour of the English but poetry is suggestive of more neutral positions - 'measure' and 'complexity'. In opposition to these considered processes is placed the speaker's father and his rendition of the 'slow lilts' of Tom Moore. But this happens in the margins of the child's experience, only occasionally, and 'at a piano pushed into a corner of the playroom' ( 52 ). The apparent return to cultural innocence seems at first to hint at the sentimental nature of Moore's work, but the speaker is brought close to tears not by the easy emotions that her father's performance evokes, but by the cigarette smoke drifting up from between his fingers. Nostalgia is troubled by modernity, though this may be an adult construct: as Boland would later write, 'it never occurred to me that eventually the power and insistence of a national tradition would offer me only a new way of not belonging' 37

\section{'Let Me Repeat Myself': Later Sequences}

The preoccupation with childhood experience confirms the pivotal role that memory will play in the formation of Boland's poetic and critical persona. Her repeated return to the landscape of loss, exemplified in London's post-war strangeness, indicates her early imaginative grasp of the combined effects of individual experience and cultural distinctions in shaping the self as writer. More importantly, in this case, it revealed the resonance of particular tropes and images in recapturing the personal and historical past, and inaugurated Boland's practice of reiterating these images in the course of her creative life. She intends this act of creative return to disclose the past to present readers - not only the past of Irish history but also the past of her own texts. Her desire to create a space in literary tradition for those hitherto excluded from it also remains 
a strong one. For Clair Wills this is a questionable aim: she argues that a more fundamental critique of the relationship between private experience and the dominant tradition is warranted; inclusivity is not in itself sufficient. ${ }^{38}$ Yet though Boland seeks to articulate the kinds of experience elided by narrative history, she wishes to retain this flawed version; the gap between present and past must remain, even as it is imaginatively bridged:

The past - in its silence and inconvenient completeness - should not be remade. It should not be open to version-making. That is what history is. The past is not a version of events. It is a record of reality. For that reason, if we are to be true to the experience of a people, the past must remain the past. It must remain in the suffering, powerless place it surely was and is. Let me repeat myself. The relation between the past and history - that awkward, charged, and sometimes mysterious distance - should be a crucial care of postcolonial studies. ${ }^{39}$

This view of history as a fixed entity has important ramifications for how Boland's poetry is read, not least because of the tension that emerges between the 'facts' of the past and the aesthetic success of their rendering. Her strategy of repetition has divided critics: some believing it a necessary means to highlight the injustices of the past; others judging it evidence of Boland's incapacity to evolve as a poet, either formally or thematically. The Lost Land, published in 1998, was the collection that crystallized these critical differences. Appearing less than three years after Object Lessons, The Lost Land returned to the themes and images of Outside History (1990) and In a Time of Violence (1994) to reinforce the rejection of exclusionary mechanisms in national and cultural history; it did so by adopting many of the same aesthetic strategies of Boland's recent prose work - repeated images and phrases, declarative modes and the use of sequences and circular narrative patterns. Its polarization of critics indicated the extent to which these strategies, far from being universally judged intellectually demanding and politically necessary, were often dismissed as limiting or indulgent. Katie Conboy, writing in Poetry Ireland Review, reinforces this view:

Even when [Boland] tries to accomplish something new with her material, she continually echoes her own earlier subjects and styles. The images of wounding and scarring, of heroism and its discontents - the themes of poetic surrogacy, of recovering 'what we lost', of divided languages and loyalties have already been so thoroughly explored in both her poetry and her prose that, for her loyal readership, these poems read almost like a parody of her earlier work. ${ }^{40}$ 
For better or worse, The Lost Land indicates clearly Boland's conviction that the literature of political confrontation requires a style of relentless reinforcement. This, as the volume's title suggests, is a new aesthetic territory formed from old, and the deliberate invocation of geographical metaphors here will come to dominate Boland's later poetry. Her aim, as the form of Object Lessons suggests, is the integration of specific memories within larger political and personal constructs: 'the lost land is not a place that can be subdivided into history, or love, or memory'. ${ }^{41}$ The representation of childhood estrangement in earlier poems can therefore be seen as a necessary precursor to its realization as a link between the personal and the political, and to the acknowledgment that political awareness must have a counterpart in instinct and experience. Yet in this scheme the landscape of Boland's personal and creative past also becomes fixed, closing down productive self-reflection and creative dialogue. From this unmoving position the vivid recollections of childhood can take on a filmic quality, their predetermined course confirming, rather than challenging, the reader's understanding of the role of memory here. Yet Boland herself refutes this impression by suggesting that even the familiar image has the power to elicit fresh meaning. 'Watching Old Movies as Though they were New' uses the grey and white half-tones of the old films to invoke the speaker's muted apprehension of her earlier life - as though the story they tell could only now be realized by the adult woman recalling them. ${ }^{42}$ Maturity can only be attained by confronting the question of identity, Boland seems to suggest here; likewise the transition towards a self-conscious creative act is a marker of artistic development.

What is most significant in The Lost Land, however, is the role of the sequence in reflecting the poet's own realization that the return to Ireland does not assuage, but instead deepens, the feelings of estrangement registered by the child in London. The dynamics of loss, around which the collection is shaped, express just this: that the growth to emotional maturity - and in this case to aesthetic achievement - involves the recognition that personal experiences of loss are indicative of the grief inherent in the human condition itself. Yet in Boland's understanding this realization is more complex: the extent to which cultural loss fuels her art, yet prevents its complete attainment, creates the unresolvable tension at its heart. Critical recognition is an important dimension of Boland's engagement with the national tradition, and is an integral part of the success of such an interaction: in order to redress the historical imbalance of power, the validity of her ideological and artistic position 
must be agreed. Such an endorsement, however, inevitably reduces the emotional power of her appeal. In other words, the broader the support for Boland's ethical and artistic position, the less reason she has to continue advocating it.

These tensions are played out in the sequence of twelve poems with which The Lost Land opens. Titled 'Colony', this group traces the relationship between the geography of the past and the lives dramatized there. One text in the dozen refers explicitly to her childhood experience in London as formative of such an enquiry - that is 'A Habitable Grief'. By the time this poem is written Boland is sure of the resonance of these memories; rather than writing her way into meaning, she finds it already present in the moment of recall: 'Long ago / I was a child in a strange country: / / I was Irish in England. / / I learned a second language there' ( $L L$ 29). The fairy-tale construction of 'Long ago' reminds us that this is a story told before, and that its preliminary facts can now be presented without embellishment. This stylistic attenuation limits the emotional power of the material, however, and the painful process of acquiring a new language is diminished here: in 'Mise Eire' it struck readers forcibly but now it is a familiar trope. ${ }^{43}$ The grief, the scar, the nation: all now constitute a familiar network of meaning in Boland's work and become, for the reader, a form of memory. Yet this is a deliberate strategy on Boland's part, giving her own texts the power of popular recall. 'A Habitable Grief' is in direct dialogue with 'Mise Eire' and the achievement of that earlier poem is made the greater by this recognition. The value of repetition, then, is not only to articulate the political position anew, but also to give her earlier poems an almost incantatory power. 'A Habitable Grief' confirms this emphasis: its incontrovertible statements concerning the past give way to awareness of the contingent relationship between language and experience; it is not the life lived but the life expressed that creates lasting dynamics of intellect and emotion:

A dialect in which

what had never been could still be found:

That infinite horizon. Always far and impossible. That contrary passion to be whole.

The creative force of language is shown to extend into the past and future here, uncovering a history that never existed and projecting an unattainable desire. Conversely, though, the intertextuality that is now 
part of Boland's practice reminds us that this has already happened, that new poetic forms will stage this 'far and impossible' state and render it no more attainable than before.

The sequence expresses this sense of duration, of living (and reading) through a series of historical circumstances that not only shape the creative sensibility but the literary culture of Boland's time. To open the sequence she returns to the darkness of seventeenth-century Ireland and to the decline of the Gaelic order. ${ }^{44}$ Here she endorses the need for poetry to engage with the brutality of experience, rather than its metaphorical substance only. Cautioning the reader against believing poetry to be 'a gentle art', the speaker argues instead that it must confront the bitterness of personal suffering and cultural loss. The sequence as a whole does not engage long with this period of history but goes on to confront the mixedness of the colonial heritage: the next three poems use the image of Dublin Bay to express the links between the two islands in spatial terms and in doing so to signal the radical differences between these cultures. The harbour conveys the dichotomy of safety and risk; made 'by art and force', it reveals Boland to be increasingly attuned to the necessity of these two processes acts of creation and discipline that both mirror historical circumstance and permit it to be rendered in good faith by the poet. The act of making is an important one: the harbour itself took more than 25 years to build and the stone used was locally quarried, emphasizing the materiality of Boland's use of history. The poem's neat four-line stanzas at first exemplify a carefully maintained order but this structure cannot contain the force for change: 'the Irish Sea rising / / and rising through a century of storms' ( $L L$ I4). Here the energies of revolution overtake the stanza break - an enjambment that once more subsides into regularity yet continues to shape the poem, together with the ships that remain beneath the water as 'slime weed and cold salt and rust' ( $L L$ I4). Declaring herself a citizen of Dublin, the speaker ends 'The Harbour' by recording the city's 'contradictions' and returns in 'Witness' to 'its old divisions' ( $L L$ I5). She again affirms herself as part of its compromised history, describing her speech acts as expressing both dispossessor and dispossessed. The form of the poem captures this doubleness - its stanza length reducing from six lines to four then to two. After its central acknowledgment of the divided self the poem builds again towards its six-line exploration of its own mixed language, alerting us to the power of this combined contraction and expansion in the construction of the poetic voice. 
In 'Daughters of Colony', the harbour is again invoked and the solidity of the built environment is set against the mobile and ephemeral figures of the colonial women, whose faces are sheltered by hats 'made out of local straw' yet who remain entirely remote from their environment.

I see the darkness coming.

The absurd smallness of the handkerchiefs

they are waving

as the shore recedes.

I put my words between them

and the silence

the failing light has consigned them to

The speaker has the benefit of hindsight; she situates the women within the larger trajectory of history, knowing that their fate is to leave Ireland and to be unremembered, thus twice removed from the national imaginary. The sea creates a perspectival instability though; for a moment it is difficult to discern what is moving and what is staying still and this means that both the poet and her subjects are temporarily past and present. Their shared contingency is the means by which Boland signals her affinity with them but also the way in which she ensures that she, as poet, remains the object of her own poem.

Another important space of memory that this sequence confronts is that of the city street. Throughout Object Lessons Dublin's geography, as well as its history, shapes the poet's treatment of the process and material of memory, and in these poems the city is also the locus of the political and military past - 'the long ships, the muskets and the burning domes' that the poet summons from history ('The Scar', $L L$ 19). In some cases these are visionary moments: 'Suddenly, / without any warning, I can see them. / / They form slowly out of the twilight. / Their faces. Arms. Greatcoats. And tears' ('The Colonists', LL 25). In others, human figures are turned to stone, commemorating the past in the city's monuments. The dynamics here are very different: the ephemeral figures emerge and fade in the mind of the poet, whereas the statues testify to a version of history that privileges the heroic male past - 'a lost land of orators and pedestals' ('City of Shadows', $L L$ 2I) and then 'a street of statues: / iron orators and granite patriots. / Arms wide. Lips apart. Last words' ('Unheroic', $L L$ 23). The key contrast here is not between the colonial and the national, between Ireland before and after independence, but between the fixed power structures of 
history and the mobile figures of ordinary men and women: the man 'on the road from Youghal to Cahirmoyle' $\left(L L \mathrm{I}_{3}\right)$, the speaker walking through 'City of Shadows' or bound for home. It is a contrast that evokes the dichotomy between the fixed forms of the printed text and the repeating images we find there.

The sequence continues to be an important dimension of Boland's recent work. A Woman Without a Country, published in 20I4, has a title sequence of thirteen parts - seven poems and six prose 'lessons'. Again it revisits key tropes and stories from the past 30 years of her writing: her grandfather's life as a seaman; her grandmother's death in the National Maternity Hospital; her mother's marriage; Irish women born and made. The structure of the sequence charts a movement between poems that paradoxically calls attention to the difficulty in bridging these glimpsed encounters with the past. The prose lessons are condensed pieces exhibiting a characteristic combination of statement and question; they encapsulate Boland's desire to restate the details of her personal history at the same time as she questions its place in the larger cultural context.

The spaces of the past here move progressively from the experiential to the symbolic, while the idea of legacy informs the whole. 'Sea Change' questions the poet's inheritance from her grandfather: 'What did he leave me, my grandfather, / [...] / / With his roof of half-seen stars / His salty walls rising higher and higher / [...] / He built nothing that I could live in' (WWC 29). The importance of the habitable space, serving past, present and future is contrasted here to the mobility of the ocean and its ever-changing perspectives:

And no one lay at night

Seeing these unfold in their minds with

That instinct of amendment history allows

Instead of memory.

(WWC 29)

The suggestion here that history is open to revision, in a way that memory cannot be, places the apparently fixed points of the national past in question. Yet the 'remembered hatreds' of the landscape and its buried dead are persistent in Boland's imagination, making her unable 'to bring land and ocean together' (WWC 29). It is the power of experiential memory that separates the generations here and that stimulates the prose reflection on her grandmother's life that follows. She died in 1909 at the age of $3 \mathrm{I}$ and the details on her death certificate form Lesson 2 of this sequence. Before that, though, the silence that surrounded her life is 
contemplated in 'Art of Empire'. The end of empire is made possible by the contingent nature of memory: 'If what was not said was never seen / If what was never seen could not be known' (WWC 3I). Acts of witness are conditional here. The course of history is changed, it seems, by the deliberate diversion of memory and the silencing of speech.

There are images to be gleaned from these fractured histories, though, and these combine those already familiar from Boland's earlier writings and the new poems to which we bear witness for the first time as we read. The late nineteenth-century photograph compels the grandmother not only to silence but also to stillness. For once the compulsion of history ('our old villain') is not to blame; instead it is the photographer himself, 'muttering under black cloth' (WWC 32). Increasingly in this sequence it is not the narrative of history that excludes marginal experience but the specific acts of representation that fix the past: the carved figurehead; the 'figures in glass cases'; the 'whole woman' as a copperplate figure of destitution. Boland's endless return to the processes of representation, then, may be seen as a desire to keep the past always in motion, always in productive exchange with the present.

Boland's achievement as a poet is closely linked to her realization of these complex relationships and to her awareness of the necessity for continuous re-engagement with the processes of memory. Her representation of childhood experience is an important means of linking personal and cultural memories and thus of transforming a remembered experience into an interrogation of the nature of memory itself. Halfway through a recent essay on the woman as citizen-poet, Boland states that her real subject is reading: 'How we read a poem. How we fail to read it. Beyond that, my subject is the moral responsibility of the poetry reader.' 45 The significance of the reader's position - and its close proximity to that of the poet - are essential aspects of Boland's poetic imaginary, reflecting the importance of relationships in all aspects of her personal and creative life. The personal past comes to embody the precarious nature of both emotional attachment and the intellectual processes needed to interpret it. It is a testament also to the interwoven conditions of remembering and being remembered which are crucial to how Eavan Boland is positioned in Irish poetry criticism today.

\section{Notes}

I Jody Allen Randolph, in the introduction to her study of Boland, explores the significance of the poet's work - and her critical reception - in setting the agenda for many of the debates on Irish women's poetry in the past 30 years. See Jody 
Allen Randolph, Eavan Boland (Lewisburg, PA: Bucknell University Press; Cork: Cork University Press, 20I4), pp. xv-xxxi.

2 Marianne Hirsch and Valerie Smith, 'Feminism and Cultural Memory: An Introduction', Signs: Journal of Women in Culture and Society 28.I (2002), p. I5.

3 Catherine Kilcoyne, 'Eavan Boland and Strategic Memory', Nordic Irish Studies 6 (2007), p. 90.

4 The profound changes in Britain's social and cultural life in the immediate post-war period can be traced in the diverse responses of writers living and working in the capital during these years, from texts that reflect anxiety at the loss of political power to those exploring avant-garde modes to engage directly with the processes of cultural change. See Alistair Davies and Alan Sinfield (eds), British Culture of the Postwar: An Introduction to Literature and Society, 1945-1999 (London: Routledge, 2000) and Robert Hewison, In Anger: Culture in the Cold War 1945-60 (London: Methuen, 1988).

5 Boland's isolation from the more dynamic aspects of London's culture during this period is due both to her geographical location and her social position within the city. She lived at the Irish embassy in Grosvenor Place and went to a convent school in Hampstead and in this way she remained largely insulated from the lives of the less privileged. Just as the embassy itself is Irish 'territory', so Boland's experiences are markedly different from those of other London citizens. I am grateful to Jody Allen Randolph for clarifying some details concerning Boland's early years.

6 Eavan Boland, A Journey with Two Maps: Becoming a Woman Poet (Manchester: Carcanet, 2OII), p. 48.

7 James Conlon, 'Cities and the Place of Philosophy', in Sharon M. Meagher (ed.), Philosophy and the City: Classic to Contemporary Writings (New York: State University of New York Press), p. 203.

8 For further elucidation of the transition from memory as reproduction to memory as representation, see Richard Terdiman, Present Past: Modernity and the Memory Crisis (Ithaca, NY and London: Cornell University Press, 1993).

9 Catherine Kilcoyne has suggested that Boland's movement from margin to mainstream has the potential to threaten the poetic authority she derives from being outside Ireland's (male-dominated) poetic tradition. Kilcoyne argues that memories of Boland's own past exclusions allow her continued identification with a marginal position. Kilcoyne, 'Eavan Boland and Strategic Memory', p. 90.

Io Jody Allen Randolph, 'Interview with Eavan Boland', Irish University Review 23.I (Spring/Summer, I993), p. II7.

II Roland Barthes, 'Semiology and the Urban', in Mark Gottdreiner and Alexandros P. Logapoulous (eds), The City and the Sign (New York: Columbia University Press, I986), p. 96.

I2 Immanuel Kant, 'Towards Perpetual Peace' and Other Writings on Politics, Peace and History, trans. D. L. Colclasure (New Haven, CT and London: Yale University Press, 2007), p. 82.

I3 Jacques Derrida, Of Hospitality, trans. Rachel Bowlby (Stanford, CA: Stanford University Press, 1997), p. 75.

I4 Jody Allen Randolph, 'Interview with Eavan Boland', p. I29.

Is Simon Critchley, Ethics-Politics-Subjectivity: Essays on Derrida, Levinas and Contemporary French Thought (London and New York: Verso, 1999), p. 63.

I6 Clive Barnett discusses the ways in which Derrida problematizes this dynamic 
- and Levinas's treatment of it - in his essay, 'Ways of Relating: Hospitality and the Acknowledgement of Otherness', Progress in Human Geography 29.I (2005), pp. 5-2I. The presence of intention means that acts of hospitality are often ones of incorporation, designed to eliminate the specific otherness of the visitor. A failure on the part of a visitor to enact such a smoothing out of identity difference will result in rejection.

17 Eavan Boland, Object Lessons: The Life of the Woman and the Poet in Our Time (London: Vintage, 1995), p. 234.

I8 Julia Kristeva, Strangers to Ourselves, trans. Leon S. Roudiez (New York: Columbia University Press, I99I), p. I8I.

I9 Eavan Boland, Object Lessons, p. IOI.

20 Eavan Boland's mother was the artist Frances Kelly. Born in Drogheda, Co. Louth, in 1908, Kelly studied at the Metropolitan School of Art in Dublin and later with Léopold Survage in Paris. Critically acclaimed from an early stage, her first solo exhibition in 1934 was praised for the 'delicate, subtle observation of her work'. Later, her role as ambassador's wife took precedence over her career as an artist. She exhibited no work after 1954 (Dictionary of Irish Biography).

2I Boland recalls learning the Thomas Hood poem: 'I remember, I remember / The house where I was born' (Object Lessons, p. 38). Here she reprises part of the key phrase, replacing the comforting sense of origin with a recognition of displacement and loss. The poem also echoes Philip Larkin's 'I Remember, I Remember' and its articulation of the emptiness of the past.

22 It exemplifies Catherine Kilcoyne's assertion that 'the poetic originality of Boland's use of memory is the gap that it creates ... between the sought after memory and the same memory unattained, the memory which is desired but always out of reach'. Kilcoyne, 'Eavan Boland and Strategic Memory', p. 90.

23 Boland, Journey with Two Maps, p. 20.

24 Barnett, 'Ways of Relating', p. 6.

25 Maurice Halbwachs, The Collective Memory, trans. Francis J. Ditter and Vida Yazdi Ditter (New York: Harper Colophon Books, 1980), p. 79.

26 Pierre Nora, 'Between Memory and History: Les Lieux de Mémoire', Representations 26 (Spring 1989).

27 Sam Wineburg's distinction between memory as 'knowing the past using the ordinary sense-making capacities' and history as 'knowing it as the result of disciplined habits of mind' adds support to the linking of the writing of history with specific agency. See Sam Wineburg, Historical Thinking and Other Unnatural Acts: Charting the Future of Teaching the Past (Philadelphia, PA: Temple University Press, 200I), p. 248.

28 This material is elaborated upon in Object Lessons (1995), pp. 38-9:

the vista was almost always, that first winter anyway, of yellow fog. If the windows were open, it drifted smokily at the sill. If the doors were open and you went into the street, you entered a muddled and frightening mime. Passersby were gagged in white handkerchiefs. The lights of buses loomed up suddenly. All I knew of the country was this city; all I knew of this city was its fog ... It was March, my first one in England. A swell of grass, a sort of hummock, ran the length of the window and beyond. It had been planted with crocuses, purple, white, yellow. I may not have seen them before; I had certainly never seen so many. There and then I appropriated the English spring. 
29 Allen Randolph, 'Interview with Eavan Boland', p. I28.

30 Ibid., p. I27.

3I Anne Fogarty, "I was a voice”: Orality and Silence in the Poetry of Eavan Boland', in Elke D'hoker, Raphael Ingelbien and Hedwig Schwall (eds), Irish Women Writers: New Critical Perspectives (Berne: Peter Lang, 20Io), p. Io.

32 Ibid., p. I8.

33 Catriona Clutterbuck, 'Irish Critical Responses to Self-representation in Eavan Boland, 1987-1995', Colby Quarterly 35.4 (1999), p. 278.

34 Boland herself has acknowledged the self-consciousness of the poet, of the need 'to create an artifice to replicate the way I built my thoughts' (Journey with Two Maps, pp. 19-20) so that the immediacy of experience can be combined with a measure of objectivity.

35 Derrida, Of Hospitality, p. 89.

36 Boland, Object Lessons, pp. 55-6.

37 Boland, Journey with Two Maps, p. 51.

38 Clair Wills, Improprieties: Politics and Sexuality in Northern Irish Poetry (Oxford: Oxford University Press, 1993), p. 59-60.

39 Eavan Boland, 'Daughters of Colony: A Personal Interpretation of the Place of Gender Issues in the Postcolonial Interpretation of Irish Literature', Eire-Ireland: A Journal of Irish Studies 32.2/3 (Summer/Autumn 1997), p. I3.

40 Katie Conboy, 'Lays of the Land'. Review of The Lost Land by Eavan Boland, and Meadowlands by Louise Gluck, Poetry Ireland Review 60 (Spring 1999), p. 97.

4I Eavan Boland, quoted on cover of The Lost Land (Manchester: Carcanet, 1998).

42 Though this poem evokes the years Boland spent in America as a child, many of the techniques of recollection are similar to those describing her London experience.

43 'Mise Eire', from The Journey and Other Poems, ends: 'a new language / is a kind of scar / and heals after a while / into a passable imitation / of what went before' ( $\mathrm{III}$ ).

44 The poem was inspired by the life of Dáibhi Ó Bruadair, who was born in 1625 and, though an accomplished poet, ended his life as an impoverished labourer. Ó Bruadair was an inspiration to Michael Harnett, whose translations of his work were published by Gallery Press in 1985 . See Jody Allen Randolph, Eavan Boland, p. 136.

45 Eavan Boland, 'A Woman Without a Country: A Detail', PN Review 4I.2 (November/December 20I4), p. 49. This issue of PN Review features a celebration of Boland's work, edited by Jody Allen Randolph and Michael Schmidt. Contributors include Mark Doty, Lorna Goodison, Máighréad Medbh and Paula Meehan. 


\title{
Between Here and There
}

\author{
Migrant Identities and the \\ Contemporary Irish Woman Poet
}

Ireland's dual tradition is a catalyst for debate on cultural diversity in both language and literary production. For more than a century Ireland's relationship to its diasporic populations has been important in the formation of a body of literature that exceeds the territory of Ireland itself and facilitates new relationships between the Irish tradition and writing in other languages and from other cultures. From the r990s until the onset of recession in 2008, the direction of this movement was reversed, so that Ireland became home to a significant immigrant community, enriching its cultural and linguistic life. ${ }^{1}$ In an era of global mobility, geographical movement becomes an important part of artistic formation, as well as a human experience shared by many; recent critical perspectives reflect the significance and connective potential of this phenomenon. ${ }^{2}$ This mobility can vary in expression from writers who choose to live and work abroad for months or years, to those who, for economic or political reasons, need to leave their place of origin. Irish writers have a long history of emigration, and for the most famous exemplars - James Joyce and Samuel Beckett - both exposure to new cultural environments and distance from Ireland provided a fruitful perspective for innovative creative work. In recent decades migrants coming to Ireland have also challenged traditional representations and offered collaborative potential to resident writers.

Migration has often been linked to marginality, as both the cause and the effect of the journey away from a place of origin. This dynamic calls attention to the subjectivity of the individual migrant, and to their particular relationship to place: for this reason the migrant's 'departure' 
from their home may precede the actual journey, marking a detachment from that society which is later articulated in geographical movement. ${ }^{3}$ For contemporary Irish poets who have chosen to live abroad, the decision to leave is often framed by careful reflection - a process exemplified by Thomas Kinsella's long poem 'Phoenix Park' that immediately preceded his departure for the USA. ${ }^{4}$ For women poets there may be less textual deliberation, though attentiveness to the journey itself and to the early days in a new country can yield significant poems as Mairéad Byrne and Vona Groarke have shown in their writing of America. Often, questions of identity, and of belonging, are raised by the process of movement itself - it is the experience of being an outsider that prompts the individual to reflect on his or her own subjectivity in new ways. Exposure to forms of thinking and expression that are distinctly different from our own also challenges our customary intellectual and creative practices. For some writers, such as Byrne, this has meant an increasingly innovative approach to form and style; others choose to extend theme and idiom within the lyric mode. For any artist or writer, not consciously knowing 'what she or he will be in the next time and space' has a significant impact on both the imaginative roots and the aesthetic execution of the work. ${ }^{5}$

Temporality is key to the interpretation of the migrant state, and to the way in which home is conceptualized. Philosophical writings by Martin Heidegger and Gaston Bachelard, among others, develop an understanding of home that is bounded and therefore marks a special relationship between the individual and place. 6 More recent thinking, however, construes home as dynamic and in flux, as globalization changes the nature of attachment to place and community. This change has prompted a radical re-evaluation of the concepts of home and belonging:

'Being home' refers to the place where one lives within familiar, safe, protected boundaries; 'not being home' is a matter of realizing that home was an illusion of coherence and safety based on the exclusion of specific histories of oppression and resistance, the repression of differences even within oneself.7

This fundamental change in how home is read finds expression in the work of contemporary women poets through their questioning of private or domestic spaces, ${ }^{8}$ as well as through their reflection on connections to place that are simultaneous and overlapping: 'Rather than movement from one place to another uprooting or deterritorializing migrants' identities - as has been intimated - what scholars witness 
among contemporary migrants is a strengthening and deepening of ties to multiple places.'9 Thus migrants themselves do not have singular identities but rather networks of connection with the places where they have lived. Mairéad Byrne exemplifies this condition, as her comments in a conversation with Rob McLennan suggest:

Before I lived [in Providence, Rhode Island], I lived in Oxford, Mississippi, before that Ithaca, New York, and before that Lafayette and West Lafayette, Indiana ... I'm very aware of place but move on easily, or at least I have so far. But I still think about the places I have lived; and the places members of my family have lived: all their smells and atmospheres. ${ }^{10}$

Byrne values the mobility that her life choices have offered but still retains an artistic, even sensory, attachment to the places of the past. Similarly, Mary O'Malley's work reflects her close links to the west of Ireland, but also to Lisbon and to Paris - places where she has spent formative periods of her life; in a somewhat different mode, Celia de Freine moves among different geographical spaces of reflection and creativity. ${ }^{11}$ For some the new place quickly becomes 'home' and the self/other binary that informs all migrant experience is changed by the process of integration. For others, the idea of returning home remains a stable element in their ever-changing life, and its articulation emphasizes what John Steinbeck has called the 'outward sign of want' that marks all migrant lives. ${ }^{12}$

Migrants may come to express the problematic boundaries between individual and collective positions in important ways, and in doing so to highlight the role of language, and of literature, in exploring these dynamics. To join an immigrant community is often to question the relationship between individuality and group identities, in part because of the discursive tendency to homogenize diasporic experiences in spite of their 'contradictions, diversities and instabilities.'13 For example, none of the contemporary Irish women poets who has lived in the USA identifies directly with Irish America, preferring instead to reflect on cultural difference in more contingent ways. Yet many of these poets do contemplate their life outside Ireland as one of private and public significance, insofar as their cross-cultural movement prompts reflection on patterns of historical and cultural particularity. For this reason there are close, if subtle, links between the consideration of personal experience and identity politics in these poems. The concept of home at once shapes private aspirations and operates as a founding principle of the nation state that in turn unifies the spatial and temporal aspects of home. Though this association has tended to obscure its personal 
resonance, ordinary people nonetheless 'engage in theorizing about and acting in the narrative(s) of nation'.14 This privileging of the conceptual over the experiential may itself mask the capacity for individual circumstance to be delimited by larger symbolic structures, an issue that relates not just to nationalism but also to movements specifically hospitable to the marginalized. Some of the key critical interventions in this area, including Chandra Talpade Mohanty's Feminism Without Borders, have problematized the identification of feminism itself as a 'home': Mohanty expresses the desire to unsettle 'not only any notion of feminism as an all-encompassing home but also the assumption that there are discrete, coherent and absolutely separate identities.'. ${ }^{15}$

Salman Rushdie sees migrants as metaphorical beings, suggesting that the spatial journey is expressive of less visible forms of border crossing - between one political or ideological belief and another, for example, or between the past and the present. ${ }^{16}$ This temporal shift is an important one for migrants, giving memory a particular valency in defining their past selves and in recording the transition they have undergone:

Memory - understood as the complex relation of personal experiences, the shared histories of communities and their modes of transmission - must be seen as a privileged carrier of diasporic identity ... It is not by chance that the right to remember, the responsibility to recall and the 'sense of the dangers involved in forgetting' are central issues of debate among diasporic communities and in their relations to their cultural and political surroundings. ${ }^{17}$

The originary identity of the migrant is held in memory and is capable of transcending the specific circumstances of his or her present experience, yet it does not facilitate the direct retrieval of the past but rather a continuing state of being that juxtaposes the lost past and a yet-to-be-achieved future. The process of remembering is an unreliable one, however, further adding to the instability that displacement brings. ${ }^{18}$ Since memory is not reproduced from the original conditions of experience, but rather represented from the perspective of present conditions, ${ }^{19}$ it becomes transcultural, interweaving distinct forms of habit and identity together. The mixed character of memory's form and function leads to original perspectives from migrating poets. 


\section{Remembering the Future: Mairéad Byrne in America}

Mairéad Byrne's work shows a complex alignment between her evolving poetic style and the cultural space in which this occurs. Born in Dublin, she moved to the USA in 1994 (with $\$ 400$ and a seven-year-old child) and now teaches poetry at the Rhode Island School of Design. ${ }^{20}$ The relationship between Ireland and America plays an important part in her work, especially in the earliest poems, which combine lyrical elements with found poems to create formally challenging texts, laying the groundwork for her more radical experimentation of recent years. The evolution of her style is crucially linked to her cultural position, and this is often the subject of deliberate scrutiny in her poems. Ireland is at once past and present in these texts - a memory of earlier experience and a continuing part of her creative life. Nelson and the Huruburu Bird, published by Wild Honey Press in 2003, expresses the importance of these transitions in shaping Byrne's ongoing work. The poems in this volume are taken from three unpublished books, An Interview with Romulus and Remus, Cycling to Marino and The Pillar - all are maintained as separate groupings in this printed volume. This structure does not privilege a narrative of poetic influence and development, however, but rather presents an intermingling of Irish and American material and experiences. This is indicative of Byrne's close creative connection to her immediate environment, which questions, rather than affirms, notions of national affiliation and tradition.

Many of her early poems engage directly with Dublin, specifically the Dublin of her childhood and early adulthood. 'Cycling to Marino' begins with an evocative description of cycling to school in autumn, but soon becomes more concerned with the classroom as a place of difference: 'We know someone's / not clean, and someone's poor ... Where are those places / other people live?' (NHB 46). The shift from a singular to a collective viewpoint marks the speaker's arrival at the school and her entry into an undifferentiated world of childhood experience, where the individual conditions of each child's life become visible only when they mark a variation from some unstated norm. Both the particularity and the ephemeral quality of these early experiences are rendered here, and, with these, a sense of what the craft of making can yield:

We're learning how to sew, to knit, each stitch has singularity, then holds its shape in partnership with the next, and next - 
The initial Yeatsian resonance here ('The children learn to cipher and to sing, / To study reading-books and histories, / To cut and sew, be neat in everything') is turned against itself in the singularity of the young girl learning a craft. ${ }^{21}$ As the metaphor demonstrates, the unique creation becomes an essential part of the collective entity, just as the individual perspective is inextricably linked to its cultural context. The complex relationship of part and whole may be framed aesthetically too: each line of the poem 'holds its shape / in partnership with the next'. The energies of the young girl give rise to abrupt and exhilarating changes in language and perspective from ethically curious 'but what does poor mean?' to the self-consciously poetic 'I dismount, / escorting her through the bowers that I know best, / stern arch of branch, cascade of leaf' $(\mathrm{NHB} 46-7)$. In the child's response to place the sensory immediacy of present engagement - the sound of rain beneath the tyres of her bicycle, the 'Metallic taste of ink on lips' - is tempered by a growing awareness of the need to withhold these experiences from adult awareness. In this way the personal past remains interiorized until the poem at once records and breaks this privacy.

Elsewhere too, the relationship between individual and collective experience is probed. 'The Pillar', explores Dublin in both space and time, using Nelson's Pillar as a pivotal point around which private and public observation moves.22 In this way, Byrne uses the physical environment of the city and its monumental history to create a dynamic space in her poem, in which the relationship between what is fixed and what is changing is a key both to ideas that circulate in the poem, and to the formal strategies she adopts.

Clouds scud, what else, in the gray sky, and yes,

gulls hang all the way out, to the bay, I guess,

[...]

that old familiar drizzle

emptying the dawn, down all the days, the yellow city nights; and his head sleek

like a lizard, like a cobra, like a basilisk

inserted in our heavens, in the bells'

clamor, clangor, Nelson, lord of us all.

(NHB 82)

Nelson's head, in the sky, typifies British ambition, but offers a point of surveillance that serves the poet well in her investigation of the relationship between the larger patterns of history and the materiality of lived existence in the city - a concern that will persist in her later 
work. Even in this early poem her treatment of temporality is already striking: Dublin life is first seen in dynamic terms 'battering', 'clattering', 'clip-clopping' and then with a kind of trapped energy - 'Henry Street, / the gorge chock-a-block, rain melting down its windows, / and the women's rough mouths like O's roaring Toblerone or / Get the last of this or that' (NHB 82). In this crowded sensory world, words and phrases in the Irish language brim over at intervals, together with the hibernicisms that bridge the two languages with sound patterns familiar to the Irish ear:

So this was dubh le daoine and we were shoulder to shoulder ag baint dhá thaobh den bóthar, drink or no drink, for sure, we were iseal, right enough, as iseal as iseal could be beneath our uasal, casting his long shadow on us, and we in our stew, in our soup, in our mate and potatoes mess. ${ }^{23}$

(NHB 83)

Sounds are vital to the energy of this poem and internal rhyme is often used as a vehicle for wit, and to knit together a wide range of experiences, past and present. This strategy demonstrates the uneasy mix of tradition and modernity that shapes Dublin. Events - both historical and everyday - are telescoped, leaving Nelson on his pillar as the still monumental centre around which frenetic action takes place: 'He was there all that time and before that time. / He was there through Cinerama and Panorama and Senssurround / He was there in all the pantomimes' (NHB 85). Nelson's omnipresence in the life of the city robs him of his real significance, however; all his exploits - both attested and apocryphal - are denied: 'He never routed privateers from Montego to Honduras / nor terrorised Americans as captain of the Boreas / [...] / nor lost an eye at Calvi an arm at Tenerife / in the dog-days in the lion sun nor his heart to Lady Hamilton' (NHB 86). In 35 lines, his rich and varied career is reduced to his symbolic presence at the centre of Dublin, a testament to the capacity of the Irish to make all things relevant to their predicament. Yet the textured and jaunty rhyme scheme at once makes much, and makes light, of the admiral's exploits. The blowing up of Nelson's Pillar by the IRA in 1966 dismantles the myth of Nelson and the literary associations of the monument. Though Byrne does not dwell on the political connotations of this event, it is nonetheless present in the poem and resonates with the social instabilities also revealed through observed detail.

This view of Dublin, and of Ireland, is far more complex than the energetic, often flippant, tone suggests and it is a hallmark of Byrne's 
work that difficult social and emotional states are carried by a vivid materiality in her texts, highlighting the varied human responses to place. As Rebecca Seiferle has commented, Byrne 'eschews the poetic "I" in favour of a listening to other presences'.24 This dynamic reveals her awareness of the relationship between physical and creative spaces, and her recognition of the distance between her work and much of what was being published in Ireland at that time:

before I left Ireland, a poet called Joan McBreen said to me, 'Your poems are not lyrical.' I was surprised but it seemed true. In the context of Irish poetry it was sort of like hearing, 'Your poems are not poems.' It was time to go. ${ }^{25}$

Humour is vital to Byrne's creativity and often determines the way she frames her work: 'Humor in women isn't valorized. Humor in poetry isn't valorized', she observes in her zoro conversation with Sina Queyras; later she admits 'I should be thinking about global warming but I like to laugh', a comment ironically revealing the seriousness of conviction underpinning her poetry. This playful quality is present from her creative beginnings. In Nelson and the Huruburu Bird memories of her early working life - 'Cycling to Marino', 'Early Morning, Dublin' - mingle with alphabet games that play with the cultural resonance of car brands: 'A is for Acclaim. / B is for Buick. / C is for Chevy' (NHB 34-5). In this way Byrne productively disturbs the linearity of memory, which would place the structures of childhood in an Irish context and those of more recent adulthood in America. This mingling of effects shows the broader cultural interpenetration of Ireland and America, especially from the 1960s onward, and the extent to which globalization subverts narrow national boundaries. ${ }^{26}$ In 'The Irish Discover America', Byrne reflects directly on her own move to America, emphasizing the sensory nature of the experience:

\footnotetext{
We hit land and suddenly everyone has an American accent.

How did I get here?

I traveled the few inches, thousands of miles, in my own skin boat, my currach, my Boeing.

For the first time I look at the outside world.
}

(NHB 32)

In likening her journey to America to the Brendan voyage, which claims that Irish saint Brendan traveled across the Atlantic ocean before Christopher Columbus, Byrne not only highlights the importance of the step but also its perilous nature. ${ }^{27}$ From the beginning, a sense of the 
provisional shapes the poem - 'If Saint Brendan crossed the ocean ... if I have flown the same trail' (NHB 32) - and this act of questioning is matched by the fragmented memory of the journey itself: 'I have turned the world inside out. / I know it in my bones but can recall fragments only'. Contemporary and historical perspectives mingle in the poem, linking the insular experience of flying across the ocean to the physically and psychologically demanding character of early voyages. Language is one of the casualties of this radical experience - 'language, / at this altitude, ceases to exist' (NHB 33) - and with it the historical perspective necessary to understand complex cultural relationships. Here the 'Red Indian' is envisaged arriving on a jumbo jet in a strangely disorientated version of American history. Yet this native girl 'who stares so calmly and so long' may be linked to the speaker's young daughter, so that what was once so intimately known becomes other in this new and strange space.

'Reflex' is another poem that links geographical change with important alterations of personal circumstance. Its title suggests the instinctive reaction that the subject may make to such changes. From its opening, then, this poem interleaves the immediacy of emotional response with the considered process involved in the making of a poem, and alerts us to the fact that so much of Byrne's work keeps these elements in delicate balance:

It is not, after all, the water, slate of the bay, nor the promontory, curve of the regulated city, salt rush, that I miss, nor heading out somewhere with you.

(NHB 45)

The remembered place is already a boundary, a place on the edge of land, telling us much about the speaker's sense of being in the world. The first line of the poem also foregrounds the relationship between feeling and thinking - on reflection, it is not the sight and smell of the coastline that evokes the sensation of loss, nor even the experience of sharing that place with someone. Instead it is what is beyond description - 'some things which never / got a name' - which tethers the speaker to the past $(N H B$ 45). Yet by the end of the poem we learn that this is only part of the story. It is the 'you' invoked in the opening stanza whose loss finally moves the speaker: the sight of the 'full / lips of a stranger' calls forth a strong emotional response that relates not only to similarity of appearance but the complete sensory connection to another person, and the tears this prompts are an answering response from the eyes 
that witness the scene. In this short and seemingly simple poem Byrne conjures the circulation of emotions between places, objects and people, and, though the poem suggests the displacement of loss from the deeply personal connection to one more broadly cultural, instead we might read all forms of connection as valid - each one proximate to the others.

Byrne's American poems in this volume have a dramatic energy that partakes of the confidence of the culture in which she has settled. Marked by the prevalence of verbs, and by their exclamatory style, they are indicative of the ways in which language itself is shaped by shifts in culture and perspective, as the poem 'Commercial Street' demonstrates:

This is not home and I don't have to stop to pass the time of day or night with you or anyone. I'm free of that, home too, and greedy for the sights

(NHB 40)

By linking 'home' with the demands of community and connection, Byrne at once suggests the freedom and limitation of American materialism. Her new twist on an old-fashioned phrase, such as 'to pass the time of day', shows American expansiveness in subtle ways - 'day or night', 'you / or anyone' - calls up the range and multiplicity of American experience over its more muted Irish counterpart. This variety is figured in terms of appetite - the speaker is 'greedy' for the sights, wants 'to gobble this week's crop / of extras' - and she devours the new vocabulary as eagerly, wanting to 'cruise / the block, the beat, this neat New England zoo' (NHB 40). This particular line exemplifies not only the incorporation of an American idiom but the desire to play with this language shift as constitutive of the poetic line. Her choice of the 'block' as a descriptor of urban space invokes the origins of rap music, which has already been rendered in the tightly repeated sound patterns of 'shop ... sort ... sift' and is in turn reinforced in the alliterative 'beat', with its suggestion of the cruising car, loud with rhythm. The 'beat-neat' rhyme is the outcome of this MCing technique but is only made possible by the American meaning of 'neat' as pleasant or excellent, marking a shift away from urban subculture towards small town American boosterism. In taking in this new language - in its many forms - Byrne also transforms her tone towards the cheerful exclamatory presentation that is associated with the positivity of American life, a strategy that for her combines optimism and irony. This 'trying on' of language is both a sharp cultural observation and a natural play of voice that will become still more important in her later work. 
The adaptation of lifestyle and of language that Byrne's poetry fundamentally addresses can be seen strikingly in Talk Poetry, a volume of short prose poems published in 2007 and which Byrne herself describes as a 'breakthrough'.28 The volume itself, like the 2010 The Best of (What's Left of) Heaven, reveals how Byrne's innovative approach to language drives her handling of found and imagined texts. She has commented on the importance of performance to her creativity and this clearly influences the combined intimacy and reach of her work: 'Public readings are integral to my practice and process ... [They] are a type of interdisciplinarity, or collaboration for me'. ${ }^{29}$ Her evolving practice has shaped the reception of her work in other ways too. The Best of (What's Left of) Heaven is a volume comprised of blog poems, intensifying the role of the internet in Byrne's writing. She discusses how this has shaped her practice in the Queyras interview, revealing the role of technology in the change:

As far as writing goes, the title or concept and a cluster of lines, maybe the first few lines, usually came first. I collected those immediately in a notebook. Then I'd put them in Word documents ... These days I am much more inclined to compose in HTML, or Photoshop. I like to compose in the medium of publication; it's also a way to learn. ${ }^{30}$

In this way the poem, as well as the poet, are shown to have migrated to a new environment - one that is closer to the energies of the public space. The present moment shapes many of Byrne's preoccupations too, yet, though much of her recent material emerges from the immediate environment, there are other, less direct, influences at work. These demonstrate how significant the act of border crossing can be in shaping aesthetic practice: 'The Best of (What's Left of) Heaven doesn't mention Ireland once,' she observes, 'but it's an intensely Irish book, in structure and attitude' (Queyras interview). The virtual world has also helped her to create a new kind of mobility as an artist: 'Regarding Ireland: I did not fit the role of poet in Ireland in any way ... The internet gave me a shoe-horn. Now I can walk around quite happily there' ${ }^{31}$ In this way, cyberspace, though less intimate than a personal encounter in real time, offers Byrne a way of dealing with the estranging effects of exclusion from a national literary culture. It does this not only by reconfiguring the concept of community but by offering a compositional space that validates her desire for experimental modes. Likewise, 'A Hive of Home' from Talk Poetry returns to the idea of home as a concept constantly remade. The person who is 'unreasonably fond of home' (TP 37) is not rendered immobile but 
rather seeks home everywhere: 'Libraries are de facto homes. Bookstores are hotels. Hotels are homes though I don't usually stay in them in Providence. A bus can be a good home' (TP 37). This attitude obliquely clarifies the relationship between Ireland and America in her work both environments are constantly evolving and thus the relationship between them is in a productive state of flux.

'After Valentine's Day' is a poem that examines the dynamics of separation and connection more distinctly. It captures the beginning of the thaw, towards the end of a harsh winter, suggesting both the potential for greater ease and a degree of exposure as the insulating snow retreats. The formal regularity of the poem - four stanzas alternating between ten and twelve lines each - marks the containment of the subject position, and the structures underpinning this uncertain life. From the beginning, though, the thaw suggests a transition with power to disturb: the opening image of lost gloves 'sprouting' on the sidewalk hints at the speaker's own sensation of being separated or adrift in a strange landscape. The possibilities for communion with others are impressive but fleeting:

Strangers move toward me

as if to say hello;

they carry their faces like cups,

which tilt, at the instant of passing,

spill out such radiant smiles!

(NHB 67)

The neighbours who come bearing red roses, in an approximation of a Valentine's gift, make no impact on the speaker, however, who 'takes[s] what's given' and resumes her work. The poem suggests the difficulties in giving and receiving the appropriate meaning in a culture within which one is isolated: neither poetry nor roses functions as a means of communication, except to the extent that they provide material for this poem. This consciousness of the poem as the space within which life unfolds, at once randomly and deliberately, sees language as an instrument of estrangement as well as of connection. Byrne's increasingly self-reflexive mode of writing suggests that this may be the truest reflection of mobility and change - a poetics always aware of its own contingency and attentive to the larger cultural meanings this generates. 


\section{Sinéad Morrissey between Belfast and Japan}

Sinead Morrissey is a poet for whom movement, transition and adjustment are key explorations. Her most recent collection, the award-winning Parallax (2013), draws attention in its title to the relationship between the object under scrutiny and the angle of view. ${ }^{32}$ A collection filled with visual and material signifiers of the past - from Dorothy Wordsworth's Grasmere Journal to John Wright's electroplating workshop - it marks the poet's awareness that material culture offered more evidence of the world's flux than of its stability. Throughout Morrissey's work to date, that sense of changing perspectives has been key to the responsiveness of her poetic voice as well as to her aesthetic evolution. Growing up in Belfast, she was struck early by the complications of religious faith and the difficulties involved in the growth towards autonomy. Many of the poems in There was Fire in Vancouver (1996), her first collection, are strongly anchored in childhood - in the streetscapes of Belfast and the communist politics important in the lives of her parents. This ideological background, to which she returns in later poems, meant she identified with neither community in Northern Ireland and was beginning to problematize the process of identity formation before she ever left the province. Gerald Dawe has drawn attention to the capacity of poetry to transcend simplified forms of cultural memory,33 and in mediating these political territories Morrissey acknowledges their importance for poets and readers: even indirect representation reveals the subtle ways in which memory is politicized. The violent weather of this first book - with its 'frightening rain' (TFV I2) and a wind that blows 'as though the angels are angry, sitting in the sky / With heads in hands and howling it out all over us' (TFV I7) - contributes to its risky handling of spiritual matters as well as of the realities of terrorist violence. At times, this early poetry lacks subtlety but it provides an important foundation for Morrissey's later, more assured and complex poems and prepares the reader for the unflinching quality of her art. This early work also prompts reflection on the role of textual memory in Morrissey's work; the way in which later poems return to images and ideas already explored.

One of the enduring strengths of Sinéad Morrissey's work is her exploration of the poet as a conduit between people and cultures. Morrissey's 2002 collection, Between Here and There, captures formally the sense of liminality that has been present in her poems since the start. The second of her five published collections to date, this book 
marks a significant consolidation of both theme and form. The structure of this collection traces the specific cultural transition that lies at the heart of this volume: the period that Morrissey spent living and teaching in Japan. ${ }^{34}$ The second half of the book is dedicated to this experience and presents a series of poems with interwoven themes and images, rendering her engagement with Japanese culture in succinct, even minimalist ways. The extent to which her own poetic style is shaped by this cultural encounter indicates the formative nature of this period for Morrissey, and reflects both the strange and enlightening quality of the experience. She has acknowledged the extent to which Japan helped to shape her creative development at this time: 'When I went to live in Japan my writing changed immediately and profoundly. My line became much longer, the imagery more surreal. The poetry became a great deal more ambitious.' ${ }^{35}$ Between Here and There is prefaced by a poem that contemplates this significant change of voice: 'My voice slipped overboard and made it ashore / the day I fished on the Sea of Japan' (BHT 9). This prefatory poem is divided into two parts, mirroring the shape of the collection and suggesting the precision and balance required in embedding these experiences in the larger trajectory of her work. The escape of the voice, and its 'lonely sojourn' on the Honshu coast, happens almost imperceptibly while the speaker is preoccupied with the mastery of a new language and of different and challenging circumstances. The return of the voice, now marked by its new experiences and discoveries, is essential to the achievement of this volume, suggesting that shifts not only in culture but also in language, are essential to creative development.

The first poem in Between Here and There is 'In Belfast', so that it suggests a writing process that is both other to, yet the same as, her initial collection, which also places Belfast in the foundational opening text. This act of 'writing back' to her first book reminds us that the Here and There of the title are not only spatial but also temporal; Morrissey wants to remember her earlier poetic self and to contemplate obliquely what this growth and change have meant for her as an artist. 'In Belfast' is a poem in two perfectly balanced parts, affirming the dialogue between the halves of Morrissey's creative life at this point. Just as the voice of the prefatory poem goes out and returns, so this poem concerns itself with the place and the dynamic movement associated with it. In the first part of the text the relationship between place and history is investigated through the city's architecture and the atmosphere that surrounds it: City Hall is a ship 'steered' 
by Queen Victoria; shop fronts breathe the air of the city, while the headquarters of the Transport Workers' Union 'fights the weight of the sky' (BHT I3). Here the elements seem to encroach on the city, shaping its mood and indicating the challenges of pursuing normal life there. The opening line of Part II of the poem declares the speaker's return 'after ten years to a corner', interweaving ideas of shelter, entrapment and punishment in that single word. This process of return is a sensitive one for the migrant: as Paul Walsh acknowledges, to return may in fact be to begin again, in a place that resembles the past but can never be identical with it. ${ }^{36}$ At first Morrissey must convince herself that the city is 'real' before concluding that it is 'More real, even, with this history's dent and fracture / / splitting the atmosphere' (BHT i3). This sense of Belfast as a place apart complicates the poet's treatment of it as home, since not only the physical structure of the city and the lives of its people but the very mood of the place is shaped by its history of division and violence. The speaker's own ambivalence adds to the feeling of uncertainty - the 'unravelling of wishes' suggests a reluctant re-engagement with the city of her birth, but with an 'unencountered' past and an 'unspoken' future it is the immediacy of the present moment that strikes the reader most vividly. In some ways she remembers the city only through the evidence of its troubled past, not through her direct recollection of these actions unfolding. Its intensity is also a form of privacy, so that in spite of its visibility to the world it is hard to 'see' clearly.

'In Belfast' is balanced by the text that follows it. 'Tourism' positions the speaker now on the inside of this city, observing the influx of visitors with an ironic air. This pairing of poems is significant in drawing attention both to the shift in perspective and to the complex temporality that Morrissey invokes in this collection. Though our attention is directed towards transitions between spaces, the poet is also concerned with the passage of time, and with the severance between different stages of experience. As Astrid Erll and Ansgar Nünning have argued, past events can be remembered in many different ways; this often reflects both temporal and spatial relationships to these occurrences. ${ }^{37}$ 'Tourism' deliberately exoticizes Irish heritage sites from its opening, linking Newgrange - a Stone Age passage tomb in County Meath with Eastern Markets and purification rituals. From the start, commerce and spirituality are yoked together, and their impact on space and its representation obliquely suggested: 'the relief of markets' captures the vibrant, uneven texture of a foreign city at the same time as it hints at the 
financial stability brought about by the ceasefire in Northern Ireland. ${ }^{38}$ The manipulation of meaning through image suggests the power of visual culture to influence public perception and the role of language too as a way of mediating the presence of the past in everyday life. The arrival of 'the Spanish and the Dutch' is a testament to the ability of Northern Ireland tourism to return the province to the European tourist map and a hint at earlier politics of allegiances with Spain and Holland that helped to shape the fates of both Catholic and Protestant communities in Ireland. ${ }^{39}$ In declaring 'Our day has come', the poet ironically resituates the catchphrase of resurgent nationalism - Tiocfaidh ár lá - in the context of renewed commercial buoyancy. The optimism offered by this new status remains in a language caught between holy war and political negotiation - 'They bring us deliverance, restitution' (BHT I4) - but northern pragmatism prevails and the people provide what the visitors want: a complex combination of global sophistication and primal violence:

We take them to those streets

they want to see most, at first,

as though it's all over and safe behind bus glass

like a staked African wasp. Unabashedly, this is our splintered city, and this, the corrugated line between doorstep and headstone.

(BHT I4)

The containment of past violence here is illusory: the subtle shift between four-line and three-line stanzas suggests only a tentative stabilization and the 'corrugated line' is a crude and temporary barrier between life and death. Nevertheless, the tourist strategy - which begins by touring the sites of the Troubles, and ends with a visit to the shipyard where the ill-fated Titanic was built - permits a convivial interlude, 'a pint with a Bushmills chaser', to contain the visitors' engagement with the violence of Belfast's recent past. This movement is a microcosm of the longer journey envisaged in the poem 'In Belfast', and its containment limits the potential for deeper reflection. The approach in 'Tourism' also signals a position that is the opposite of the emphasis on present experience in the previous poem - the tourist version of the city treats everything as though it is safely past; a practice in direct opposition to the notion of trauma as belated experience, always present to the affected person. ${ }^{40}$ As Aleida Assmann has argued, however, forgetting becomes a crucial means of overcoming violent cycles of history. ${ }^{41}$ Thus absence proves more potent than presence here and 'Our talent for holes that 
are bigger / than the things themselves' suggests the hollowing out of cultural meaning in the exhibition of loss. Finally, the poem presents a deal to the tourist: an unpredictable optimism in exchange for the paraphernalia of 'the European superstate / we long to join ... new symbols, / a new national flag, a xylophone' (BHT I4). The emptiness of imported symbolism and the incongruous appearance of the xylophone suggest the limits of superficial engagement with the other.

The Japan sequence marks a significant shift of tone and perspective from the sharp observation of Belfast at the turn of the twenty-first century. Its more meditative approach reveals the shaping effect that a new cultural experience has on the observing self. Not only is the sense of the past radically changed for Morrissey by this experience but her relationship to language is reshaped to accommodate a strongly visual dimension that reflects not only this important stimulus in her adopted culture but the poet's specific interest in the pictorial qualities of the Japanese alphabet. 'Goldfish' begins by recording the complex imaginative debt that Morrissey owes to Japan:

The black fish under the bridge was so long I mistook it for a goldfish in a Japanese garden the kind the philosophers wanted about them so much gold underwater to tell them what waited in another element like breathing water they wanted to go

to the place where closing eyes is to see

The transition recorded in this opening stanza is accompanied by a new fluidity of line and a renewed openness to other states of being. This aligns the act of observation with that of inner perception that transcends the limitations of the material world. The significant relationship between self and environment is mirrored in the attention of the philosophers to the particular conditions in which they live and work. The speaker herself enacts this close connection to her surroundings by realizing the power of all her senses. Closing her eyes, she learns what it is to 'see' with her hands, to apprehend the smallest changes in her surroundings and to 'read' their meanings. The language of the eyes ('I closed my eyes ... I saw ... saw what I had seen') gives way to a more tenuous grasp on presence and absence, and with it a more finely tuned awareness of the self's place in the world. The endless speeding freight trains configure the space-time continuum in a completely different way. They exemplify the continuous presence of commodity culture in all parts of Japanese life, even while the meditative connection with the natural world is revered and preserved. Led by the 
'you' who offers a narrative to guide the speaker through these new and diverse experiences, a kind of synaesthesia is produced whereby images are communicated in a range of sensory ways: 'I saw / music as pulled elastic bands drums as the footprints of exacting gods' (BHT 43). Just as the Zen masters descend into an element devoid of sensory distraction, so this poem reveals the emotional significance of a similar deepening of meaning through storytelling - 'I, / falling into you, story by story' (BHT 43). The otherworldly quality of the love connection here sees the encounter with otherness as a profoundly sustaining one in which difference is a mark of unity and growth.

The title poem marks another form of engagement with Japan's complex spiritual identity. In four stanzas separated by asterisks Morrissey explores the sacred spaces she encounters, questioning the symbols and practices she observes and exploring a form of cultural memory that is entirely new to her. This encounter creates both exhilaration and anxiety in the speaker; if, as Minnie Bruce Pratt suggests, loss of home is a fear of loss of selfhood - a fear of 'going too far' - then involvement in the ritual of a strange religion faces the possibility of such loss directly. 42 From the opening lines, symbolic and pragmatic merge: the stone babies in temples are dressed in aprons and consoled with teddy bears and toys. This warm human response is starkly contrasted to the graveyard for miscarriages in the second stanza. '[A]s stark as a bone field', this process separates the head from the body, fundamentally severing the unity of personhood. The breaching of these structures reveals the impossibility of containing life - no matter now briefly manifest - in rigid categories. Even the dead possess energy here, and a corresponding ability to inspire. The encounter with 'Japan's greatest Buddha' in 'the biggest wooden building in the world' is at once transcendent and ironic: enlightenment is figured as an act of falling but this fall is also an elevation to the heights of the very building within which the Buddha is found. So the meaning must be constructed in material human terms: the limits of human understanding risk belittling the spiritual power of the experience and Morrissey captures both the possibilities of spiritual growth and its material containment here. This dichotomy is developed in the final depiction of Nagasawa who must set aside essential parts of himself in order to reach a prayerful state.

When Nagasawa visits the house of the dead he leaves at the door his camera and tripod his champion karaoke voice his miracle foot massage his classroom dynamics his rockhard atheism 
and slips onto the tatami of the prayer room

as the man who can chant any you-name-it soul

between here and Ogaki to paradise

(BHT 46)

The coexistence of both atheism and spiritual connection in the single being is testament to the capacity for dual perspectives, so that the form of the poem itself, its dialogic arrangement, reveals the essential importance of doubleness, not only in the observer but also as an integral part of the culture itself.

The four-part structure of this poem is mirrored in 'Night Drive in Four Metaphors', which uses the form of the pictogram as an organizing principle for unfamiliar landscapes and experiences. This process by which lived experience and the artifice of language itself are drawn together reveals this country in vivid ways and examines how form is used to create meaning. The landscape, viewed through the window of the car, is creatively reassembled by the speaker to approximate the shapes of Japanese writing and thus to create meaning directly out of the strangeness of unfamiliar territory. The rhythm of the poem itself indicates the delicate balance that exists between observed reality and the imaginative schemes that shape metaphorical meaning. The speaker and her companion are being driven at night 'by rice fields on the narrowest roads', but once the likeness between the straight road and one stroke of the pictogram has been established the sky is read solely in terms of its visual meanings:

A moon on its back under the shadow of its circle is a unique moon.

It means home is under the weight of a stone and that brightness can come from under a shadow -

The whole weight of a cold ball breathing on it and look how it smiles.

(BHT 45)

By interspersing these metaphorical structures with the vivid image of the shirts of Brazilian factory workers hanging over balconies to dry, Morrissey grounds the larger meanings of the scene in its specific cultural conditions, tethering cosmic metaphor to the reality of clothing and hair. This diversity is expressed in the vastness of the scene that the poem attempts to comprehend: from the window at the other side of the car, a different sky can be seen and a different reading of the cosmos formed. The final image of the poem is important in bringing these readings together, however: 'Two worlds split open to each other, stars spilling from each' (BHT 45) suggests spaces that are at once distinct and together. 
In asserting their separateness, these worlds reveal their secrets to one another, just as the intimate relationship that is glimpsed in this poem does not overwhelm the singular vision of the speaker but prompts her to reflect on the nature of perspective itself. Morrissey's attentive treatment of cultural transition here signifies the growing maturity of her aesthetic and a deepening of her engagement with a variety of material contexts in her work.

\section{Eva Bourke: The Music of What Happens}

As well as Irish-born poets who have travelled and written abroad, there are others, born outside the country, who have made their homes in Ireland and built a creative life there. Eva Bourke, a German-born poet resident in Ireland for many years, carries with her a European past that is a complex blend of personal and culture references. Her imaginative engagement with the phenomenological world does not employ Morrissey's strategy of setting real and imagined in dialogue but rather uses observation and experience to engage with philosophical concepts which themselves attempt to tease out human meaning in its particular context. While much of her work is grounded in Irish landscapes and materials, the European city - and its intellectual traditions - is a recurring presence in her work. Just as Eavan Boland's work draws on the city as a space in which to explore the dynamics of familiarity and estrangement, Bourke considers the temporally layered and spatially complex character of urban life. 'Berlin Notebook', the final sequence from Travels with Gandolpho (2000), exemplifies her engagement with European history through the unifying lens of place. It reveals the vital importance of cultural memory to her aesthetic, explored by means of transporting the reader back in time to the lived experience of the past. Like so many of Bourke's poems, it uses the epigraph to prompt the reader to think deeply about key issues underpinning the poem. This strategy emphasizes the ways in which intellectual and experiential processes are entwined and makes us consider too the relationship between philosophical and poetic discourse. 'Berlin Notebook' has not one epigraph, but two; the first is from Samuel Beckett - 'There is no escape from yesterday because yesterday has deformed us or been deformed by $u s^{\prime}$. It is significant that memory is linked here to a practice of mutual distortion: here the extent to which the past is shaped by the needs of the present is clearly suggested. The second epigraph, from Walter Benjamin, roots our thinking further in the tradition of German intellectualism: 
in using a photographic trope to argue that only the future is capable of developing the images of history he also sees the relationship between present and past as a two-way process. Bourke's eight-part sequence probes this important dynamic in a variety of ways.

The poem opens with a vision of order that at once evokes the military discipline of Germany at the start of the First World War and the imaginative power that draws aesthetic order from disparate energies. The regularity of the Huzzars who 'clack down the streets / in twos and twos, strait-laced as rhyming couplets' (TG 80) suggests a discipline at once purposeful and elegant. Yet in spelling this 'strait-laced' rather than 'straight-laced' here, Bourke chooses not to send us back to the opening image of the poem - 'Drawing board avenues in straight / double rows' (TG 80). Instead, she emphasizes the perilous consequences of military confidence. These young men who are 'trying to steal a march on death' confirm the gulf between reality and ideal states, yet they exist in a charmed world held in delicate balance between the hellish underground, complete with Cerberus and overheated air, and the sky 'closed as the grave' (TG 80). This image provides the title for the second poem, which opens in contemplation of anti-war graffiti on a graveyard wall. At the centre of this poem, E. T. A. Hoffmann lies buried - a name that subtly draws together the literary and musical references here, and whose gothic significance increases the deathly quality of the sequence. ${ }^{43}$ Yet it is nature, rather than art, that binds this poem with the next. The dead rabbit found in the graveyard draws animal life into the orbit of human activity, emphasizing the uncanny witnessing of death. This is picked up in the nightingale whose song shapes the third poem in the sequence - a poem in prose with the wrought sentences of the sensitive observer. Potsdam at midnight offers a means to contemplate the relationship between present and past, the 'old music box city' set alongside the 'to and fro' of train engines. This poem presents a moment of delicate balance for the individual standing on the railway bridge viewing the city below: 'Down there my old life con- / tinues while here on the bridge I have started something new' (TG 82). This doubleness of perspective exemplifies the multiple existences of the migrant writer, who draws life and inspiration from both 'there' and 'here'. Though the speaker is stopped and asked for identification, the elevated perspective of the poem is suggestive of freedom, in contrast to the underground dimension of 'Bunkers':

No other place seems so versed in death and water so many graveyards, so many rivers, canals, watertowers 
and the soil light to the spade, liquid almost.

A special gate in every street for refugees, asylum seekers, another admits winter only sailing down from Siberia on its ice plough.

(TG 82)

Here the dampness of the city is not suggestive of its fertile or regenerative nature, but rather of transience, of its capacity to degenerate or be swept away. Yet this urban space is a guarded one, with its 'special gate' for refugees. Moses ben Mendel (renamed Mendelssohn) ${ }^{44}$ must pay to be admitted: though the subject of his writing is transcendence, he too must attend to the commercial side of personal and political freedom. The city has been regenerated with 'glass, marble and steel ... like polished crystals dropped from the air' (TG 83), yet the centre of this poem remains below ground, in the bunkers and cellars that provided hiding places for the persecuted. In this way, the city space becomes an important repository of cultural memory, which - though buried beneath a new and glossy surface - remains present to contemporary urban life. The deathly current that runs through the sequence sparks through the character of Lily, who unites sex and death in her tenement existence. She draws death into the life of the city, telling 'how coffins used to be stored in trees, / market was held in the graveyards' (TG 85). This acknowledgment of the darkness of the past is important in that it moves the interpretative centre away from the speaker and towards a character permanently inhabiting Berlin and a part of its evolving history. Here networks of memory connect those still living in the city to those who have moved away, confirming the possibility of both imaginative and actual return. 'Kreuzberg Nuptials' has a similar focus on the life of the building, and the wedding celebrations that mark an important moment of transition in the lives of those living there. As well as developing the investigation of Jewish-German heritage, this wedding scene draws together ideas and images from elsewhere in the sequence: the contrast between family and community and the built space of the city, in particular its bleaker elements; the 'outburst of cymbals' and 'clashing bells and gongs' are closer and more vigorous version of the 'tin- / kle and chime of bells and gongs' in 'Nightingale' (TG 82). The name 'Meyerbeer', barely discernible above the door of an adjacent building, echoes the figure of Mendelssohn in being the name of his great-grandson. These details record the subtle ways in which the relationship among the sequence of poems becomes closer as we read, the laces of history tightening on the city.

The auditory quality of these poems does not just add to their 
sensitive rendering of the city space but is suggestive of the need to be attentive to the past as it emerges in word and sound. This dimension of the sequence becomes thematically important as this work draws to a close: 'The Nightsinger', the second to last poem, directly addresses the meaning carried in sound, especially as night draws in and the city's soundscape becomes more subtle. The singer, who turns up 'at exactly the hour / / when ears are most receptive' (TG 88), is a universal figure, tantalizing the urban listener with the power of song. Yet part of this power is the fleeting quality of the experience, the fact that the singer may already have passed before we become aware of the song. It draws particular attention to the relationship between the song and the listener, and implicitly then between poem and reader. Bourke's art is one requiring concentration and a mind open to ideas and associations, at once involving us in the world of the poem and reminding us of the necessary distance that reflection demands. In closing the sequence with a poem on amber, Bourke draws us back towards the spatial configuration of time. The opening image of the bright train rushing through a submerged space is a startling reminder of the relationship between material meanings and the act of observation itself. This image is striking by virtue of its ability to conjure at once what is seen and unseen: the fast-moving object 'below the water table' challenges the actual power of witness, but it can be seen in the eye of the imagination, which emphasizes the fixed yet dynamic character of the scene. In the train, a woman fingers an amber pendant, an object that conjures multiple layers of memory from 'mother's necklace from holidays / at Travemunde' to the ancient insects embedded in its glowing substance ( $T G$ 89). Recalling the flea markets where Polish women sell amber, the speaker links the female figure (as purveyor and wearer) to this capturing of the past, in both its deliberate and random forms. Opening with the very shape and order of the city, and its masculine, military dimension, this sequence moves gradually inwards towards enclosure and acute observation of the private lives of subjects, tracing the necessary centring of perception and concentration of meaning in the individual figure.

More than ten years later, Bourke is representing that city again, in 'A View of Berlin' from Piano (20II). This poem presents an interesting counterpoint to 'Berlin Notebook' in its return to key elements of the city explored in that earlier poem. As a single unified work, though, 'A View of Berlin' presents a smoother perspective and highlights the visual quality of the act of present and past engagement. It is sunset in late May and 'wispy grey / fabrics are lowered over rooftops, dreary 
post-war / tower blocks. Darkness embraces the lindens' ( $P$ I4). The watery quality of the city persists, both in the situation of the speaker, seated on the deck of a boat, and in the 'flow' of darkness across the city. This trope has a less sinister dimension here than in the earlier poem, and the movement of the past through the built and human spaces of the city has a stimulating though not a traumatic effect. The small boats are buffeted by the wake of the coal barge, just as the different dimensions of the city record and respond to the actions of others. Once more we sense city and poem operating on different levels, and, just as Bourke dwelled on both submerged and elevated perspectives in 'Berlin Notebook', here too the speaker watches 'tourist boats being lifted to the next level, / strings of light bulbs looped around prow and rail' ( $P_{\text {I4 }}$ ). The new 'diaphanous' city can be seen in the distance and once again the lightness of glass is contrasted with the signs of war, here in the recollection of bombers 'spilling their

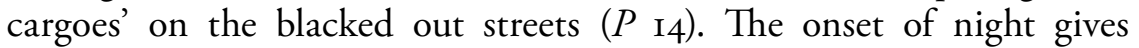
these cultural memories particular power:
And now the night releases its spillage of black
oil and the gas lanterns lining the long
streets spread the dim glow of bad
memories. Again the rough drafts of yet
another beginning - but how could one on such nights,
you ask, imagine the perfect machinery of control
that severed the river once

Yet even in this dark mood the speaker acknowledges how distant the images of war and the terrible aftermath of a divided Germany have become - the 'barbed wire, mines / watch towers, guards' to prevent people attempting to swim across the river to freedom. This imaginative distance is bridged, however, by the power of poetic language itself to conjure up these vivid scenes, and to strike both poet and reader with their capacity to shape present experience. This power is broken by music: the nightingale - already heard in 'Berlin Notebook' - 'strikes up its midnight song' ( $P_{15}$ ) swelling to fill stanzas with its Classical and Romantic associations and its arresting beauty 'calling across distances as the world goes round / on tiptoe forgetting all about its business' ( $P$ I5). As all who can hear it pause to listen, the song becomes associated with the wildness of nature and thus with a beauty that precedes human power and wilful destruction. The bird calls 'to return to the 
unmutilated garden' and thus is both a reproof to human vanity and a potential agent of transcendence.

For Bourke, Berlin itself carries an enduring capacity to prompt reflection on the relationship between the weight of history and the immediacy of lived experience. While the legacy of the Second World War plays an important role in her work, it is mixed with a longer view of Berlin's cultural identity and a strong sense of personal connection. Her treatment of Ireland has very different resonances, moving away from a concern with family and cultural history towards acute observation of the radical changes that Ireland has undergone in the years that she has been resident here. 'Notes from Henry Street', a two-part poem from her most recent collection Piano, again constructs a dialogue with her earlier collection from 2000 and uses the concept of 'Notes' to create a sense of continuous thoughtful engagement, as well as an auditory dimension. In the opening section, Henry Street, near the centre of Galway city, becomes the epicentre of recessionary affect. Opening in the aftermath of a storm, the speaker observes the detritus in the garden, a microcosm for 'our street of Club Paradiso, sex shop / plus blackjack club' with its For Sale signs and dispiriting new apartment blocks. The speaker here is a letter writer, and addresses someone due to return home to this scene: 'the fireplace / with its dusting of ashes, the veins / of slug slime and mould' ( $P$ 7 I $)$. Again, dampness pervades the environment, because this is a coast on the edge of Europe and its exposure - climatically and economically - is intimately linked to this location. The speaker's own life is 'full of bluster' suggesting both the turbulence of contemporary existence and the need to talk over and around it, to avoid confrontation with the darker realities of experience. The poem acknowledges 'apologies to Montale', perhaps referring to the tendency of the Italian poet to address poems to an absent other. The second part of the poem directly addresses Montale himself, contrasting the fountains and courtyards of Italian urban life to the Texaco stations and investment premises of Celtic Tiger Ireland. Though this night is as bright as day aided by the omnipresence of street lighting - it again prompts sombre reflection on Bourke's part: 'memories return nocturnally, sere and raw' $(P 72)$. For this reason, the speaker welcomes the return of storm winds as a way of clarifying ethical and personal quandaries and introducing a cleansing energy into a world racked by endless political and economic strife. Instead, the movement remains muted, as the striking rhyme between 'flickering' and 'bickering' suggests, together with the parallel juxtaposition between 'critical mass' and 'trickling down the glass' 
that mark these four lines out in rhyming containment. Ending with an affirmation of speaking to the dead, Bourke interweaves the poetic conversation with Montale with her habitual sensitivity to familial precursors. Yet, in asserting the presence of the dead in contemporary life, she at once emphasizes the continuities of inspiration and experience and the haunted quality of contemporary life in Ireland.

All three poets show how the processes of travel and migration alter their understanding of the past, bringing concerns of time and space to the forefront of their creative work. Their poems constitute a dialogue with distant cultural spaces and in doing so embrace the particular formal and linguistic challenges that this diversity brings. These experiences have proved productive of experiment for these poets, whether formally, in their engagement with new poetic modes, or philosophically, in the dialogue they construct with their earlier selves. To live in an entirely new culture is to court estrangement, but also to be made sensitive to both cultural and linguistic differences. These poets show how a migrant perspective not only informs a particular phase of their work but also alters their aesthetic development in fundamental ways.

\section{Notes}

I The growth of significant migrant communities in Ireland has given rise to a greater diversity in literary production. Landing Places: Immigrant Poets in Ireland, an anthology edited by Eva Bourke and Borbála Faragó (Dublin: Dedalus Press, 20Io), represents a range of poetry produced by writers born outside Ireland. Some of these settled in the country decades ago; some are recent arrivals. See also Borbála Faragó, "I am the Place in Which Things Happen”: Invisible Immigrant Women Poets of Ireland', in Patricia Coughlan and Tina O'Toole (eds), Irish Literature: Feminist Perspectives (Dublin: Carysfort Press, 2008), pp. I45-66.

2 Nadia Setti notes that the crossing of borders ranges in significance from 'an ordinary act without consequences (study, business, tourist journeys) [to] ... an act of survival for those who leave their homes to escape disease, war and poverty': 'Migrants' Art and Writing: Figures of Precarious Hospitality', European Journal of Women's Studies 16.4 (2009), p. 326.

3 Paul White discusses this dual process of departure in the introduction to Russell King, John Connell and Paul White (eds), Writing Across Worlds: Literature and Migration (London: Routledge, 1995), p. 2.

4 This poem was first published in Nightwalker and Other Poems (Dublin: Dolmen Press, 1967).

5 Setti, 'Migrants' Art and Writing', p. 327.

6 Among more recent critics, Douglas Porteous, David Sopher and Yi Fu Tuan offer a stable, even soothing, reading of 'home', argues Rosemary Marangoly George, The Politics of Home: Postcolonial Relocations and Twentieth-century Fiction (Oakland, CA: University of California Press, 1999), p. 22. 
7 Chandra Talpade Mohanty (with Biddy Martin), 'What's Home Got to Do with It?', Feminism Without Borders: Decolonising Theory, Practicing Solidarity (Durham, NC and London: Duke University Press, 2003), p. 90.

8 The idealization of home is linked to its significance as a gendered space, to which men may choose to come for comfort and sustenance but to which women remain tied.

9 This changing philosophical conceptualization of home is traced by David Ralph and Lynn A. Staeheli in 'Home and Migration: Mobilities, Belongings and Identities', Geography Compass 5.7 (July 20II), pp. 517-30 (p. 52I).

Io Rob McLennan, 'I2 or 20 Questions: with Mairéad Byrne' (November 2007), http://Izor2oquestions.blogspot.ie/.

II De Fréine has participated in writing residencies in the USA (Connecticut), Portugal (Coimbra) and Slovenia. These periods abroad have shaped her work since 2010 in important ways.

I2 White, 'Introduction', in King, Connell and White (eds), Writing Across Worlds, p. 7.

I3 Sheobhushan Shukla and Anu Shukla, Migrant Voices in Literatures in English (New Delhi: Sarup, 2006), p. 2.

I4 Mary Layoun remarks on this apparent contradiction. See Marangoly George, The Politics of Home, p. I6.

Is Mohanty, 'What's Home Got to Do with It', pp. 85-I05.

I6 Salman Rushdie, Imaginary Homelands: Essays and Criticism, I98I-I99I (Harmondsworth: Penguin, 1992), p. 278.

I7 Marie-Aude Baronian, Stephan Besser and Yolande Jansen (eds), Diaspora and Memory: Figures of Displacement in Contemporary Literature, Arts and Politics (Amsterdam: Rodopi, 2006), pp. II-I2. This includes a quotation from Paul Gilroy, 'Diaspora and the Detours of Identity', in Kay Woodward (ed.), Identity and Difference (London: Sage, 1997), p. 318.

I8 Baronian et al., Diaspora and Memory, p. I2.

I9 See Richard Terdiman, Present Past: Modernity and the Memory Crisis (Ithaca, NY and London: Cornell University Press, 1993).

20 Mairéad Byrne in conversation with Rob McLennan. At the opening of a 2005 interview with Rebecca Seiferle, Byrne is described as 'both an Irish and an American poet; the first by birth and the second by choice'. Rebecca Seiferle, 'An Interview with Mairéad Byrne', The Drunken Boat 5.3/4 (Spring/Summer 2005), www.thedrunkenboat.com/byrne.html.

2I W. B. Yeats, 'Among School Children', in Daniel Albright (ed.), W. B. Yeats: The Poems (London: Everyman, 1992), pp. 26I-3.

22 Nelson's Pillar was a key Dublin landmark. Erected in 1808-9 at the junction of Sackville Street and the Carlisle Bridge, it was blown up by an IRA bomb in 1966. It appears in many literary representations of Dublin, most notably James Joyce's Ulysses (1922) and Finnegans Wake (1939). See Yvonne Whelan, Reinventing Modern Dublin: Streetscape, Iconography and the Politics of Identity (Dublin: UCD Press, 2003), pp. 44-50.

23 Dubh le daoine means 'black with people', that is, crowded. Ag baint dha thaobh den bóthar, 'taking both sides of the road' or weaving from side to side, whether from drink or another cause. Iseal and uasal are antonyms: iseal meaning lowly or common, uasal noble or lofty - this is especially suitable given Lord Nelson's 
social and physical elevation here. 'Stewed' as slang for drunkenness leads easily to soup (redolent of the soup kitchens of the nineteenth century) and to 'mate and potatoes', meat and potatoes hibernicized. This movement between languages and registers makes use of patterns of alliteration and assonance in both languages as well as the auditory links between iseal and uasal, suggesting the noble and the common may not be so far apart after all.

24 Seiferle, 'Interview with Mairéad Byrne'.

25 Kent Johnson, 'Poetic Comedy, September II, Truth, the Lyric, Mississippi, the Persecution of Gabe Gudding by Trent Lott Radio, the Cohabitation of Poets, and Prison Teaching: An Interview with Mairéad Byrne and Gabriel Gudding', VeRT 6, http://epc.buffalo.edu/mags/vert/index2.html.

26 Christopher Morash's examination of Irish media from the 1960s onward shows Telefís Éireann's reliance on American programming. He attributes this to economics - the cost of screening an American series was just $£ 20$ per hour and this proved the only way that Irish television could compete for viewers with its British counterpart: 'To put it simply, without American television, there would have been no Irish television'. Christopher Morash, A History of the Media in Ireland (Cambridge: Cambridge University Press, 2010), p. I75.

27 St Brendan is known for his legendary journey in search of $\mathrm{Hy} \mathrm{Brasil,} \mathrm{or} \mathrm{the}$ Island of the Blessed, described in the ninth-century manuscript 'The Voyage of St Brendan the Navigator'. Though the location of the island is unknown - and often assumed to be allegorical - it has been speculated that it is North America. Tim Severin's 1978 film The Brendan Voyage demonstrated that it would have been possible for St Brendan to have made the crossing to America in a leather boat. See also Glyn S. Burgess and Clara Strijbosch, The Legend of St Brendan: A Critical Bibliography (Dublin: Royal Irish Academy, 200o).

28 'Patrick Kavanagh used to talk about wanting to "play a true note on a slack string". There's some of that in Talk Poetry ... The textured, collaged, appropriated work of my chapbook An Educated Heart (Palm Press, 2005) seems a long way from me now'. Rob McLennan, 'I2 or 20 Questions: with Mairéad Byrne'.

29 Rob McLennan, 'I2 or 20 Questions: with Mairéad Byrne'.

30 Sina Queyras, 'A few words and poems: Mairéad Byrne', Harriet, April 30, 20Io, www. poetryfoundation.org/harriet/20Io/o4/a-few-words-and-poems-mairead-byrne/

3I Seiferle, 'Interview with Mairéad Byrne'.

32 'Parallax' is defined as 'the effect whereby the position or direction of an object appears to differ when viewed from different positions' (Oxford English Dictionary). Fran Brearton draws attention to the relevance of this to Morrissey's poetic practice in her review of the volume in the Guardian, September 6, 2013. Parallax won the T. S. Eliot Prize and the Poetry Now Award for 2014.

33 Gerald Dawe, 'Poetry as Commemoration', in Eberhard Bort (ed.), Commemorating Ireland: History, Politics, Culture (Dublin: Irish Academic Press, 2004), pp. 216-17.

34 The influence of Japan on Irish poetry has been explored in a number of publications, most notably in Irene de Angelis and Joseph Woods (eds), Our Shared Japan: An Anthology of Contemporary Irish Poetry (Dublin: Dedalus, 2007) and in Irene de Angelis's monograph, The Japanese Effect in Contemporary Irish Poetry (London: Palgrave Macmillan, 20I2).

35 Irene de Angelis, 'Sinéad Morrissey: Between Northern Ireland and Japan', Journal of Irish Studies 20 (2005), www.carcanet.co.uk. 
36 White, 'Introduction', King, Connell and White, Writing Across Worlds, p. I4.

37 Erll and Nünning point out that a war can be remembered as a mythic event, an aspect of political history, a traumatic experience or as a part of family history. Cultural Memory Studies, p. 7.

38 In December 1993, a Joint Declaration on Peace, more commonly known as the Downing Street Declaration, was issued by John Major, then British Prime Minister, and Albert Reynolds, the Irish Taoiseach at that time. On August 3I, 1994 the IRA announced a cessation of military activities; this lasted until February I996 when an IRA bomb was detonated in the London Docklands. After a renewed ceasefire in July 1997, the Good Friday Agreement was reached in April 1998. This agreed mechanisms for devolved, inclusive government in the province as well as arrangements for prisoner release and decommissioning. See Paul Bew and Gordon Gillespie (eds), Northern Ireland: A Chronology of the Troubles, I968-99 (Dublin: Gill \& Macmillan, 1999); also Graham Spencer (ed.), Forgiving and Remembering in Northern Ireland: Approaches to Conflict Resolution (London: Continuum, 20II).

39 The involvement of the Spanish in the Battle of Kinsale in I6oI, which saw the defeat of Gaelic Ireland by the English, situated this event within the larger conflict between Protestant England and Catholic Spain. Nearly 90 years later, the Battle of the Boyne was fought between two rival claimants of the English, Scottish and Irish thrones - the Catholic James VII and the Protestant William III who had deposed James in I688. William was also governor of Holland, Zeeland, Utrecht, Gelderland and Overijssel of the Dutch Republic. The battle, fought near Drogheda, was won by William. This ensured the continuation of Protestant ascendancy in Ireland. See Pádraig Lenihan, I69o: The Battle of the Boyne (London: The History Press, 2003).

40 See Cathy Caruth, Unclaimed Experience: Trauma, Narrative, and History (Baltimore, MD and London: Johns Hopkins University Press, 1996), p. 7.

4I Aleida Assmann, 'To Remember or to Forget: Which Way Out of a Shared History of Violence?', in Assmann and Shortt, Memory and Political Change, pp. 153-7I.

42 Marangoly George, The Politics of Home, p. 27.

43 E. T. A. Hoffman (1776-1822) was a German Romantic author as well as a composer and music critic. Offenbach's opera, The Tales of Hoffmann, was loosely based on his writings; he also wrote the stories from which the famous ballets The Nutcracker and Coppélia were derived.

44 Though this poem depicts 'the gate keeper' as changing the name from ben Mendel to Mendelssohn, the decision to do so was in fact taken by Moses Mendelssohn himself. See Michael P. Steinberg, 'Mendelssohn and Judaism', in Peter MercerTaylor (ed.), The Cambridge Companion to Mendelssohn (Cambridge: Cambridge University Press, 2004), p. 35. 


\section{Private Memory and the Construction of Subjectivity in Contemporary Irish Women's Poetry}

The relationship between private and shared memory is a complex one and the search for a way of conceptualizing it has preoccupied theorists of memory in recent years. Maurice Halbwach's perception of collective memory is both a foundational and a controversial construct, especially in the ways that it links individual psychology and group practice. ${ }^{1}$ As Astrid Erll has acknowledged, however, 'societies do not remember literally; but much of what is done to reconstruct a shared past bears some resemblance to the processes of individual memory.2 In its layered construction of subjectivity, poetry has the potential to extend how the dynamics of self and other can be understood, offering new ways of reading the relationship between the emotional life of the individual and the larger social and political contexts that have shaped these perceptions. This chapter explores the role of private memory in the work of contemporary Irish women poets, examining it as a catalyst for philosophical and social enquiry. These poets use acts of remembering to investigate subjectivity in challenging ways; they reveal aspects of the personal past while problematizing its relationship with the lyric mode. This potential to move beyond individual experience without negating its importance can be traced in the way these poets situate deeply personal material in a larger cultural context, contemplating not only close personal relationships but also the capacity for empathic connection with the stranger. In doing so they confirm the representation of personal suffering as an important dimension of ethical reflection and a means of understanding one's place in the world.

Three poets explore these dynamics in important ways: the work of Mary O’Malley (b.1954) and Paula Meehan (b.1955) shares some 
important characteristics, including an understanding of the relationship between personal experience and collective responsibility. Close in age, yet drawing inspiration from very different environments - the streets of inner city Dublin and the coastal communities of Galway - these poets came to creative maturity at a time when the gap between the public perception and the actual experiences of women was coming under particular scrutiny. For both poets memory serves to investigate the bonds of family and community and to recognize these as the sites of both supportive and damaging relationships. To the work of these two women, the poetry of Colette Bryce (b.1970) provides an interesting counterpoint. Growing up in Derry during the Troubles, Bryce's understanding of the relationship between personal and political has been shaped by the claustrophobic nature of domestic and civic life in the province and by the impact that sectarian violence has on the lives of individuals. Her recent representations of the familial past are formally innovative in their investigation of the spaces between private and public experience. In this respect, the poems exemplify the need to create a new story from the ordered narrative of history. ${ }^{3}$ The generational difference reflected in the choice of these three poets, together with their changing perspectives on the relationship between individual and community in different parts of the island of Ireland, offer new ways of reading the poetic representation of the traumatic past.

\section{Poetry, Memory, Selfhood}

The personal and the political are entwined in different ways in the work of all three poets examined here. While Bryce's upbringing in Derry draws attention to her presence there at a time of particular political significance, both Meehan and O'Malley are also concerned with the processes of bearing witness to one's own place and community. Yet this act involves self-scrutiny too. If poetry is for Meehan 'an act of resistance, an act of survival', it aptly demonstrates that with human endurance must come an acknowledgement of the fragmentary and often inexpressible self.4 Many of her poems - from the earliest work through to the recent Painting Rain (2009) - return to a difficult personal past in order to explore the fraught attempts of the individual to find meaning in a hostile and confusing world. ${ }^{5}$ Memory is at the core of this exploration, not just in providing significant material for the poet's art, but in emphasizing the continuing dynamic between present and past selves; a dynamic that relates not only to individual self-identity but 
also to how this is mediated in the creation of larger communities and national groupings.

All identity debates involve the concept of alterity, it is in response to this that personal and cultural boundaries are determined. The relationship between self and other is often ethically constructed, placing the 'other' in an adversarial position. This dynamic inflects national self-perception as well as definitions of community and family, and its significant shaping of class and gender debates informs Meehan's work at all levels. The concept of estrangement itself foregrounds the responsibilities of the self and the implications of the self's boundaries. Richard Kearney, in tracing these issues through the work of Emmanuel Levinas and Jacques Derrida, considers the consequences of any obstacle in the relationship between self and other. In Derrida's terms there can be:

No hospitality, in the classic sense, without sovereignty of oneself over one's home, but since there is also no hospitality without finitude, sovereignty can only be exercised by filtering, choosing and thus by excluding and doing violence. ${ }^{6}$

In figuring home as the place where the processes of inclusion and exclusion begin to occur, Derrida draws attention to that most personal of spaces as the foundation of larger phenomena - a process that is central to Meehan's own poetic. For Meehan the dynamics of exclusion and violence overshadow a real world of social deprivation and economic struggle, so that her consideration of otherness and estrangement is always shaped by an understanding of their actual social effects.

For both Meehan and O'Malley home is experiential rather than conceptual, however, and it is central to how selfhood can be investigated and understood. In O'Malley's case, the fact that she has spent a significant amount of time - perhaps even the greater part of her adult life - outside Ireland has shaped her awareness of the importance of choice in the formation of relationships between individuals and places. Her Connemara home, though on a geographical periphery, is in no sense isolated from the sustaining network of places that have supported her creative life. Many poets of the younger generation have also made homes outside Ireland; 7 Colette Bryce's sense of self is shaped by periods in Barcelona, London and Dundee, as well as in the North of England where she now lives. Her 2008 collection, Self-Portrait in the Dark, depicts a dislocated self, fleetingly glimpsed in cars, in planes, on railway lines, taking a 'zig-zag route along a scrawl of narrow, stony roads' (SPD 23). Though the memories these 
poets invoke are often firmly rooted in personal experience, their approaches exceed a narrow biographical focus, exploring instead the philosophical and cultural implications of the concept of privacy and its role in larger constructions of identity.

The passion for justice that underpins Meehan's poetic explorations is one that requires openness to the other - what Levinas would see as the infinite responsibility of self to other. Yet such a state of openness is rendered more complex by the difficulties of establishing a clear perspective on the self, a full understanding of what 'the self' actually is. For Meehan, an awareness of the problematic nature of self-representation is always to the fore: 'I don't use a trustworthy $I$ in the poetry ... I'm playing all the time with $I$ because I don't have an identity.' 8 American poet Annie Finch writes of a similar need to question the unitary self in her work:

I now see language as a place where the poetic self can dissolve without throwing the world the poem represents into chaos. I appreciate poems that 'problematise' the self, to use one common critical term, rather than pretending that the selves of the speaker of the poem and its reader are simple, solid entities. ${ }^{9}$

Meehan's declared lack of identity has not yielded to poems of radical instability; instead, they seem, in Finch's terms, to emphasize the contingent nature of the self without rupturing linguistic coherence. In addition, this lack of singular identity may indicate not an absence but, in fact, an excess of identities - an endless movement among different versions of the self that emerge under the pressure of situation. The treatment of alterity, then, is not only a function of experience but also an existential concern that is repeatedly mediated through attention to the immediate world of the poet.

For O'Malley, this excess of identities is expressed through attentiveness to personal evolution; many of her poems recognize the disjunction between past and present selves though the depiction of a woman on a journey, moving between spaces that are at once real and imagined. From the early poem 'The Journey', through 'A Question of Travel' (200I) to the 'Resident at Sea' sequence from Valparaiso (20I2), O'Malley uses this process to explore creativity, so that an evolving understanding of writing and selfhood become intimately connected. This emphasizes the notion of the creative self as always in a state of process - a condition that shapes the dynamics of private and public in this work, so that, though O'Malley's poems are in and of the world, a dimension of her work resists easy disclosure. As the poet explains: 
The world of the poems is a very intense and total world and I suppose I don't really share that with anybody, actually. I don't usually write about domestic things, not because I want to deny them but because I don't allow myself those poems, maybe ... The forces that make me write are darker and deeper and infinitely more powerful - to use a very inadequate word - than can normally be expressed in any kind of domestic setting. ${ }^{10}$

This rejection of the domestic has meant that even very personal experiences mark a departure from realism or, as Eamonn Wall has argued, are conceived in a 'magic-realist mode'.11 Her openness to the material of the Irish folk tradition helps to shape the imaginative aspect of this transition and she sees this as an important and continuing aspect of her art: 'the possibility of a visit from the marvelous is part of being a poet'. ${ }^{2}$ The marvellous may also come from a receptiveness to other cultures, and just as Eva Bourke's dialogic relationship with German life, both past and present, raises important philosophical questions so O'Malley's European attachments ensure that the experiencing 'I' must be seen to take many contingent forms.

Colette Bryce's work expresses itself in similarly transformative ways. Many of her early poems, from 'Day' to 'Cabo de São Vincente' depict a movement through landscapes and across national borders. Uncertainty attends this dynamic, though; while the energies of these poems suggest the freedom of self-invention, there is a subtle sense of entrapment in the apparent necessity of return. If ' $\mathrm{t}$ ] he journey back was a nightmare' ('Epilogue', $H B$ 26), there is all the more reason to refute this dynamic completely: 'If you think that I'll be coming back / you're on the wrong track' ('Riddle', FRT 43). These impressions conspire to suspend Bryce's speakers in an unresolved space or show them to be 'pulled in several different directions at once'. 13 This ambiguous relationship to place also troubles the sense of a unitary self, so that the speaker is simultaneously visible and concealed from the reader; at once here and elsewhere. In this way, past and present selves can rarely be distinguished with certainty in Bryce's work.

Such an awareness of the multiplicity of selves leads away from a self / other binary; instead, the other is enclosed within the self so that self and non-self become one and the same. For this realization, Julia Kristeva's work on the stranger within the self is of vital importance. In seeing the unconscious as vitally shaped by the other, Kristeva posits the response to the stranger, or the foreigner, as a manifestation of unresolved dynamics within the self: 'The foreigner comes in when the consciousness of my difference arises, and he disappears when we all acknowledge ourselves 
as foreigners, unamenable to bonds and communities.'14 The difficult negotiations between individual and community that take place in Meehan's work testify to this tenuous integration. Both her poems and many of O'Malley's too investigate the deepest reaches of the self, where the painful struggle between the desire for intimacy and the terrible price its loss exacts continues to be felt.

Freud is a significant precursor here: his concept of the unheimliche or the uncanny speaks of that which comes from within, that which would otherwise be repressed: 'Unheimliche is the name for everything that ought to have remained hidden and secret and has become visible.' 15 In Freud's terms, clear boundaries between the familiar and the strange cease to exist. This aspect of estrangement is central to Kristeva's work on the stranger within - the idea that what we recognize as strange is in fact a crucial part of the self, one that demands recognition. However, as Sara Ahmed argues, the failure to recognize the stranger does not in fact mark a lack of knowledge since the stranger is not someone we do not recognize but rather 'someone we recognise as a stranger'. ${ }^{16}$ In each case, the concept of estrangement is one linked to scrutiny, not only of the present situation but also of the cumulative nature of knowledge itself. This is the point at which the act of memory becomes one of particular philosophical importance, not only in relation to poems of clear personal significance but also to those that deal with the larger boundaries of identity on a community or national level.

By introducing the role of memory into this dynamic, the question of growth becomes central: how far is our understanding of otherness based on deeply rooted convictions that emerge repeatedly through our interactions with the unknown. Maurice Halbwachs has highlighted the cultural aspect of the act of remembering: 'it is in society that people normally acquire their memories. It is also in society that they recall, recognize and localize their memories'. ${ }^{17} \mathrm{His}$ controversial work on collective memory emphasizes the need to contextualize even the most personal of past experiences, and Meehan's explorations of the pasts of family and community seem to bear out this necessity. Yet they also reveal the importance of local memory as a counterpoint to the national narrative, and in this they are consonant with contemporary efforts on the part of nation states to respond sensitively to the perceptions of the past in previously marginalized communities. ${ }^{18}$ Meehan herself fundamentally questions the notion that memory can be separated from subjectivity: 'Is there such a thing as the past? Or is there only a relationship with that past?'. ${ }^{19}$ It is a form of interrogation 
that emphasizes the idea that the past is contained within present perception. In this respect, the act of memory becomes crucial to the process of estrangement. For Meehan, it is the paradox of identification with, yet separation from, the past self that is the model for the complex relationship between self and other that exists in much of her poetry.

The concept of experience requires probing here, since the splitting of present and past selves suggests interpretative discontinuities. The role of experience within feminist debates itself reveals divided critical opinion: it may be read as a sign of authenticity or as an entirely private phenomenon that cannot be extrapolated into a form of collective representation. ${ }^{20}$ In the same way, experience can be seen to exist as either an interior or an exterior perspective - as a process that is unique to, and internalized by, the individual, or as one that is marked by the interaction between the subject and the real world. Ernst van Alphen asserts not just the close connection between experience and its expression but the idea that experience exists only in its representation and that, in turn, subjectivity itself is constructed in this way. ${ }^{21}$ For writers, then, subjectivity is a particularly complex phenomenon, since the discursive construction of their reality is a highly self-reflexive one. Meehan's return to past experiences - a practice that forms an important part of her most recent collection, Painting Rain (2009) - has resulted in the concept of estrangement becoming internalized. Yet, ironically, this internalization has yielded a more philosophical approach to the need for self-understanding. For O'Malley, the interweaving of language and place reveals a preoccupation with the relationship between individual utterance and human connection. Increasingly, her work explores the responsibility to self and other that emerges through engagement with threatened landscapes and ecologies. It is by interrogating the self, then, that both poets reach sustained understanding of the world around them. In the same way the traumatic past must be confronted individually and culturally so that the extent and nature of its impact may be comprehended.

\section{Family Histories: The Poetry of Witness}

The passage of time shapes these difficult acts of self-interrogation in important ways. As Dominick LaCapra points out, 'the experience of trauma is ... bound up with its belated effects or symptoms, which render it elusive'.22 Something of this delayed response is recorded in Meehan's 'This Is Not a Confessional Poem', which indicates her struggle to come to terms with the revelatory dimension of poetic representation 
as well as with the ways in which the finished text will be read and understood. The poem's title challenges us to reflect on the assumptions we make concerning the personal underpinning of the modern lyric. Though the text begins in the midst of an act of writing, the speaker hesitates before continuing - 'I do not know that I've the right to say such things' (PR 78). Such tentative claims to the right to speak stem from the need to exercise caution in bearing witness to the past, together with an increasing awareness of the inadequacy of a singular perspective on complicated human dynamics. Yet the speech act also indicates the desire to come to terms with the past by ceasing to repress its truths: 'traumatic silences and gaps in language are, if not mutilations and distortions of the signifying process, ambivalent attempts to conceal'.23 The poem tells of a mother's attempt on her own life, a memory that emerges suddenly in a warm and evocative Greek landscape and thrusts the poet back in time to a Finglas garden on a winter's night, where her mother lies 'curled to a foetal question' $(P R 78)$ in the eerie silence of the sleeping estate, after having been rescued from the kitchen by her father: 'I found her with her head in the oven. I I dragged her outside' (PR 79). The sight of her exhaled breath in the cold air is proof both of her continuing life and of the irreversible change that her action will bring to the family: 'We carried her in between us, / my father and I, never again that close, / or complicit. Never again the same as we were' (PR 79). The bonds created by this shared act of witness do not alter the poet's singular responsibility in representing the experience in language, however. Part of this process involves an acknowledgment of the past as past and an assertion of the distanced perspective of the present self: 'And that is how I leave them now: / I pull the door behind me firmly closed' (PR 80).

Bryce's 'Re-entering the Egg' also offers a glimpse into the private space of the family past but in a less explicit mode. Presenting the home like a doll's house - the front of which can be opened to reveal all the rooms at once - the poet gives us a version of the past at once innocent and audacious. Each figure appears as a circus performer but separated from the rest of the troupe:

A tiny family fills the rooms.

In one, a wife is breathing fire,

genies whirling in the air.

In one, we hear the Strong Man's snores

rumbling under a mound of clothes

like a subterranean train.

(WRU 6) 
A series of children appear as 'spangled girl', conjoined twins and mermaid. Though living in close proximity, all these figures seem to inhabit separate worlds just as, on the topmost bunk, 'the smallest girl's soft breath / knits round her like a shell' (WRU 6). Identifying with this girl, and her creation of a protective cocoon, the speaker asserts the right to privacy of these diminutive figures: 'Out of time, they go about their lives / unaware of our scrutiny. / Close it up. That's enough for now' (WRU 7). This last stanza reveals that the difference between observer and observed is not one of scale only, there is also a temporal distance between them. The family is made tiny by the fact that its actions belong to the past. It is a past that can be revisited, but prolonged exposure to it - and of it - is unwise, recalling Freud's allusion to what ought to remain hidden. The ethics of breaching family privacy remain a concern for all three poets.

Van Alphen sheds light on the role of trauma in destabilizing the subject position, so that speakers in recounting their experience may deny their own role as subjects, seeing themselves as acted upon rather than acting. Conversely, the failure to act can erode a sense of self, so that the anxiety as to whether one has been 'enough of a subject' can become overwhelming. ${ }^{24}$ The difficulties that have existed for Meehan, on both social and domestic scales, reveal an acute awareness of these tensions. This is why Dharmakaya (2000) is such a significant volume for the poet - because it is the book in which Meehan embraces the idea of non-being, not fearfully, but with an awareness of its necessity in the creation of meaning; as Catriona Clutterbuck puts it: '[Meehan] can "find her centre" only through the risk of freefall, not, as her previous work suggested, despite that risk.'25

Meehan has long been concerned to trace the complex dynamics of belonging and estrangement and their effects on her own subject position in language. The poem 'Return and No Blame', collected in The Man who was Marked by Winter (199I), indicates the importance of family relationships in determining identity. The poem is addressed to the father, who represents a fixed place of return for the speaker here. This dynamic is immediately seen as a cyclical one: the father's 'sunny smile / is a dandelion / as I come once again through the door' ( $M M W$ 23). The seemingly endless renewal of this common flower is matched by the pattern of the speaker's disappearance from and return to her father's life - movement that reflects the ever-changing nature of the speaker's own subjectivity. Like so many of Meehan's poems, the work seems at first to lay bare its meanings, yet this is fundamentally a poem about 
concealment: the father's eyes holding 'a question / [he] will not put' $(M M W 23)$. This reluctance to question shows a willingness to allow the speaker her own space, yet it also reveals the gulf that exists between the two of them:

Father, my head is bursting

with the things I've seen

in this strange, big world

but I don't have the words to tell you

nor the boldness to disrupt your gentle daily ways,

$(M M W 23)$

Here the 'I' in the poem has split into two: the 'I' that has witnessed the strangeness of the world and the 'I' that struggles to find language adequate to the experience. The failure of language here is partly willed, however. Just as Meehan chooses words for this poem, so the speaker acknowledges that language is more than freedom of expression: it is a conscious means of constructing relationships. The process of estrangement represented here is complex too. It is the world outside that generates this feeling, yet it is brought into the home so that exposure to the extraordinary now makes all things, even the most familiar, strange in their turn. The key dynamic that exists in this poem, then, is between what is spoken and what is unspoken, perhaps unspeakable; between the significant experiences of 'elsewhere' and the difficulty of assimilating these; between the experiencing and speaking selves that constitute the field of the poem.

The maternal relationship is not often evoked in Meehan's work, but an early poem, 'The Pattern' - also from The Man who was Marked by Winter - is important in exploring the poet's construction of the female subject in her work. The poem begins with estrangement, marking first the small number of objects and experiences that connect the speaker to her mother: 'a sewing machine, a wedding band, / a clutch of photos, the sting of her hand / across my face in one of our wars' ( $M M W_{\mathrm{I}}$ ). Here the materiality of the past is linked to bodily experience, and the lingering effect of this remembered slap carries over to the second stanza, where the mother's death is also recorded. Her short life is rendered in the dozen lines of the first section of the poem, giving us the 'pattern' of her existence before she is remembered in evocative detail. The contraction of time here mirrors that of the mother's own foreshortened life but Meehan's unsentimental treatment highlights not the pain of loss but rather an instinct for survival. The decision of the speaker not 
to return to her mother's grave marks her resistance to the past as a site of grief in favour of a continuing creative present.

This decision is reflected in the form of the poem itself, which is episodic. Its seven sections are a mixture of fixed and open forms some rhythmically regular with full rhyme; some deliberately halting with no discernible sound pattern. In keeping with this shape the intimacy of mother and daughter waxes and wanes, so that tenderness and estrangement are in dynamic relation throughout the poem. The mother's cleaning rituals situate these memories in the context of a house-proud, working-class woman, yet the speaker is more concerned with the goal of self-knowledge. We glimpse the self-consciousness of this process: 'I have her shrug and go on / knowing history has brought her to her knees' (MMW I8) (my italics). Elsewhere, though, the poet is notable for her apparent absence. The mother's story of punishment at the hands of her father is presented directly, so that we cannot read the emotional response of the daughter who is sizing / up the world beyond our flat patch by patch' and exercising her imagination on the exotic other - 'Zanzibar, Bombay, the Land of the Ethiops' ( $M M W$ I9). The mother's creativity emerges through sewing and then knitting; it is practical and down-to-earth - 'She favoured sensible shades: / Moss Green, Mustard, Beige'. Her daughter dreams about 'a robe of a colour / so pure it became a word' $(M M W 20)$. This relentless difference between the earth-bound and the transcendent, the need to follow a pattern and the urge to explore freely, marks both a personal and a generational difference. It reveals a connection to the past at once repressive and grounding; a female subjectivity that must be acknowledged though it remains in the past.

Colette Bryce's most recent collection returns often to the figure of the mother, so that she becomes an almost ghostly presence, keeping the book anchored in the personal past. In 'A Little Girl I Knew when She was my Mother' the gulf between mother and daughter is invoked by the older woman's removal into a space between sleeping and waking; a fairy-tale world resonating amazement and fear. The form of the poem expresses the dissociation felt by both speaker and reader witnessing the girl-mother as she

emerged from the pages of a bed from sheets the colour of old snow crawled from the petals of the Weeping Rose from silks suffused with smoke and sweat 
The room, with its tossed bedclothes and swirling-patterned carpet, mutates to an ephemeral world of snow and rose petals. The sheets alter their substance to become silk, then Virgin's robes, winding cloths and finally black flags. Sound patterns assist this transformation: the ' $s$ ' sounds of 'snow', 'silks', 'smoke' and 'sweat' slipping down through the poem; the movements shaped by the opening out of lines:

uncurled her limbs

$$
\begin{aligned}
& \text { like an opening fist } \\
& \text { free of the winding cloths }
\end{aligned}
$$

\section{(WRU 37)}

At the turn of a page, the poem contracts into single-spaced couplets as the mother reaches a dressing table, where she is reflected in a triptych of mirrors. The multiple images intensify the gulf between the inner self and the outward appearance - the many versions of the individual on display to the world suggested by the pronoun shift here: 'There's a woman trapped in the centre of their body / that no one can remember' (WRU 38). The second part of the poem also recalls its title, which invokes the childlike quality of the elderly and the blurring of the generational divide. The title in turn is borrowed from the artist and sculptor Louise Bourgeois, whose works evoking sexualized bodies and emotionally troubled childhood experiences are consonant with the arresting treatment of the mother's body in Bryce's poem.

A more conventional, though equally uneasy representation of the mother can be found in O'Malley's 'Poem for my Birthday'. Its opening line, 'This is between you and me alone, Mother' confirms the privacy of this address as the source of its difficulty yet denies the relationship a space of personal resolution, entering it instead into the public realm of printed language $(B H$ I8). The speaker renounces the poetry of maternal intimacy - 'I have never liked those fleshy poems / wet milk and birthslime' ( $B H$ is) - and in doing so rejects not only the embodiment of this closest of human ties, but the forms of expression available to address it. Like Meehan, O'Malley often seeks not only to represent a new perspective on familiar experience but also to challenge our expectations regarding poetic voice. In representing herself as 'no easy infant' and as 'a scrawny crow', the speaker offers a form of subjectivity already restless and dissatisfied and a lively precursor to the questioning adult artist. The mother here is the figure specifically associated with the suppression of the child's voice: the 'crowtalk', even the 'odd sweet note I hit' offer no means to connect 
( $B H$ I8). Both childhood confusion and adult pain remain unassuaged by the mother, signalling a separation not bridged by time or shared experiences. The unasked question in the poem - 'what right have I now ... what right have I to ask?' - is a measure of the yet-to-be established right to speak; one to which the poet's own career stands as testament.

\section{Stories of Love: Remembering Loss}

Adult relationships also give rise to the states of estrangement for all three poets, signalling the deepening of turbulent emotional states. Again, relationships of intimacy trouble the boundaries of the self and the ability of the speaker to consign the relationship to the past becomes an important indicator of her capacity to transcend this trauma. A number of O'Malley's poems from the early years of the new century explore the pain of marital breakdown and interrogate a loss of home that has still larger cultural and linguistic significance. Here the role of memory is a subtle one, an unstated perspective of long attachment from which the grief of separation grows. 'The Ice Age' renders this emotional change as a seismic shift, as a new form of weather that sweeps all familiar structures away. The icy temperature speaks of long-felt alienation coming to expression at last: 'Here we are after the real winter. / It froze so deep that the meltwater / / runs thick with old debris' ( $\mathrm{BH}$ 17). This debris contains both actual and psychic material, yet the protagonists seem trapped in the position of witness:

\section{The stark}

truth seems to be that we are ourselves stuck among things that will not float yet, artefacts

of the constructed life, its seams unravelled.

$(\mathrm{BH} \mathrm{I} 7)$

Here the current of the poem, its rhythm, runs counter to its observations: emotional blockages hold up the momentum towards a new mode of existence. The overheard song is in a language the speaker can't understand, yet the line - part of Mahler's Kindertotenlieder, or Songs on the Death of Children - means 'now I see clearly', even though such clarity is not acknowledged directly by the speaker. This is increased by the ambiguities of the English language: 'It has been twenty-two years. Cleave, / I think. Cleft. The words pitch like holed vows' ( $\left.B H_{17}\right)$. The verb 'to cleave' means both to split and to adhere, so that the speaker 
is drawn towards her husband at the same moment as she is divided from him. The leaky vessel of language cannot fully express this state, yet its variability captures the mixed emotions poignantly.

Meehan's "Not alone the rue in my herb garden ..."' also addresses the breakdown of a marriage but from the perspective of hindsight, on a return visit to the speaker's former home $(P T 42-4)$. Once more, the act of return, whether literally or imaginatively, prompts Meehan to re-engage with the experiences of the past and to consider the relationship between her present and former selves. The garden provides the governing metaphor of this poem, highlighting the contrast between the creativity and nurturing that shaped the marriage in its early days, and the neglect that is both cause and effect of the relationship's collapse. As one of Meehan's longer poems it handles the passage of time deftly, moving between present response and past memory in ways that illuminate the alteration of the relationship and the sustaining growth of the individual.

The garden is the place of difficult and important work for the speaker: the labour of shaping nature is analogous to the building of the marital bond, to the corresponding 'poetry and story making' that are both part of the texture of this relationship and the means by which it is reflected upon (PT 42). Though the speaker considers herself 'the luckiest woman born' to have forged this existence, the 'fatal rhythm of the Atlantic swell' hints at the turbulence that marks the finite nature of such an idyllic life (PT 43). It is significant too that the growth of the individual means relinquishing aspects of personal history: the integration of her life with that of her husband permits her both to nurture and to bury past events:

I did not cast it off lightly,

the yoke of work, the years of healing,

of burying my troubled dead

with every seed committed to the earth, judging, their singular, particular needs, nurturing them with sweat and prayer

to let the ghosts go finally from me.

The evocations of the cycle of birth and death here are telling. Just as regrowth is predicated on letting go of dead matter, so the present inevitably becomes a new form of past which must be confronted in its turn. The past of this poem is thus multilayered, and its final appeal does not speak only to the 'abandoned husband' but to every facet of 
the life that has been left behind (PT 44). The reality of such a history must be accepted in order for the appropriate meaning to be reached: 'Oh my friend, / do not turn on me in hatred, / do not curse the day we met' (PT 44). This is an unusually declarative poem for Meehan and the direct personal voice is an important facet of the poem's success in negotiating difficult emotional territories. Its shifts mark the existence of poetic conventions and their interiorization: the poetic voice moves smoothly between the demotic ('Cranky / of a morning when the range acted up') and the lyrical ('Oh heart of my husband') (PT 42; PT 43). The poem also reminds us that, though the lyrical impulse commonly evokes a coherent self, it is possible for a poem that is not experimental in formal terms to highlight the limitations of this subject position with a subtle slippage of temporal structures.

Bryce offers a more overtly fractured subject position in her 'Self Portrait in the Dark (with cigarette)'. Here the end of a relationship prompts the speaker to turn to self-scrutiny, becoming her own 'other', a solitary observer of the night scene. As in so many of her poems, the starting point is literary: 'To sleep, perchance / to dream? No chance: / it's 4 a.m. and I'm wakeful / as an animal' (SPD 4). Here the line breaks disrupt the natural flow of meaning, reinforcing the restlessness of half rhymes - 'perchance'-'chance', 'lack'-'insomniac', 'amber'-'downpour' (SPD 4). The sight of the headlights of a distant vehicle draws the speaker's attention to her lover's car, still parked in the street outside. Invoking, then dismissing, the self-help terminology of 'moving on', she suggests that she has been 'driving it illegally at night / in the lamp-lit silence of this city' (SPD 5), thus projecting herself into the 'slow vehicle' which prompted her original reflection. But, no, reader and ex-lover are reassured, the car is fine, 'gleaming' and 'upright', the small flashing light confirming its security system has not been breached. Though the apparent reality of the poem reinforces the distance between the speaker and the object of the beloved, its metaphors bridge the gap: the tiny red light is likened to the speaker's cigarette, flaring in the dark. In this way, the emotional distances that have opened up in the poem appear foreshortened and the trick of representation signalled in the poem's title is made meaningful. While the poems by Meehan and O'Malley configure the end of a marriage in terms of slow and cyclical change, Bryce's retains the raw energy of recent loss, together with the whimsicality of the still unsettled perspective. 


\section{Transforming the Past in Language}

The work of the two older poets, as well as representing more gradual change, reflects directly on the role of memory as an important agent in the process of self-understanding. This process highlights the intersections between the acts of remembering and writing, emphasizing the power of poetry not only to engage with the past but also to reflect upon the transformative capacity of language. Increasingly, Meehan returns to childhood trauma as a means of investigating the practice of writing itself.

If this poem, like most that I write,

is a way of going back into a past

I cannot live with and by transforming that past

change the future of it, the now

of my day at the window

The transformative power of poetry is asserted directly here, yet 'past' - as the final word of two consecutive lines - slows the pace of change with a weighted, reflective pause. The idea that re-engagement with past experiences can change the course of a personal narrative suggests too that both past and future are fundamentally shaped, if not created, by the act of writing itself. Meehan herself acknowledged this possibility in interview: 'Remembering for its own sake wouldn't interest me, but memory as agent for changing the present appeals to me greatly.' ${ }^{26}$ In 'Fist' the return to the past self is not a point of estrangement but rather one of positive difference, within which an emotional continuum is established between child and adult. The threatening fist that the poet experiences in the present propels her immediately to the childhood experience of anger and helplessness. The cupping of the child's fist between the adult's two hands reshapes the gesture to one of support and connection. By erasing the time between present and past selves, Meehan obliquely investigates the continuing presence of the child in shaping adult perceptions and creativity. By turning the child's fist into an open hand, Meehan shows how language can enact - from a point of distance - what could not be done literally and in time; it reveals too how the cycle of violence can be broken through imaginative connection. Her bloody mouth becomes 'a rose suddenly blooming' as present pain

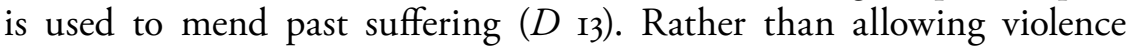
to estrange and fragment the self, Meehan's writing of memory offers 
redemptive possibilities, not only through confronting past trauma but reimagining a response to those circumstances.

Another striking representation of the experience of physical distress is O'Malley's 'Miss Panacea Regrets'. In contrast to Meehan's technique, O'Malley chooses the form of the sequence to mark the rhythms of pain and the attempts of the speaker to endure its near-impossible challenges. The shape of the poem therefore works both with and against its language, since poetry itself is the redemptive element set against the deadening force of physical pain.

They have pierced my breast.

The wound, unstitched, blossomed and like Philoctetes I am unhealed.

All that lovely month I limped on half-sail, half-life in the rose-scented mornings,

A hot-house virgin on a May altar

$(K W 22)$

This wound, like Meehan's, is likened to a blossom - an abjection that can yet be seen as a thing of beauty and promise. The estrangement that necessarily grows from this experience is one that brings the speaker to a stark realization of the fragility of the self. The struggle to represent physical ordeal yields a text divided between description and apostrophe, as the speaker addresses the medics into whose hands her body has been delivered: 'You will not stitch breath / with such blunt instruments. / [...] I What you hear with your stethoscope I Is not the true beat of her heart' $(K W 24,25)$. Yet the poem is also a dialogue with a literary precursor: prefacing her text with a quotation from Marina Tsvetayeva, O’Malley goes on to question the solidarity of sufferers - 'Marina, I would hold your pain / but who would contain mine?' (KW 22). In directly addressing the poem's epigraph, its speaker moves closer to the poet's own perspective, preparing us for the later exploration of poetry's power to represent suffering. From the start, biblical and mythical references are an important means by which O'Malley retains coherence in the escalation of physical turmoil: 'They have pierced my breast' is repeated with slight variations throughout. ${ }^{27}$ This practice suggests that the necessity of return can be formative of the sequence structure itself, much as Eavan Boland has used it as a means to renew her engagement with a seemingly irresolvable dynamic.

Later, in 'Miss Panacea Regrets', poetry itself acquires this penetrative power: 'Poems like spears / pin me between earth and sky. / The moon sneers' $\left(K W_{32}\right)$. Sound patterns shift and repeat to emphasize at once the 
immediacy and the extent of the pain - the 'p' and 's' sounds interspersed with pulsing broad and narrow vowels. Poetry itself is implicated in the suffering. The self that is so repeatedly cut and pierced is invaded also by language, a replacement for faith in this poem but one that is rife with ambiguities and oppositions:

It has been excised,

a weak spot in my breath

cut out and the tear stitched.

It is healing well. In time

it will become a faint mark,

my stolen language, an echo that tugs,

the need for a word not known

like grá or brón for love or pain.

$(K W 3 \mathrm{I})$

The required excision marks a loss that is not only physical but also linguistic, since the poem is written in English rather than in the Irish to which the poet feels drawn. The representation of bodily trauma does not assuage distress but instead confronts the poet with the inextricable ties between language and self-understanding. The removal of language is a direct negation of the knowledge that this operation might have offered: instead of being laid bare, words are excised from memory. As well as the battle with uncontrollable pain, the poet must also grapple with the creative process itself, with the difficulties of expressing the intensity of pain in words.

\section{Writing Estrangement: Changing Selves and Environments}

The complexity of the subject-position in the poem is revealed through the layering of forms of self-representation throughout the oeuvres of all three poets under consideration here. Each articulation of self must be seen not only in the context of its immediate realization but in relation to the poet's earlier representations of the subject position, so that self-representation becomes an acknowledgment of one's double existence as object and subject of the poetic process. This results in a heightened perception of the role of writing, and of reading, in the construction of an estranged position; the intensified absorption in language is not at first an expressive asset but one that may separate the speaker from her peers. This dislocation from ordinary life forms a parallel to the idea of the stranger as 'between' languages, with speech and actions that may be incomprehensible to the onlooker. ${ }^{28}$ It also reflects the more subtle 
relationship that the stranger bears to poetic conventions and traditions. Meehan's 'Swallows and Willows' illustrates this gulf of understanding powerfully. Once more the childhood memory of the speaker expands - this time to include the power of poetry not only to represent the self but in certain contexts to mark the reading self as 'other'. At the opening of the poem, the speaker has already been caught at the corner / with the curly headed green eyed boy' and the punishment for this forward behaviour is to copy a poem a hundred times $(D$ 53). In choosing an extract from Sylvia Plath's 'The Jailer' - and not from a 'set' text, as required - the speaker refuses to allow poetic language to be put to mechanical use, instead determining that as reader, as copyist, and ultimately as poet herself, she allows both Plath's poem and her own to express the truth of her situation. 'The Jailer' itself marks a fundamental estrangement from a powerful male presence, yet what eludes the reader here is the meaning that follows from the five copied lines. The 'impossibility' referred to in the final phrase is, in fact, 'being free'.29 Plath's poem concludes with a fierce reflection on the destructive nature of interdependence: 'What would the dark / Do without fevers to eat? / What would the light / Do without eyes to knife'30 The speaker in Meehan's 'Swallows and Willows' at first tries to be neat, then yields to disaffection and its freer expression, 'a looping downward scrawl' ( $D$ 53). Alienated by the teacher's refusal to accept her efforts, she becomes 'sulky, lonely, and cruel', manifesting not just passive or internalized feelings but finally an outwardly directed one. Like Kristeva's stranger she is ' $[b]$ etween the two pathetic shores of courage and humiliation'.31 In her estrangement from the class and from the processes of learning, she turns to nature: 'Out the window - swallows / and willows and sun on the river" ( $D$ 53). This provides not only a form of imaginative escape, but reflects (while seeming to prefigure) the importance of nature for the adult poet, in whose work it becomes a vital aspect of self-development and cultural critique.

This poem, like so many of Meehan's, tacitly engages with both past and future, vividly rendering the shaping events of the later writing self after that later self has in fact been formed. In doing so, it emphasizes the continuing importance of the other within the self and reminds us of the fact that identity is always in formation. It is this awareness that drives Meehan's rewriting of particular landscapes of experience in order to understand them more fully. One of the most striking poems in Painting Rain also concerns the continuing significance of the act of reading in the formation of self. 'A Remembrance of my Grandfather, 
Wattie, Who Taught Me to Read and Write' is a sonnet that renders the familiar landscape of Meehan's poems in a new way. The speaker is traversing a snowy streetscape on her way to the Natural History Museum, when looking up into the branches of a tree she sees a book:

There, like a trireme

on an opalescent ocean, or some creature of the upper air come down to nest, a cargo with a forest meme, only begotten of gall, of pulp, of page, of leaflight, of feather.

The irony that the book, coming from the same material as the tree, should ultimately come to rest in it marks a perfect unity of Meehan's commitment to her art and to the environment. That it appears while she is on her way to the Natural History Museum reinforces the restorative power of momentary observation, of what is brought to the poet by chance. The wonder of this sign makes it a fitting tribute to the man who introduced her to the wonder of all signs: this poem allows the speaker some measure of comfort in that important connection and a sense of freedom from her own history, which the use of the present tense in the poem itself enacts.

Throughout her career to date, Meehan's attentiveness to the city of her birth has created some poems of extraordinary vividness, and has also released the possibilities of transcendence in the midst of estranging experience. As Luz Mar González-Arias has demonstrated, Meehan's response to Dublin is both physical and adaptive. ${ }^{32}$ In 'A Child's Map of Dublin' the speaker's failure to find 'Connolly's Starry Plough', either in 'nightskies' or in the National Museum - where history itself is being renovated - is matched by the feeling that the city itself has changed radically from the place of her memory:

I walk the northside streets

that whelped me; not a brick remains

of the tenement I reached the age of reason in. Whole

streets are remade, the cranes erect over Eurocrat schemes

down the docks. There is nothing

to show you there

(PT I4)

Meehan has always constructed selfhood in terms of place, both in the problematic relationship with the family home and in the larger dynamics of city and country. Even in this poem of urban community, she is imaginatively drawn by creatures - 'oriole, kingfisher, 
sparrowhawk, nightjar' - and finds creative sustenance and an extended sense of belonging from this connection. The trajectory of this poem is associative, so that the spatial quality of the city experience is expressed directly in poetic form. These imaginative shifts ultimately affirm human intimacy; at the close of the poem the speaker bids her companion to slip 'between the sheets' and then to 'play in the backstreets and the tidal flats' ( $P T$ I5). There is potential double-meaning here, since the 'flats' more commonly encountered in Meehan's poems are places of overcrowded city dwelling, while we, as readers, are accustomed to the spaces between her sheets. Such interpretative slippage marks the ease with which different environments are rendered in Meehan's work, yet it is an ease that reveals an acute sensitivity to the relationship between individual and environment. For Meehan, even the public spaces of this poem have the intimacy of combined familiarity and new discovery.

Elsewhere, though, the private/public relationship is less easily assimilated. In the sequence 'City', this dynamic is reflected both in the relationship among the poems and in the shape of individual works. 'Hearth', which contains an early image of the 'fire' of sexual expression, is balanced at the close by the cooler: 'You slip your moorings, cruise the town' (PT 19). Here the woman out in the street merges with the night city in both familiarity and invisibility:

\section{You take Fumbally Lane}

to the Blackpitts, cut back by the canal.

Hardly a sound you've made, creature

of night in grey jeans and desert boots,

familiar of shade.

('Night Walk', PT 20)

In spite of the integration between the figure in the poem and the anonymity of the night, the work itself contemplates the oscillation between the desire for intimacy and for escape, a movement that is integral to Meehan's exploration of estrangement. The sexual affirmation of the third poem, 'Man Sleeping', is muted by the evocation of the man deep in sleep, as though under the sea, and therefore remote from all but physical response. The shift of perspective in the following poem plays with the female identification of the moon: 'She's up there. You'd know the pull, / stretching you tight as a drumhead' ('Full Moon' PT 22). The repetition of this phrase at the opening of the final poem, after the woman has deduced her lover's infidelity, accentuates the shift in tone and image pattern that follows: 'Choose protective colouring, camouflage, / know your foe, every move of him' (PT 23). Here the intimacies of the 
earlier poems are permanently ruptured and the estrangement of the woman is marked most strikingly by the divergence of her private and public personae: while outwardly she is 'dead casual', inside an unsprung wildness is coiled. The internalization of this manifestation of alterity is significant for Meehan, in that it affirms the psychological depths at which these dynamics operate.

For Bryce, memories of place are linked to the trauma of growing up during the Troubles in Northern Ireland. Her 20I4 collection, The Whole and Rain-domed Universe, is preoccupied by the intersection between domestic and political worlds, envisaging the family unit within a wider context of violence and instability. This connection reflects complex relationships of authority that are expressed both within the family and in the wider world. As Jenny Edkins explains: 'events seen as traumatic seem to reflect a particular form of intimate bond between personhood and community and, most importantly, they expose the part played by relations of power'.33 Bryce's long poem 'Derry' situates the tension between belonging and estrangement in these terms. Mimicking the opening lines of Louis MacNeice's 'Carrickfergus' - 'I was born in Belfast between the mountain and the gantries / To the hooting of lost sirens and the clang of trams' - Bryce's poem invokes both the sensory immediacy of the older poet's work and his status as an outsider. ${ }^{34}$ Published in 1937, against the backdrop of escalating political tensions in Europe, MacNeice's poem dwells on memories of childhood upheaval during the First World War. Bryce's poem likewise explores insecure identity within a set of domestic and historical co-ordinates: 'I was born between the Creggan and the Bogside / to the sounds of crowds and smashing glass' (WRU 2). The poem remembers and interweaves inherited text and immediate experience, breaking and re-making both in the process. The smashed glass of this first stanza becomes the 'fixed' looking-glass of the second, in which the face of the speaker cannot be told apart from those of her siblings. Other boundaries are equally blurred: the overlapping nature of religious and regional affiliations is reinforced by remembered prayers and poems: 'Hail Holy Queen' combines with St Columba's poem of Derry to prefigure the scene of children singing in the back of the family's red Cortina. This scene of innocent play is interrupted by the car's arrival at a checkpoint and by the transformation of the landscape of the poem into a desolate and threatening scene: 'the ancient walls with their huge graffiti, / / [...] snarling crossbreeds leashed to rails' (WRU 3) - the enduring nature of the city's violent past exacerbated by the crowded consonants of now barely restrained aggression. 
The dark mood that permeated the province in the 1980s is expressed in the poem through the close interaction between different forms of violence: the hunger strikes in the Maze prison, the crowning of Barry McGuigan as World Featherweight Champion and the domestic violence in the speaker's own home. ${ }^{35}$ It is only at the realization of this private conflict that the shared perspective gives way to the singular - the 'we' becomes 'I' - and the syntax begins to reflect the immediacy of the disturbance: 'My bed against the door, / I pushed the music up as loud / as it would go and curled up on the floor / to shut the angry voices out' (WRU 4 ). This acknowledgment of domestic strife marks a transition towards maturity on the part of the speaker and a greater attentiveness to the ways in which political ideologies and actions are mediated. One of the significant achievements of this poem is its retention of youthful energy, even light-heartedness, in the midst of serious retrospection. For Bryce, to confront what is concealed in a close-knit family structure is to acknowledge that estrangement is felt most acutely in a context of shared experiences. This combined sense of intimacy and distance is an important dimension of traumatic representation in all these works.

\section{The Lives of Others: Intimate Strangers}

For O'Malley, intimacy and estrangement are also closely intertwined, but the landscapes in which she chooses to explore these conditions are not those of domestic suburbia but rather coastal communities where the familiarity of the place is balanced by a sense of being on the margins of shared experience. As Eamonn Wall suggests, 'to be on the sea is to be liberated from the constraints that underline life on the land, and to enter the realm of folklore and mythology'.36 Many of O'Malley's poems, such as 'The Maighdean Mhara' (WRF) and 'The Otter Woman $(K W)$ are inspired by this transition, yet she also represents the western seaboard as a place of continuous vibrant life, rather than as a community essentially lost to history. ${ }^{37}$ This space is both the one that she is most familiar with and the one that has shaped much of her creative life, marking her poetic fidelity to lived experience: 'nothing that you can conjure, or manufacture, or make up, is anywhere near as powerful as the [images] you bring with you out of childhood'.38 Yet as well as being a place of familiarity and inspiration it is also a place where the awareness of security and threat meet, exemplified in the poem 'Seascape, Errislanaan'. Here a wild sea yields flotsam, including 
a strange object gathered by the speaker's companion - 'a pretty toy or case / powder compact size but thicker' (BH 23). This turns out to be an anti-personnel device that floated in on the tide; a mechanism especially treacherous for children who are curious about them and unaware of the danger. Both speaker and reader experience the same distress at the unfolding of this narrative, and then sudden fear:

There are times when the world empties of sound.

When you said, 'Disarmed, of course,' and smiled the tight skin on my hand tasted almonds. Then the rush of wind falling, the words' backthrust.

Even in a place of safety, the speaker is reminded of the sudden proximity of death and destruction. Though the threat is an impersonal one, its immediacy is striking and, like Meehan, O'Malley registers both the need for vigilance and the exhilaration of risk. This tension acknowledges the subject position of the poem as one of potential exposure that can only be reversed with the power of hindsight.

There are other poems by O'Malley that register the fate of the innocent in war, but few are more thought-provoking than 'The Abandoned Child'. The poem evokes the starkness of its circumstances from the outset: 'This is a simple photograph, a black and white picture / of a child lying in the dust. She has no name. / Call her Baby, Beauty, Unbeloved, she is the face of our time' ( $\mathrm{BH}$ IOI). In the choice of this subject matter, and in the framing of this girl as a symbol of modern strife, O'Malley show how individual experience must be of universal concern. Yet she moves beyond this symbolic construct. Though '[e]very poem pauses here', O'Malley continues by asking the crucial questions, most pertinently, perhaps, 'how long / do the doomed beauties last with the cameras gone?' ( $\mathrm{BH}$ IOI). Acutely aware of the act of representation as one that brings responsibilities, the poet imagines the futures of this girl from washerwoman to physicist. The recurring image of the cosmos draws together this ambitious intellectualism with the disappearance of the marginalized from view 'into the black hole of heaven'. Though light streams into heaven it emits no signs of hope:

She has no name, this beauty lying in the dirt between well made sonnets and free verse, without an I or you or us, between the hand's release and the rattle of the Gorta box. Read her eyes 
This unnamed woman has no subjectivity except that provided by art or charity, yet in being invited to read her eyes we enter into intimacy with her, forced by the perspective of the poem to draw close to her human plight. This alters the treatment of estrangement significantly, confronting us not with the other within the self, but instead the self within the other. In this way self-knowledge is shaped as much by the response to the suffering stranger as it is to one's own suffering.

This dynamic is also central to Meehan's most widely read poem, 'The Statue of the Virgin at Granard Speaks'.39 The poem focuses on the death of Ann Lovett in childbirth: in life, Lovett concealed her pregnancy; her death brought the double standards of Irish sexual life to national attention. In voicing the divine, Meehan not only draws attention to human failing, but to the complicity of religion in the girl's victimization. The isolation of the statue from human life hints at the experience of the girl herself and her loneliness in death:

The whole town tucked up safe and dreaming,

even wild things gone to earth, and I

stuck up here in this grotto, without as much as

star or planet to ease my vigil.

$\left(M M W{ }_{40}\right)$

The desolation of the landscape combines realism and pathetic fallacy - Meehan's layered poetic process is capable of working as direct representation and for symbolic purposes. The violence that is such an important part of Meehan's social critique is evident here both in the 'ghetto lanes / where men hunt each other' and in the bloody Christian imagery of the 'man crucified: / [...] / the thorny crown, the hammer blow of iron / into wrist and ankle, the sacred bleeding heart' ( $M M W$ 4I). By juxtaposing these dark and terrible scenes, Meehan emphasizes the distorted nature of potent Catholic mythology. In doing so she also renders the perspective of the Virgin as one of passivity and alienation, one whose being 'cries out to be incarnate, incarnate'. Yet her vision of the 'honeyed bed' of human sexuality is an ironic one, since her very presence excludes the free expression of love, valorizing instead the self-denying figure of the Virgin. The early moments in the poem, when the positions of statue and girl could be conflated, are tellingly refuted at the close:

I did not move,

though she cried out to me in extremis

I didn't lift a finger to help her, 
I didn't intercede with heaven,

nor whisper the charmed word in God's ear.

$(M M W 42)$

The relentless nature of this denial simultaneously marks the girl's estrangement from all the sources of support and comfort that should have been available to her, and the alienation of religion from humility and compassion.

This deeply felt conviction on Meehan's part is at the core of her poetic achievement: that the world of the spirit has an important role to play in addressing human suffering and deprivation. 'Dharmakaya', the title poem of her groundbreaking collection published in 2000, moves towards a direct engagement with the spiritual through a meditation on death. Influenced by Buddhist thought, both poem and collection consider the relationship between being and non-being: inseparable conditions, together constitutive of meaning. As Kathryn Kirkpatrick has pointed out, the breath is the structuring device of this poem, marking its stanzaic structure. ${ }^{40}$ It could also be argued that the entire poem exists after the last breath, since it begins 'When you step out into death / with a deep breath' and ends with death as the 'still pool' in the midst of the 'anarchic flow' ( $D_{\text {II }}$ ). Poised thus on the threshold between being and non-being, the poem releases its tensions through the slow trajectory of its meaning and the deliberate pauses, such as those that take place between the second and third stanzas: 'Breathe / slow- / ly out before the foot finds solid earth again'. The poem is also significant for drawing together urban and natural worlds - 'the street' and 'the woods' - to approach human experience in its essential states. It is possible to argue that all the states of estrangement represented in Meehan's work are leading here: to an awareness of the fundamental sameness of self and other. The representations of estrangement within familial and love relationships are not only traumatic memories reclaimed in language, they also represent the perfect ambiguity of the familiar and the strange. They are suggestive too of the incorporation of the stranger within the self, which is such an important part of Meehan's poetic journey.

This poem, which expresses so eloquently the ways in which the individual woman is failed by the culture of which she is a part, speaks to an element of O'Malley's work which also seeks to unite private grief with patterns of trauma and loss brought about by the Great Famine. As a native of Connemara, O'Malley feels a close affinity with the patterns of death and emigration that shaped Irish experience in the wake of the famine. 'The Boning Hall', title poem of her 2002 collection, sets these 
historical events in a specifically feminist framework, invoking American poet Adrienne Rich's demands to reach the material substance of the past, rather than its narrative presence. ${ }^{41} \mathrm{Her}$ poem, 'Diving into the Wreck', is used by O'Malley to contemplate the horror of the coffin ships on which so many died journeying to America:

No one goes diving into coffin ships but if they did with the desire for pearls quelled they'd see wonders: limbs streaming by, the rush of blood, oxygen, water, bubbling with the slipstream.

(BH $\left.\mathrm{I}_{4}\right)$

Juxtaposing underwater treasures with the loss of human potentiality, O'Malley does not flinch from the immediacy of the abject body, its loss of integrity the direct result of social injustice. In this poem she rejects the metaphorical rendering of underwater life - the essence of what has been lost slips past the clichés of the submerged world with its 'fabulous galleons' and gold coins. Though ephemeral, it is relentlessly itself, bearing witness to the sufferings of history that are not distant but immediate and individually felt. This experience is represented by the song of the bone-harp, 'not of the names for things you cannot say / but the long round call of the thing itself' ( $\mathrm{BH}$ I4).

This confrontation of what is traumatic in the Irish past acknowledges what is traumatic in the lived present. These three poets, from different backgrounds and regions, articulate the complex and changing relationship between writing and the realization of self-knowledge. All three meet the aesthetic and ethical challenges that attend the representation of private matter in poetic form, either by addressing the practice of representation directly or by creating an imaginative world within which subjectivity itself acquires new perspectives. These practices allow the representation of the personal past to shape more extensive forms of ethical questioning in the work of many Irish women poets writing today.

\section{Notes}

I Some of Halbwach's contemporaries, in particular Marc Bloch, objected to this transition from individual to group perspectives. Recent scholars have questioned the value of the concept of collective memory itself. See Astrid Erll, 'Cultural Memory Studies: An Introduction', in Astrid Erll and Ansgar Nünning (eds), Cultural Memory Studies: An International and Interdisciplinary Handbook (New York and Berlin: Walter de Gruyter, 2008), pp. I-2 and Barbara A. Misztal, 'Memory and History', in Oona Frawley (ed.), Memory Ireland, vol. I, History and Modernity (Syracuse, NY: Syracuse University Press, 2oIo), pp. 4-6. 
2 Erll, 'Cultural Memory Studies', p. 5.

3 Jenny Edkins, in Trauma and the Memory of Politics (Cambridge: Cambridge University Press, 2003), argues that traumatic memory fundamentally disrupts the linear view of history by keeping the past alive in the present and creating a 'new story' of these experiences (p. xiv).

4 Eileen O'Halloran and Kelli Maloy, 'An Interview with Paula Meehan', Contemporary Literature 43.I (Spring 2002), p. 7.

5 For an examination of Meehan's work from a psychoanalytic perspective, see Anne Mulhall, 'Memory, Poetry and Recovery: Paula Meehan's Transformational Aesthetics', in An Sionnach: A Journal of Literature, Culture and the Arts 5.I-2 (Spring/Fall 2009), pp. I42-55.

6 Jacques Derrida, Of Hospitality, trans. Rachel Bowlby (Stanford, CA: Stanford University Press, 1997), p. 55.

7 Among the younger generation of Irish women poets, Sara Berkeley, Colette Bryce, Vona Groarke, Sinéad Morrissey and Caitríona O’Reilly have all lived abroad for extended periods.

8 Paula Meehan, untranscribed interview with Danielle Sered, Special Collections Archives, Woodruff Library, Emory University, Atlanta, GA, 1999. Quoted in Kathryn Kirkpatrick, 'Between Country and City: Paula Meehan's Eco-Feminist Poetics', in Christine Cusick (ed.), Out of the Earth: Eco-Critical Readings of Irish Texts (Cork: Cork University Press, 2009), p. I24.

9 Annie Finch, 'Coherent Decentering: Toward a New Model of the Poetic Self', in Kate Sontag and David Graham (eds), After Confession: Poetry as Autobiography (Saint Paul, MN: Graywolf Press, 200I), pp. 137-8.

Io 'To the Island: Mary O'Malley in Inishmore', RTÉ Radio I documentary, produced by Lorelei Harris, I994 [28:22].

II Eamonn Wall, 'Tracing the Poetry of Mary O'Malley', Writing the Irish West: Ecologies and Traditions (Notre Dame, IN: University of Notre Dame Press, 20II), p. 84 .

I2 Patricia Boyle Haberstroh, My Self, My Muse: Irish Women Poets Reflect on Life and Art (Syracuse, NY: Syracuse University Press, 200I), p. 44.

I3 Charles Bainbridge, 'The Great Escape'. Review of The Full Indian Rope Trick by Colette Bryce, Guardian, January 29, 2005, www.theguardian.com/books/2005/ jan/29/featuresreviews.guardianreviewI2.

I4 Julia Kristeva, Strangers to Ourselves, trans. Leon S. Roudiez (New York: Columbia University Press, 199i), p. I.

I5 Sigmund Freud, The Uncanny, trans. David McLintock (London: Penguin, 2003), p. 125 .

I6 Sara Ahmed, 'Who Knows? Knowing Strangers and Strangerness', Australian Feminist Studies 15.3I (2000), p. 49.

I7 Maurice Halbwachs, The Collective Memory, trans. Francis J. Ditter and Vida Yazdi Ditter (New York: Harper Colophon Books, 1980), p. 38.

I8 See Ian McBride, 'Memory and National Identity in Modern Ireland', in Ian McBride (ed.), History and Memory in Modern Ireland (Cambridge: Cambridge University Press, 200I), p. 7.

I9 O'Halloran and Maloy, 'An Interview with Paula Meehan', p. I3.

20 Negative critical responses to Eavan Boland's repeated use of personal experience in both her prose and poetry often comment on the poet's privileged position, 
suggesting that private revelation can affirm an experiential gap between speaker and reader rather than the desired affinity. See Batten, 'Boland, McGuckian, Ní Chuilleanáin and the Body of the Nation', pp. 173-86; also Charles I. Armstrong, Figures of Memory: Poetry, Space, and the Past (Basingstoke: Palgrave Macmillan, 2009), pp. 160-6.

2I Ernst Van Alphen, 'Symptoms of Discursivity: Experience, Memory and Trauma', in Mieke Bal, Jonathan Crewe and Leo Spitzer (eds), Acts of Memory: Cultural Recall in the Present (Hanover, NH: University Press of New England, 1999), p. 25.

22 Dominick LaCapra, History in Transit: Experience, Identity, Critical Theory (Ithaca, NY and London: Cornell University Press, 2004), p. II7.

23 Gabriele Schwab, Haunting Legacies: Violent Histories and Transgenerational Trauma (New York: Columbia University Press, 2010), p. 4.

24 Van Alphen, 'Symptoms of Discursivity', pp. 28-30.

25 Catriona Clutterbuck, 'The Artistry of Freefall'. Review of Dharmakaya, Metre io (Autumn 200I), p. III.

26 O'Halloran and Maloy, 'An Interview with Paula Meehan', p. I3.

27 In 'To the Island' O'Malley comments on the importance of the poetic process in shaping the representation of trauma: 'good poetry refines the pain that is felt - it's a constant refinement and cutting away' [29:II].

28 Kristeva, Strangers to Ourselves, p. I5.

29 Sylvia Plath, 'The Jailer', Ariel: The Restored Edition (London: Faber \& Faber, 2004), pp. 23-4.

30 Ibid., p. 24.

3I Kristeva, Strangers to Ourselves, p. 8.

32 Luz Mar González-Arias, 'In Dublin's Fair City: Citified Embodiments in Paula Meehan's Urban Landscapes', An Sionnach: A Journal of Literature, Culture and the Arts 5.I-2 (Spring/Fall 2009), pp. 34-49.

33 Jenny Edkins, Trauma and the Memory of Politics, p. 4.

34 Louis MacNeice, 'Carrickfergus', Collected Poems (London: Faber \& Faber, 1966), pp. 69-70.

35 Over the summer of 198I ten Republican prisoners in the Maze Prison died on hunger strike. The campaign, which demanded Special Category Status for political prisoners - including the right to wear their own clothes and exemption from prison work - was called off after the families of the remaining hunger strikers indicated their intention to seek medical intervention for the men. Barry McGuigan, a Monaghan-born boxer, became World Featherweight Champion in 1985 after he defeated Juan Laporte in London. McGuigan, a Catholic married to a Protestant, was popular across both communities in Northern Ireland, as well as with both Irish and British audiences. He became a symbol of neutrality at a time of sectarian tension.

36 Wall, 'Tracing the Poetry of Mary O’Malley', p. 74.

37 Ibid., p. 79. Wall compares O'Malley's poetry to Boland's in this respect: where Boland sees the voices of women from the west as in need of recovery, O'Malley 'does not separate the historical West from its present condition'.

38 'To the Island' [8:38].

39 On the afternoon of January 31, 1984, I5-year-old Ann Lovett was discovered in a grotto just outside the town of Granard, Co. Longford by passers-by. She had given birth to a baby boy, who had already died. Ann herself was suffering from shock 
and died later that day in hospital. Coming just months after a divisive referendum on contraception and abortion, Ann Lovett's death became the focus for national debate on attitudes towards single parenthood. See 'Ann Lovett: The Story that Wouldn't Remain Local', Scannal, RTÉ I television documentary, produced by Sarah Ryder, 2004.

40 Kathryn Kirkpatrick, “Between Breath and No Breath”: Witnessing Class Trauma in Paula Meehan's Dharmakaya', An Sionnach: A Journal of Literature, Culture and the Arts I.2 (Fall 2005), p. 50.

4I 'I came to explore the wreck. / The words are purposes. / The words are maps. / I came to see the damage that was done / and the treasures that prevail.' Adrienne Rich, 'Diving into the Wreck', The Fact of a Doorframe: Selected Poems I950-200I (New York: W.W. Norton, 2002), pp. IOI-3. 

II

Achievements 



\section{Eiléan Ní Chuilleanáin's Spaces of Memory}

Eiléan Ní Chuilleanáin is one of the most significant poets to emerge in Ireland in the second half of the twentieth century. The relationship between past and present is important in her work, not only because memory often shapes her subject matter but also because of the uncanny ways in which temporal difference is elided, creating gaps in meaning, or places where language is used in cryptic ways. ${ }^{1}$ These give rise to the formal challenges of her work: 'the world she creates in a poem has an enigmatic centre', writes Eamon Grennan, 'one sees the facts clearly enough, but the purpose and point of these clearly realised facts aren't easy to pin down.2 For Ní Chuilleanáin the overlapping territory of memory and history is often marked by silence - many of her poems are concerned with what is withheld from expression and what this means both for the individual and the community. In her work there are aspects of the private that can never become fully public: experiences or phenomena that remain resistant to observation and analysis. Her engagement with these elements creates a pattern in her work - a repeated concern with the ways in which knowledge materializes in the lives and practices of both individuals and communities. This chapter examines her poems as objects that carry the past without giving direct expression to it. In this way, Ní Chuilleanáin's oeuvre provokes us to consider how the past is mediated, and in particular how the private, unstated past relates to ideas of shared narrative.

This emphasis on privacy has important ramifications for the operation of memory in Ní Chuilleanáin's work. In particular, it draws attention to the relationship between private and shared spaces as both physical and linguistic entities. The recurrence of personal and familial memories draws attention to the question of shared narratives and their broader implications for how we might understand the past. 
Psychologist Frederic Bartlett found that people recall 'not the presented [narrative] material directly, but a judgment which they made about this material when they saw it originally'. ${ }^{3}$ This dynamic is applicable to some of the processes of remembering in Ní Chuilleanáin's work, where perspectives slip between a story recalled and other, more fleeting, impressions. For her the political is not judged to be outside the private sphere but is an important dimension of it - an understanding that has its roots in her family history. ${ }^{4}$ Born in Cork to a literary family with a Republican lineage, Ní Chuilleanáin gained an early appreciation of the significance of the Gaelic past, especially for Munster literary history: 'History', she writes, 'has been particularly alive for me as for many Irish people. We are [...] told it is bad for us. But like others who share my linguistic background, I am aware always of the presence of the past and the strangeness, the untypical edge on the way I read history.'5 This 'strangeness' seems to stem from Ireland's dual language tradition, and from the ways in which the experiences of the past are shaped by the language through which they are understood and discussed. Later in the same essay, Ní Chuilleanáin elaborates on the specificity of linguistic experience by recording her dislike of the 'blurred' boundaries that constitute 'Anglo-Irish' literature. Her wish that languages 'keep their sharp edges, their strangeness to one another'6 confirms the idea that language can function as an agent of concealment, as well as one of expression.

Her concern with the intersection of narrative history and folk tradition has shaped her reflection on the relationship between individual and shared versions of the past, which in turn has problematized the function of collective memory. It acknowledges in particular the symbiotic relationship between memory and identity, as John Gillis has suggested: 'The core meaning of any individual or group identity, namely, a sense of sameness over time and space, is sustained by remembering; and what is remembered is defined by an assumed identity.' ${ }^{7}$ The transition from memory into history is important in this context. According to Maurice Halbwachs, history arises when the past 'is no longer included within the sphere of thought of existing groups'. ${ }^{8}$ Since group memory is focused on its own networks of meaning its construction of the past is not ruptured but smooth. ${ }^{9}$ Thus it is in the formation of history that certain perspectives are subsumed and lines of memory broken. This is especially true of groups that are marginalized, either politically or socially, by the prevailing power structures, and Ní Chuilleanáin's attention to the lives of women, and to those 
in religious life, shows her sensitivity to these discontinuities in the narrative of history.

She came to this position early: in her introduction to Irish Women: Image and Achievement, a book she edited for Arlen House in 1985, she suggested that 'the study of the Irish woman's image through history is also the study of the gap, most easily appreciated in the last couple of centuries, between that image and what many Irish women have actually experienced'. ${ }^{10}$ This distinction calls attention to the dynamics of memory and history, to the differences between experience and representation and to its intellectual and ethical implications. History may seem remote from the life of the individual, which is expressed through personal recollection of experiences. Yet the contingency of memory is a key dimension to the understanding of the past, and to its simultaneous presence and absence in literature. For Ní Chuilleanáin this has been an important motivation in her creative life:

It seemed to me that it was not language or image but subject that really defined me as a poet; I wished to look at the feminine condition through the equal glass of the common language, making it my subject on my own terms. Was a female subject one which came merely from an assemblage of concerns that have been brushed into a corner labeled 'women'?11

She has disputed Eavan Boland's notion of women being 'outside history', not least, it seems, because of its metaphorical formulation: 'I think, on the other hand, that women are very much there in history. They are often there as the victims or the people being labelled or enclosed, shut away in a way for us unimaginable.' 12 The correlation here between physical and linguistic concealment is an important one in Ní Chuilleanáin's poetry, which often represents architectural structures - churches and convents as well as private homes - as places of both containment and revelation. The extent to which these can be the particular focus of imaginative states reveals their importance as spaces not just of memory but of possibility. ${ }^{13}$ In an interview published in Eire-Ireland Ní Chuilleanáin speaks of the significance of 'dreams about houses which you have lived in, in which you find there's an extra room or something has changed, something remarkable has happened to it [...] I think the house and the body both come into that'. ${ }^{14}$ In linking the house and the body here she strengthens the emphasis on place as formative of identity: both house and body carry layers of experience, representing time by material or sensory means. These formations allow her poems to remain distinct yet also suggest spaces of return, where past experience coexists with present knowledge. This 
act of return is an important dimension of Ní Chuilleanáin's creative practice too, as images and phrases reappear to remind the reader of the ineradicable nature of memory and of its power to shape the development of thought.

\section{Personal Effects: Towards The Magdalene Sermon}

The individual's relation to his or her own past, and to the shared past of their family, is used by Ní Chuilleanáin to extend and interrogate the representation of history in her work. Patricia Boyle Haberstroh has acknowledged the oblique form of this investigation, describing how Ní Chuilleanáin 'revises well-known figures and narratives, sometimes using the present, or her own personal experience, as an entrance into the past'. ${ }^{15}$ In her poems domestic space and the private lives of families create the tensions from which meaning can emerge. Yet in these settings memory and meaning can be at once closely connected and strangely divergent - often it is the sense of what is unspoken or unknown that governs action in the poem, reminding the reader of the partial nature of all interpretation. For this reason, the circular shape of Boland's oeuvre and the emphasis she lays on repeated statement form no part of Ní Chuilleanáin's aesthetic, in which key tropes are layered and transformed in each new collection. For the speakers in Boland's work the need to articulate experience becomes a self-conscious one, as Guinn Batten suggests:

In the gap between Boland's view that a woman writer finds her voice by becoming her own subject and representing it faithfully, and Ní Chuilleanáin's that the woman writer finds that voice through the objects of her poem ... we might locate an important and ongoing theoretical debate concerning the possibility of a fully democratic community. ${ }^{16}$

Here the contextualization of memory becomes an important issue, drawing the reader outward from a stated poetic subjectivity. Batten sees Ní Chuilleanáin's desire to represent, without claiming to speak for, the experience of others as an important achievement in her work.

The textual environments that this poet creates are significant in other ways too, especially for their attention to the power of the world of physical objects to shape our understanding of present and past. This relationship is a complex one, especially in its links between the environment of the poem and its visual impact; the object therefore works on two levels, as both image and context. This is an important dimension of Ní Chuilleanáin's work given the overlapping worlds of Renaissance 
scholarship and poetic craft that shape her writing. In negotiating the past through objects, the poet can create a network of signification that moves back and forth in time. The artefact, surviving from the past, becomes part of present experience: Ní Chuilleanáin shares with Boland a sense of these objects as bearers of meaning, but in the former poet's work they are used to question the notion of fixed meanings rather than to operate emblematically. Ní Chuilleanáin's treatment of memory is therefore closely linked to the specificity of individual lives as a conduit for the larger patterns of history.

This dimension is present from the poet's earliest work. The Second Voyage, published first in 1977, begins and ends with poems of private space: texts that conjure imaginative and intellectual processes through built structures. 'The Lady's Tower' unites water and sky: while the grey wall 'slices downward and meets / A sliding flooded stream', the thatch 'Converses with spread sky, / Heronries' (SV II), and it is from the elevated bedroom that the imaginative transformation of the entire tower is realized. The final poem, 'A Gentleman's Bedroom', returns to the image of the 'high windowpane' as one that gives a vantage point over the surrounding scene. Yet this room is empty and its objects suggest the detached character of its sometime occupant; the large bed is matched by the masculine paraphernalia of scholarship - the 'blue volumes shelved at hand', the fountain pen and cigar box (SV 68).

This exploration of male and female experiences through differentiated spaces is intensified in The Magdalene Sermon (1989), a collection that marked a transition towards greater integration of personal and historical material. 'The Liturgy', placed second in the collection, records the division between the masculine performance of ritual and the as-yetunrealized actions of the waiting females. Suggestive of the different roles of men and women within the religious life, the poem is ambiguous concerning the relationship between action and motivation. The man seems attracted by a life of words, planning to study 'the epigrams incised I On millennial plaques', yet he is marked out by the 'sacred metal' he carries and drawn into ceremonial acts. The obscurity of the ritual and its context is heightened by the use of direct statements throughout the poem: 'He has been invited ... / He stands ... / They are waiting ...' (MS Io). The clutter of the boat and the energy of the natural scene is set against the emptiness of the house in which the women remain, enclosed yet not quite shut away: 'They hear the hinges of the big door closing, / They know the length of the ceremony, they know / They have just forty minutes' ( $M S$ Io). Here the power of 'habit memory' - the 
memory enacted through ritual and observance - is challenged by the intentions of the women, intentions that are still unknown to the reader at the close of the poem. ${ }^{17}$

'MacMoransbridge', from the same collection, is similarly suspended between past and future. Beginning with the word 'Although', it is a text that hinges on apparent contradictions. The sisters who stay on in the house after the death of their brother leave his will unopened, so that 'his posthumous plan of slights and surprises' - with all its alliterative neatness - is never enacted (MS 19). Written texts have no agency here: the dead man's will remains in the drawer and his 'diaries and letters [are] posted abroad' (MS 19). A later poem, 'The Secret', will invoke similar documentary evidence - the books, the 'signatures on slips of ravelled paper' $\left(B S{ }_{42}\right)$ - to suggest a process of collective forgetting: 'Instead of burning the book or getting its value / They hid it and were silent, even at home, / So that the history of that lost year / Remained for each one her own delusion' ( $B S 42$ ). Here both written and spoken words remain undisclosed, so that even within the confines of the family the secret is preserved. Yet the memory that kept these women isolated must in the end be superseded by action; by the selling of their land and even their bodily resources. Likewise, in 'MacMoransbridge', the house resounds with the activities of the women: their constant movement, the cooking, washing and reckoning of household accounts. Ironically, it is their preservation of the markers of their brother's life - his dropped dressing gown and extinguished fire - that thwart his ability to wield power after death. The everyday objects he intended for sale are still being used with pleasure by the women themselves, while the adornments left to them remain hidden:

The tarnished silver teapot, to be sold

And the money given to a niece for her music-lessons,

Is polished and used on Sundays. The rings and pendants

Devised by name to each dear sister are still

Tucked between silk scarves in his wardrobe, where he found

And hid them again, the day they buried his grandmother.

$(M S$ iq)

Ní Chuilleanáin's poems are filled with such objects - personal and domestic items that act as interpretative clues, not only for the reader, but also for the characters within these texts. As well as playing an important role in the creation of historical and cultural context, the materiality of these texts speaks of the transmission of memories through objects themselves: 'As physical materials, artefacts provide an authentic 
link to the past and as such can be reexperienced'.18 Their prominence in these poems reminds us that texts themselves are artefacts to which the reader can return to reiterate and renew meaning. Throughout the work, written materials - letters, documents and books - are mixed with other household and personal belongings in ways that emphasize their continuous use and their significant presence in the poems. In 'Consolation', the wife of a dead man retrieves his personal effects, yet these tell an ambiguous story of his life: the 'codes, / Lists, cards, his multiplied signature' are suggestive of subterfuge or even espionage, and the cause of his death uncertain. The repetition of the transgressive verb 'to rifle' reinforces the apparent personal attack that the poem records yet, in spite of this impression, 'It seems little was taken' (MS 30). The ambiguity of this interpretation is increased by the 'repeated story' of the man's preparedness for death, a version that gains little imaginative purchase within the poem itself. Yet this serves only to emphasize the untrustworthy nature even of shared narratives and the impossibility of knowing anything with certainty. Just as the woman struggles to understand the exact circumstances of her husband's death, neither can he himself recall in detail the incident he experienced. The shifts in the poem between hospital basement and alleyway, as well as between omniscient perspectives and direct speech, suggest the limitations of memory: though its images are vivid (the man recalls seeing a 'sliver of an arch' and 'one trickling thread'), the act of remembrance is incomplete. The severance that the poem explores is thus both spatial and temporal and has a disturbing effect on the listening wife within the poem, as well as on the reader.

Though past and present often coexist in Ní Chuilleanáin's texts, there are many poems in which the relationship between these states becomes the particular focus of scrutiny. 'The Informant' again begins with an object - it describes a photograph 'Of the old woman at her kitchen table / With a window beyond (fuchsias, a henhouse, the sea)' (MS 36). The document of the past contains both these unspecific details and the written record of 'her name and age, her late husband's occupation'; in this it draws attention to the relationship between the general and the particular, and the levels of meaning that can be drawn from these details. A young man is listening to a recording of the woman recalling folk beliefs, but attempts to fix the past prove fraught with difficulty: the tape-recorder breaks down, 'the machine, / Gone haywire, a tearing, an electric / Tempest. Then a stitch of silence. / Something has been lost' $(M S$ 36). Our mediation of the past can be destructive, resulting not in 
increased understanding but in a loss of meaning. As Borbála Faragó remarks, "The Informant" seems to resist interpretation which is wedded to communicative action. We cannot expose or recover what "actually happens" in this poem.' ${ }^{19}$ Here a gap opens between the mysterious accounts of the supernatural realm and the reasoned questions that provoke and limit them, especially at the close of the poem where a twist of humour at once makes the uncanny experience more normal and more extraordinary for listener and reader alike:

You find this more strange than the yearly miracle

Of the loaf turning into a child?

Well, that's natural, she says,

I often baked the bread for that myself.

$(M S$ 37)

Here the individual is the repository of meaning, which cannot be transferred to any other medium with ease, so that attempts to bypass the human agency are doomed to failure.

This realization of the complex relationship between the experience of the woman and the way in which the interviewer can access and present this information compels the reader to contemplate how the experience of the single individual, the poet herself, enters and shapes the work. Biographical readings of poetry by women can overdetermine meaning, but the role of the poet's individual perspective in selecting and synthesizing material remains important. In particular, Ní Chuilleanáin's own comments on this poem problematize decontextualized readings:

In 'The Informant' I was actually writing about - which I've never done, and I don't usually identify with - a particular death in the north, the deaths of the soldiers who were dragged out of a car at a funeral and shot ... It seemed particularly awful ... I was writing again about ways of speaking about these things. ${ }^{20}$

This oblique perspective on an event noted for its horrific visibility is significant. Yet, like Paula Meehan, Ní Chuilleanáin is concerned with the difficulties of speaking about traumatic events, about the tenuous relationship between language and memory. Just as the traumatized subject does not directly remember the events, but exhibits the memory as sensation, so the details of the killing are displaced for the poet into an exploration of the difficulties of bearing witness to experience. This displacement is characteristic of Ní Chuilleanáin's work. Though she rarely deals explicitly with the narrative of modern Irish history, its events can be foundational to her texts; the apparently unbreakable 
chain of violence alluded to here reveals connections between past and present that demand interrogation. Her poetic practice draws attention to this necessary transition and to the important role of the individual perspective on ethical questions. 'Can I be the only one alive / Able to remember those times?' asks the speaker in the later poem 'A Witness' $(B S 43)$, yet, in spite of the desire for silence, the hope that 'others' will bear the burden of memory and speech, it is the individual experience that will shape our understanding of the poetic world and make the search for objective meaning ultimately futile.

\section{The Book of Revelation: \\ Poem as Reliquary in The Brazen Serpent}

While 'The Informant' obliquely addresses the role of individual memory in mediating traumatic group events, other poems by Ní Chuilleanáin explore the intersection of private experience and cultural memory in more historically distant but no less resonant contexts. A poem such as 'Saint Margaret of Cortona' plays with the links between the past and language, here using the biography of the Italian saint - and her connection to Ireland as the patroness of one of Dublin's lock hospitals - as a means to explore the imaginative challenges presented by history. ${ }^{21}$ The poem begins with the creation of cultural memory; the priest tells the early story of the sanctified woman, drawing attention to the importance of the name as a signifier of identity: 'She had become, the preacher hollows his voice, / A name not to be spoken, the answer / To the witty man's loose riddle' ( $B S$ 24). Attention is drawn to the mouth and its imagery: the hollowed voice, the jaws, her teeth. These last physical signifiers, the slowest to decay, remain present to the congregation as a relic of the saint. Just as her life story is subject to omissions and embellishments, so the fragments of her physical body are concealed by ornamentation:

Under the flourishing canopy

Where trios of angels mime the last trombone,

Behind the silver commas of the shrine,

In the mine of the altar her teeth listen and smile.

(BS 24).

By contrast, the words used to describe this woman are omnipresent, transformed into living entities with agency of their own: 'The names flew and multiplied; she turned / her back but the names clustered and hung' ( $B S$ 24). Two specific names appear clearly: that of the 
saint herself, which is the title of the poem, and the italicized word 'whore' - unspoken yet visible in the text of the poem. The trauma of memory persists here, as past violence continues to haunt the saint: 'the bloody scene: the wounds / In the body of her child's father / Tumbled in a ditch' (BS 24). This is one of two significant deaths in the poem: and the other is that of the saint herself, which does not mark the beginning of change and decay but instead a refutation of it. Language threatens to be the source of damnation, yet it is also at the root of redemption - the names clustering at her shoulder bones resemble angel's wings. The poem 'contains' the history of the saint but only partially reveals it. The tension this creates heightens the poet's exploration of how verbal and visual metaphors function to interpret the past without fully disclosing it.

'The Real Thing', also from The Brazen Serpent, again links Ní Chuilleanáin's representation of the female with questions of revelation. The material world once more plays an important role in the interpretative scheme but here - and in many of her poems of religious life - it has acquired the specific power of metaphor, and with it a greater weight of meaning. Within this poem the relic is a symbol of religious significance - and thus a symbol of symbolism itself - as well as being constitutive of new poetic meaning:

True stories wind and hang like this

Shuddering loop wreathed on a lapis lazuli

Frame. She says, this is the real thing.

She veils it again and locks up.

(BS I6)

Objects that express religious truths are enclosed to ensure their integrity but this concealment keeps them at a distance from the human subjects who would benefit from the revelation. Likewise, poetic meaning may be obscured by the materiality of the text and its particular mode of transmission. In both cases, the significance passes to the object itself rather than to its underlying meaning; it is the presence of this object that ensures the continuity of religious or literary tradition. Sister Custos - her name means guardian - is an apparently unimportant figure, yet she is the living channel between past and present meaning. In the course of the poem she is transformed from a victim of circumstance, unable to liberate herself from the constraints of her existence, to a speaking subject; 22 as Ní Chuilleanáin herself puts it, 'this woman, her life is not really all that great, and she is looking after a fragment, but it is real'.23 The poem draws more lasting attention to what is hidden than 
to what is revealed, suggesting that the 'real' is in fact what is intangible, what cannot be expressed in language. In this way, shared beliefs about the past are more smoothly disseminated than the perspective of the individual. The bones of the saints are venerated at the expense of the body of the living nun, whose experience is unrecorded and whose story remains untold:

Her history is a blank sheet,

Her vows a folded paper locked like a well.

The torn end of the serpent

Tilts the lace edge of the veil.

The real thing, the one free foot kicking

Under the white sheet of history.

$(B S$ I6)

To suggest that 'the real thing' is in fact the nun herself, involves an acknowledgement of the importance of this woman's history, and a movement away from a version of the past that venerates its significant objects while leaving narratives of the marginal life untouched. Yet the seclusion of some of these lives makes the revelation sensitive - a breaching of private life intentionally chosen. Ní Chuilleanáin's oblique style indicates the delicate balance between the visible and the invisible in the material of her poems, and reminds us of its ethical implications.

For Ní Chuilleanáin, all forms of memory are relational, a characteristic highlighted by the spatial construction of temporal interactions in her poetry. The past is often examined through a heightened attention to place and, in particular, as Irene Gilsenan Nordin has pointed out, to the relationship between interior and exterior spaces. This relationship provides an apt metaphor for the larger dynamics of private and public that shape Ní Chuilleanáin's deployment of memory in her work. Her marked interest in the role of women in religious life leads her to explore the relationship between the individual nun and her community by means of spatial constructs. 'The Architectural Metaphor' uses a religious building to highlight the arrangement of meaning and, in particular, to draw attention to the ways in which the worlds of the body and the spirit can overlap. Eamon Grennan has commented on the importance of architectural references in Ní Chuilleanáin's work and in this thematic context claims that 'the palpable force and solid presence of architecture itself, so reassuringly there, can stand as some form of endorsement for this intersection (and therefore continuum) between these separated worlds. ${ }^{24}$ The title of this poem draws attention to the deliberate play of meaning: the 
partly ruined convent is the place from which the layers of human relationship unfold. Its quiet enclosure is ruptured thus:

Now light scatters, a door opens, laughter breaks in,

A young girl barefoot, a man pushing her

Backwards against the hatch -

It flies up suddenly -

There lies the foundress, pale

In her funeral sheets, her face turned west

Searching for the rose-window. It shows her

What she never saw from any angle but this:

$\left(B S_{\text {I4 }}\right)$

The sudden intrusion with its sexual energy gives way with equal suddenness to the body of the nun: movement turns to stasis, life becomes death and a new angle of view - this time on the past. Revelation is powerful, but here it occurs when everyday life beyond the convent walls is made manifest, rather than with the appearance of a spiritual vision. This reversal brings a renewed acknowledgment of the distance that religious life imposes on its adherents: 'Help is at hand / Though out of reach' (BS I5). 'The Architectural Metaphor' is a poem full of thresholds of experience and understanding and these occur at several levels: the speaker who is hearing the history of the convent explained; the young barefoot girl in a moment of sexual anticipation; the foundress seeing her past self; the reader absorbing all of these moments. The use of tercets emphasizes the unexpected nature of the poem's semantic progression; its uneven line lengths, syntactical digressions, shifting consonantal patterns all contribute to this effect. These thresholds of meaning are imitated also in the imagery of the poem - the changing border near which the convent was built; the wall behind which the radio whispers; the opening door admitting the young lovers; the hatch which flies up disclosing the foundress and the rose window to which her head is turned. The sheer proliferation, and permeability, of these divisions stands in marked contrast to the locked reliquaries and bricked up windows of 'The Real Thing'. Here past and present cannot be definitively separated; memory becomes experience, rather than the other way around. 


\section{Spaces of Mourning in The Brazen Serpent}

Though The Brazen Serpent, published in 1994, features many poems in which history is the focus of attention, it is also a volume that is illuminated by events in the poet's own life, in particular by the deaths of her mother and sister. As well as including some poems that address these experiences directly, the collection as a whole considers the difficulties inherent in representing grief; how what cannot be 'spoken' may yet be expressed in meaningful ways. Here Ní Chuilleanáin traverses these difficult personal memories with particular care and subtlety, with such subtlety in fact that without some explanatory comments it would be difficult to determine the exact emotional focus of some of these poems. Here love is expressed in understated ways, as though in support of Julia Kristeva's assertion that the language of love is an allusive one. ${ }^{25}$ Kristeva also suggests that feelings of love are akin to those of fear: 'fear of crossing and desire to cross the boundaries of the self'.26 In this way, we begin to understand the constructed boundaries depicted elsewhere in the book - its containment of human actions and artefacts - as part of a larger investigation of emotional restraint. Ní Chuilleanáin's explorations of subjectivity deepen at this stage in her creative life, emphasizing the importance of private memory as a shaping force on her poetics.

The structure of The Brazen Serpent is important in drawing attention to this dynamic: it begins with the section 'Two Poems', dated 1994, before continuing with 'Poems I989-1993', yet the opening works, though presented separately, are in many ways integrated into the prevailing concerns of the book as a whole. One of these concerns is the keeping of secrets, which Ní Chuilleanáin sees as a means to self-expression. 'Passing Over in Silence' accentuates this aspect - the woman witnesses an event of violence and abjection yet does not disclose it: 'She never told what she saw in the wood'; 'She kept the secret of the woman lying in darkness'; 'She held her peace about the man who waited' $(B S$ 23). Though the poem is set within a natural landscape, it is one of containment and obscurity and these qualities are expressive of what cannot otherwise be stated in the poem. For this memory to remain private affords it an oblique power. It is unclear whether it is the trauma of the event that prevents the woman from articulating it - to describe it would force her to relive it - or whether the scene has more power for her because it remains unshared. ${ }^{27}$ The discovery that the poem concerns the death of the poet's sister from a brain tumour 
which is the 'hooked foot' here, at once clarifies some of its meaning and complicates the act of representation, since the explanation undermines the poem's putative silence by speaking itself and giving us glimpses of the unexplained horror. The second stanza enters a different, yet similarly enigmatic space:

\section{I went into the alehouse and called for a drink,}

The girl behind the bar could not speak for tears,

The drops of beer flowed down the sides of the glass;

She wept to think of the pierced head,

The tears our Saviour shed.

$(B S 23)^{28}$

The idea of atonement - that of Christ for our sins and of the man for his crime - is matched by the poet's desire that grief should atone for the act of speaking the unspeakable here. Yet the grief is displaced from the woman, who is a witness to suffering, to another woman inexplicably bearing the signs of distress. The girl's grief is not only for the bodily suffering of Christ, but for his consciousness of suffering - for the emotional distress that accompanies the physical pain, making his pierced head significant. In this way, empathy is addressed conversely through emotional distance, and specifically through the power of imaginative language both to express, and to reflect upon, the relationship between feeling and sensation. The folktale mode offers a form of emotional displacement, allowing the text to carry the weight of personal feeling precisely because of its impersonality. These textual shifts are important to Ní Chuilleanáin in other ways too: the text resembles a sonnet yet resists the kind of closure associated with this form, both in structure (it is one line short) and in meaning (the links between the first eight lines and the remaining five are difficult to clarify without explanation). The idea that fixed form is a way of containing poetic meaning - that is, of providing an apt vehicle for meaning as well as a technique for limiting its interpretation - comes under scrutiny here. It is by overturning expectations of how forms may be used or how apparently disparate ideas may be linked that Ní Chuilleanáin both problematizes continuities in her own work and questions the notion of fixed interpretative strategies.

At least three other poems in The Brazen Serpent are directly concerned with processes of illness and grieving. 'That Summer', 'The Pastoral Life' and 'A Hand, A Wood' explore the lived and the remembered life as well as the act of mourning - the shared, yet individual responses of family members to the loss. Ní Chuilleanáin comments: 
'A Hand, A Wood' is factual, about the physical absence of Máire from the house in Palmer's Green, the sense that every time one washed, one was washing away something of her, and every time one used up something from a jar she had labeled. The second half was written in Italy after her death and the scattering of her ashes in a little wood on our land beside our Italian house. ${ }^{29}$

'A Hand, A Wood' is thus a poem in two parts: it explores first how body and then place bear the imprints of the lost woman: 'I am prising you from under my nails' and 'the sparse / Ashes are lodged under the trees in the wood' (BS 46). In this way, as Mary O'Malley has shown so powerfully, both the human body and the natural landscape become repositories of the past. Everyday life is resumed reluctantly, but while the living body continues its routines, objects express the power of memory: the sister's handwriting and diary entries remain, even in the face of passing time. This disjunction is itself a painful one - it is the continuing experience of living that heightens the pain: 'I am wearing your shape / Like a light shirt of flame' where the word 'light' both lessens the violence of the sensation yet also threatens to make this pain more visible. Memory, then, can be both elided and intensified by the immediacy of experience.

Set alongside the loss of Ní Chuilleanáin's sister is that of her mother, which occurred four years later. This further emphasizes the importance of relationships among women and calls attention to the role of the passage of time in determining the shape of the book. The first of the two opening poems is 'Fireman's Lift', which is individually dated 'Parma 1963 - Dublin 1994', again an explicit acknowledgement of the intersection of past and present that occurs in this volume. Written after the death of her mother, the poem is set in Parma cathedral and explores the maternal not just through its representation in Italian painting but by depicting an experience shared between mother and daughter, the experience of looking at, and responding to, a work of art. Once again, the built environment preserves and frames the meaningful object, offering ways to establish perspectives on the created past. This kind of layered meaning is at the core of Ní Chuilleanáin's work: the past is not merely known or remembered, but re-experienced and re-contextualized by the speaking voice in the poem as well as by its readers:

I was standing beside you looking up

Through the big tree of the cupola

Where the church splits wide open to admit

Celestial choirs, the fall-out of brightness. 
The Virgin was spiralling to heaven,

Hauled up in stages. Past mist and shining,

Teams of angelic arms were heaving,

Supporting, crowding her, and we stepped

Back, as the painter longed to

While his arm swept in the large strokes.

We saw the work entire

$(B S$, Іо $)$

One of the most significant aspects of The Brazen Serpent is highlighted from the opening line of this poem: it is the emphasis on angle-of-view that draws attention to the spaces of memory and makes all acts of interpretation conditional. It is especially true in this case, as the poet seeks to recapture the occasion when she and her mother visited the Duomo in Parma and experienced first-hand Correggio's Assumption of the Virgin, which is among the most remarkable of Italy's artistic achievements. The art object is an important presence in Ní Chuilleanáin's work and a means by which she draws together visual influences from a range of periods and cultures in her poetry. She uses these to explore the act of looking itself and to examine the ways in which knowledge is both communicated and disrupted by this framework. This emphasis on the visual also demands that the reader should consider the spatial as well as the sequential construction of meaning and memory, scrutinize the poems for the pattern of interpretation rather than expect a logical progression towards resolution. Here her mother's closeness is recalled, but in the act of recollection the fact that her death has also made her infinitely distant is finally inescapable. Intimacy and remoteness are both present in this poem and affect the act of reading in particular ways. The observer here is the poet, but also crucially the reader, since we must assume her position first, as part of the act of reading. The poet subtly affirms this in the distinction she draws between the painter, struggling to articulate his vision while able only to see a portion of that act of creation, and she and her mother who 'saw the work entire' (BS Iо).

The painting depicts a group of saints and angels that merge into a sea of faces and limbs, lifting the Virgin towards Christ in heaven. It is a work of art that draws attention to the human body and its relationship to artistic space. The painting is viewed somewhat humorously by the poet, who later described her perspective as akin to looking up the Virgin's skirts. ${ }^{30}$ Commenting on her writing of the poem, Ní Chuilleanáin says, 'I could only concentrate on one aspect, the way it shows bodily effort and the body's weight.' 31 Here the merging of art and 
architecture is vital to the poet's purpose, as the Virgin's body is part of the church's own structure - 'The back making itself a roof / The legs a bridge, the hands / A crane and a cradle' - as well as an important part of the institution's doctrine. Dillon Johnston comments that 'the painting could be said to reflect and celebrate the female body' in elevating it at the expense of a rather childlike Christ. ${ }^{32}$ In doing so, it also advances the feminine side of Catholicism at the same time as it draws attention to the complexity of the relationship between the Virgin Mother and her son. As Guinn Batten has noted, bodily experience plays an important role in the function of personal memory for Ní Chuilleanáin:

Insofar as we may find, in her poems of grief for her mother, sister, and father, the balm of sweet odours surviving the lettered slab, they also enact, or engage, a bodily labour - the neck wrenched by the effort of following the body, heaved by nurses out of the room, legs and wrists cramped by the slow toil of carrying water for a dying mother from the end of the world. 33

This particularity plays an important role in the merging of past and present in the poet's work, yet the sensory impact of memory does more than reveal the body as an essential conduit to past experience. It also bridges the imaginative gap between contemporary and historical representation, allowing the poet to interweave her scholarly interests in the Renaissance world with the cultural landscape of modern Ireland. This nexus of materials emphasizes the interwoven nature of the processes of remembrance and leads to a treatment of the past layered with discrete interpretative acts. By imagining The Brazen Serpent as a space where she actively constructs distinct and overlapping perspectives on the past, the poet reveals her increasing use of the book not just as a gathering of work but as a dynamic association of ideas and practices, offering new ways of understanding the relationship between personal and shared histories.

\section{Other Rooms: \\ Listening and Reading in The Girl Who Married a Reindeer}

The interrelationship among texts has become increasingly important in Ní Chuilleanáin's work and certain poems from The Girl Who Married the Reindeer, though not constituting an explicit sequence, are connected through image and reference. These subtle links, threaded throughout the volume, emphasize the processes of creative return that pairings or groups of poems initiate. The volume picks up the religious resonances of The Brazen Serpent, with a particular emphasis on the celebration of feast days and on the performative dimension of church practices. Drawing on 
earlier poems, such as 'A Midwinter Prayer' $\left(S V_{45}-7\right)$ and 'The Liturgy' ( $M S$ IO), these works emphasize the power of spoken language and music in spiritual and aesthetic communication. 'The Chestnut Choir' is one poem that explores this form of expression in ways that highlight the relationship between the individual listener and the collective purpose of the performers. This relationship is first broached in the preceding poem, 'Sunday', where the speaker's intention to hear to the choir is expressed. Here a spiritual experience is privileged over social obligation, but the journey to the mountain convent marks a return to an uncertain past - though the speaker has made this journey before, she knows she will not be remembered. The process of recollection is one-sided; it is only of significance to the individual. The singular perspective remains strong in 'The Chestnut Choir': the woman breaks her journey by stopping in a bar where she encounters a small girl, 'crouched / Staring into the wood stove's flaming centre' (GMR I4). Female attraction to spaces of warmth and light, first the bar and within it the wood stove, again indicates the importance of containment in the quest for revelation. The woman's entry into the chapel and into 'the box pew at the back' (GMR I4) indicates another kind of enclosure, in which the flames witnessed earlier are realized again in musical form. The singing resonates through the stone of the wall, entering the woman's body as she leans against it and uniting her experience of the sensory world with her search for transcendence. In the silence the candle flames carry the motif of fire that links secular and religious spaces, reminding the woman that she is in transition between them. An ambiguous dynamic between singular and collective emerges in this poem: 'She knew / They were still there while she, / The wanderer, was free to be away' (GMR I4). At first this seems to evoke the family group of the previous poem, but it applies equally - and perhaps more powerfully - to the choristers themselves. They, like so many of the figures in Ní Chuilleanáin's poems, are rooted to place and community, marking the passage of time through their repeated practices of faith. A similar force that first impelled the woman to travel to hear the choir now prompts her to leave, though the terrain outside is unpeopled and even threatening. This reinforcement of the singular perspective suggests that meaning is created by the perceiving self; by that particular encounter with an image or sound that is the catalyst for remembrance and return.

The significance of religious experience that is located in space is confirmed elsewhere in this collection. In 'The Cloister of Bones', entry to the past is again effected through the built environment. The opening 
perspective is a view from above: instead of ascending the mountain to a convent chapel, the speaker adopts the vantage point of a bell tower. This perspective allows human and natural environments to be combined: the tops of heads, cobbles, ledges and growing plants, all coincide below. Surveying this dynamic scene, the speaker searches for a cloistered space where devotion and recreation may be pursued in peace:

I am searching for a shape, a den, watching

For the cloistering blank of a street wall,

A dark reticence of windows

Banked over an inner court,

Especially rooves, arched and bouncing

Naves; a corseted apse,

And always, even if the chapel sinks

Deep inside, lit from a common well,

I search for hints of doors inside doors,

A built-in waiting about

Of thresholds and washed floors,

An avid presence demanding flowers and hush.

$(G M R$ I6)

This place can be detected by reading the shapes of the buildings, the particular configurations of window and door. The space will be one concealed from the street, set between or below buildings, inhabiting another dimension - a meaning not readily available to the passer-by. This other dimension is also a space of cultural memory, where now vanished religious communities once flourished. The speaker's search for 'doors within doors' alerts us to the similarity of the places of prayer and those of poetry, which too require practised engagement and painstaking investigation. The sense of enclosure here is confirmed in echoic effects and subtle mirroring of words: 'blank' becoming 'banked', 'cloistering' moving to 'corseted'. Modernization yields subtle changes in form and language that take place within the arc of Ní Chuilleanáin's own poetic development. The architectural details of wall and court, nave and apse, return us to earlier texts yet also project the future discovery of a place where the experience of prayerful reflection as well as meaningful community can be attained. In the preceding poem, the significance of the act of building itself has been invoked. 'The Angel in the Stone' gives voice to 'the stone the builders passed over', which is now 'trampled in the causeway' where it registers the extremes of the elements. This continuing attention to the materiality of stone is an important part of the poet's investigation of how structures 
are formed and made. All aspects of this material culture of family and community are subject to her investigation and constitute an enduring aspect of her art.

As these pairings of poems have shown, this collection marks a preoccupation with the relationship between secular and religious, as well as between domestic and institutional, settings. The volume also contemplates the dynamics of family and community in new ways. The poem 'In Her Other Ireland' makes its location explicit in its title and in addition gives a specifically female viewpoint from which to interpret the material of the poem. Yet even this level of certainty is problematized by the notion of 'otherness', paired as this poem is with the preceding text 'In Her Other House' - which is printed on the opposite page. Though Ní Chuilleanáin uses personal material obliquely in her latest poetry, links between private and public concerns afford her opportunities to explore important issues through the shaping of individual perspectives. 'In Her Other House' invokes a return to the past with which the representation of the house often engages. Rather than emphasizing the passage of time, however, the poem suggests the imaginative simultaneity of past and present. To return endlessly to the past is not to render it explicable but to alert the reader to the inseparable nature of moments of intense experience. As Gaston Bachelard argues, 'we are unable to relive duration that has been destroyed [...] memories are motionless, and the more securely they are fixed in space, the sounder they are'. ${ }^{34}$ 'In Her Other House' invokes this straight away; the place is 'other' from the start. The 'her' of the title becomes 'my' and the focus of the poem shifts to a dreamlike memory. The otherness in this poem seems to interrogate the very notion of home but it may indicate the immediacy of the lived and imagined past, where the vision is selective, even deliberately limited, and 'the table is spread and cleared by invisible hands' (GMR 20). In this home, books are the distinctive feature and supersede the domestic detail, become the nurturing centre of the household together with the fire and the meal. The imaginative power of the home is a textual one, so that the role of language in reclaiming this space is crucial: it is a house of texts, where past, present and future are there to be read as much as to be experienced. To be at home, then, is to be among written words. The poem's final lines are especially significant in this regard: 'In this house there is no need to wait for the verdict of history / And each page lies open to the version of every other' $(G M R 20)$. Here chronological time is disturbed by the presence of the dead. These books seem to refute the logical progression of meaning in favour of freer interpretation, and in 
doing so suggest that acts of poetic interpretation need to remain alive to the dynamic range of influences that shape the writing process.

Throughout The Girl Who Married a Reindeer, Ní Chuilleanáin reflects on the ways in which language gives form to the past. So it is significant that the main body of poems in this collection ends with 'Gloss / Clós / Glas', a work that explores the unearthing of word-lore and the act of translation itself, as though to prepare the way for the poems that follow in the 'Coda'. Memory, at once powerful and unstable, often finds expression through the speech act and many of Ní Chuilleanáin's poems have a clear affinity with oral narrative: poems often begin by telling stories (or at least alluding to them); they mention anecdotes and events, both past and present. Yet how these elements can be framed has always been a matter for debate. Paul Connerton's work sheds light on this problem:

Oral histories seek to give voice to what would otherwise remain voiceless even if not traceless, by reconstituting the life histories of individuals. But to think the concept of a life history is already to come to the matter with a mental set, and so it sometimes happens that the line of questioning adopted by oral historians impedes the realization of their intentions. ${ }^{35}$

So it is, that in the midst of these speech acts, Ní Chuilleanáin's poems often seem to escape to another realm, one beyond the narrative context we first encountered. Eamon Grennan argues that she is 'often inclined to [...] extend the narrative into a species of reflection, which can compound what is already difficult. For it is not a question of the narrative and the reflection existing in quite separate containers. The borders between them are laid over one another, so no division is seen'.36 This complexity is an important dimension of Ní Chuilleanáin's interrogation of the transmission of history and, in particular, of her resistance to the idea of fixed forms of identity. Both her treatment of voice and of the environment in which forms of understanding emerge reveal the capacity of the poem to destabilize the act of reclamation itself.

'Gloss / Clós / Glas' explores the relationship between the sound and meaning of words so that the text itself seems conjured from the scholar's act of linguistic investigation. The first hint of this occurs when, bearing his stack of books, he 'walks across the room as stiff as a shelf'; his own body becomes the books' repository, a man-made object rather than a living organism. The scholar is charged with finding two words of opposite meaning yet almost identical; an idea suggestive of the way different semantic pathways open in a poem. 'Clós', is suggestive of both the English 'close' and the Gaelic word for enclosure. Already the 
networks of linguistic and cultural connection between Ireland, England and Scotland are hinted at and these are extended in the idea of the musical note translated from one instrument to another. There follows a series of images associated with fiddle-playing - the wood; the finger depressing a string; the bow drawn across the strings - images expressing proximity but also close to one another in the texture of the poem. The sheer mobility and contingent nature of language emerge clearly here, through its zealous scholar and through its chosen imagery and the flexibility of its lines and thought-pattern:

The rags of language are streaming like weathervanes,

Like weeds in water they turn with the tide, as he turns

Back and forth the looking-glass pages, the words

Pouring and slippery like the silk thighs of the tomcat

Pouring through the slit in the fence, lightly,

$(G M R, 46)$

Though described as 'rags' and 'weeds' - words that can themselves be linked through the image of the garment - language reveals the movement of powerful forces here. The print of dictionaries, sufficiently small to require a magnifying glass, is also reflective of the world itself, even the familiar image of the cat sliding through a gap in the fence. 'Pouring' is a word tried twice, as though to test and confirm its precision of expression before the poem turns to conclude on the double-meaning of the last of its terms - 'glas' - which can be translated as both lock and green: 'Who is that he can hear panting on the other side? / The steam of her breath is turning the locked lock green' $(G M R$ 46). The word for 'his' and for 'hers' is the same in the Irish language, so that the barrier of meaning is overcome by the exhalation, releasing the scholar from his labours and the poem into near-silence. That the poem itself is formed not from new language that may yield familiar interpretation but rather from a point of linguistic convergence that offers extended meanings expresses the subtlety of Ní Chuilleanáin's art.

\section{Poems at the World's Edge: Memory as Vertigo}

The function of memory takes on new significance in the formation of the poem sequence, where the temporality of reading becomes an important dimension of interpretation. Memory also has a special purpose in cases where poems are reprinted in different locations, creating new networks of meaning in each situation. Two poems from Ní Chuilleanáin's most recent volume, The Sun-Fish (2009) also appear 
as part of the sequence 'Vertigo', published in Voices at the World's Edge: Irish Poets on Skellig Michael, a volume edited by Paddy Bushe in 2010.37 The word 'Vertigo' itself invokes movement - significantly, a sensation of movement - and a unifying element across the sequence is the motion of the tides, which is both endlessly repeated and constantly changing. This tidal rhythm draws attention to the pattern of repetition and change in Ní Chuilleanáin's work as a whole, in which related memories find new forms and meanings. Here the poems help to convey at once the significance of particular observations and the duration of the experience with its changing patterns and moods. The sequence oscillates between moments when the human perspective of the journey is foremost, and those in which nature alone features, reflecting the island's isolation and its history as a monastic settlement. Formally, too, each poem's most striking features are to be found in the relationship between its shifting viewpoints and rhythmical structure. In the opening poem, 'The Litany', the most significant juxtaposition is between the visual and auditory aspect of the environment. Its quiet logic is shaped by the structure of its first stanza:

As every new day waking finds its pitch

Selecting a fresh angle, so the sun

Hangs down its veils, so the ancient verbs

Change their invocation and their mood.

(VWE III)

The 'pitch' of the opening line alerts us to the importance of sound; spatially, too, the poem's alternating stanza lengths reflect the ebb and flow of the sequence's tidal pattern. Though the historical significance of the island is immediately invoked in the reference to 'ancient verbs', we see that these are capable of changing with the passage of time: the 'long gap in the story' is suggestive of the narrative power of human life and history, yet the monks' habitation of the rock was brief in the context of the island's natural history. Thus the slow passage of time is essential to seeing human activity in its true proportion, and though this is an isolated place its relationship to elsewhere is considered. Just as Heaney's 'timeless waves' of Aran come from America, here the wave, receding from Skellig Michael, is 'called back to Brazil'.38

The wordless sounds of nature that form the 'litany' in this first poem acquire a more specific 'voice' in the second, but it is one that calls the subject position into question, since it is unclear whether the 'old strong voice' speaks from the historical or the personal past. That the monks should have chosen the most challenging environment for their life of 
prayer is expressed through the arrival of the storm in this second poem. Here the force of the waves is recorded in the poem's insistent verbal pattern - reaching and snatching; faltering and returning; slamming and roaring. The doubling of these verbs again reinforces the ebb and flow as well as the fear and compulsion that drove the monks onward, and represents the larger dilemmas of the human state. Yet the voice could equally be that of nature itself, prompting, or uniting with, the spiritual contemplation of the monastic life.

The third poem in the sequence retreats indoors, and its four-line stanzas invoke the quietness and relative order of the shelter, compared with the preceding storm. Yet it is a reflective space in more ways than one - its light and glassy surfaces draw attention to the visual, now that the auditory bombardment has died away. In spite of this, the environment proves not an easy one to read: the glass is iced up, making objects indistinguishable. What is man-made takes on a natural aspect: the boat mimics the anatomy of the fish, the lamp compensates for the darkness of daylight hours, shedding a partial light over the timeless interior. Here the tidal rhythm is applied to language itself; speech retreats into silence, creating a powerful impression of the interiority of language. The mysterious wordless woman, appearing at the close, seems to come from outside the world of the poem. She reminds us of the unexplained figures and situations that appear frequently in Ní Chuilleanáin's work, their stories forming beneath the familiar narratives of history:

As in the five days she lay without a word,

Five glasses of milk huddled on a shelf,

Congealed, the sun of a winter afternoon

Breaking through curtains, piercing the shining whey.

(VWE I13)

The glasses of milk, at once opaque and translucent, are a fitting image with which to contemplate the play of light and revelation. Here they also mark time - the five speechless days of the poem's silent ending

This figure of woman - perhaps the sister whose early death has preoccupied the poet - gives way in the next poem to an evocation of the father, and the adjustment needed occurs for both speaker and reader. The ways in which memory alters human relationships is rendered in the father's fragmented representation here: he becomes the many images of his own experience. Here the relationship between language and the material world is interrogated, as it is in the next poem, 'Outdoors', which begins with a junction, and therefore a choice of direction. Yet 
this station - which is both the literal train station and the station of pilgrim experience - has lost its human markers: the name of the place and the time of day are obscured by vegetation. The act of waiting described here, and the uncertainty of progress, unites both the practical and the existential dimensions of the sequence: the island is hard to reach in bad weather, and visitors have to wait onshore for conditions to improve. This poem then evokes the actual condition of waiting, as well as the state of human uncertainty - 'Nobody thinks we'll go on our travels again' (VWE II5). However, the final poem - which is also the title poem of the sequence - introduces the pilgrim experience in a vividly observed way. In the poet's observation of the black-clad woman and her daughters, the human engagement with this island space is fully realized. The challenge of the harsh terrain is suggestive of the difficulty of accommodating the world of objects to the world of process. The woman struggles to take off her shoes and stockings, 'which she adds to the black bag, already encumbered / With rosary beads tangled in keys, all the stuff / She's dragged from home' ( $V W E$ iI6). As the world of commodity becomes superfluous, the time frame of the poem begins to slip, and the past merges with the present. It is fear, rather than desire, that surrounds the idea of revelation at the close: the woman is terrified of heights, 'but she does look down, and at last sees what is there, / / The dimensions, the naming. Yes. / A broad slick widening, an anachronism, / Ambiguous as a leaf floating where never / A leaf has blown' (VWE II7). What is glimpsed is the void, where the religious imagery of death and resurrection gives way to a strange, and estranging, ambiguity. What is experienced is an emerging realization, a thing misplaced, appearing where it should not be. Yet this is both the physical edge of the island and the edge of human consciousness, 'where everything pours away'. In this sequence, Ní Chuilleanáin explores the potential of the island experience to situate the past in a philosophically challenging way, deepening our engagement with familiar images and drawing us simultaneously into profound and alienating states.

Ní Chuilleanáin's body of work represents a varied and challenging engagement with the past and one that confronts important questions about how history is mediated, for both individuals and cultures. Her emphasis on the silences of the past - what history fails to disclose - has both political and aesthetic significance: it signals the concentrated yet resistant form of the poem as an important means to explore the intellectual and emotional processes that the search for meaning necessitates. In this way, Ní Chuilleanáin's work illuminates 
the subject of poetic memory, in the complexity of its figuration of past and present and in its pivotal engagement with the materiality of language and text.

\section{Notes}

I Nicholas Allen notes 'the collapsed distance between past and present [that] is part of her writing's enduring difficulty', “Each Page Lies Open to the Version of Every Other”: History in the Poetry of Eiléan Ní Chuilleanáin', Irish University Review 37.I (Spring/Summer 2007), pp. 22-35.

2 Eamon Grennan, 'Real Things: The Work of Eiléan Ní Chuilleanáin', Facing the Music: Irish Poetry in the Twentieth Century (Omaha, NE: Creighton University Press, 1999), p. 283.

3 Oona Frawley discusses the ramifications of Bartlett's work for the Irish context in 'Towards a Theory of Cultural Memory in an Irish Postcolonial Context', in Oona Frawley (ed.), Memory Ireland, vol. I, History and Modernity, p. 24. See also Frederic Bartlett, Remembering: A Study in Experimental and Social Psychology (Cambridge: Cambridge University Press, 1954 [1932]), p. 52.

4 Her father, Cormac Ó Cuilleanáin (1903-1970), was Professor of Irish at University College Cork. Her mother, Eilís Dillon (1920-1994), was from a politically active family during the War of Independence; Dillon later became an acclaimed writer for children.

5 Eiléan Ní Chuilleanáin, 'Acts and Monuments of an Unelected Nation: The Cailleach Writes about the Renaissance', Southern Review 31.3 (I995), p. 57 I.

6 Ibid., p. 573 .

7 John R. Gillis: 'Memory and Identity: The History of a Relationship', in John R. Gillis (ed.), Commemorations: The Politics of National Identity (Princeton, NJ: Princeton University Press, 1994), p. 3.

8 Maurice Halbwachs, The Collective Memory, trans. Francis J. Ditter and Vida Yazdi Ditter (New York: Harper Colophon Books, 1980), p. I06.

9 See ibid., pp. 85-6.

Io Eiléan Ní Chuilleanáin, 'Introduction', Irish Women: Image and Achievement (Dublin: Arlen House, 1985), pp. I-12.

II Eiléan Ní Chuilleanáin, 'Nuns: A Subject for a Woman Writer', in Patricia Boyle Haberstroh (ed.), My Self, My Muse: Irish Women Poets Reflect on Life and Art (Syracuse, NY: Syracuse University Press, 200I), p. 23.

I2 Patricia Boyle Haberstroh, 'Interview with Eiléan Ní Chuilleanáin', Canadian Journal of Irish Studies 20.2 (December 1994), p. 72.

I3 Elsewhere I have developed the relationship between the representation of the house and the exploration of subjectivity. See Lucy Collins, 'Architectural Metaphors: Representation of the House in the Poetry of Eiléan Ní Chuilleanáin and Vona Groarke', in Scott Brewster and Michael Parker (eds), Irish Literature since I9oo: Diverse Voices (Manchester: Manchester University Press, 2008), pp. I42-59.

I4 Kevin Ray, 'Interview with Eiléan Ní Chuilleanáin', Eire-Ireland: A Journal of Irish Studies 3I.I-2 (Spring/Summer 1996), p. 67.

Is Patricia Boyle Haberstroh, The Female Figure in Eiléan Ni Chuilleanáin's Poetry (Cork: Cork University Press, 2013), p. 39. 
I6 Guinn Batten, 'Boland, McGuckian, Ní Chuilleanáin and the Body of the Nation', in Matthew Campbell (ed.), The Cambridge Companion to Contemporary Irish Poetry (Cambridge: Cambridge University Press, 2003), p. 186.

I7 Paul Connerton emphasizes the importance of habit as a means of transmitting collective memory - building in this respect on Henri Bergson's work. Paul Connerton, How Societies Remember (Cambridge: Cambridge University Press, 1989), loc. 527 [Kindle edition].

I8 Andrew Jones, Memory and Material Culture (Cambridge: Cambridge University Press), p. 3.

I9 Borbála Faragó, “"The Informant”, Eiléan Ní Chuilleanáin’, Irish University Review 39.2 (Autumn/Winter 2009), p. 301.

20 Ray, 'Interview with Eiléan Ní Chuilleanáin', p. 64. The event that the poet refers to took place in March 1988 when two plain-clothes British Army corporals drove, it seems accidentally, into the midst of an IRA funeral. Three days earlier there had been an attempt to kill IRA members at the funeral of the 'Gibraltar Three', in Milltown Cemetery. Reportedly, members of the crowd mistook the British Army personnel for loyalist gunmen and, fearing a repetition of the earlier incident, dragged them from their car. The initial violence was captured by television cameras at the funeral. The two soldiers were later beaten and killed by Republicans. See Bew and Gillespie, Northern Ireland: A Chronology of the Troubles.

2I Saint Margaret of Cortona (I247-I297) was an Italian saint whose reckless early life as the mistress of a wealthy man was altered by his violent death. Leaving his home she went to the Franciscan Friars in Cortona and was later admitted to the order. Lawrence Hess, 'St Margaret of Cortona', The Catholic Encyclopaedia, vol. 9 (New York: Robert Appleton Company, I9ro).

22 Irene Gilsenan Nordin, Reading Eiléan Ni Chuilleanáin: A Contemporary Irish Poet (Lewiston, NY: Edwin Mellen Press, 2008), pp. 68-70. See also Irene Gilsenan Nordin, "Betwixt and Between": The Body as Liminal Threshold in the Poetry of Eiléan Ní Chuilleanáin', in Irene Gilsenan Nordin (ed.), The Body and Desire in Contemporary Irish Poetry (Dublin: Irish Academic Press, 2006), pp. 226-43.

23 Patricia Boyle Haberstroh, 'Interview with Eiléan Ní Chuilleanáin', Irish University Review 37.I (Spring/Summer 2007), p. 46.

24 Grennan, 'Real Things', p. 285. See also Dillon Johnston, “'Hundred-Pocketed Time”: Ní Chuilleanáin's Baroque Spaces' and Patricia Boyle Haberstroh, 'The Architectural Metaphor in the Poetry of Eiléan Ní Chuilleanáin', both in Irish University Review 37.I (Spring/Summer 2007), pp. 53-67; 84-97.

25 Julia Kristeva, In the Beginning Was Love: Psychoanalysis and Faith (New York: Columbia University Press, 1987), p. I.

26 Ibid., p. 6.

27 This uncertainty can be directly connected to the issue of traumatic memory and its somatic effects, yet it also suggests that the power can be derived from a refusal to disclose troubling events. See also 'The Secret' $\left(B S{ }_{42}\right)$.

28 The poet has elucidated the second stanza of the poem as follows: in a folk tale a man who commits a crime is told the forgiveness is impossible 'unless he can find a woman in a public house that is holier than a nun in a convent. He sees a woman weeping as she pulls a pint of beer and she tells him it is because the drops of beer running down the outside of the glass remind her of the blood of Christ running down his face. So he is forgiven after all.' Eiléan Ní Chuilleanáin, quoted in John 
Kerrigan, 'Hidden Ireland: Eiléan Ní Chuilleanáin and Munster Poetry', Critical Quarterly 40.4 (Winter 1998), p. 93.

29 Quoted in Haberstroh, The Female Figure in Eiléan Ni Chuilleanáin's Poetry, p. 57. 30 Introduction to a reading of the poem, Trinity College Dublin, April 1999.

3I Ní Chuilleanáin, 'Acts and Monuments of an Unelected Nation', p. 578.

32 Dillon Johnston, “'Our Bodies' Eyes and Writing Hands”: Secrecy and Sensuality in Ní Chuilleanáin's Baroque Art', in Anthony Bradley and Maryann Gialanella Valiulis (eds), Gender and Sexuality in Modern Ireland (Amherst, MA: University of Massachusetts Press, 1997), p. 192.

33 Guinn Batten, 'The World Not Dead After All': Eiléan Ní Chuilleanáin's Work of Revival', Irish University Review 37.I (Spring/Summer 2007), p. II.

34 Gaston Bachelard, The Poetics of Space (Boston: Beacon Press, 1994), p. 9.

35 Paul Connerton, How Societies Remember (Cambridge: Cambridge University Press, 1989), loc. 435 [Kindle edition].

36 Grennan, 'Real Things', p. 287.

37 Skellig Michael is a rocky island off the west coast of County Kerry. A Christian monastery was founded there between the sixth and the eighth centuries and the island remained in continuous habitation until the twelfth century. It is now a UNESCO World Heritage Site. In 20IO, Irish poet Paddy Bushe commissioned a dozen other poets to spend a night on Skellig Michael and write about the experience.

38 Seamus Heaney, 'Lovers on Aran', Death of a Naturalist (London: Faber \& Faber, 1966). 


\section{Medbh McGuckian's Radical Temporalities}

Medbh McGuckian's abstract and challenging work has fascinated and puzzled readers in equal measure since she first began publishing in the 1980s. ${ }^{1}$ Her language describes, and dwells in, an inner world and retains the freedom to explore a multiplicity of identities and to respond to both real and imaginative worlds, past and present. The strangeness of McGuckian's language makes it memorable for the reader, and in this way the processes of memory and estrangement are closely woven into each poetic encounter. In keeping with these practices her engagement with acts of remembrance is oblique but, as I will argue in this chapter, both her recurring themes and compositional strategies are linked to a desire to alter the linear relationship between past, present and future in order that new ways of understanding experience can be achieved. In this way her poetic process privileges the practices of memory over those of the conventional historical narrative as her means of accessing the past depends upon its imaginative presence to both poet and reader.

The world of McGuckian's poetry is an intimate one in the relationship it suggests between the reader and the sensory world of the poem. Yet these works do not represent the self directly, nor do they interrogate ideas of selfhood except by abstract or associative means. This reflects the poet's convictions concerning the radical instability of language: as well as the subjective processes of writing and reading, McGuckian attributes these challenges to communication to 'Irish and English and the language problem, and the way that the language was killed through the fighting, that the language was lost by that awful trauma but very recently, only one hundred and fifty years ago'. ${ }^{2}$

This concern for the changing dynamics of language in Ireland is reflected in her metaphorical uses here, in her references to language being 'killed' and to the trauma of its loss. ${ }^{3}$ Unlike Mary O'Malley, 
who mourns the loss of the language but connects with it through place and landscape, McGuckian initiates more fundamental challenges to the contemporary lyric mode. Shane Murphy argues that the kind of decolonization in which McGuckian engages does not appropriate English but 'deterritorialises the English language, subjecting it to a radical displacement. ${ }^{4}$ The strategic nature of this approach creates further receptive tensions: 'The extraordinary logical and associative disjunctions that typify her poetry offload sense-making almost entirely onto the reader', writes Eric Falci, 'while keeping an esoteric and exclusive mode of authority - an authority effect - for the poet'.5 These 'disjunctions' have an estranging effect on all McGuckian's readers, but the retention of authority that Falci describes would seem to underpin the vexed critical reception of her work. The practice of displacement is not the mark of a devolved authority, then, but a contortion of linguistic temporality that has implications for the relationship between creative and critical discourses, since the latter can neither accurately express, nor claim authority for, the patterns of meaning here.

One aspect of McGuckian's handling of time that is immediately evident is the sheer proliferation of her work. In the 35 years since she began writing she has published more than eighteen volumes of original work, suggesting not only a continuous creative process but also a degree of compositional simultaneity. It is this dimension of her practice that keeps McGuckian's poems in a state of interpretative play, one with another. Her poems resonate with one another, circulating language as well as creating it anew. Borbála Faragó has argued persuasively for the importance of the creative process as an enduring theme for this poet and her recent study demonstrates the cumulative nature of the poet's investigation of creativity. 6 Though Faragós detailed close reading of the poems reveals the networks of meaning that they progressively generate, McGuckian herself has acknowledged the difficulties that her creative abundance presents for a certain kind of critical order. Some commentators, though, see this profusion as essential to the meaning of her work: fellow poet Nuala Archer describes McGuckian's poems as 'resonating prisms that amaze the mazes of partition and parturition', revealing the need for a critical vocabulary sufficiently flexible to express the originality of McGuckian's art and its arresting effects on the reader. ${ }^{7}$ The prismatic quality, and the links between self-division and pro-creativity suggested here, are especially illuminating of the intertextual dimensions of McGuckian's work, which have attracted significant critical attention in recent years. ${ }^{8}$ She describes her practice thus: 
I never write just blindly, I never sit down without an apparatus, I always have a collection of words - it's like a bird building a nest - I gather materials over the two weeks, or whatever [...] I never sit down without those because otherwise you would just go mad, trying to think of words. ${ }^{9}$

This accumulated material, often gleaned from the poet's current reading, is consciously assembled by her and reshaped to form a new poem. The memory of the earlier text becomes a specific trace that remains in the finished poem creating a multifaceted work that may or may not reveal its past selves to the reader. McGuckian rarely offers explicit signals to the texts she is drawing from, a fact that confirms the delicate balance in her work between the desire to express and the desire to communicate: 'I don't think you need to know it all to get something out of it. In fact, maybe if you know it all you get less out of it.'.10 For McGuckian, the encounter with strangeness is not an alienating but an invigorating experience and in this she has much in common with avant-garde poets such as Catherine Walsh. The partial occlusion of an interpretative history offers creative freedom to the reader. In this way, the textual past may be as important to the mood of the poem as to its detailed analysis, contributing to the textured quality of McGuckian's language without adding essential layers of meaning. Shane Murphy argues that this intellectual/personal dynamic represents McGuckian's complex relationship with her precursors, permitting her

to retain vestiges of prior writings while including a critique or commentary on them [...] For the poet, such a layered composition initiates a personal relationship to a literary precursor, a relationship wholly dissimilar to that established by literary biographers whose work she reproduces. ${ }^{11}$

Deryn Rees-Jones further maintains that the intertextual references are McGuckian's attempt 'to reconcile, rediscover, rewrite, to literally incorporate the feminine body into the body of the text as texts, often by canonical male authors, become intimately woven into the female textual body, intersecting with her "own" writing, like warp to weft."12 It is this drawing in of the world that makes the imaginative mobility of McGuckian's work so memorable to readers. Nothing in these poems is fixed; language and voices move freely from the poet's reading to her writing, reformed but never fully contained by this process.

In some respects, then, McGuckian's work may be seen as antithetical to Ní Chuilleanáin's in that it eliminates, rather than reflecting upon, the boundaries between self and other, present and past, writing and reading. For McGuckian, reading is an act of remembering, so that 
each poem has a textual past as well as a textual present - a variable pre-existence that allows her work to open imaginatively again and again as different voices are heard within the poem's compositional structure. Her poems therefore require an active form of remembering but also the ability to forget in order that new interpretations may emerge: as the poem 'Mazurka' suggests: 'A newly-understood poem will melt / And be hard again'.13 This explicit acknowledgment of the endless renewal of meaning possible in the single poem is again suggestive of the simultaneity of McGuckian's work: rather than one act of reading following another, all are open to reinterpretation. Here forgetting is foregrounded as a necessary counterpart to the processes of remembering. In order that some things are remembered, others must be forgotten: 'every act of remembrance, whether individual or collective, necessarily involves selective, partial, or otherwise biased forms of forgetting.'14 These energies make McGuckian's poetry endlessly receptive to the changing relationship between past, present and future, a relationship that has figured both thematically and formally throughout her career to date.

\section{Creating Past Selves \\ in The Flower Master and Venus and the Rain}

An appreciation of this dynamism of language is essential in approaching McGuckian's earliest work. Not only is it a hallmark of her style, and an element that set her apart from her peers, but it is an important dimension of her first two collections - The Flower Master (1982) and Venus and the Rain (1984) - both of which were republished by Gallery Press in somewhat altered form in 1993 and 1994 respectively. The evolution of these books clarifies aspects of McGuckian's relationship with her own creative past and therefore of the processes of self-remembering that are so important in her work. The Oxford Flower Master itself bore the traces of earlier pamphlet publications: poems from Single Ladies (Interim Press) and Portrait of Joanna (Ulsterman Publications) appear there, charting the gradual evolution of McGuckian's work towards a full-length collection. The titles of both pamphlets draw attention to female experience and their poems reveal the importance of gendered perspectives in this poet's earliest texts. The ambiguity of the later title - The Flower Master - is in keeping with the interplay of opposites with which McGuckian's most fully realized work always engages. Its cover illustration of Georgia O'Keefe's 'White Trumpet Flower' also brings 
the woman's body back to the centre of reading. This combination of the oblique and the immediate is exemplified by McGuckian's frequent use of the present tense: the states of being that are depicted here are vivid, sensory yet temporally complex - suggesting the layers of meaning that can be generated by intense experience. The speakers in her poems wrap the past into present sensation: there is no consciousness here of the act of remembering, instead it becomes part of bodily experience. This technique draws attention to the endurance of the somatic as an imaginative wellspring but this is not confined to the connection to traumatic experience; for McGuckian, what is joyful and pleasurable can also be recalled in this way. The poems of The Flower Master, in particular, dwell on the relationship between child and woman, on the changes of body and sensibility that mark this transition.

The opening poem of the Oxford edition of The Flower Master is a key text in this respect. Its position in the original volume marks it as a poem of transition, so that its concern with the passage from childhood to adulthood is also a herald of the creative self. This process of evolution highlights the importance of memory in recognizing how the self can coexist in its past and present forms, much as Paula Meehan uses the space of teenage rebellion to signal this dual subjectivity. McGuckian's 'That Year' signals the importance of retrospect from the start; it recalls the new interests of the soon-to-be woman in terms of material things - playing with rings, experimenting with hair colouring and wearing a bra. Immediately, subjectivity is split into two: the other - the 'you' of the first line of the poem - is on the threshold of adulthood, while the first person perspective of the rest of the poem moves more slowly towards this position. Childhood memories prefigure this process, combining joy and sorrow in the images of the red kite lost in the sky, and the white ball disappearing on the tide. The hints of menstruation in the red and white coloration of this stanza seem distant possibilities, from which the girl distracts herself by looking down, studying the linoleum at her feet and the stitching on her dress, dominating the poem's shifting perspective now. The power of contrasting imagery to configure the overlapping states of innocence and experience is demonstrated here. Violence and pleasure combine in the images of bee-sting (often used to describe the sensation of female orgasm) and the bullet lodged within:

It was like a bee's sting or a bullet

Left in me, this mark, this sticking pins in dolls,

Listening for the red and white 
Particles of time to trickle slow, like a wet nurse

Feeding nonchalantly someone else's child.

(FM 1982 9)

When the text appeared in the revised edition from Gallery Press it was no longer the opening poem but placed fifth in the collection under the new title 'Eavesdropper'. Its changed final line - from 'The grass is no bed after dark' to 'The grass is an eavesdropper's bed' - reinforces the subtle shift of emphasis away from the processes of memory and towards a more suggestive mode. As Leontia Flynn has pointed out, the new title makes the poem's concerns 'strangely both more and less elusive'.15 She goes on to indicate how the associations brought by these revisions combine ideas of original sin (via Eve's 'drop' into the fallen world of childbearing) with the phrase 'falling off the roof', which is slang for menstruation. ${ }^{16}$ The proliferation of meaning that even such relatively small alterations can cause is significant. For the same reason poems such as 'Problem Girl' (with its persona of dreamy adolescence) and 'The Chain Sleeper' ('Unshameable this leggy girl who sleeps and sleeps') (FM I982 II; I2) are omitted from the Gallery Press volume, making room instead for poems of multiple subjective states - 'Gateposts' or 'The Truth Room' (FM 1993 35; 50). This is in keeping with a creative strategy that moves away from subjective experience, preferring instead to see changed states as coexisting in time, where both are imaginatively available to the poet, and reader, at any stage.

The process of creative coexistence has an important effect on McGuckian's exploration of the twin states of childhood and motherhood. In her work the adult woman 'contains' the child that is her past self, at the same time as she carries the child to whom she will give birth. Thus the potentiality of birth-giving is closely linked to the processes of memory: the mature female body expresses past, present and future, and her textual manifestation opens interpretation to new temporal frameworks. Moynagh Sullivan defines the maternal aesthetic in McGuckian's work as one of experience rather than representation: 'McGuckian's aesthetic disrupts the modernist mechanism of confirming identity at the expense of the object, by making the experience of being inside her poetry one that displaces us as meaning-bestowing subjects. ${ }^{17}$ In this way, the reader is brought into an intimate relationship with the material of the poem, eliding the temporal distinctions that situate the reader as coming after, rather than in the midst of, the act of making. The maternal instinct recorded by the poet does not emphasize only the childbearing capacity of the body but rather its entire creative nature. 
'Confinement' from McGuckian's second full collection, Venus and the Rain (1984), explores the coming together of fixed images of the human subject and the contingent process of awaiting birth - that moment in which the potential child becomes actualized in the world. The 'sleepy, glassed-in child' is described as the speaker's 'fair copy', suggesting the presence of a more perfect version of the adult self, yet a version that comes after the untidiness of lived experience. The idea of doubleness is soon confirmed in the simultaneity of the poem's image patterns: 'While you were sailing your boat in the bay, / I saw you pass along the terrace twice' ( $V R$ I984 42). The child occupies two imaginative spaces at once, 'sailing' in the safety of the womb and moving freely in a liminal space, neither inside nor outside. The autumnal air of the poem, with its flying leaves and recovery from summer heat, suggests a darker reading in which the child becomes a ghost - at once laid out at the centre (the heart) of the house and haunting its marginal spaces. In this way, the memory of the unborn child becomes a kind of memorialization, a momentary stilling of the imaginative dynamic. Meanwhile, the natural world, and its creative potential, also shifts and changes, the 'river imagery' of the speaker's arms testifying to the endless flux of the maternal imaginary.

The trope of movement that is so prominent in McGuckian's early works is a means to indicate key transitions between childhood and adulthood, between single and married states, but also to speak of the impossibility of containment. This trope brings with it a number of themes and images that will recur in her poetry and that the reader can trace through their various forms as indicators of difference rather than sameness: the house, with constantly shifting perspectives; the garden, together with more extensive natural imagery; motherhood and child rearing; crafts of making. Most significantly, the metaphors by which these themes are introduced appear conjoined in inexplicable ways. First, the juxtaposition of inner and outer spaces means that houses and landscape are rendered simultaneously, making the boundaries between them hard to read. As imaginative creations of place, they distort the function of memory by permitting no fixed point of recall. Further, the identification of material elements with complex emotional states means that such shifts in spatial representation - or the evocation of a range of disconnected objects - also trace the mutation of feeling and perception in the poem. Many of these early poems use the trope of moving house as a means of addressing the dynamic ways in which the subject position is realized in poetry. 'The Flitting', the poem that won the National Poetry 
competition in Britain and first drew critical attention to McGuckian's work, exemplifies the unfixed position of the speaking voice, a strategy in keeping with one of the poem's themes - the disorientating shifts that new domestic arrangements must occasion. The first phrase of the poem registers the connection between states of emotion and states of the body, drawing explicit attention to a relationship already discernible in earlier poems from this collection: "You wouldn't believe all this house has cost me - / In body-language terms"' (FM 198248$)$. The inclusion of direct speech here is comparatively rare in McGuckian and separates these lines from those that follow, though they seem continuous in their representation of the experience of domestic upheaval. The current state is invoked first, before the process that helped to form this state is addressed. In this way, present emotion is constituted from memory, though no direct perspective on the past is offered. Likewise, the sense of human connection that this movement fosters is replaced by a more anxious readjustment to new space and experience.

Art provides the means to bridge this gap: the 'living' walls of the house - likened to strawberries and tomatoes - are covered with paintings of Dutch interiors, their female protagonists testifying to the new importance of the domestic realm as a world of metaphorical meaning. ${ }^{18}$ The implicit treatment of Vermeer's 'Girl with a Pearl Earring' reveals the importance of visual memory here and draws on its power to represent complex states simultaneously, rather than sequentially as language requires. It extends McGuckian's reflection on states of interiority: the girl's 'unconscious / Solidarity with darkness' explores the relationship between the female subject and the dark background of the painting, a field created by the painter and of which the girl can have no knowledge. Like Boland, in her textual treatment of Chardin's female subjects, McGuckian records the fact that much is concealed by the act of representation itself since the narrative of women's experience extends far beyond the static image. ${ }^{19}$ Yet there is also a suggestion that the process of illustration itself creates significance: 'Her narrative secretes its own values, as mine might / If I painted the half of me that welcomes death' (my italics). Value, then, may be at once concealed and generated by the shape of the girl's life story; it may not be inherent in the life, but rather be found in the afterlife of the work of art - a partial though not a false representation. Just as the boundaries between art and life are challenged by McGuckian here, so past and present merge as the speaker takes on the garments of seventeenth-century Holland, much as she relished the 'fraternity of clothes' that shaped her twentieth-century 
transition from one house to another. Neither can nature and technology be held apart - the digital clock is 'well-earthed' and the train 'plough[s]' through 'the cambered flesh of clover and wild carrot' (FM 1982 48). Creative futures merge with timeless landscapes that are both real and literary: 'I postpone my immortality for my children, / Little rock-roses, cushioned / In long-flowering sea-thrift and metrics' (FM I982 48). The postponement of full artistic realization marks a recognition that while the poem may be in the process of creation - and therefore present to the poet - its materials are already past and move freely among visual and linguistic traditions, to form new meanings and connections.

Art in various forms has concerned McGuckian throughout her career. Sometimes she uses aspects of conventional representation as much to question the nature and reception of the artistic act as to create a subtle intertext with the life and work of the chosen artist. At other times, it is the act of creation itself that offers an equivalence to her own poetic formation and to the complex temporalities that attend the conversion of nature into art. 'The Seed-Picture', from McGuckian's first collection, draws attention to this act of making by combining nature and artifice in inextricable ways. It is also a text that exhibits the poet's preoccupation with the relationship between word and object. Here they are conflated, seeds becoming words and words seeds - the conglomerate picture is made, bringing natural and poetic worlds into alignment. Here the seed as the originator of life is also its completed representation, suggesting a cumulative form of signification that contains its point of origin within its final state. Each instance of creation carries within it a memory of nature that is supported by the subtle shift that can be observed here from the male, as the expected seed-bearer, to the female as the agent of making. These seeds are on the surface of picture and poem, offering themselves in a depictive pattern, yet they are also buried, hidden within their fruits. The poem itself sprouts and grows from apparently inconsequential beginnings and the child within it forms through the textures and colours of the natural world:

\section{Her hair}

Is made of hook-shaped marigold, gold

Of pleasure for her lips, like raspberry grain.

The eyelids oatmeal, the irises

Of Dutch blue maw, black rape

For the pupils, millet

For the vicious beige circles underneath 
Just as in McGuckian's numerous flower poems, closeness changes perspective here. The detailed focus links human and natural patterns; flowers becoming not merely flowers but powerfully sensual objects. This process affirms the role of the reader in bringing such observations to light and, in particular, in drawing inferences from the creative materials chosen. The arresting visual elements in such poems highlight the importance of form for both image and poem, while female sexuality, which is so often the force behind both, finds a curiously blatant yet delicate expression. Through these visual elements, McGuckian accesses a range of disciplines, from physics to painting, from linguistics to botany, and there are interesting after-images of all these fields to be found in her work.

The significance of art emerges again in 'The Sitting', from Venus and the Rain, which is a form of self-portrait - 'My half-sister comes to me to be painted' ( $V R$ I984 I5). It highlights one of McGuckian's most familiar strategies, the extension of a speaking poetic self into another persona. This displacement allows strangeness and familiarity to be combined. The ambiguity of her use of pronouns serves this purpose, leaving the boundaries between selves fluid in order that emotional territory can be most freely explored. The self that is presented in this poem is reclusive, seeming to affirm the view of Clair Wills that there is a tension in McGuckian's work 'between her wish to represent the self in order that it be more perfectly understood, and her wariness of opening herself up before the public'. ${ }^{20}$ Sarah Broom sees a further consequence of this mixed motivation: 'McGuckian's is a poetry which invites (though not without anxiety) the intrusion of others, and welcomes as a source of inspiration the "fragmentation" which results from full interaction with others. ${ }^{21}$ This interaction between self and other takes place both inside and outside the poem and so affects McGuckian's relationship with her own readers, courting the blend of intimacy and estrangement noted from her earliest work. Even as she is acquiring considerable critical attention, McGuckian can remark: 'I began to write poetry so that nobody would read it', thus transforming her own readers into strangers. ${ }^{22}$ 'The Sitting' continues: 'She is posing furtively, like a letter being / Pushed under a door, making a tunnel with her / Hands over her dull-rose dress' (VR I984 I5). The disowning of the physical body is contrasted to the attentive representation of it, as though art can reclaim what is lost in life and offer intimacy in place of distance. Again, the detail ('painting it hair by hair') causes the reader to shift perspective and to see the value in minutiae here. This close-up approach also goes some way to address 
McGuckian's apparent reluctance at this time to deal with larger political and historical issues, revealing a double existence that is focused on the vivid representation of individual subjectivity, yet revealing of the larger dynamics shaping social and political events. Even the precise forms of representation create ambivalent tones: the mixed feelings involved in self-revelation become clear here in the held-back pose; the scepticism concerning the accuracy of the rendering; the paradoxical desire to evade artistic capture just at the moment when the representation is complete.

The explicit exploration of the role of the artist - and thus obliquely of the writer - is an important development of this visual dimension. McGuckian's second major collection, Venus and the Rain, engages more fully in this process. This is a more stable collection than the first: though it appeared in two separate editions, its revisions are not as radical as those that can be traced in the transition of The Flower Master. Its opening poem, 'Venus and the Sun', uses planetary configuration to consider the relationship between space and time, and thus the relationship between the artist and her own creative identity. Venus, the first planet inside the earth's orbit, is associated with the capacity to apprehend wholeness while maintaining an intimate connection to the experiences of earth. In this poem, it is the relationship between Venus and the sun - or between artist and inspiration - which is key. The sun provides creative energy but the artist in turn shapes this inspiration to realign the cosmos: the moon and stars are curved into new relation to one another, an inclusive and binding form. Though describing herself as 'the sun's toy', the speaker loves to test the boundaries of such authority. It is a marker of McGuckian's confidence that, at the threshold of her second volume, she can announce her ambitions in this way, and suggest the freedom that a break from temporal restrictions will bring:

If I travel far enough, and fast enough, I seem

To be at rest, I see my closed life expanding

Through the crimson shells of time

(FM 19849 9)

Yet the universe that the poet creates at this point in her career is an expanding one: the stars 'fly apart / from each other to a more soulful beginning' - moving, that is, towards their origins, which are singular rather than collective. In the final line, Venus and Mars, female and male elements, are brought into alignment as the speaker speculates how she might 'double-back' from her extraordinary creative trajectory to inhabit a masculine space - the 'dullest blue of Mars' ( $V R$ I984 9).

The companion poem to this one, and the title poem of the collection 
Venus and the Rain, is situated halfway through the volume, as though suggesting the symmetry of such doubling-back and embedding new temporal freedoms into the physical space of the book. Again, the poet is concerned with the relationship of the parts to the whole, but here the bright flames of the sun are replaced by the icy fissures of a distant planet:

my gibbous voice

Passes from leaf to leaf, retelling the story

Of its own provocative fractures till

Their facing coasts might almost fill each other

And they ask me in reply if I've

Decided to stop trying to make diamonds.

$(V R$ 1984 3I)

This fractured voice again tells of time's reversal, here of the drawing together of continents. The creation of diamonds from the compression of rock might find a parallel in the diamond-like appearance of the frozen raindrop - one a hard and lasting form, the other endlessly changing in relation to its environment. As Catriona Clutterbuck has argued, the making of diamonds is also an allusion to the creative process and to the critical questioning that McGuckian's challenging style has inevitably provoked.23 Instead of a fixed art, the speaker privileges its alternative, offering forms of water which - as well as being mutable - are unpredictable in their flow. Though she teases us with the thought that the 'cruising moonships' of criticism might 'find / Those icy domes relaxing' $(V R, \mathrm{I} 984 \mathrm{3I})$, ultimately, the poet asserts the power of the meltwaters of poetry and their energizing flow. Again we enter a strange and timeless realm; however, now McGuckian asserts this not as a by-product of more personal themes but as a clear expression of freedom from cause and effect and one that will go on to shape her political poems of the nineties and beyond.

\section{Intimate Remembrance:}

\section{Shelmalier and Had I a Thousand Lives}

McGuckian's relation to the specific cultural circumstances of her writing has occasioned much debate. Though the work of all Northern Irish poets is read against the backdrop of the violence in the province, McGuckian has explicitly resisted the view that her work represents the Northern conflict: 'the "Troubles" affect my life and enter my poetry 
that way,' she says, 'but I avoid them as a subject as I avoid taking arms against a sea'. ${ }^{24}$ Though she has acknowledged that the violence had little direct impact on her family,25 yet she is aware of the shaping forces of the environment on her creative process: 'I was brought up in Belfast. I wouldn't have been a poet, I don't think, if I had lived anywhere else.'26 The significance of place does not find expression in a direct representation of experience, whether of the individual or the community, but rather in a synthesis of the less visible or tangible elements of the conflict both for herself and for her readers. This process draws attention to the importance of cultural memory in shaping opinion, past, present and future: 'cultural memory contains a number of cultural messages that are addressed to posterity and intended for continuous repetition and re-use'. ${ }^{27}$ The 'cultural messages' carried by poetry, however, are subtle ones. Here it is not the role of the poem to represent violent conflict directly, but rather to achieve an understanding of its effects. McGuckian has remarked on the sense of dislocation that the Troubles have brought and of the role of suffering in shaping writing, yet before the publication of Captain Lavender in 1994 there was little to indicate that politics were a direct influence on her work. ${ }^{28}$ That collection clearly marks the transition towards a more politically motivated poetics, but one that does not mark a stylistic break with her earlier collections. Flynn argues that McGuckian's 'keen political intelligence' is already evident in her work, especially in her engagement with historical suffering in other cultures. ${ }^{29}$ This lays the foundation of her later treatment of Irish political violence through the lens of history. The atemporality suggested by Republicanism, which understands armed resistance as both the result of (and therefore coming after) lengthy political conflict and ideologically coexistent with Ireland's revolutionary past, allows McGuckian to assimilate this material into her existing preoccupation with synchronicity. Her choice of a quotation from Picasso as an epigraph - 'I have not painted the war [...] but I have no doubt that the war is in [...] these paintings I have done' - is a testament to the subtlety of her approach.

McGuckian's treatment of political material is not markedly different from her engagement with personal relationships, yet the poems in the second part of Captain Lavender present more uncertain emotional territory for poet and reader. Here the greater effect of sectarian violence becomes more visible in her work: the mood becomes darker and a whimsical sense of difference gives way to estrangement. Poems like 'The Albert Chain' expose the distortion that the province suffers under terrorist violence - the shortened watch chain of the title indicating 
this constriction. Vibrancy is set against stagnation and destruction in the opening stanza where fruit hangs from a dead tree; the wild cat is stripped of its skin; the squirrel stoned to death. There is something deliberate about this state of affairs, however, as though the deathliness is both cause and effect of the actions of nature: 'Like an accomplished terrorist, the fruit hangs / from the end of a dead stem' (CL 68).

The speaker returns to the situation of war and finds it to be a dark and threatening place, much as Heaney felt his return to Northern Ireland after a year abroad was like 'putting on an old dirty glove again'. 30 In this way she remains trapped between past and present, registering the trauma of both and powerless to reach a place of peace and reflection. This entrapment indicates the cyclical nature of the violence in Northern Ireland, and the extent to which it draws its iconography from a long history of divided political allegiances. The repetition of violence ties its citizens to the past, so that though the poem may posit a single speaking voice, the exploration of subjectivity is layered and volatile. This returns us to Thomas Docherty's contention:

Often it is difficult to locate any single position from which the poem can be spoken. [...] It reads as if the space afforded the 'I' is vacant: instead of a stable 'persona', all we have is a potential, a voice that cannot yet be identified. ${ }^{31}$

This issue, which is what makes McGuckian's poetry so distinctive, is also what offers the greatest challenge to readers and divides critics most forcefully. Shane Murphy refutes Docherty thus: "The voice may be "unidentified", but this does not void it of "identity"; and although the "I" may be multiple in the poem, he is incorrect to consider this as nullifying its actuality.' ${ }^{32}$ Eric Falci has also argued that McGuckian's use of the 'I' reinforces rather than eliminates subjectivity: 'the "I" of most poems consistently asserts its own gravitational pull'. 33 This debate is one of no little significance for women writers, whose struggle to establish a voice is inextricable from the reader's willingness to engage seriously with it, whether it be singular or multiple. McGuckian's complex use of the voice is what makes her work so important in any study of poetry by women, because it enacts the shifting and often unfathomable aspects of identity politics in immediate ways. She registers the familiarity as that of being buried alive 'like a dead man / attached to the soil which covers him'; one that involves a dissipation of the self 'in little pieces, like specks of dust' ( $C L$ 68). The figure of the prisoner, hands 'bruised against bars', foreshadows the men that will later populate Shelmalier (1998) and 
Had I a Thousand Lives (2003). The personal trauma associated with the death of her father becomes part of the larger cultural distress to which she bears witness. Though her father's death had no direct association with the political conflict, McGuckian has linked it to the Troubles: 'I felt I had to avenge his death, in a sense, myself, that my father was my Republican.'34 The extent to which she felt the lives of her parents' generation had been limited by social circumstances and political violence is clear from her remarks, as Helen Blakeman concludes: 'McGuckian mourns the death of her father as a casualty of war, relating his "imprisonment" within a lifetime of conflict to the actual imprisonment of political prisoners.' 35 By thinking politically about these personal events, McGuckian displaces feelings of grief and loss into ones of estrangement, memorializing her father through a renewed sense of the injustices inherent in the Northern political situation.

This realization lays the foundation for two important volumes that commemorate Ireland's revolutionary past. Shelmalier (1998) centres on the United Irishman rebellion of 1798 and links this landmark period of Irish history with the contemporary violence in Northern Ireland. As Falci has pointed out, however, even these parallels are untimely: 'considering that many of the poems [...] were most likely written between the IRA cessation of military operations in August 1994 and the Good Friday Agreement in April 1998, McGuckian's conflation of 1798 and 1998 becomes aggressively anachronistic'. ${ }^{36}$ This observation confirms the poet's tendency to create her own temporal frameworks, which may bear only passing resemblance to the chronologies of recorded history. In calling the book 'the dawn of my own enlightenment', she is, Faragó argues, 'explaining her role as the reader of history, before her role as the writer of poetry'. ${ }^{37}$ This dynamic adds a new layer to the temporal play of McGuckian's work, emphasizing the process by which she reads and uses other texts, rather than the intertextual product that is the result of this practice. Here the shaping of the book around a central concept allows the displacement of meaning to acquire a centrifugal force.

The book is divided into five sections, each of which combines different moments of history and different perspectives on the interweaving of national and personal material. Each begins with an italicized poem that resonates with the texts that follow, sounding a note that is taken up in other voices and forms. Though the unified nature of the collection might come as a surprise to McGuckian's readers, the indeterminacy of voice is already a familiar strategy, here made more politically significant by the poet's exploration of national history. The opening poem of the 
book, 'Script for an Unchanging Voice', speaks of forms within forms: 'Here is a stone with a stone's mouth inside, I a shell in which a lighter shell has died' $(S \mathrm{I} 6)$. Linking this image to the Yeatsian 'stone in the midst of all', Eric Falci traces its departure from this solidity to express a form of negation: the mouth 'is made non-functional by being placed inside of a stone, where, if nothing else, it will not work as a mouth. This figure for utterance is canceled by the act of its figuration'. ${ }^{38}$ Yet the image also speaks of replication: of the present as a harder, more obdurate version of the past, which it has subsumed. This accounts both for the ruthlessness of terrorist violence and for the failure of coherent speech in the face of oppression. The layered nature of past and present results in the close connection between the speaker in these poems (usually female) and the men of 1798 . This is a collection animated by ghosts who are, as Guinn Batten has observed, paradoxically more alive than the speaker herself. 39

Yet in spite of the new and unified purpose of this volume, it retains links with McGuckian's past texts as well as with history, in this way memorializing not only armed confrontation but also the kind of poetic resistance that McGuckian has been practising since the beginning of her writing career. One poem from the opening section explores the subtle yet enduring nature of the past. "The Sofa in the Window with the Trees Outside' reintroduces an image from one of McGuckian's earliest poems - the 'serious sofa' which there signified the creative process itself - and thus records the creative changes that her work has undergone. The title here draws attention to divisions of space even as it dismantles them. As in the earlier poem, internal and external blend, the gold forget-me-nots appear alongside the hedge thick with flowers;

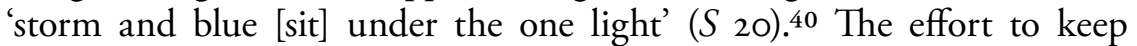
things separate seems doomed to failure. To accompany these spatial shifts there are shifts in time:

The dead among the spices of words

brush their eyes over me, as if

all my limbs were separate.

They are pearls that have got

into my clothes

$\left(S_{20}\right)$

This deathly presence within the language of her poetry comes from the earth. In 'The Feastday of Peace' the dead who 'steer' the speaker's dreams are 'Deep in time's turnings / and the overcrowded soil, / too familiar to be seen' $(S$ 23). In 'Cleaning out the Workhouse', 'Your eighteenth-century fingers spice the soil / with blood and bone' ( $S$ 30). 
These overlapping words and images reinforce the unity of the collection and emphasize the power of language, like the earth, to contain and renew the materiality of the past. In this way, burial without commemoration is an unfinished process. ${ }^{41}$ This suggestion can be linked to the claim made by Luke Gibbons that Emmet's speech indicates a deferral of writing rather than a refusal to write: 'The inability to achieve the full inscription of the word within a subaltern or colonial culture points to a lack of definition, a transitory, indeterminate condition at odds with the homogeneity of the "imagined communities" of print culture'. ${ }^{22}$ In words the speaker brings the dead to life: her 'joyful / fighter' comes to the door, she can feel 'his breath's / smoothness' but blocks out the memory of his ravaged body, preserved at the dark centre of the poem, itself a kind of grave ('Green Crucifix', $S$ 46). His missing backbone is replaced by the 'straight mast' of the cross: it is not the fighter only but also the witness who attains the identity of a Christ - a sacrificial figure bound by fate to suffering. This unification of fighter and speaker is an important dimension of these poems, and suggests not only the linking of contemporary Ireland with its revolutionary history but the unification of female and male, of witness and participant in ways that make the past present. 'Shoulder-Length, Caged-Parrot Earrings' $(S$ 48) is formed around such tensions. It begins by associating 'female eyes' with a 'male hand', and by depicting the open throat of the fighter as at once expressive and deathly. The poem's Yeatsian echoes - 'How lightly then your rich body weighed' ('They weighed so lightly what they gave') - reinforces its unification of opposites, and its sense of the sacrificial rebel as transcending earthly realities, and watching from a heightened vantage point. 43

The Face of the Earth (November 2002) and Had I a Thousand Lives (July 2003), published barely eight months apart, reveal the different strands clearly emerging in the poet's work at this time, yet paradoxically assert the overlapping nature of the emotions they involve, for both writer and reader. The former is a meditation on death and loss, situating these in a philosophical rather than a political frame; the latter commemorates the deaths of Robert Emmet and Thomas Russell, organizers of the $\mathrm{I} 803$ rebellion, and considers the role of personal sacrifice for a political cause. McGuckian's work of this period confronts the trauma to be found in private as well as public lives; its presence in both these books confirms that it is distinct yet simultaneous - the publication of Had I a Thousand Lives does not consign The Face of the Earth to the past, but rather keeps it present to the reader. In spite of 
this process, the opening poem of the second book meditates on the difficulty of 'saying' anything in a culture where past and present are fraught with violence. The title 'River of January' implies a temporal movement that belies the frozen language of rebel and poet: 'I have nothing to say which I can say' (HTL I3). The security of ordinary people who 'walk about as if they own / where they are, and they do' is juxtaposed to the feelings of others who yearn for a unity that is expressed here in primeval terms, through the image of the forest. Yet this place of symbolic richness cannot yield actual comfort - the poem questions the attempt to create a 'flower-rich shelter [...] / [...] in a wood left untouched / by the prospering suggestion of orchards' (HTL 13). The 'old meanings' of the forest persist, in spite of the blasted landscape depicted here - the 'treeless, herbless, overfished sea', a reversal of the Elizabethan colonists appreciation for Ireland's rich landscape and evidence of the ways which language can accommodate oppositional meanings. The metaphor of belonging has become more important than the reality of community.

The persistence of ideological commitment in the face of social change is noteworthy here, and a partial representation of the past becomes essential to this dynamic. Memory and forgetting are keys to Had I a Thousand Lives both because of its commemorative impulse and because the individual creative act is linked to the process of memory itself. 'My body cannot forget your body' begins 'The Chamomile Lawn' - a poem concerned with the tenuous separation of life and death (HTL 78$)$. Even the roses only 'give the impression' of existing in the present; it is the scent of earlier roses that endures. The presence of death has both individual and collective significance: 'I hear my Death speak, / making silencing gestures while he speaks / through all the other deaths in the room' (HTL 78). This 'speaking through' is ambiguous, in that it uses another's experience as a channel for communication at the same time as it obliterates the suffering of the other in order to assert that of the self. Here McGuckian articulates the anxieties around ideas of collective memory that may invalidate the recollections of the individual subject. Elena Esposito argues, however, that the seat of collective memory is 'not in society, but indirectly in the consciousnesses (or in the minds) of the individuals taking part in it'. ${ }^{44}$ This doubleness is reassuring for the speaker in 'The Chamomile Lawn' since, at the same time as these anxieties emerge, the necessity of collective action seems to be asserted in two different ways. First, the sacrifice of a leader must be matched by that of countless anonymous rebels, whose commitment to 
the cause lends gravitas to the event. Secondly, those who die fighting for nationalist causes join a host of other who have died similarly over the course of centuries. The relationship between action and emotion is significant here: the movement beyond violence towards fear in this poem marks a crucial confrontation with the self. This turbulent sense of selfhood is closely linked to the nationalist struggle in the desire for self-determination it indicates. It also ties the rebel leader to succeeding generations who benefit from his sacrifice:

\author{
My head \\ and heart line up behind him, my legs' darkness \\ fold around his waist. He pours his blood out \\ striving to free his $I$ from the $I$, \\ and finds himself to be so non-masterfully \\ that indescribably delicate personality \\ of light by which he sees, this quartered \\ death is worth a whole life, my life, me.
}

(HTL 79)

The sexual connection between speaker and rebel here is integral to McGuckian's poetic technique: 'my legs' darkness / fold around his waist' mimicking her practice of folding disparate meanings into her poems, of subsuming the past into the present. Bodily movement drives the enjambment here but it is the darkness between the legs that can take in and offer in return the blood the dying man pours out. In striving for freedom, he is both actor and acted upon - the subject and object of violence, verb and adverb in these lines. His fragmented body demands a response from the living who, in their wholeness, must atone for his past suffering even as they recognize its continuing presence.

The legacy of the insurgent is featured again in 'Petit Bleu' and once more the issue of self-expression emerges. The rebel's prison existence radiates meaning: 'You burn like an extra- / special sunset / in the warmth of your bed, / the very soul of the prison' (HTL 20). More importantly, the sprinkling of 'small pieces of torn letters' around the prison yard, suggest the partial yet memorable communication of the experience of incarceration and sacrifice. The poem itself is composed of fragments, the first two of its three sections ending in ellipses. The struggle to find language adequate to experiences of death and torture has informed modern literature in significant ways; in problematizing linguistic coherence, it demands a new approach to expression - 'Physical pain does not simply resist language but actively destroys it, bringing about an immediate reversion to a state anterior to language, to the 
sounds and cries a human being makes before language is learned'. ${ }^{45}$ McGuckian's work further recognizes the struggle for any form of expression given the choices and pressures inherent in language itself. Though liberty may be 'the eternal letter $L$ ' that drives this poem, it is marked by confinement and truncation, even the place of execution is set apart 'On the north side / where no one walks / except in new shoes returning / from Mass' (HTL 20). Yet this sense of being set apart will fuel the memorialization of 'the doomed in all but name'.

The inspirational nature of sacrifice is explored in this collection both through McGuckian's recognition of the legacies of history and, more specifically, because she records the writerly aspects of this exploration directly. 'A Religion of Writing' chooses the motif of inscription to examine the lasting nature of texts and the problematic relationship between words and meaning ('the remoteness / of name to meaning'). The inscribed gravestone is at once a marker of identity and an indication that identity has been lost through the death of the body. The writing here is fragmented into letters, which themselves have no coherent meaning: 'Such unsteady capitals, / / the backward $S$, the $L /$ with its foot slanting sharply / downwards' like the mutilated figures of the executed (HTL 22). For Conor Carville, this leaves us to infer the name or epitaph on the tomb, suggesting 'a degree of imaginative freedom, of interpretation on the part of both the narrator and the reader'.46 This drawing together of the processes of narration and reading increases the sense of containment created in the poem. Enclosure is emphasized for both text and body: 'letters of smaller / size placed inside others' are paired at the close of the poem with 'a death's head carved / with a human head inside it', recalling the earlier 'stone with a stone's mouth inside' of Shelmalier (HTL 23; $S$ I6). Within the representation exists the life itself, so even as McGuckian creates oblique palimpsestic poems she acknowledges the primacy of human feeling within them.

\section{Transformations: The Book of the Angel}

In McGuckian's most recent collections, especially those published since Had I a Thousand Lives in 2003, there is a pronounced emphasis on the representation of the spiritual as a means of engaging, once more, with the relationship between the revelatory power of language and subjective experience. This development might be seen as the natural outcome of her search for ways to unite past and present. By figuring the act of commemoration as one of personal connection - an expression of 
intimate relation to the past - McGuckian seeks to construct meaning through the breaching of physical and semantic boundaries. So the intrusion of the divine into the human world, and the corresponding challenge to rational systems that it presents, is suggestive of McGuckian's poetic project as a whole, and the important role the strange and the inexplicable play within it. Throughout her work, codes of meaning are exposed to sudden interpretative shifts; time frames extend and collapse without warning. As a result, our normal strategies of reading must change, because the progression of our interpretative acts demands it. Reading McGuckian's latest poems requires us to remember our earlier encounters with her work and to allow its continuities to illuminate her recently written and yet-to-be-created texts. Through her representation of the divine, in particular of the figure of the angel, McGuckian explores the temporal implications of the creative process, extending her experimental uses of language and deepening her engagement with the body as the experiential nexus of knowledge.

The Annunciation is an important trope for the poet: it is a moment of the utmost significance for Christian civilization, yet it is also a turning point in the life of the individual woman. Its role in cultural memory, and its endurance as a subject of textual and visual representation, can sometimes obscure the complex temporalities it invokes. As a transformative event in the understanding of individual and world, it demands a rethinking of time, projecting meaning from the moment of revelation into the newly significant future. This dynamic suggests an estrangement from the past and thus an implicit detachment from earlier texts, causing us to rethink the implications of McGuckian's intertextual strategies. Thomas Docherty has commented on what he calls McGuckian's 'untimeliness', which he further defines as 'the gap between what is said and the voice that says it." ${ }^{47}$ In McGuckian's recent work the disjunction of voice and language is highlighted by the presence of 'voice' within poems not as a speech act but as an entity in itself. The voice is not therefore 'heard' as much as it is understood conceptually through a kind of representation that moves beyond the auditory.

I encounter now my only

language, an eye that opens

at a summit, something prior

to the sentences we speak,

as if, in the eloquent

survival of that voice, 
spirit said something

I wanted to say

That the voice should exist prior to, yet also come after, wordless expression is significant when exploring the concept of the Annunciation itself. Between the momentous articulations of John the Baptist and of the Angel Gabriel lies the silence of private experience. This is the gap between the foretelling of the event and the event itself; between the significance of the Word and its implications for the listening subject.

The Annunciation is of course the prelude to the Word made flesh: the stage of pregnancy before it is manifest bodily, when its statements occur in language only. For Julia Kristeva, this is an event that calls attention, in turn, to the 'gap' in language between the analytical and the poetic. Her text 'Stabat Mater' combines a study of the cult of the Virgin Mary with reflections on her own experience of maternity that fragment - or merge with - the main text. This double discourse confirms the presence of the subjective within the intellectual; it forms part of our understanding of the argument throughout.

Words that are always too/distant, too abstract for this/underground swarming of seconds, folding in unimaginable spaces. Writing/them down is an ordeal of discourse, like love. What is/loving, for a woman, the same/ thing as writing. ${ }^{48}$

This struggle to fit words to the maternal experience is the result of the kind of folding inward that Kristeva describes here; the same kind that creates private spaces in McGuckian's poems, making them resistant to interpretation. This process is also one in which the strange and the familiar meet: the intimacy that makes both love and creativity testing experiences permits these processes to be reconfigured, so that the subject is at once knowing and unknowing. Again, the hollow body redolent of McGuckian's concern with childbirth - is the empty space through which a plurality of inferences may circulate. Culturally and textually, this collection affirms that what is missing from the poems can be at the centre of their meaning. The Magnificat is the unspoken text in The Book of the Angel (2004), for example: its absence at once constitutes the system of belief that underpins the poem's linguistic structure and emphasizes its radical strangeness to the human mind.

The Book of the Angel meditates on representations of the angelic that inflect medieval and Renaissance art, linking these to contemplation of poetic purpose and cultural conflict. Here the intrusion of the divine 
into the secular world can seem both passive and active - an aesthetic representation and a dynamic mystifying force. This unifying theme also draws attention to the theatrical aspects of the poems and to the spiritual nature of the poet's creative quest, a quest that has involved the persistent excavation of personal and cultural memory. The continuing significance of religion in McGuckian's work has been acknowledged by the poet herself: 'I realised I had some kind of message to hand on and that I was in some degree a priest'. ${ }^{49}$ However, the topic of religion clearly bears uneasy relation to the circumstances of her Belfast upbringing. Borbála Faragó argues that its appearance in her poems 'cannot ... be interpreted simply within the context of her politicised surroundings, but rather as the symptom of the development of a highly personalised moral code'.50 In this collection, McGuckian uses the revelatory potential of the angel to address the connections among religion, national identity and artistic expression, as well as to effect the transcendence of historical time. The angel as a transitional figure - one that belongs neither to heaven nor to earth, and whose gender is ambiguous - could be seen as akin to the poet in mediating between spiritual and material worlds, and between different forms of experience, the kind of messenger that McGuckian has already recognized in herself. Aspects of the poet's involved style suggest that the angel might better be interpreted as of both heaven and earth, however, since throughout McGuckian's poetic career apparently separate realms have been cast together in arresting ways. In this regard, especially, the political dimension of the collection becomes clear: both sides of the Northern community are inextricably linked through the experience and performance of suffering so that neither, in a sense, can exist without the other.

Such duality is in evidence throughout the volume. 'Angel in Two Parts' draws specific attention to the role of the poem in the act of revelation: since the work itself contains two sections, the angel is not only represented within it, but in some senses 'becomes' it. There is a familiar blend here of containment and freedom, beginning with a question that casts doubt on the position of the speaking subject: 'How often, truly, have we found ourselves in that square' ( $B A 50$ ). This opening line reveals just how nuanced such an apparently straightforward question may become. The inflected 'truly' does more than question shared memory, it seems to reveal its inherent powers of collusion. By undermining the shared understanding of 'we', McGuckian implicates not only the figures within the poem but writer and reader too. In this way, she opens the traumatic past to new forms of scrutiny, examining how the 
shared bonds of suffering can be transcended by singular reflection. The holocaust may be evoked in the image of the train reaching the 'end of beaten track / end of final roofs'; man-made civilization yields to nature, though even nature is damaged and distorted. This apocalyptic vision is attended by an angel: 'The last angel / sings the words, at first so dazzlingly severe' ( $B A$ 50). Here, as elsewhere in McGuckian's work, language bears witness to its own intensity: when Wittgenstein dwells on the language of meaning (as opposed to the mere rehearsal or repetition of words) he invites people to sing their sentences, since this is how the sign can be made 'alive'.51 In this poem the angel achieves both intensity and a transcendent lightness in a context that suggests cultural trauma. The first part of the poem renders the continuous present and the single instant of experience. By questioning the truth of specific memory, McGuckian dismisses the possibility of a logically formed sequence of meanings in favour of impressionistic, repeatable moments of being: 'It was here, more than anywhere, / that we met, the sky unfeathered and burned, / as if a valley were pounded into it' (BA 50). The second half of the poem dwells on time itself: calendar time is telescoped so that it can be experienced in multiple ways: 'Even though it has time, still, / / the mountain above the door is weatherless, / supplying time for time' ( $B A$ 5I). The last phrase suggests that time itself is what facilitates the temporal in being absorbed or understood, seeming to support the symbiotic relationship between past and present that the process of memory itself may suggest. ${ }^{52}$ This is an idea that raises particularly interesting questions concerning the relationship between the act of reading and the passage of time, since McGuckian's work renders the temporal both outside the realm of her consideration (she refuses to adhere to its rules) and at the centre of an endless process of interpretation within which no closure can be reached. 'Supplying time for time' also suggests a sleight of hand, by which one appreciation of time is replaced by another, without our frame of understanding ('the door') being disturbed. There are ambiguities of punctuation in this final stanza too: the hyphenation of the 'angel- / boatman' turned 'angel- / doorkeeper' stresses the angelic as a qualifying characteristic, yet elsewhere it seems an essential of identity, especially since the word 'angel' concludes two consecutive lines. Charon and St Peter merge, allowing the final threshold to be both structured (the door) and unstructured (the river).

If the metaphor of the Annunciation is about the power of language to create the real, to intervene between what is known and what is believed, 
then it has significance for the relationship between memory and imagination. In McGuckian's hands the metaphor probes the relationship between the visual tradition and the meanings it accumulates. The Book of the Angel has five parts, ${ }^{53}$ which may hint at the Joyful Mysteries, since the Annunciation unifies some early poems in the book with painterly detail: 'It is impossible to tell / from the brocade and feathers / of the robes, wings and hair of Gabriel / [...] / / whether he has already spoken' ('A Chrisom Child', $B A$ 30). In this sense, McGuckian seems to take account of 'what great art leaves out', choosing to move beyond the generic expectations of each art form to ask awkward questions about its purpose and meaning. Certainly, the overlapping of verbal and visual expression disturbs our codes of reading, as in 'Studies for a Running Angel', which opens Part 2 of this collection:

She prolongs with words the growing fields

and, to make draperies, skies and clouds

on the larger arched surface,

or knots of gold cord on the ceiling

$(B A 28)$

Here realistic representation and decorative elements fill a structured space, much as the poems themselves combine moments of emotional directness within a richly imaginative terrain. Increasingly, the importance of painting introduces a stillness at the core of many of these works, an instant of perfect repose around which the dynamic of the poem moves. The idea of the Annunciation itself demonstrates that death is an important driving force from the beginning - the seeds of Christ's suffering lying within the announcement of his imminent birth.

One does not give birth in pain, one gives birth to pain: the child represents it and henceforth it settles in, it is continuous [...] a mother is always branded by pain, she yields to it. 'And a sword will pierce your own soul too ...'54

McGuckian herself has admitted: 'Death is always a crux around which I write [...] Death is what poets are supposed to define, not deal with death or even understand or to cope with it, and not give answers but just meditate ....'55 There is an interesting paradox here between the apparent fixedness of death itself and the flexibility of McGuckian's writing, the endless renewal that attends her poetic process. Hers is not a monumental art but one that is continually transformed as new versions of familiar tropes and images are inscribed in the texts. In this way her work is both familiar and strange, her recognizable style always challenging interpretation. Within a poetic scheme that seems to 
resist fixity, there exists an imaginative endurance that has a significant impact on McGuckian's development. Towards the end of The Book of the Angel we find poems that stand firm against dissolution, enacting an alternative kind of memorialization. 'Charcoal Angel' begins with a momentous quality, a time set apart from others, 'A moonlit night a hundred years ago [...] / / Sky as hard as a wall. / Sea drowned in the sand' ( $B A$ 82). Here the most changeable of forms become fixed; water and earth exchange properties. The ' $\mathrm{t}]$ wo knowledges' that come into conflict may be indicative of the increasing divide between West and East - two cultures and two sets of belief. Yet the phrase 'one face upon another' seems at once to suggest the combativeness of coming 'head-tohead' as well as the idea of two identities so similar that they can't be told apart. This possible binary resolves itself into a seemingly singular 'he':

\footnotetext{
Absence of pupils, but he has eyes

in his voice, that scarred voice

that seemed so near, it's by his voice,

it's in his voice that he dies.
}

$(B A 82)$

The synaesthesia so often evident in McGuckian's work emerges here: the idea that speaking is an act of observation not only alters the sensory process on the part of the experiencing subject but also for the onlooker too, who may be forced to consider whether the act of reading itself has now changed. If it is through language that we bear witness to the past, then the speech act lays vital claim to that process, yet there is an implicit suggestion here that our acts of remembrance engage all the senses. This emerging Poseidon is first and foremost a voice - it is at once the means of his continuance and the instrument by which he loses his identity. Here speech sustains feeling and understanding even as the elements blow the markers of death away. McGuckian's imagery is tricky though: further consideration reminds us that the angel is made of charcoal - a porous, organic substance, not the enduring marble that is most familiar. The inscription is in ivory, again emphasizing a material once living, so that this collection ends with these contradictions held in balance.

The underlying resistance that this poem explores suggests that strength is not to be found in stasis but in constant change, in the mutability of existence itself. In this sense the artistic process overlays the foundation of Christian imagery that McGuckian explores. She represents an altered attitude to authority in her use of intertextuality and her rejection of the idea of closure. Every poem gives into another, collections are shaped around repeating images and textual patterns, and themes are picked 
up from one volume to the next. Her radical attitude towards memory is expressed through the changing relationship between diffusion and concentration in her work. Multiple subjectivities may be temporarily accommodated in a kind of visual representation that itself expresses variety in unity. The persistent importance of art in McGuckian's work suggests that for her it represents an act of remembering as well as one of creation. Similarly, her tropes of intimacy, both maternal and sexual, are at once reinforced and transcended by the spiritual character of her later poems. In this her own career exemplifies the capacity to retain the concepts of past, present and future at the same time as she allows the distinction between them to disappear. These radical temporalities shape our reading and interpretation of her work in fundamental ways.

\section{Notes}

I Her work has also divided critics: she has been variously described as 'fluid' and 'mannered', as 'forward-looking' and 'non-visionary', as 'humorous' and 'whimsical'. In a review of Venus and the Rain, James Simmons described her work as a 'hoax' ('A Literary Legpull?', p. 27) while Patrick Williams castigated her for 'insistent womanliness - or as I find it, pseudo-womanliness' ('Spare that Tree!, p. 52).

2 María Jesús Lorenzo-Modia and Cristina Fernández-Méndez, "Longer and Longer Sentences Prove Me Wholly Female": Medbh McGuckian and Feminism(s)', in Manuela Palacios and Laura Lojo (eds), Writing Bonds: Irish and Galician Contemporary Women Poets (Berne: Peter Lang, 2009), p. 40.

3 Brian Friel approaches the same issue from a different perspective, emphasizing the capacity for language to prompt shared engagement: 'I think that the political problem of this island is going to be solved by language, not only the language of negotiation across the table, but the recognition of what language means for us on this island'. For further discussion of Friel and the Field Day project, see Elmer Kennedy-Andrews, 'The Language of Memory: Translation, Transgression, Transcendence', in Frawley, Memory Ireland, vol. 3, pp. 247-7I.

4 Shane Murphy, 'Sonnets, Centos and Long Lines: Muldoon, Paulin, McGuckian and Carson', in Matthew Campbell (ed.), The Cambridge Companion to Contemporary Irish Poetry (Cambridge: Cambridge University Press, 2003), p. 200.

5 Eric Falci, Continuity and Change in Irish Poetry, 1966-2010 (Cambridge: Cambridge University Press, 20I2), p. 9I.

6 Faragó's study explores the role of creativity and performativity throughout McGuckian's poetic career. She does this by dividing the work into four broad chronological groups, emphasizing both continuity and evolution in the poet's career. See Borbála Faragó, Medbh McGuckian (Lewisburg, PA: Bucknell University Press; Cork: Cork University Press, 20I4).

7 Nuala Archer, 'Nuala Archer on Blue Farm', Two Women, Two Shores: Poems by Medbh McGuckian and Nuala Archer (Baltimore, MD: New Poets Series; Galway: Salmon Press, 1989). 
8 Shane Murphy is the foremost critic to examine Medbh McGuckian's intertextual strategies. See, in particular, Shane Murphy, 'Intertextual Relations in the Poetry of Medbh McGuckian', in Patricia A. Lynch, Joachim Fischer and Brian Coates (eds), Back to the Present, Forward to the Past: Irish Writing and History Since 1798, vol. 2 (Amsterdam: Rodopi, 2006), pp. 27I-85; Shane Murphy, 'Roaming Root of Multiple Meanings: Intertextual Relations in Medbh McGuckian's Poetry', Metre 4 (Winter 1998), pp. 99-I09; also Shannon Hipp, “Things of the Same Kind are Separated Only by Time": Reading the Notebooks of Medbh McGuckian', Irish University Review 39.I (Spring/Summer 2009), pp. 130-48.

9 Shane Murphy, 'Obliquity in the Poetry of Paul Muldoon and Medbh McGuckian', Eire-Ireland: A Journal of Irish Studies 31.3-4 (Fall/Winter 1996), p. 85.

Io Quoted in Shane Murphy, "You Took Away My Biography": The Poetry of Medbh McGuckian', Irish University Review 28:I (Spring/Summer 1998), p. I2I.

II Murphy, 'Obliquity in the Poetry of Paul Muldoon and Medbh McGuckian', p. 86.

I2 Deryn Rees-Jones, 'Motherlands and Mothertongues: Writing the Poetry of Nation', Consorting with Angels: Essays on Modern Women Poets (Newcastle upon Tyne: Bloodaxe Books, 2005), p. 177.

I3 Medbh McGuckian, 'Mazurka', On Ballycastle Beach (Oxford: Oxford University Press, 1988), p. 22.

I4 Assmann and Shortt, Memory and Political Change, p. 5.

Is Leontia Flynn, Reading Medbh McGuckian (Dublin: Irish Academic Press, 20I4), p. $2 \mathrm{I}$.

I6 Ibid., 30.

I7 Moynagh Sullivan, 'Dreamin' My Dreams With You: Medbh McGuckian and the Theatre of Dreams', Metre 17 (Spring 2005), p. Io6.

I8 Dutch interiors flourished during the seventeenth century when there was a transition from aristocratic and religious patronage towards the middle-class or merchant buyer. The demand for domestic themes in art not only meant the introduction of more accessible images but the transformation of real-world scenes into richly metaphorical texts. See Mariët Westermann, A Worldly Art: The Dutch Republic 1585-I7I8 (New Haven, CT: Yale University Press, 2007).

I9 Works by Jean-Baptiste-Simeon Chardin (1699-1779) feature in a number of poems by Boland, including, 'From the Painting Back from Market by Chardin' and 'Self-Portrait on a Summer Evening' (NCP I7; J I2-I3).

20 Clair Wills, 'Voices from the Nursery: Medbh McGuckian's Plantation', in Michael Kenneally (ed.), Poetry in Contemporary Irish Literature (Gerrards Cross: Colin Smythe, 1995), p. 382.

2I Sarah Broom, 'McGuckian's Conversations with Rilke in Marconi's Cottage', Irish University Review 28.I (Spring/Summer 1998), p. 44.

22 Laura O'Connor, 'Combrá: Conversation between Medbh McGuckian and Nuala Ní Dhomhnaill, Southern Review 28.I (1995), p. 590.

23 Catriona Clutterbuck, 'A Gibbous Voice: The Poetics of Subjectivity in the Early Poetry of Medbh McGuckian', in Shane Alcobia-Murphy and Richard Kirkland (eds), The Poetry of Medbh McGuckian: The Interior of Words (Cork: Cork University Press, 20IO), pp. 4I-67.

24 Kathleen McCracken, 'An Attitude of Compassion: Q \& A with Medbh McGuckian', Irish Literary Supplement 9.2 (Fall 1990), p. 2I. 
25 Lorenzo-Modia and Fernández-Méndez, “'Longer and Longer Sentences”, p. 37.

26 McGuckian, in Sommerville-Arjat and Wilson, Sleeping with Monsters, p. 2.

27 Erll and Nünning, Cultural Memory Studies, p. 99.

28 McGuckian, in Sommerville-Arjat and Wilson, Sleeping with Monsters, p. 2.

29 Flynn, Reading Medbh McGuckian, p. I46. Flynn notes McGuckian's engagement with Russian writers as evidence of her prior political engagement. Renate Lachmann also examines stylistic elements of Russian writing that are relevant to McGuckian's practice: 'One can ... note a metonymic tendency in authors such as Pushkin, Akhmatova, and Mandelstam, primarily in their use of anagrams, syllepses, quotations, hidden allusions, rejoinders, and repetitions, and in their surpassing of other texts as well as their attempt to identify or to merge the time of their pre-texts with the time of their own texts'. Lachmann, in Erll and Nünning, Cultural Memory Studies, p. 306.

30 Seamus Heaney, 'The Poet Who Came Back', Belfast Telegraph, November 23, I97I.

3I Thomas Docherty, 'Initiations, Tempers, Seductions: Postmodern McGuckian', in Neil Corcoran (ed.), The Chosen Ground: Essays on the Contemporary Poetry of Northern Ireland (Brigend: Seren, 1992), p. 192.

32 Murphy, "You Took Away My Biography", p. II2.

33 Falci, Continuity and Change in Irish Poetry, pp. 90-I. With reference to 'Harem Trousers' from On Ballycastle Beach, Falci specifically refutes Elmer Andrews' contention that McGuckian seeks 'to eliminate the "I" altogether, to escape from a rational, unified self ('Some Sweet Disorder', p. I40).

34 Lorenzo-Modia and Fernández-Méndez, "'Longer and Longer Sentences”, p. 39.

35 Helen Blakeman, "I am listening in black and white to what speaks to me in blue": Medbh McGuckian, interviewed by Helen Blakeman', Irish Studies Review II.I (2003), p. 6I.

36 Falci, Continuity and Change in Irish Poetry, p. Ioo.

37 Faragó, Medbh McGuckian, p. 8I.

38 Falci, Continuity and Change in Irish Poetry, p. Io3.

39 Batten, 'Boland, McGuckian, Ní Chuilleanáin and the Body of the Nation', p. I82.

40 In referencing Louis MacNeice's 'Snow' the poem reminds us that it too is 'soundlessly collateral and incompatible'. Louis MacNeice, Collected Poems (London: Faber \& Faber, 2002), p. 30.

4I The relationship between burial and inscription would become more vexed in the case of Robert Emmet, executed following the later rebellion of 1803 . His famous - and contentious - speech from the dock sees the executed rebel as a figure impossible to consign to the past: 'Let them and me repose in obscurity and peace, and my tomb remain uninscribed, until other times, and other men, can do justice to my character; when my country takes her place among the nations of the earth, then, and not till then, let my epitaph be written.' See Marianne Elliott, Robert Emmet: The Making of a Legend (London: Profile Books, 2003).

42 Luke Gibbons, "Where Wolfe Tone's Statue Was Not": Joyce, Monuments and Memory', in Ian McBride (ed.), History and Memory in Modern Ireland (Cambridge: Cambridge University Press, 200I), p. I47.

43 W. B. Yeats, 'September 1913', The Collected Works of W. B. Yeats, vol. I, The Poems (London: Simon \& Schuster, 20I0), p. Io8.

44 Elena Esposito, 'Social Forgetting: A Systems-Theory Approach' in Erll and Nünning, Cultural Memory Studies, pp. I8I-90. 
45 Elaine Scarry, The Body in Pain: The Making and Unmaking of the World (New York and Oxford: Oxford University Press, 1987), p. 4.

46 Conor Carville, 'Warding off an Epitaph': Had I a Thousand Lives, in AlcobiaMurphy and Kirkland, The Poetry of Medbh McGuckian, p. II8.

47 Docherty, 'Initiations, Tempers, Seductions', p. 192.

48 Julia Kristeva, 'Stabat Mater', in Toril Moi (ed.), The Kristeva Reader (London: Blackwell, 1986), p. I62.

49 Laura O'Connor, 'Combrá', p. 596.

50 Borbála Faragó, 'Medbh McGuckian: The Angel in Two Parts', European English Messenger 13.2 (Autumn 2004), p. 47

5I Joachim Schulte, “'The Life of the Sign”: Wittgenstein on Reading a Poem', in John Gibson and Wolfgang Huemer (eds), The Literary Wittgenstein (London: Routledge, 2004), p. 152.

52 Jeffrey K. Olick explores the suggestion that what is remembered is determined by present need. The Politics of Regret: On Collective Memory and Historical Responsibility (London: Routledge, 2007).

53 It also mirrors the structure of Shelmalier, inviting parallels between political and religious beliefs.

54 Kristeva, 'Stabat Mater', p. 167.

55 Blakeman, "“I am listening in black and white", p. 63. 


\section{Catherine Walsh}

\section{A Poetics of Flux}

Throughout Catherine Walsh's work, innovations of form challenge the stability of temporal perspectives and subjective positions. Though this is a familiar dynamic in contemporary avant-garde poetry, the stylistic experimentation that Walsh practises grows directly from her particular enquiry into the nature of being, and the limits of human understanding. What Michael Begnal has described as the 'scientific' character of Walsh's work, is borne out by the absence of a clearly located self in the work, a strategy which, together with constant shifts in vocabulary and tone, problematizes the role of the singular speaker in this environment and further indicates the impossibility of such stability in any context. ${ }^{1}$ This radical reconfiguration of subjectivity has implications for how the past may be understood and represented in poetry. By altering the formal and linguistic structures of the poem, Walsh challenges the linearity of thought, redefining how past and present operate in the reading mind. Yet this strategy does not merely reprise larger assumptions concerning forms of postmodern identity, instead the tension between lived experience and existential questioning pulls the normal registers of language apart, giving rise to particular complexities of rhythm and tone. These innovations of form and technique fundamentally alter the relationship between past and present in the work, eliding the boundaries between them in more radical ways than other texts. For Walsh, this adjusted temporality has an impact too on how space is conceived, so that cultural as well as poetic spaces must be seen from new perspectives. This has important implications for the ways in which cultural memory is shaped by political and linguistic environments:

Personal memories are purely virtual until they are couched in words or images in order to be communicated. Collective memories are produced 
through mediated representations of the past that involve selecting, rearranging, re-describing and simplifying, as well as the deliberate, but also perhaps unintentional, inclusion and exclusion of information. ${ }^{2}$

The dismantling of subjectivity, and the formal and linguistic impact of this, is an important preoccupation of contemporary poetry, as the exploration of Medbh McGuckian's work has demonstrated. The problems of unitary subjectivity are not always expressed in formally innovative ways, however; widely read poets, such as Eavan Boland and Paula Meehan, use a range of strategies to challenge assumptions of coherent identity and to problematize the relationship between public and private selves in the poetry. Indeed, Clair Wills has argued persuasively against the distinction between so-called 'mainstream' and 'experimental' poetries:

it is not that 'expressive' poetry naively falls back on a stable individuality, and experimental work explores the radical absence of subjectivity. Both are responses to the reconfiguring of the relationship between public and private spheres which makes the 'private' lyric impossible, and in effect opens it out towards rhetoric. ${ }^{3}$

Others, most notably Marjorie Perloff, have attributed the impossibility of the private lyric to the pre-eminence of electronic media in contemporary life, ${ }^{4}$ and this complex refashioning of the creative self as a mediated entity has ramifications on both linguistic and ethical levels. In particular, it challenges the relationship between the singular subject and creative and critical processes. Immanuel Kant's notion that the ground of the subject is the ground of thought itself is relevant in this regard, since any process of thought, including the questioning of subjectivity, may be interpreted as emerging from the single consciousness. Henri Lefebvre expresses the idea in these terms:

Kantian space, albeit relative, albeit a tool of knowledge, a means of classifying phenomena, was yet quite clearly separated (along with time) from the empirical sphere: it belonged to the a priori realm of consciousness (i.e. of the subject), and partook of that realm's internal, ideal - and hence transcendental and essentially ungraspable - structure. ${ }^{5}$

If subjectivity is called into being by that which is outside the subject, however, then the relational elements come to the fore, and the links between singular and collective identity demand further investigation. ${ }^{6}$ This issue has a particular resonance for women poets, for whom the dynamics of private and public identity are always in play. Many politically engaged readers and practitioners are concerned about the 
implications of innovative poetry's elision of clear subject positions, fearing the abandonment of gender and class debates. Caroline Bergvall, herself an experimental poet, argues that feminist literary criticism distrusts innovative writing, and continues to privilege issues of representation over questions of radical technique: 'Can female poets in fact afford to dispense with identity-seeking when positive female identification is still culturally and politically so vulnerable?'7 In spite of these suspicions, however, textual experimentation continues to produce new spaces in which radical political engagement can take place - spaces with both a creative and a critical function. ${ }^{8}$ For Catherine Walsh, the dispersed perspectives that fragmented form make available are vital to the interrogation of singular and the collective states. They allow the poet to problematize personal experience and to unsettle the notion of linear thought processes as the necessary pathway to knowledge. Eric Falci argues, however, that although Walsh rejects 'lyric's varieties of formal closure and coherence', she adopts instead a page-based lyric practice. 9 The challenges mounted to formal categorization by both poetic and critical modes problematize the relationship between memory and knowing, not by breaking the rules of temporal order as much as by positing different interpretations of what those rules might be.

In this respect, the mode of publication is a significant dimension of the work, shaping not only the dissemination of the poetry but determining how specific strategies of reading are developed. Doreen Massey's work on spatial representation explores the links between it and temporal frameworks:

Representation is seen to take on aspects of spatialisation in the latter's action of setting things down side by side; of laying them out as a discrete simultaneity. But representation is also in this argument understood as fixing things, taking the time out of them. The equation of spatialisation with the production of 'space' thus lends to space not only the character of a discrete multiplicity but also the characteristic of stasis. ${ }^{10}$

Yet for some Irish poets the space of textual experimentation does not dispense with time as an influential dimension of the reading practice. Maurice Scully's extraordinary 25-year project, Things That Happen (I98I-2006), suggests new temporal and spatial possibilities for the poet, ones that Catherine Walsh has also tested, though in less extensive ways. These approaches not only indicate the continuous nature of the poetic process, and its potential for non-linear articulation, but suggest the importance of simultaneity too - the idea that meaning is in a single instant here and elsewhere, each manifestation informing the other in 
unique ways. The scope of Scully's work, in terms of both intellectual ambition and material reproduction, is remarkable. It challenges the concentration of the reader at the level of the volume and of the single page, where fragmentary syntax and the absence of formal boundaries, together with the appearance of symbols or sketched images force us into new territories of reading.

The rejection of linear thought in poetry is not a recent phenomenon, but for many contemporary poets working with print media the deployment of visual strategies to signify states of rupture and fragmentation has become a means of testing the possibilities of language. For some, formal disturbance may be scarcely visible on the surface of the poem; for others, such as Susan Howe or Paula Claire, radical typographical strategies make the poem a site of immediate intellectual challenge. ${ }^{11}$ This differentiation at the level of production and design has tended to separate experimental work from the mainstream, making comparative modes difficult to achieve, and creating critical challenges in describing and quoting from the material. The size of the page and the type of printing become important considerations in the act of reading, and they may create an unnatural boundary to the formation of meaning. At times it is difficult to determine whether there is continuity between one page or opening and the next - for Catherine Walsh, the single page often appears to be the unit of meaning. Eric Falci has identified two sorts of pages that Walsh produces: dense ones and sparse ones. The dense ones he characterizes as including 'partial or fractured narratives and [...] longer continuous (if not always coherent) blocks of text'. The sparse pages 'feature more white space, and they often consist of much smaller syntactical units; words and phrases hang apart on the page, as though they repulse each other's pull'.12 These differences enrich the reading experience and increase the complexity of the process. The nature of this challenge is registered on many different levels, from a first encounter (where do we begin the act of reading?) to an attempt at sustained criticism (is it possible to capture and embed aspects of this text in any recognizable form of critical discourse?). In this way, innovative poetry not only tests the boundaries of poetic language, but of the language of personal self-reflection and of academic criticism too. It presents an experience of radical estrangement to the reader, one that reflects the impact of existential questioning on the textual encounter. In doing so, it also disturbs cumulative notions of reading, according to which we expect a puzzling impression to come before, but never after, our close engagement with the text of the poem. Yet 
experimental poetries encourage the coexistence of these states - of the past and present of reading - so that the contingent nature of meaning, and the text's capacity to surprise, can be preserved. These provisional acts of engagement inflect both the representation and the experience of subjectivity for poet and for reader

\section{'Making Tents': A Dislike of Beginnings and Endings}

'Making Tents', a gathering of four poems first published in 1987, deploys some of the features that Walsh will later develop in her extended manipulation of poetic time and space. ${ }^{13}$ John Goodby offers as its contexts 'those of migrancy and the necessary provisionality of the attempt to make the self at home in the world and in language'.14 Its short opening poem, 'Nearly Nowhere', plays with the slang phrase 'half-past hangin' time, time to go rob' in ways that draw attention to the unnatural transition between speech and writing. Using the solidus, or forward slash, typical of the line-break mark, Walsh deliberately interferes with the transparency of the voice on the page, emphasizing the visual denotation of rhythm and disrupting the flow of the street-speak that emerges in her longer poems. The lines that follow - 'Encapsulate it / and escape it' - demonstrate the role of language in the push-pull of poetic engagement here. The creative power to render a scene can constitute a barrier to it, a form of separation that alters the temporal relationship between the poet and their material. The word 'Timeless' constitutes at once the shortest and the most eye-catching line of the poem, reminding us that the paring back of language can also be a way of releasing it from too rooted a temporal context. The two longer poems in 'Making Tents' are more evocative of their particular environments, and in turn invoke remembered scenes and experiences more fully. 'Snow for the Morning' opens with the notion of renewal and repetition: 'Same place / time / dream' (IEMT 6I), the river that first 'flows' and then 'meanders' among fields and houses. Though language renders landscape clearly - if not conventionally - here, the ten lines on the next page are bracketed, suggesting new permutations of continuous reading. These lines alternate between single words - 'Centred', 'Weightless', 'Happening' - and short phrases. The changing environment that is suggested here in the conjunction of 'new place / / Happening' is first hinted at in 'A vacancy / fulfilled', with its play of meaning between needs met and a sense of emptiness reinforced. This insertion of an extra syllable into one word of a phrase in order to alter its meaning in subtle ways will be familiar 
to readers of Walsh's work. As well as permitting the coexistence of different meanings, it draws attention to the preconceptions that language generates in the mind of the reader.

Already, then, the relationship between past and present is uncertain and made more so by intense patterns of repetition within certain sections of this poem: 'I needn't think / of needing not to think / not thinking I need you / needing [...]' (IEMT 63). The interdependent relationship between thinking and needing is foregrounded here, and the extent to which emotional states are mediated by thought remains a subject of recurring interest in Walsh's work. It is the first of two points of human connection in the poem, the second being a recalled encounter, the meaning of which remains ambiguous:

It

was her touch, almost

no more

a way

fondness

greeting

it seemed to me

(IEMT 65)

Here the fragmentation of language works to destabilize the speaker's own conviction concerning the events represented. She admits 'presumption', however, suggesting an interpretation had been arrived at, but was later reconsidered. Attention turns back to the landscape, before swerving again to the human predicament - an acknowledged 'dislike of beginnings / and endings' and a preference for 'song / a continuum / we carry' (IEMT 67). The mingling of sensory environment and human experience in this poem, and the deliberate obfuscation of ideas of sequence, or of cause and effect, will become an important dimension of Walsh's developing art, making the concept and operation of memory in these poems endlessly complex. The extent to which language remakes the past emerges strongly at the end of the poem:

repeat the changes change the repeats the change repeats the repeat changes change it repeat change it

(IEMT 7I)

Wrapped into these lines is the ambiguity of repeating change - at once impossible, since change is a point of differentiation with what 
came before, and (in Derridean terms) appropriate, since repetition in difference could be seen as a function of language

'Return Ticket', the other long poem from 'Making Tents', begins the oscillation between different cultural spaces that will be a central trope of Idir Eatortha. The opening phrase - 'Where do you want to go?' - suggests the potential of this mobility, though the title has hinted at the inevitability, or perhaps the necessary pretence, of return. The list of places - 'Dan's yard / The mill field / The bog ...' - confirms secure identity, 'everything / still / in the same place' (IEMT 76), but the poem moves towards strangeness. The environment changes: extremes of sun and shade give way to text from a language teaching manual and then to drifts of conversation 'snatched and strange' coming up the ventilation shaft. Differentiation in language increases as the poem progresses, as it remakes Virginia Woolf's 'take two coos, Taffy' to render its variant possibilities, first with logic (considering first cows and then wood pigeons), then in sound: ' $\mathrm{ka} \mathrm{cu}$ coo / khaki kacu' (80). ${ }^{15}$ Yet in spite of the increased intertextuality of the work, it projects a listening subject, though this may be the speaker herself. It speculates 'how much / more uncomfortable / you must have been' (79), permitting the later 'imagine me appreciating the metro' to function both as interjection and creative invitation. The strange consonance of commodity and tradition reflects the power of the mind to move across texts and experiences, reworking both in language: the speaker, lying in the bath, listens to sounds of human speech and of nature; recalling literary texts and reading cosmetic ones ('you scrub your face with it / it removes I, perhaps 2 layers / of skin'); thinking of the process of churning butter. Some reflection on this multitude of impressions is finally offered:

noting many things frequently what

I hear is not anachronistic but

diplomatically sound

(IEMT 82)

\section{Returning Memories in 'Idir Eatortha'}

'Idir Eatortha', appearing before 'Making Tents' in the combined volume, but in fact written after it, intensifies Walsh's treatment of the spaces between - Spain and Ireland, rural and urban, past and present. As Falci puts it: "These lyric pages attempt to capture the singularities of experience, as well as the different modalities of flux that emerge when 
this manner of poetic capture is inevitably also one of mutation.'16 Its opening words echo those of 'Snow' - 'the same / / sky / / close your eyes'. The moment between sleep and waking, or between the act of visualizing one's environment and being in one's own mind, is an important one for Walsh, as a moment when observed reality merges with recollected experiences and with the play of language. This poem begins with a feeling of motion, as befits the title of the sequence and its use of Irish. The rhythm of 'riding home / riding back' is intensified in the image of 'rotating feet / on pedals around / tracks', its tightening sense of circular movement seeming to entrap. Here space and time are implicitly connected; to go back is to move through space but also to revisit past experiences, reinforcing existing memories rather than creating new ones. Yet the mood of this section is an expansive one; the speaker observes the moon's corona in 'the $\mathrm{V}$ of bottlenecked blackened treetops' while further away lies the 'fumed blue / city line' (IEMT 7). These two different forms of light, yellow and blue, converge as the longest line on this page slips to the shortest, creating an awareness of space and distance here. The night environment is also redolent with drunkenness, the drifting lines and closing eyes creating a sense of half-conscious observation and disorientation. Read in another way, the 'yellow' moon, 'cold tap', 'corona' and 'bottlenecked' are suggestive of a beer popular in the 1990s - an overlap between landscape and material culture which invites us to think about the dynamics of the permanent and the disposable, and the different attitudes towards time these invoke.

The vividness of Walsh's language draws the reader into the midst of the experience, but the final line of the page positions this as a memory, and of questionable accuracy at that: 'but / wasn't that somewhere else?' $(I E M T$ 7). A journey is recalled, apparently in two voices, showing divergent versions of experience: the weather, the bumps and the fact there are 'no coffee houses along this cateyed road' (IEMT 7). Yet again, it is difficult to discern whether the experiencing subject here is singular or multiple. The environment represented changes constantly, and with it the texture and presentation of the language. The poem 'that was the day' attempts to locate the memory in time, but a gale blows words about and the speaker struggles to keep her 'momentum' (IEMT 8). This disturbance can be seen as part of a larger pattern of movement across the globe, so that the puzzling phrase 'nothing / the same / nothing / changed' demands that we broaden our perspective: if we are in turmoil, someone else is in stillness. Alongside these reflections are also questions, implicit and explicit, for which there are responses, 
of a sort, in the continuous present: 'knowing' and 'writing'. But these purposeful processes become less sure with the repetition of 'missing' and the prospect of 'sailing / an upside down canoe' (IEMT II). There is a tension for the speaker - and perhaps for Walsh herself - between the explicable action and the crazy plan, so that the creation of poetry itself can seem a reckless voyage on an upturned boat, one that occupies past and present, and presumably future, for the poet herself. Qualified description becomes important here as adverbs float to the right of the phrases they qualify - a technique that will proliferate in Walsh's later work as she riffs on particular parts of speech. Darkness and light, indicative of confusion and inspiration as well as of the passage of time, have coexisted from the beginning of this sequence, and here they begin to alternate, creating fluctuating emotions as they do so. These fluctuations are best expressed here in a multidirectional text created to facilitate different permutations of reading and to reflect on the interrelationship between varying emotional states:

hope

satisfaction satisfaction

$$
\text { of }
$$

hope

\section{(IEMT I2)}

The temporal play inherent in the projection into the future of a state that relies for its meaning on past need is significant here. All of Walsh's work oscillates between the possibilities created by language and the emotions that result from these possibilities and the actions or experiences that ensue.

The discrepancy between the potential and the actual becomes greater at this point in the poem as the act of screaming and a 'percussive NO!' finds the centre of the page. The square brackets and added forward slash marks suggest a stagnation and self-division also expressed in language: '[one step on 2 / back / what I've been saying for / / so / / long' (IEMT 13). The image of the snail with which this page ends is a negative one - 'trailing stickily [...] home on back' (IEMT I3) but gives way to a freer movement of text on the following page, where the distant rhymes of '[singing] ... Ringing / all over sky / blue' offers a welcome moment of release before the crowded space that follows where 'anonymity teems / [...] / variety / screams / exert ion' (IEMT I5). Once again human and non-human worlds overlap; the flattened furrow and (as yet) unproductive seed suggestive of creative opportunity lying fallow. The 'supposéd silence' soon introduced draws greater attention to the spaces in the text, and to the gaps between past and present in Walsh's 
creative practice. Repeated silence, dwelt on here, could be a condition of reflection or a kind of creative death, and the facing blank page starkly demonstrates the anxiety of continuance and thus, implicitly, the importance of memory in supporting thought and language. Yet continue the poem does, moving into territory more immediate - the 'partially vetoed' motorway, mediated images, the 'sadness' and 'disgust' that grow from lack of consensus and a failure of democratic process. In a betrayal of implicit hope and effort, apparent possibilities offer nothing: the optimistic 'there you are you see you can reach the top from here' is grimly reconfigured within a mere quarter of a page as

there you are there's not much you can do from here bar visit the sights windowless

not given to demonstrations of well anything

another in the long lore of traffic triteness

(IEMT i9)

The previous 'you see you can' is reprised in the windowless sightseeing that proves to be the only activity on offer. 'Demonstrations', whether instructive or revolutionary, are unlikely, and the subject is at once too old and too young to make use or sense of this dynamic. A generational split is accentuated by rapid social change. Those in the middle ground, who can neither avoid nor make the most of the transformation, are in a position of difficult witness. "[D]o they only reach out to kill each other?' (IEMT 20) is a dystopian view of an atomized and endlessly competitive society in which the innocent granting of wishes has no part. Yet understanding must still be sought, and the sea - its waves both buoyant and deathly - may offer it. But, in the nets of meaning, joy jumps 'back out the holes', implying that the emotion is integral to the sea's organic ever-changing nature and cannot be captured or limited by structure. This passage sheds implicit light on Walsh's poetic practice, revealing as it does the necessity for linguistic flux and all-encompassing, variable forms so that both intellectual and emotional challenges can be addressed. As in Medbh McGuckian's work, the past is enfolded in the present here, but for Walsh this is more than a sense of inclusive subjectivity: it is an essential breaking of temporal and subjective boundaries that can only be achieved through destabilizing syntactic clarity using fragmentation, repetition and unheralded shifts in style and register. At 
this stage in the text, Walsh directly challenges the reader's expectations of art: 'wonder' is linked to the 'endless strata of/conceptual errors' (IEMT 22). From the sea, we are thrown skyward and forced to consider the origins of matter, the relationship between 'intense light' and 'dark matter', the creation of energy. Temporality suddenly becomes a much more problematic category - a human construction designed to make sense of the void. This realization affirms the meaning-making capacity of memory at the same time as it suggests its relative insignificance. In both explicit and implicit ways, Walsh's work invites us to consider the construction of human meaning in this larger context.

Nature, its patterns and processes, offers ways of engaging with these questions that permit issues of human perception careful consideration. Just as the poem began with the light of the moon behind trees, dominating the distant city horizon, so the idea of repose in nature (and of the drawing together of the natural and the man-made) remains a possibility at this stage in the poetic process. Moss offers a mental 'resting place': birds return and leaves block the sink overflow. But there are alternative resting places: 'clear / nights across car / park lights waiting / for joy / / riders' (IEMT 25). 'Joy' acquires new meaning here with the postponed addition of 'riders' and the poem veers back to the bleak urban setting of '[smoggy haze / [roads circling the city' (IEMT 26), square brackets suggesting at once their presence within, and their separation from, the reader's imaginative range. The words 'foreclosure' and 'improvident' suggest the financial strain of Ireland's now growing economy:

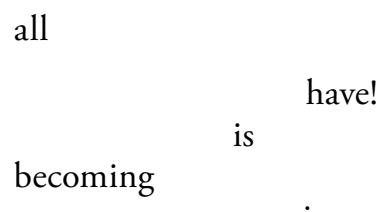

$$
\text { going }
$$

(IEMT 28)

This creates a progressive disjunction between ownership as self-defining ('have! is becoming') and as fleeting ('have! is going'). What is more interesting to Walsh, though, are the liminal states - 'each nebulous atom inbetween' - that permit vivid yet various forms of perception from nature to the Barcelona streetscape, which is rendered in a condensed section beginning with 'pigeons the ledge opposite scritching round the roof', moving into a description of pavement and grassy areas, the smell of markets, 'every zippy tripper / mooch by through barrios advancing 
streets return in / on themselves alien I all Gaudi centres been bought into / at specified times [...]' (IEMT 3I). The crowdedness of the scene lends a sensory immediacy and is one of several passages in the last third of the poem that present a continuous scene to the reader. The most arresting is an extended treatment of illness (the occluded subjectivity here makes it hard to determine whether it is the ill woman or her carer who is the experiencing self in the poem, though again the complex variety of language suggests that experience is mediated). Memory plays an important role in several ways; first, because of the visceral recollection of feelings of nausea; secondly, because of the woman's memory of a dairy in Meath: 'or that smell emerging remembrance / game hanging in the dairy / unwittingly walking into stench' (IEMT 34). The Irish context continues on the next page in the reference to 'Back Lane', its proximity to Guinness's brewery confirmed by 'malt high on the air' (IEMT 35). This carries echoes of Thomas Kinsella, whose poem 'Back Lane' specifically addresses the failure of civic responsibility in Dublin, and whose work set in the area around Thomas Street and Wood Quay renders the immediacy of experience in the context of Dublin's social and economic history. Kinsella's representation of the margins of city life and its relation to the wider environs may be naturally triggered by the urban woman's memory of the farm in Meath, as well as by the representation of the suffering body: another recurring theme in Kinsella's work. The 'currents of unease' that Walsh catches here hint at the deprivation in the area: the instability of the environment recalling the instability of memory itself.

The next riff relates to the act of translation, toying with the exact choice of adjective and preposition, but, surprisingly, though the context has moved between Ireland and Iberia, here the language shift is implicitly between Irish and English. The first ambiguity is between 'grey' and 'green' - both 'glas' in Irish, and a linguistic overlap that recall's Eiléan Ní Chuilleanáin's 'Gloss / Clós / Glas'; then Walsh plays with 'of' and 'off' and the possibilities of 'off of'. The attempts to identify particular grammatical functions - whether 'if I had' signals the conditional or a dependent clause hints again at language teaching, but now the action is of manual labour: '[scraping of shovel on concrete] ... [clattering of spade, brush on wooden cart]' (IEMT 37). Here the environment contemplated in the text (the grey grainy pavement) becomes manifest in the auditory effects of the poem, and its rough texture fits the scene of tough physical work. Immediately, language and sound begin to synchronize, so that the rhythm of brushing determines the words: "'grainy, grainy 
green, greyey green, just green"' (IEMT 37). From rhythmic language, meaning begins to emerge as sentences are formed and a tone set. These pages affirm the extent to which significance develops from the play of language, rather than language being manipulated to express meaning. Here a response to the failure of language - the act of throwing the spade and brush onto the wooden cart and trundling it off - is what in fact creates new linguistic possibilities and deeper questions.

A human interaction offers more layers to the accumulation of meaning here. Casual racism intrudes as the passers-by, presumably English, pass judgement on the labourer: " I don't know George, drunk" / "this time of the morning, dear? don't know" / "well, Irish, Scottish perhaps" (IEMT 39). The dismissive response diverts into a meditation on space, with its "ah well, and up yours to with a, stop there. stop right there. / / here. here, there, any place. space. stop right there' (IEMT 39). As this considers how our efforts to contend with space lead us to 'box it, label it, extend / language fencing' there is a screeching of brakes and exclamations from an irate driver. We are reminded that even the most involved and abstract thinking here takes place in the world and must fight for space among the everyday activities of others, their criticism and anger. The power of language in the creation of an experiential environment is clear though. The question, 'have you ever seen snow' (IEMT 42) triggers a memory of sliding 'on teatrays', of a 'barrage of snowballs', of digging out paths and assembling basic provisions. Other memories contend for expression: next seashore and shingle occupy two separate columns of words suggesting both multiple and interwoven experiences. The evocation of a child's drawing brings us back into the moment: 'tonight windy that / summer way' (IEMT 45) - or else it was the present weather that first prompted thoughts of playing in the snow and on the beach, as well as the piece of art: 'heart trees sun / trees people trees' (IEMT 45). The movement towards abstraction may be the inevitable outcome of these memories as the speaker must find for them a larger framework. The desire 'to notice some quality of / all ways interminable / almost / redemption' (IEMT 46) could be the driving force of the poem itself - a need not to create but rather to discover meaning through the play of words. Since 'the word I tried to remember to say to you / was saraband' (IEMT 47-8), even this potential for singular meaning is lost: 'saraband' can describe several different kinds of dance as well as the music that accompanies them. The reference does return us to Spain though, and more specifically to Catalonia, it seems: 'I would fan / you if you were / / 700 years and 6/ not a separatist / 
people' (IEMT 48). Whether the difference that exists between the region and the country is 'manufactured' or inherent is a subject for debate here, as the speaking voice deploys the language of cultural politics: 'problematic', 'divisive', 'role defining', 'part of a whole socio-linguistic pattern' (IEMT 48). The poem seems to escalate towards a collision with 'shards of / glass / hairline cracks / bicycling stops' (IEMT 49), but what is smashed is language itself. The final word of the poem is 'acceptation', printed alone on a large white page - the speaker is determined 'to quit' the established sense of words for something more daring and more free. Yet this is hardly a form of closure but closer to the impulse that has governed the poem's composition from the start. The desire to challenge linear thinking must be consciously renewed, it seems, so that the fullest potential of language can be grasped

\section{Temporal Geometries: City West}

The flux that characterizes existence is realized throughout Walsh's recent poetry by means of an intensified process of philosophical questioning and formal innovation. While linguistic experimentation remains the raison d'être of Walsh's work, here it interrogates more closely the atomization of existence on the margins of urban life at the turn of the twenty-first century. In this way, form and purpose become further unified, the texture of the work exemplifying the crisis of identity and representation that gave rise to it. Thus the disrupted relationship between past and present in Walsh's City West complicates the construction of both individual and collective identities, and does so in the context of debates on Irish poetic tradition. Though the work of Irish experimental poets may indicate the influence of modernism and of the work of the Language poets of the USA, these links do not necessarily indicate a rejection of national identity. Poets such as Maurice Scully and Walsh herself use Irish material repeatedly in their work. Walsh not only includes specific references to place and to contemporary events in Ireland, but also embeds passages in the Irish language within her poems. The term 'citywest' itself denotes (among other things) a digital park on the outskirts of Dublin, and a conflation of urban and rural life - one that became common for Irish commuters during the boom years. ${ }^{17}$ This speaks of diminished humanity, now reduced to its capacity to consume, and the apparently random arrangement of words in parts of this poem suggests a telling absence of order and reflection. Yet, in spite of these links between 
experimental form and cultural context, Irish innovative poets remain more likely to be compared to their British counterparts than to their mainstream Irish peers, and innovative poetry as a category still tends to be viewed as elitist, in spite of its encounters with varieties of social experience. Harriet Tarlo, editor of the recent anthology of innovative poetry of the natural world, The Ground Aslant, has argued that radical experiment can in fact be radically democratic: since no one has the tools to interpret the work, everyone must depend on their instincts as readers, rather than on established theories. ${ }^{18}$

City West is neither a collection nor a sequence of poems, but rather a single poem that exhibits abrupt, dramatic shifts in style and register, moving between minute attention to the observed world and more abstract meditations on human understanding, and on the function of language itself. The poem is divided into three unequal parts: 'City', 'Tangency' and 'Plane'. The latter two terms are suggestive of geometrical construction - in particular of relational situations of increasing complexity - and imply a movement from two-dimensional to three-dimensional space; from the dynamics of line and curve to those of plane and globe.

The most immediate syntactical quality that strikes us about City West is its absence of personal pronouns; not only of the lyric 'I', but of any clearly delineated human perspectives. Though her earliest work manifests some of the characteristics of the personal lyric, the work after 'Making Tents' (1987) becomes radically indeterminate and, in the words of Alex Davis, 'shatters practical language in its rejection of a transparent or normative discourse'. ${ }^{19}$ From this point onward, Walsh's poetry clearly demonstrates the use of innovative techniques, cutting itself adrift from both the sentence and the stanza as units of meaning, and using syntax and layout to challenge our assumptions regarding the poetic line. In this respect, Walsh now exemplifies Barrett Watten's idea of poetry as a continuous reflexive encounter with language. ${ }^{20} \mathrm{~A}$ significant feature of City West is its strong emphasis - especially in the first section of the poem - on verbs, in particular on verbs in the continuous present tense. This strategy emphasizes the (sub)urban flux and sets some of the terms by which individual and collective human experience is figured in this work: subjectivity is multiple and simultaneous, and the writing subject is just a part of this field of meaning. There is a strong sense that, as Eavan Boland affirms, 'poetry makes nothing happen ... [it shows] that something else happened at the same time'21 - in other words, it draws attention to what exceeds normal human perception and record. 
Walsh's poem begins with a four-line section, rare for this work in its condensed and expressive attributes:

- the physical quality of life, that's

living and not the analysis

afterwards or the moments of

discord or premonition -

$(C W 9)$

It could be read as a warning to critics that what is valuable is the immediacy of language and not the results of analytical scrutiny. It is an impossible proposition though, since everything, once perceived, is already in the past. Unusual, too, in that innovative poetic strategies usually run counter to a conviction that there is a 'real' world, instead emphasizing the self-reflexive nature of language. From the dynamics of past and future in this short section grows the inexplicable 'discord', and with it the assumption that all living things tend towards dissonance. Temporality, it seems, will be a key to the sequence, even though this may mean the elimination of the normal co-ordinates of time. We are sensitized here to the processes of reading: we must live 'in' the language, rather than expecting the questions it generates to be resolved. Instead of reading progressively, and accumulating meaning, we must encounter each word or phrase as though it were the first. Fittingly, then, processes of linear reading are troubled from the outset of this poem: the second page presents words in two parallel streams. Almost exactly the same words occur in each case: it is the arrangement of them, and the spaces between them, that determine how we read: 'there is a clearer light / / stark boles / bark lifting / / layer of defence the curved / circumference of V's' ( $C W$ Io). The second rendition immediately reprises these phrases with some changes - the appearance of the word 'experience' and the removal of prepositions. We are alerted to the use of the verb: 'curved' becomes 'curving' to change an impression of completion to a state of continuous movement. This alteration is important in emphasizing process and simultaneity: actions are both in the present and in the past, and the 'physical quality' of language is further affirmed. We become aware too, that each one of the sections of this book could be similarly reprised, with new slants on meaning becoming visible with the change. It is in this way that the dynamics of tangency may be seen to shape the sequence as a whole, and in this respect the absence of prepositions here, and elsewhere in the poem, is noteworthy. It interferes with our sense of how the parts of the poem relate to one another - at the level both of individual words and of longer sections. Implicitly, this removal fits 
our sense of Walsh's work as occurring on the margins of the urban, not in a place of historical and cultural density but in a transitional space, a newly created commercial environment where meaning is necessarily provisional.

The intersection of domestic and natural worlds can be detected early in this poem, and images of vegetation and growth will form some kind of pattern in the pages that follow. These images bear comparison to Paula Meehan's representations of nature in inner city Dublin, though they have a less direct relationship to the human energies of the poem. They call attention to the cycles of life, to the natural processes that mark the passage of time. Their recurrence encloses a memory of earlier iterations and confirms the presence of the past throughout this work. The spreading bloom is linked to the creaturely vitality of the natural world, to hunger and thirst, and later to the act of breathing ( $\left.C W_{\mathrm{I} 4}-\mathrm{I} 5\right)$. This association of nature with the act of breathing offers a faint echo of Thomas Kinsella, ${ }^{22}$ while textually it calls attention to the role of the breath in establishing the pace and thus the meaning of the poetic line, the 'long / tight' breath suggesting control, a measured - or partly withheld - exhalation. Another feature of this work is initiated here, that is, the dynamic linking of opposing verbs ('push' and 'pull') affecting the rhythmic patterns built in the poem and creating a sense of tension and release on the part of the reader. At this point, the human energies that might be linked to the specific voice, or to the operation of the speaker in the world, are displaced into the spaces of nature and the larger dynamics of the living earth. Thus we may be inclined to interpret nature itself as acquiring a distinct subjectivity here: 'a little today! / yes. for me. overdue. she says' $(C W \mathrm{I} 5)$.

By contrast with these more meditative early sections, human existence seems fraught with the dispersal of energies in multisyllabic words and awkward rhythms: 'people / conglomerating / material / items foisting on categories' ( $C W \mathrm{I} 6-\mathrm{I} 7)$. Even the emotions are implicated in a frenetic activity heightened by internal rhyme and cumulative meanings:

where?

heart

readying steadying giving taking

loving making breaking coming in going out

spending whiling listening playing

tuning tiptoeing crossing

shh sleeping

$\left(C W_{\mathrm{I} 7}\right)$

The movement here is layered with idiomatic resonances: where we 
might expect 'going' (ready-steady-go), we have 'giving' (give and take); lovemaking (with the appropriate contraction) and the idea of 'make or break'. These suggestions are more than just amusing additional layers to the text: they fundamentally question the forward momentum of our reading. There are other - more typographically daring - ways of interrupting this typical movement, but Walsh's strategies are particularly subtle, offering us almost conventional lines but forcing our reading to oscillate by inviting us to double back over words for new meaning. This act of doubling back has played an important role in how memory is constructed and understood by all the poets explored in this book. For an experimental poet, such as Walsh, it becomes essential to all processes of reading and a way of releasing meaning from the myriad observations and encounters of everyday experience.

We are immediately brought back to the neighbourhood world, though, and to the overheard voices that form such an important part of Walsh's acoustic landscape. Punctuation intervenes to create distancing effects; here, as elsewhere, square and round brackets are used singly, to open but not to close embedded phrases. It is not clear whether the overheard speech is that of a living being or the disembodied voice of a radio, but it invokes a domestic world of prams and shops that increasingly comes to infiltrate the more meditative natural spaces, and to trace the impact of commodity culture on the processes of thought and action: white plastic appears amid the rosebushes, and overhanging branches 'doom' footballs ( $C W$ I8). The importance of choosing a peripheral urban space as the environment for the poem begins to become clear: it is the point of encounter between multiple human subjectivities and the clear space that both precedes them (in temporal terms) and lies beyond them (in spatial terms). The idea of the past as an empty space radically alters our understanding of personal and cultural memory as crowded with impressions that help to shape the individual subject and the larger community. In the present, though, these impressions continue to play a significant role. The teeming emotional and intellectual energies to which these subjectivities give rise are the focus of representation here, rather than the particularized subjects themselves. In this way, we sense the force of human life without the perspective of individual motivation, and are thus remote from the affecting dynamics of the personal.

The encounter between natural and human world is figured spatially here, but is reprised with a temporal slant. A subject position briefly emerges: one capable of contrasting proximity to nature ('run thumb 
/ along smaller / spines detaching / minute leaves') $(C W$ 20) and an aggressive populated environment:

having been used to sitting a room when

mine yellow blind up reading the window filled in

canal cider parties teenaged couplings dogs nicked

cars smashing bollards chain junkies

$(C W 20)$

Some level of the self-referential can be inferred here, though the condensed language suggests that these features are all implicated in one another's existence. Likewise, an observing consciousness becomes clear for a moment, looking out at the scene, and another (or the same?) walking and cycling through the landscape, named for the first time as Islandbridge and Sandymount, suburbs of Dublin that straddle the city in almost equidistant measure - Islandbridge to the west near the Phoenix Park, Sandymount to the south east on the coast. ${ }^{23}$ This grounded approach gives way to a more philosophical mood, in keeping with the larger rhythmic patterns of the sequence: 'is it time? (what time? / (what's time?)' ( $C W$ 22-3). There is a mathematical rendering of syntax here, as though the final phrase is arrived at through the addition of the earlier two: so existential questioning is fundamentally linked to the language of everyday life. We can trace an echo of T. S. Eliot's The Waste Land (1922), a model relevant to Walsh for a number of reasons, not least because of the many voices that can be heard throughout that text. The figure of Prufrock also shadows the hesitation before action in evidence in City West, surely displacing the stated desire for the 'physical quality' of life, in favour of the need for reflection. ${ }^{24}$ But 'do I mean?' has the role of both clarifying precise meaning and questioning whether meaning can be attached to the singular subjectivity at all. Walsh suggests that it can only be constructed through the play of language over multiple forms of existence and through the shifts and changes, the fragmentation and obscurity, that arises. This is not the first of her works that can be read in this way. Of Pitch (1994), Ian Davidson writes: 'It is a fabrication, which may be made up of occasions or events, but it is not a report on those "instants". 25 The episodic nature of the work, then, does not detract from the importance of the organic whole. Language is self-consciously addressed in this passage of City West, most clearly in the 'dashing gerund' phrase, and it is not the substance of debate itself - 'should? ought one be seen to?' - but the formulaic nature of its expression in words that becomes so affected and tedious (or 'boring' 
in the words of the speaker) ( $C W$ 22). There is a realization here of the deflationary possibilities of language and the fact that the struggle towards representation may reduce, rather than increase, the importance of ideas. '[B]eing in doing' returns to the initial importance of the physical life, 'and in / doing while / duration' emphasizes temporality again $(C W$ 22). 'Being in span' encapsulates both the simultaneity of multiple subjects and the endurance of this vigorous and varied life.

Into this abstract meditation bursts the vibrant actual, and the 'atomistic method' yields for a time to 'naming linking / describing' $(C W 24)$. Both strategies contribute to the act of composition itself interruption generates both fear and anticipation, as the loss of creative momentum is balanced by the intrusion of a new energy that will in turn impel language forward. This tension between the static and the dynamic shapes the text of City West and reflects the complex relationship between the process of reflection and the world of urban modernity, which overwhelms the human subject with vivid sensory impressions and events. The constant oscillation between these two states expresses their coexistence, so, at the same time as the quiet garden is observed ('son's / buttercup garden's coming on') ( $\left.C W_{2} 28\right)$, technological devices are competing to transmit the voices and experiences clamouring to be heard:

slow repetitious advice crystal radio sets hams cavity bricks foreign insects 'phones off hook faulty digital clocks cheap transistors relative quantities of silicon

For Walsh, as for so many innovative poets, it is the act of transmission itself that preoccupies, and this extends to non-verbal communication too: 'no / more / than / breathing / 2 / us / reality / running still' $(C W 32)$. Here the breath intervenes to steady the awareness of human experience, and the form of the poem is drawn into a vertical wavering line as though through a process of inhalation. This results in a minimizing of form and a refinement of perception - if not to a unique subjectivity then at least to a singular human process.

The title of the second section of City West, 'Tangency', implies divergence of meaning, yet divergence within a set of unifying mathematical principles - a correspondence suggestive of the shape of the book as a whole. At first the emphasis here is on processes, on verbs of making that invoke the sprawling urban infrastructure which 
the poem both expresses and critiques: 'wide sweeps housing on roads leading round / housing cul de sacs closing encircling roads / one or two towards motorway main / roads roads bearing incessant / weight' $(C W 38)$. The continuous present is an apt mode in which to capture the dynamic yet directionless energies of modern engineered dwelling. Verbs double as nouns (sweeps, housing) to imply at once materiality and flux. Suddenly, the reader encounters an almost empty page, an impression of silence and space that the environment itself lacks, and an opportunity for reflection and questioning. In spite of this pause, the rhythmic connection between the stimulus of the world and the quiet contemplation of the mind continues, now incorporating the dynamics of continuance and cessation with new textual significance. Later, this pattern will be played out in a passage that combines the lexical emphasis of the telegram with the visual rhythm of changing traffic lights: 'flossy past light stop by hind retreating wreaking / daylight every point stop hugely now light stop so / fine regarding seeking daylight very pointed / stop justly soon light stop on time depending' ( $C W$ 47). First, though, a distinction is made between stopping and finishing - 'should one place be better to stop / than another / / always / definitively / / or stop as pause ? / / at all?' (CW 40). These are, of course, important considerations for the creative artist, and in particular for the writer of the long poem, for whom sustained engagement with the problem of writing itself is key concern. Rachel Blau DuPlessis reflects on this issue:

Writing a long poem has an interwoven private and public temporality. Because of the number of variables set in play, one has (as a producer) deeply to desire that kind of activity in time. It's a kind of erotic charge as well as an ambition - both expressing excess and desire - a longing and a sense of vow. ... It isn't so much making a big Thing, but entering into a continuing situation of responsiveness, a compact with that desire. ${ }^{26}$

That combination of excess and desire can be traced in the texture of Walsh's writing, in particular here in her verbs, as the interleaving, folding and weaving reveal how language itself is changed by the process of making. It is a process that accords with comments made by Martin Gubbins on temporal dynamics in the long poem: 'the duration of the poem is not only a time of waiting but also a time of transformation ... The poem starts to dissolve. Its letters/molecules start to move, heat and melt'.27 The emphasis on the processual aspects of poetic creation suggests that the extension of the imagination required for a poem of this duration must inevitably be matched by periods of contraction and 
concentration, a cosmic rhythm that also finds its way into Walsh's reflections on science and nature. Thus the poem facilitates the shifting attention of the observing mind, the awareness of a world scarcely visible or audible:

$\begin{array}{ll}\text { how } & \\ \begin{array}{l}\text { many } \\ \text { shapes }\end{array} & \text { miniscule } \\ \text { shifting } & \text { patterning so } \\ \begin{array}{c}\text { light, dark } \\ \text { minute }\end{array} & \text { textures } \\ \text { particles } & \\ \text { affecting } & \text { making } \\ \text { shapes } & \text { material } \\ \text { living } & \\ \text { matter } & \end{array}$

$\left(C W{ }_{46}\right)$

The challenges involved in the pursuit of human-centred meaning are considerable here, and the prominence of prepositions at various stages of this sequence suggests a continuing need to see the world in relational terms. This aspect of the poem is problematized, of course, by the absence of a singular speaking subject, and also by the ways in which human meaning is submerged into the dynamics of urban life. The flux of the city is extended through Walsh's distinctive punctuation, which plays an important role in establishing the lexical energies of the poem. The use of square brackets facing outward emphasizes at once the isolation of words and the ways in which they remain embedded in collective human understanding:

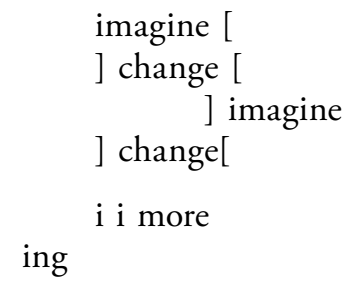

(CW 50)

Amidst these complex rhythms of isolation and connection, of reckless exteriority and quiet thought, one image becomes suggestive of both the expansive nature of Walsh's creative process and the kind of poetic quest she is enacting here. The swinging beam of the lighthouse 
indicates how space itself can be understood through a continual process of revelation and concealment. This could be seen as a metaphor for Walsh's writing: knowledge of the whole is apprehended yet its detailed manifestation never fully retained. Just after the powerful image of the moving beam makes its first appearance, the text extends again, once more making available a number of simultaneous readings. A sequence such as 'unheard / harmonic / intervals / unabstracted / scale / mathematical proportions' is the result of reading downward through the right-hand side of the text ( $\left.C W_{53}\right)$, rather than according to normal lineation. At this stage the poem's unfolding form seems to validate such a vertical alignment; indeed, throughout the work, reading strategies may best be formulated by reading forward to get one's bearings before breaking off to try a section afresh. In this pattern, to stop is not to conclude, but rather to facilitate a renewed engagement with the text. It is a strategy to which Walsh has drawn attention on several occasions, and it accords too with the panning motion that returns at the end of this section in the image of the usher's beam that might bring us into a darkened theatre, mixing too the Joycean Usher's Island reference. At the close of 'Tangency' we are aware of the power of this moving shaft of light, scanning the darkened space, offering glimpsed routes to meaning.

'Plane', the final section of the volume, begins with another whirl of repetition, though the arc of movement has tightened with the endlessly revolving wheels of the buggy: 'watching some one walking a / way down the road buggy pushing / along walking some one a / way down the road buggy pushing / along some one walking a way' ( $C W$ 59). This mundane image is followed by an apparently significant admission: 'with these problems in mind / this book was initiated' ( $C W$ 59). The irony of this statement is hard to gauge; it seems a weighty claim, yet this is a book shaped by the problems of existence, its own and those of humanity at large. The coexistence of centre and margin - 'white bay foam still face over lights / coming downhill threaded city into / once again grey walls water sounding' ( $C W 60)$ - are reflected in the proximity of commercial transactions to the great historic events that shape the narrative of Ireland.28 Yet, even as we are immersed in the experiences of city and suburb, we are reminded of the act of reading so crucial to the textuality of this project: 'Jezus - who writes these books' ( $C W 65)$. Both city and text are volatile spaces: sudden eruptions of sound and movement break through again, reinforcing the pulsating movement between interior reflection of reading and the dynamism 
of action on the street. The exploratory nature of the poetic moment is reinforced here:

there we go

tracing

lines

little excursive ploys

the curved plane

$\left(C W_{70}\right)$

Darkness and light continue to contend with one another in this text; knowledge, always provisional, giving way to uncertainty. This is a cosmic issue too, as the immediate concerns and exchanges of the human subjects here fade into the larger existential questions. A little before the close of the poem - its final words are '(time to go)' - there is a short section in Irish that touches on the relationship between ancient and modern ways of seeing the world: 'a story that unfolds in the past, in / the present and in the future / where will it all end?' ( $\left.C W_{79}\right)$. Essentially it is ideas of the continuous present that shape Walsh's poetic enquiry and her mode of writing, and this continuous present is one that allows the subjectivity of the poem to move ever outwards, encompassing a greater range of observations and insights, an inclusive response to philosophical and aesthetic concerns and a means of exceeding narrow definitions of the poetic that are limiting to creativity and intellect alike.

It is this realization that Catherine Walsh's work returns to again and again. Innovation in form does not constitute a breakdown in the structures of representation, but an extension of their possibilities across both time and space. This means a simultaneous acknowledgment of the presence of the past in language yet also its absence in the consciousness of the moment. The space of the past, therefore, can fill and empty with shifts in thought and language, meaning that the experimental poetic text can renegotiate its handling of memory as it unfolds. This applies not only to the individual subjectivity but also to shared experience. Within the multiple, the singular survives, and it is with the tenuous relationship between the two that this poetry is concerned.

\section{Notes}

I Michael Begnal, Review of Catherine Walsh's City West, B'Fhiú an Braon Fola (June 2006), www.mikebegnalblogspot.ie.

2 Assmann and Shortt, Memory and Political Change, p. 3.

3 Clair Wills, 'Contemporary Women's Poetry: Experimentalism and the Expressive Voice', Critical Quarterly 36.3 (September 1994), p. 39. 
4 In Perloff's case, the idea that personal experience has become radically shaped by its technological mediation - first in the form of television and video, but more recently through information technology, in particular through social media results in the notion of the authentic private subject becoming itself a commodity. See Marjorie Perloff, Radical Artifice: Writing Poetry in the Age of Media (Chicago: Chicago University Press, I99I), p. I2.

5 Henri Lefebvre, The Production of Space (Oxford: Blackwell, I99I), p. 2.

6 Lefebvre's own construction of three types of space - physical space, mental space and social space - draws attention to the dynamics between singular and collective. Henri Lefebvre, State, Space, World: Selected Essays, ed. Neil Brenner and Stuart Elden, trans. Gerald Moore, Neil Brenner and Stuart Elden (Minneapolis, MN: University of Minnesota Press, 2009), pp. I86-7.

7 Caroline Bergvall, 'No Margins to this Page: Female Experimental Poets and the Legacy of Modernism', Fragmente 5 (1993), p. 33. In the introduction to an interview with Caroline Bergvall, Linda A. Kinnahan emphasizes the importance of this dimension of Bergvall's work: 'Bergvall's point is to argue for a broader understanding of feminist poetics and greater attention to women poets whose work unsettles the standard lyric while refusing to evacuate the self (as advocated by certain discourses of postmodernism); indeed, in language-based poetic work, Bergvall and others have argued, the ideologically gendered construction of the self and systems of identity can be explored and transformed.' See Linda Kinnahan, 'An Interview with Caroline Bergvall', Contemporary Women's Writing 5:3 (November 20II), http://www.carolinebergvall.com/content/text/Kinnahan\%2ointerview.pdf.

8 This combination of creative and critical modes can be seen in the relationship between poetic and discursive contributions to journals such as Intercapillary Space (www.intercapillaryspace.org) and PORES: A Journal of Poetics Research (www. pores.bbk.ac.uk). It is deepened by the important role that practising poets play in the critical discourses that surround experimental or alternative poetics.

9 Falci, Continuity and Change in Irish Poetry, p. 192.

IO Doreen Massey, For Space (London: Sage, 2005), p. 23.

II Susan Howe's work is preoccupied by history; she weaves text and image from primary documents into her poems and in doing so often disrupts standard typography. See Susan Howe at the Poetry Foundation, www.poetryfoundation. org/bio/susan-howe\#about. For Paula Claire, 'the sound of words and their relationship to music [is] paramount'. Her experimentation with sound finds a parallel in the typographical innovation of her work, much of which was produced with Bob Cobbing. See 'The Paula Claire Archive of Sound and Visual Poetry', www.paulaclaire.com.

I2 Falci, Continuity and Change in Irish Poetry, pp. 192-3.

I3 Making Tents appeared first as a pamphlet in 1987 from hardPressed poetry. The combined edition, Idir Eatortha and Making Tents was published by Invisible Books in 1996 in A4 format with abstract charcoal or pencil sketches on cover, frontispiece and between the two works in the book.

I4 John Goodby, Irish Poetry since I950: From Stillness into History (Manchester: Manchester University Press, 2000), p. 308.

I5 The phrase 'Take two coos, Taffy' occurs repeatedly in Virginia Woolf's The Years: 'Take two coos, Taffy. Take two coos ...' Virginia Woolf, The Years (London: Vintage, 2004), p. 64. 
I6 Falci, Continuity and Change in Irish Poetry, p. 193.

I7 In the ten years between 1998 and 2008 Ireland experienced unprecedented economic growth. During this time its infrastructure changed considerably and large-scale building projects not only reshaped the major urban centres but also altered the rural landscape in lasting ways. Many of the apartment complexes and houses built on farmland were never occupied; these so-called ghost estates are a visible reminder of the effects of recession. Catherine Walsh's City West was published in the early stages of the Celtic Tiger phenomenon, so significantly reflects this period of growth.

I8 Harriet Tarlo,'Provisional Pleasures: The Challenge of Contemporary Experimental Women Poets', Feminist Review 62 (Summer 1999), p. 96.

I9 Alex Davis, 'Deferred Action: Irish Neo-Avant-Garde Poetry', Angelaki 5.I (2000), p. 88.

20 Barrett Watten, 'The Turn to Language and the 1960s', Critical Inquiry 29.I (Autumn 2000), pp. 139-83.

2I Deborah McWilliams Consalvo, 'An Interview with Eavan Boland', Studies: An Irish Quarterly Review 8I.32I (Spring 1992), p. 96.

22 In Kinsella's 'Another September', nature's resistance to the conscious creative subject is figured through the representation of the breath: 'Hears through an open window the garden draw / Long pitch black breaths [...] / Exhale rough sweetness against the starry slates' (Another September (1962), p. 4I).

23 Both areas of the city that have a Joycean resonance: the Phoenix Park features in Finnegans Wake (1939) and Sandymount in both the Proteus and Nausicaa episodes of Ulysses (1922).

24 'Do I dare / Disturb the universe? / In a minute there is time / For decisions and revisions which a minute will reverse'. T. S. Eliot, 'The Love Song of J. Alfred Prufrock', Collected Poems I909-1962 (London: Faber \& Faber, 1963), pp. 13-17 (p. I4).

25 Ian Davidson, Ideas of Space in Contemporary Poetry (London: Palgrave Macmillan, 2007), p. I04.

26 Rachel Blau DuPlessis, 'Considering the Long Poem: Genre Problems', Readings: Response and Reactions to Poetries, 4 (2008), www.bbk.ac.uk/readings/issues/issue4/ duplessis_on_Consideringthelongpoemgenreproblems.

27 Martin Gubbins, 'Time and Visual Poetry', PORES 3, www.pores.bbk.ac.uk/3/ gubbins.html.

28 Here Walsh's work can again be linked to that of Thomas Kinsella, both in the poet's apparent intervention in the text with comments on creative aims and in the rendering of geographical spaces closely associated with the Dublin of Kinsella's oeuvre, especially those appearing in Poems from Centre City (Dublin: Peppercanister, 1990). 


\title{
Vona Groarke
}

\author{
Memory and Materiality
}

Since her earliest poems, Vona Groarke's exploration of what it is to create meaning in the world has highlighted the importance of the place of her speaking subject and its relationship to the cultural moment out of which she writes. Her philosophical enquiries are always aware of that subject's location in time and space - their moment in history, their place of birth and belonging. These are not elements that contain or limit Groarke's poetics, but rather provide the creative moment from which complex investigations unfold. Though many of her poems have an identifiably Irish setting and material, Groarke does not see herself as an 'Irish poet' and resists a single cultural location as a central enquiry of the poetry. America, in landscape and language, is glimpsed fleetingly in poems from the period, first in Juniper Street (2006) and then in Spindrift (2009); Northern England emerges in Spindrift and $X$ (2013). Though these collections see Groarke extending her versatility of form, it is her treatment of time that is especially noteworthy. As well as mediating between present and past, these poems also offer important insights into Groarke's negotiation of the moment of experience and its assimilation in the finished poem.

The relationship between experience and aesthetics is a complex and interesting one in Groarke's work as a whole. Since her third collection, Flight (2002), there has been an intensification of her engagement with existential concerns, yet this process has occurred without loss of the vividly specific world for which her work has been justly praised. In Juniper Street, experience remains an important formative element, yet, though the specifics of Groarke's life in America shape her art, these are never straightforwardly personal lyrics. While the immediacy of 
experience is rendered directly in language, it is also transformed by it, so that a significant temporal gap opens between experience and representation. Time itself becomes a key concern: so that a transnational reading of her poems must take into account not only the visual and linguistic inflections of American and British cultures that emerge in her work but rather her extended preoccupation with ideas of the secure and the transitory - a concern that has been intensified in $X$, her most recent volume.

Her early work is especially attentive to the concept of home, most notably the poems of her second collection, Other People's Houses. This does not suggest, however, that the process of re-engagement with such material is an endless reaffirmation of belonging, but rather offers evidence of the many ways in which this concept requires to be reimagined and extended in language. For Groarke, home is an important site of personal and cultural memory. ${ }^{1}$ In the title poem of Other People's Houses, the space of relationship is deconstructed by the passage of time so that the shape of the house - and of the poem itself - is radically altered: 'There's been a fire and the roof's caved in'; 'The ceiling of the sitting room is upended / on the floor' (OPH 52). The revival of the house as an emblem of cultural survival reveals its potential as a repository of emotional meaning, especially in connection with forms of self-determination in language. In the private context, the house also provides an essential creative space within which to think and write. This metaphor offers an enduring structure for Groarke in her exploration of the relationship between memory and language and her investigation of the limits of knowledge.

\section{North American Time: Juniper Street}

The title poem of Juniper Street gives Groarke's journey to America a domestic shape, but the poem is principally concerned with the passage of time as an important determinant of the transnational experience. Implicit in the newness of this situation, and the impact of its sensory detail, is the memory of a previous existence; the unspoken other in this text. Seasonal change - the transition from a harsh US winter - is the central trope. The increasing use of run-on lines creates a surge of movement in the poem from the bare landscape of floodlights, gutters and flagpoles to the optimism of 'the gilt-edge of our neighbour's forsythia' and 'our own trim laurel shrub' $\left(J S_{52}\right)$. From the start, natural and man-made processes overlay one another: 
We go to sleep by artificial moonlight.

The floodlit stadium times itself out at midnight and a thicker weave of darkness plies the room.

We sleep under the eaves, where nights of late have eddied in the wind's plump, elevated arch.

We wake to only the dawn's blindsided glaze.

The complex interweaving of conscious and unconscious states is indicated here - sleep combining with a sensory awareness of the weather outside. Structure is prominent at the opening of the poem, as stadium and eaves create different spaces of engagement. As the movement from night to morning suggests, the passage of time is central to this poem's purpose, and the narrative continues with the children's hasty disappearance to school. Meanwhile, seasonal shifts see the snows recede and animal and birdlife become newly visible: the strangeness of this observed world is key to its power to arrest the observing speaker. Not only the actual but also the metaphorical is determined by the new American experience - its squirrels, orioles and hawks. Here the framing of seasonal change within the shape of the single day helps to contract the larger patterns into an experiential mode. Yet in spite of the seeming importance of the temporal progression here, the poem finally doubles back on itself to remember a moment when the spring was framed as an imaginative projection from the winter months:

\section{Or tell you now}

that even in January, with our snow-boots lined up in the hall, I slipped your leather glove onto my hand

and felt the heat of you as something on the turn that would carry us over the tip of all that darkness and land us on the stoop of this whole new world.

(JS 52)

This 'whole new world' conflates the idea of America with the transformation of spring itself, but in doing so it suggests that it is not just the environment that is susceptible to endless change but that the language that describes it is also in flux. As Catriona Clutterbuck has observed, 'Juniper Street, unlike Groarke's preceding work, proposes that loss of sustainable coherent meaning can both be acknowledged and recuperated, this by integrating the available remnants of that meaning with lived life as play.'2 As we saw in Sinéad Morrissey's collection Between Here and 
There, a temporal shift indicates the poet's ability to hold different states of being in imaginative connection: here in 'Juniper Street', just as the warmth of March does not eliminate the experience of snowy January, so the transnational movement suggests not one culture overshadowing another but the simultaneity of different imaginative influences.

As well as exploring aspects of American experience in detail, the work in Juniper Street considers issues of belonging and estrangement in broader ways, and in doing so returns to the personal past to probe the passage of time from that vantage point. 'The Return' evokes a house in which the speaker once lived and wrote, using a single stanza of seventeen lines to create the bridge between present and past. In choosing this compact framework for reflection, Groarke not only intensifies her return to the space of personal memory but engages too with her earlier work - especially the poems of Other People's Houses (1999) - in which the representation of the home, and its emotional and aesthetic significance, is a central aspect of the poetic enquiry. The poem begins by halting the reader at the bricked-up door of the house, impeding our access to the interiority of the domestic space. Instead, language leaves us outside, drawing attention to its own power in constituting the structure we witness - even the attempts at renovation read like a punchline to an old and tired joke. Yet the creative impulse that has shaped Groarke's choice of material here is also seen as in the past - 'I know this house: I wrote our summer here / into words that closed over years ago' $(J S$ 26). Here language is like a wound, sealing as the experience that inspired it grows more distant in time. The speaker's return does not just explore the experience of early domesticity but the complex relationship between the past and its layers of representation. Placed at the centre of the poem, the line 'Even your hand stops as I unhook the gate' could belong to either past or present, invoking the freezing of time in the stopped hands of the clock:

Even your hand stops as I unhook the gate and there it is, our young day, like the blue of your eyes, a noticed, simple thing that leaves me dumbfounded in a half-hearted ruin

(JS 26)

This movement qualifies the earlier assertion 'I know this house'; the past is in fact a shared one, and the speaker's lover is cast here as both observer and the thing observed. 'Our young day' is not quite 'like the blue of your eyes' as the shared past must be witnessed and understood by both 
of them. Though the joy of the past leaves the speaker dumbfounded, the half-hearted ruin hints that this is a singular feeling, encompassing - though not necessarily complicit in - the emotions of the lover. His apparent act of holding back ('Even your hand stops') is balanced by her movement forward ('My hand on the door'), and by her willingness to open the past to scrutiny. In her mind the layers of the past cannot be uncoupled (a word suggestive of a return to a singular state) any more that the narrative of their love can be remade.

The light that memory sheds on the growth to understanding is a recurring preoccupation for Groarke and in Juniper Street is inflected by investigations of history and its narrative retelling. Again, the nuances of language and vocabulary shape subjective perspectives in key ways, highlighting the important intersection between history, memory and language in understanding the self in a specific national and cultural context. 'To Smithereens' begins by signalling the challenges of this journey back in time: 'You'll need a tiller's hand to steer this through / the backward drift that brings you to, as always, / one fine day' ( $J S$ I6). The patterns of memory can be traced back to the clichéd childhood summer holiday, the 'marvellous haul of foam' and 'buckets of gold' exaggerating the simple pleasures of the beach life for children. Already this seems impossibly idyllic, however, and though the 'scarlet dye' hints at the graphic flow of violence through the poem, it gives way to a more knowing and complex perspective on the event. By the third stanza, as the radio brings news of the bomb that killed Lord Mountbatten further up the western coast, ${ }^{3}$ language begins to approximate the explosion: 'the news that falls in slanted beats / / like metal shavings sprayed from a single / incandescent point to dispel themselves / as the future tense of what they fall upon' $(J S$ i6).

Suddenly the scene shifts, reminding us of the need for careful steering indicated in the first line of the poem. Now the speaker is in the cinema - at the Ritz in Athlone, 'a modernist / western wall away from the Shannon' (JS I6). ${ }^{4}$ The film is Gandhi and its world begins to merge with the scene outside the cinema, Ganges and Shannon presenting a 'slipknot of darkness'.5 The 'she' accompanying the speaker is undisclosed, but presumably one of the 'mams / and aunts' that feature earlier on the beach. Here the Foxford rugs are replaced by the crimson plush of the cinema seat, but the sleeping woman is not drawn into the imaginative world of the film but rather to 'where all the journeys terminate / with the slump and flutter of an outboard engine' ( $J S$ i6). Though the 'heat and dust' of the locked projection room evokes another classic film of 
Indian independence, it is the postcolonial condition that links Ireland and India. ${ }^{6}$ Woken 'by words that spill over the confluence of the Ganges / / and the Shannon at our backs' (JS I6), the woman interprets what she hears - the word 'Smithereens' - as Indian, 'It means / to open (like an Albertine); to flower' ( $J S$ I6). This flowering, which links the petal-strewn waters of the Ganges with the Albertine rose, named after the husband of Queen Victoria, Empress of India, shows the anomaly of these colonial connections. More ironic still is the misinterpretation at the heart of this conclusion - 'smithereens' is an Irish word, meaning shattered fragments, an explosive version of the opening out envisaged in the poem. Yet the muddling of beauty and violence, of potential and destruction is an important part of the post-independent state. It echoes W. B. Yeats's awareness of these dichotomous responses and alerts us to the manipulation of language in the staging of both private and public histories.

In this collection Groarke is often concerned with the importance of the auditory in the construction of meaning; this encompasses not only the sounds of words but also the accent of the speaking voice. In exploring her new life in America, and the ways in which it shapes her poetry, vocabulary and tone prove as important as identified location: 'The Local Accent' is a poem that draws voice and topography into particularly close alignment. This is not the first time that Groarke has juxtaposed the fluidity of water with solid ground, but here the relationship between these states, and the extent to which they define one another, is marked.

This river is pronounced by granite drag.

It is a matter of inflection, of knowing what to emphasize, and what to let drift away, just as a slipping aspen leaf makes barely a flicker, one gaffe in the conversation between the current and the flow; a stifled yawn, a darkness reimbursed;

while, underneath, the thing that falls through shadow is full of its own occasion. Weighty and dull, it longs for water, the lacquer and slip of it, the way it won't allow for brightness on its back, but flips around to where its fall is a wet-wool, sodden thing about to break at any moment, and undo.

Something is coming loose like aspen leaves, or froth. Or maunder, letting itself down like rain into a river immersed in getting on with what it separates: 
the sulk of damp soil; the stiff articulation of the shore, the giddy vowels sprayed over the drag and ebb of voices leaking through the rain over the town.

The word 'pronounce' draws early attention to the sound of language as shaping of its meaning. The granite drag that determines the pace of the water's flow here is suggestive of the cultural bedrock shaping the deployment of language, the material circumstances of words. If 'knowing what to emphasize and what to let drift away' defines pronunciation - the intonation required to make language meaningful - then it also mirrors processes of understanding: what requires attention, what can be relinquished. Here Groarke toys with the practice by which what is other to language becomes absorbed within it. Just as the aspen leaf slips downriver virtually unseen, the 'gaffe in the conversation' may be unnoticed by others but meaningful in itself, 'full of its own occasion' $(J S \mathrm{I} 8)$. Water is a space of undoing for Groarke, where objects may lose their sense of coherent identity, yet can be understood to be in transition between states.

It seems, then, that the speaking voice within this poem records this point of transition as a linguistic one. The transnational subject is therefore in a productive state of undoing, where the established expectations of language and form loosen to allow new modes to emerge. This loosening of form is also an enquiry into what is coherent and identifiable in linguistic terms: what comes loose here is 'aspen leaves or froth' - the first a thing 'other' to the water, the second an organic part of it. The merging and separation of similar forms (the froth that comes adrift from the body of water, and the rain that enters it) mimics the natural ways in which forms of expression are absorbed within the body of language, while others are lost. The context suddenly enters the poem, reminding the reader of the particularity of experience from which these ideas emerge. The word 'local' suggests a version of Irishness is at stake, but given the American inflection of Juniper Street as a whole, its implications for the understanding of the relationship between place and spoken language, and in turn between spoken language and meaning, have a much greater significance. For the first time in Groarke's work language is linked directly to materiality, and with this connection comes an increasing sensitivity to the temporal dimension of language -its powers both of endurance and of adaptability. In this way, the poem text exemplifies the continuity of tradition and the breaking of this lineage to create new ways of reading the past in the present. 


\section{Losing the Past: Spindrift}

Groarke's fifth collection, Spindrift (2009), retains much of the particularity of Juniper Street but goes further in its dispersal of the continuities of form that offer sustained and sustaining meaning so that the gap between the intense reality of the observed world and the contingency of the observing self becomes ever wider. This dispersal is captured in the energy of the volume and in its rich interleaving of past and present. The recognition of this contingency emerges through the formal strategies of these poems. Spindrift's transitions of perspective, therefore, speak not only of loss and change but also of the imprint that these leave on language.

Groarke has long exhibited a sensibility attuned to loss and to the significance of absence in exerting a shaping force on present meaning. The figure of the absent father is important in her early work, helping us to read the voice of the speaker as a singular one; even enduring relationships are shadowed by the demands of self-knowledge. If Spindrift marks a transition, it is surely to the realization of radical discontinuities in the construction of meaning itself - of language's shortcomings in helping us to understand the full significance of the past. Paradoxically, though, this realization helps Groarke to push language and form towards an apt expression of this contingent position. As Richard Rorty argues, a poet is typically unable to make clear exactly what it is he wants to do before developing the language in which he succeeds in doing it'. ${ }^{7}$ Thus, we may see the dislocations of language in Spindrift as the cause, as much as the result, of a loss of faith in the continuities of experience.

In common with the poet's second collection, Other People's Houses (1999), Spindrift has a unifying image, but instead of the grounded representation of the house, this collection engages with the unceasing movement of water and singularity of past, present and future that this suggests. Spindrift itself is defined at the opening of the book as 'spray blown from the crests of waves by the wind' and this is a collection shaped not only by the motion of water but by its dispersal and evaporation. Thus it becomes an apt motif for the fear of lost selfhood in that it replaces the safety of domestic happiness but also challenges the possibility of poetic containment in conditions of personal and cultural uncertainty. The title sequence, significantly placed last in the book, dwells on the return of the past through the materiality of the present 
I

What is to be done

with a past tense

that, once recalled,

presents itself again?

You might as well

throw a stone in the sea

and be taken aback

when the same thing

is keeping you from sleep

$(S D$ 62)

As well as crossing the boundaries between present and past, the poem signals the merging of literal and imaginative worlds and the paradox of what is cast away remaining with us. As in so many of Groarke's earlier poems the house holds past lives - 'all manner of old news' - and we are especially alert to forms and structures here and their impact on both present mood and memories of the past: the sea, the house, fields, stones. The landscape is revealed gradually through the poem's numbered parts, through its expansion and contraction of lines. These parts emphasize ideas of progress and chronology at the same time as they privilege ebb and flow, so that time may be conceptualized in linear fashion, even as it carries the past with it. The reopening of the house marks a telescoping of time as the immediacy of domestic tasks provoke memories that confirm all that has changed since these tasks were last performed. Thus it is fitting that this sequence is the final one of the book, drawing together both the speaker's memories of place and the reader's of reading. The impressions of sea and land become more intense and subjective as the speaker opens to these new-old experiences and tests the power of language to evoke them truly: 'The colour of the sea today / is nothing like the name / of any colour / I can think of " $(S D$ 63). The poem then opens out to combine botanical observations with brief narratives of the children's experiences, bringing a different energy to the sequence. Memories of past summers are balanced by projected futures: the planning application that might pave the way for bungalow and landscaped garden gives a larger cultural context to the changing landscape. As the materiality of the past is lost to a new, commodified Ireland, the role of personal memory changes. For now, though, wave and sky predominate, revealing a different order of change - the endless shifts of the coastal landscape and the mutability of memory and mood. 
Observation and reflection are keys to this poem, so that when night falls light floods the scene: lit windows, a lighthouse beam, headlights of cars - all are suggestive of the patterns of human life, intersecting with the speaker's own daily routines but also exposing them to the gaze. This sense of being at once on the margins and moving within a web of life is important: all this variety is 'a kind of love song', yet not one written by the speaker but heard by her. This profound sense of witness with which the book ends at once unifies and clarifies the poems of contemplation and doubt that precede this in the book.

Spindrift's opening poem, 'Some Weather', heralds an emotional turbulence that shapes the present of these poems, but that also indicates the fragility of the apparently stable past: 'Among the things / (though these are not things) / I did to pre-empt the storm were: / upturn, stow, disconnect, / shut down, shutter, shut' (SD II). The poem immediately draws attention to the inadequacy of the well-worn phrase in favour of a more purposeful relationship between nouns and verbs the word for things and the word for actions. It is the first evidence of the unobtrusive search for newness that is present here and still more pronounced in $X$, Groarke's subsequent collection. This relationship draws attention to the dynamic between an existing material reality and the contingent nature of human intervention in this reality. The actions listed in the poem invite various interpretations: they are the precautionary measures taken in a boat entering storm conditions, but, in a larger sense, they indicate human modes of self-protection in time of crisis. The line 'shut down, shutter, shut' improvises meaning from a single word but is also suggestive of declension - a verb moving through different tenses, and as it does so linguistically mimicking its own meaning, that of defensive reduction. The contest between the human figure and the elements here is an investigation of the tension between stasis and movement, between withdrawal and expressiveness that is also the dialectic of human relationships and of the creative process. These are reminders too of the distancing effect that so many of these poems enact: the noted significance of what happens elsewhere and can be only imagined by the speaker.

From its opening poem, then, water imagery flows through Spindrift, not only emphasizing the uncertain processes of writing itself but allowing the distinctions between surface and depth to inform our reading of the work. The second poem in the collection, 'The Jetty', considers reflection (in both senses of the word) as creative of new frames of meaning, even if these perspectives exist only 'for a moment'. 
Summer-bleached and swaddling the paddle-boat and tin canoe, the jetty shoulders, for a moment, clean right angles, lichen seams heavy as voices tacking now across water, calling 'Don't' or 'Boat' it hardly matters to me. The way I scribble is like the way a squirrel or a cardinal is fumbling in the thicket to my left: at least he knows what he's looking for.

Groarke's imaginative attention rests on the jetty - that man-made construction that protrudes into the existential mystery of the lake, here 'swaddling' the paraphernalia of American literary fiction. ${ }^{8}$ The voices overheard here are discernible only by their vowel sounds, not by what their words connote, and are in any case of little interest to the poet intent on her own creative labours. This is ironic, of course, because these voices form part of the poem's final meaning, again showing that what is at a distance constantly impinges on the poet's mind. In addition to this covert attentiveness to her immediate surroundings, Groarke's poem is alive with the memories of earlier texts and as the poem progresses these may be seen to hint at a range of literary contexts, from Twain's American adventures to Wordsworth's Prelude. There are resonances here too of poems by both Thomas Kinsella and Bernard O'Donoghue, who have found analogues for their writing process in the avian world. 9 In 'The Jetty', the creative breakthrough occurs at a point of ambiguity in the natural world: 'I think I've found it when the opposite hill / throws down another version of itself / on the lake's gloss' ( $S D$ I2). As well as seeing the landscape inverted in the water's surface, the speaker also records how the acts of reading and writing add layers from the imagined and observed worlds to the text-in-process. The doubling of representation in this poem is potentially disturbing, though, as it exposes the process of repetition even in the singular space of the newly created poem.

This reaches to the heart of the tension in this collection, between, in Rorty's terms, 'the attempt to represent or express something that was already there and the attempt to make something that never had been dreamed of before.' ${ }^{10}$ This tension exemplifies the working of memory as both a reclamation of the past and an imaginative creation that may help us better to understand what we have experienced, either personally or collectively. Groarke sometimes uses the breaking of surfaces as a way of investigating the coexistence of a shared material memory and an 
original perception. The poem 'Trapdoor' records water's relationship to its environment, and how its appearance shifts and changes according to circumstance:

It fools no one.

Not the dragonflies or midges, not the pine trees or the moon, not the swimmer, me, breaststroking out

to immerse myself at its dark heart, to witness how nothing, not even silence or my own dim company, can disturb that practised and accomplished suffering.

In keeping with a reading of water that privileges it as a metaphor for subconscious states, the 'dark heart' of this lake is the repository of suffering and of concealed life. Here Groarke envisages a lake not as a continuous space of water, though, but rather one divided into different states of experience: in this way the distinction between past and present can be made clear, even as their capacity for remaining undifferentiated is also expressed. The underwater descent, so much a part of the investigation of self and psyche, is linked here to observed detail (the pike), to tragic memory (the two young deaths) and to the surreal (the dock that 'unhinges itself') (SD 35).

The concept of doubleness acquires new significance too: right through this collection Groarke dwells on the past, not only the lost past of personal experience but the pastness of her earlier texts. Many of these poems reprise ideas and images from previously published work with new or intensified meaning. The metaphorical structure of 'Trapdoor' marks a return to Groarke's first collection Shale, which is prefaced by a quotation from Elizabeth Bishop's 'The Riverman': 'I waded into the river / and suddenly a door / in the water opened inward'. Some of Bishop's ambiguous treatment of the movement between water and land, between different states of being, informs this early book, especially a poem such as 'Sunday's Well' that explores the relationship between individual identity and domestic space in ways that also disturb the existence of clear boundaries. Groarke's return to this scheme of images some is years later indicates a need to explore the development of her creative perception and to disturb any sense of easy progression towards new forms of understanding. Instead, this strategy of doubling back affirms the disjointed ways in which meaning is made. 
The water imagery that emphasizes processes of movement and readjustment in Juniper Street here becomes an apt motif for the fear of lost selfhood, not only replacing the safety of domestic happiness but also challenging the possibility of poetic containment in conditions of personal, and cultural, uncertainty. In Strangers to Ourselves, Julia Kristeva suggests that for many exiles the homeland may be represented by a time rather than a place, 'a lost mirage of the past which he will never be able to recover.'11 'Away' (the second of two poems with that title in Spindrift) presents the transnational experience in a manner that dramatizes the geographical separation of the speaker from her children. Her ability not only to speak to her children but also to glimpse their lives by technological means opens up new possibilities in the realms of virtual experience. The performative dimension of Groarke's treatment of technology is again to the fore but temporality is the most crucial factor in determining the fragility of the connection across space:

I am three thousand miles ago,

five hours in the red.

What would it take -

one crossed cyber wire,

a virtual hair's breadth awry -

for these synapsed hours

to bloat to centuries,

for my background

to be rescinded

to a Botticelli blue,

my webcam image

ruffled and pearled,

speaking vintage words

into spindrift?

$(S D$ 26)

The order that time represents is easily disturbed, Groarke suggests, and with it the codes of connection are meaningless. These codes relate both to the past - in the shape of a family unity now lost - and to the uncertain future. The simultaneity suggested by the use of Skype is refuted when the speaker contemplates viewing her children's lives on Google Earth - a visualization that is at once intimate and frozen in time. In this scheme, the distinction between past and present is problematized. It suggests that Groarke's poetic progression is an 
assimilative one, always turning back on itself to produce new meanings and perspectives. Although her work is acutely attentive to the individual moment of experience, it often gives the impression that the speaker has already absorbed this experience; that it has been reflected upon not only deeply but also in an enduring way. Thus, Groarke's openness to American culture, here and in Juniper Street, is not a dynamic of change and development, but rather one of return, as the core concerns of her poetry find new materials of expression. It is in illuminating the complex temporal modes of Groarke's writing that her transnational experience is most valuable.

The sense of isolation, even of fear, that shadows the subject position in this collection is also reflected in its changed domestic representation. For Groarke, the interior or domestic space has always been a site of investigation, one in which the relationship between self and world can be explored. Even where the domestic space has been signalled as apparently secure, the relationship between the singular viewer and this space is often one of disturbed vision. A striking example of this is the poem 'Orange' from Flight (2002), which sees a fissure open through the centre of the poem as the speaker surveys the brightly lit family home from outside in the wintery dark. The separateness that enables the speaker to look at her family from a distance, yet closely, also creates apparently contradictory feelings of belonging and being excluded. It is a strategy that Groarke employs in increasingly complex ways in Spindrift, where feelings of estrangement are ironically accompanied by some of the closest scrutiny of the material world we have yet seen in this poet's work. Capturing a moment of perfect attention is by now a hallmark of Groarke's poetry and in Spindrift it finds particular significance when set against the wilfulness of natural processes that storms and tides invoke. Within these states of uncertainty and flux are to be found the most resonant of features - a tear in the satin lining of a handbag, the sound of scissors cutting, a car headlamp reflected on a gatepost - details that are not just evocative of an instant of human experience, but confirm that our relationship to the world is often cast in just this fleeting way. It is as though the awareness of mutability brings the impulse to record in detail, to lay down memories for the future. Now the space of the house is no longer a place of security but instead one that is breached or darkening. A poem such as 'The Stairwell' uses wordplay to generate the imagined well at the centre of the house, the deliberate rise and fall of the machinery marking a strange state somewhere between sleeping and waking. The absence of 
the speaking subject from this mechanistic process, and her abdication of future responsibility, is a significant indication of the future loss of meaningful involvement in shared domestic processes. The instability of the boundaries of the home is evident in the shape of the collection as a whole; in the way the poems resonate with one another, just as 'the open plan of this last house / pulses and contracts'. This poem, entitled 'The Box', concludes in fear that shared experience and understanding may be irretrievably lost: 'that all the years we lived here drain away' (SD 3I). This is ultimately the fear that discontinuity and meaninglessness lie at the core of human existence. Both the fear of loss and its acceptance mark Spindrift, yet it does not simply represent emotional responses to lived experience, instead it engages fundamentally with the making and the loss of meaning.

The rich possibilities of the material world are also present in the poem 'Beyond Me', where again what is beyond the bounds of human subjectivity and understanding is the subject of scrutiny. The interwoven nature of time and space is immediately apparent: 'The hours stack up like saucers' ( $S D$ 43). The poem, like several others here, progresses by means of association - the image of saucers is followed by that of knives 'resting on their polished sides'; the 'stream' of light leads us to 'Rain falls in reams' (SD 43) (my italics). The ability of language to guide our thought-processes by sound and association lends particular significance to the act of writing and to its role in making, rather than describing, meaning.

Rain falls in reams: whatever else there is allays

a loneliness plump with your absence, that balances, tightrope and fall, to either side of me.

What do I ask? To make something of these lines extend to you; to have you turn in my direction; the long-life bulb by my front door illuminate your hand.

Even a single hair on your pillow knows all there is of you: even more than I, though I have thought of you, made much of your fern eyes and speckled wrist

The absence at the core of this poem is expressed in the image of the tightrope and the corresponding fear of falling, yet the finest line between meaning and emptiness is of course the poetic line. The word 'line' itself offers multiple meanings and the speaker here makes clear that her poem is a means to reach the absent figure and to draw him 
back into the very world the poem inscribes. In this way the ideal reader is the absent 'you' of the poem, and our awareness of this missing figure prompts us to consider the distance that has opened up between speaker and reader throughout the collection, suggesting that uncreated meanings shadow every poem. The limitations of knowledge have become integral to the poet's awareness of the process of writing itself - that it can be no more than one version of lived experience. The DNA to be found in a single hair reveals more of the individual than the creative act. To press a version of the person 'between unyielding sheets' is to preserve in the manner of the pressed flower and to render as a text - unyielding because printed, ineradicable. The absent figure both opens up and closes down creative response: the speaker must 'rest' from the labour of representation and attend to the material of her own poem. At this point, 'Beyond Me' begins to turn back on itself: the speaker becomes the poet tinkering with the first images. The earlier question - 'What do I ask?' - is answered: 'I have nothing to ask' (SD 43). The line of the poem extended to the absent figure is cut in two in the truncated final line: 'It is not over. I will not again' (SD 43). These syllabically balanced yet strangely incomplete sentences test the relationship between present and future, being simultaneous expressions of continuance and finality, hope and despair.

\section{$X:$ No Curve or Arc to Double Back?}

Many of the preoccupations of Spindrift can be traced again in $X$, published in 20I4. Its elusive title - the definitions of which are more numerous than for Spindrift - alerts us to the further fragmentation of meaning in this volume. The title poem signals the juxtapositions that the book as a whole creates: 'straight lines only / no curve or arc / to double back' ( $X_{\mathrm{I}}$ ). This sense of forward motion is belied by the extent to which this collection is in dialogue with Groarke's last volume, especially in its depiction of the crucial intersection between space and time. John McAuliffe sees it as marking an important transition for Groarke: it 'inhabits the empty space it describes in a way that feels new in Irish writing: the poems tell a story of reclaimed and recovered spaces, albeit haunted by memory'. ${ }^{2}$

$X$ becomes a puzzle not easily revealing how its parts fit together, and in this way it alerts us to the significant relationship between the individual poem and the volume as a whole, as well as between the human being as a singular and relational entity. In the absence of the 
'O' that would confirm this letter to be a kiss, we are given - but given to question - the sensual image of the slipping shoulder strap of the dress. This seems to be a glimpse of the past, the tangled nature of which takes years to unpick. But the parts are also indicative of the relationship between lovers, intersecting at the point of intensity then moving in opposite directions:

as if here and now

were equal lines

fused the way lovers are fused

for as long as it takes

to pass through the eye of love

to recover, to egress.

$(X \mathrm{I} 4)$

The intersection of time and place is important here, as it will be in the volume as a whole. They are seen as 'equal lines', briefly conjoined yet divergent in meaning; their identical shape before and after this moment of unity suggests both a purposeful movement and an 'egress'. Here the nuclear family represents the state of completeness, making the four-sided shape 'full of itself' before being 'cornered, quartered, hinged' - a depleted condition reinforced by the dwindling stanza that follows. The uneven shape of the poem as a whole belies the exact symmetry of its central image; later in the text the prevalence of single lines marks the opening up of blank space and the slowing, then the cessation, of shared time. This process has some affinities with changes that sites of collective memory undergo: when these memories fade, Jay Winter suggests, 'the sites of memory decompose, or simply fade into the landscape'.13 In Groarke's poem, though the speaker contemplates the interdependence of presence and absence: 'as crosshairs train on a blank page / / as arrows turn in on themselves / / as the blades of a bedroom ceiling fan / come to / / a perfectly obvious stop' ( $\left.X_{15}\right)$. The loss of momentum seems, after a certain point, inevitable. It brings our focus back to the present moment much as the speaker in 'Fate' rejects the conflation of past and future that a fairy story represents, in favour of the chance to 'walk in the room / of my own breath' ( $X_{23}$ ), a containment that paradoxically expresses the potential for personal liberation.

Other poems in this volume continue the engagement with domestic materiality that is a defining feature of Spindrift. These texts produce light - they are full of reflective surfaces, from 'A Pocket Mirror', with which the book opens, to the glass bowls of 'Where She Imagines the Want of Being Alone', ' 3 ' and 'Midsummer' ( $X_{17}$; 18 ; 36), to the 
antique silver box and 'unscheduled silver' of the photograph ( $X_{31}$; 75). White - all colour and no colour - predominates in the first half of the book, speaking of the urge to embrace the world yet also expressing a profound sense of emptiness. As Sherry Turkle has argued, the meaning of objects shifts according to time and place: 'objects speak in a way that destroys any simple stories we might tell about our relations to nature, history and the inanimate; they destroy any simple sense we have about progress and our passage through time.' ${ }^{14}$ This places the volume, as its title poem suggests, at a pivotal point between past and future, where the radical break with an earlier existence has not yet yielded a transformed existence. The signs of renewal can be glimpsed in the second half of the book; at first, though, this potential is tentatively expressed. The opening poem begins with the image of a snowdrop, which finds its analogue in the white poppy from the garden sequence; interiors have 'white door handles' and 'off-white walls' ( $X_{17}$; 18 ). 'The White Year' is explicitly concerned with the dynamics of remembering and forgetting:

I am told that memory can't afford

to care less about what it brings to light

just as I'm told the table does not

occupy itself with cleanliness

nor the made bed with desire,

but it is difficult to believe.

$\left(X_{\mathrm{I} 2}\right)$

Here memory is linked to the material world - it resembles an object more than a process, suggesting that it is prompted by the sensory stimulus that everyday life provides. The speaker resists this apparent arbitrariness, but the touch of irony does not negate the imaginative significance of material objects for the poet, or the creative necessity of reading these objects as an important part of the individual's negotiation with the world. In this poem, the light / dark binary indicates the shifting mood that grief for lost love induces: what memory 'brings to light' prompts a 'contingent darkness'; trees 'toy with shadows of themselves' $\left(X_{\text {I2}}\right)$. Ultimately, the speaker judges, neither memory nor forgetting is randomly linked to the materiality of the present tense. Instead, time moves gradually onward, confirming the sequential character of making meaning: 'night after night, city after city, / word after functional word' $\left(X_{\mathrm{I}}\right)$. The past self is not subsumed into the present, but neither does their coexistence rule out the demand of the "whole body [...] to be in possession of itself' $\left(X_{\mathrm{I}}\right)$ and capable of unfettered action in the world. 
This contemplation of multiple selves finds later expression in two poems invoking ghostly presences. 'The Ghost on the Road' conjures a figure from shadow and rain, a presence moving towards the house from which the speaker watches. His relationship to the past is ambiguous, though; he is created by, and from, an act of observation. He looks up at the speaker's window just once: 'but I know that look / and everything that will come of it / given ink and time' (X 62). This contemplation of self and other emphasizes not intimacy, as is more commonly the case in Groarke's work, but an enigmatic distance and an awareness of the power of writing to create from almost nothing: 'the ghost on the road / is a ghost on the road / / for all I make of him' ( $X$ 62). Yet if this ghost is conjured by language, he manages to acquire an identity independent of it, suggesting once more the coexistence of multiple versions of the past, each one created by a separate attempt at understanding. In the poem that follows this one, simply called 'Ghost Poem', the revenants are not singular but multiple, and they have the same effect of slowing time 'so one minute is cavernous / / compared to the next' ( $X$ 64). Unlike the ghost on the road, these invoke bodily memories - 'your wrist / on my breast', 'your veins in silverpoint mapped / on my skin' $(X 64)$ - yet this shared life is 'made up', conjured by words. This has important connotations for the relationship between language and memory, suggesting that both the original emotions and the memory of them exist primarily in language.

Centrally placed in $X$ is the 'Garden Sequence', comprising thirteen poems in varying forms. Though in Renaissance times the garden was construed as evidence of fitting authority, its modern representation is suggestive of physical and mental renewal. For Groarke, it combines the energies of growth with questions of structure and form and marks a significant transition from her earlier representations of nature. Though landscapes have played a prominent part in her work, she describes herself in a recent interview as 'more given to investigating how nature might mirror human psychological experience and states, than to the act of description'.15 Earlier, indoor and outdoor spaces were often presented in oppositional ways, signalling divergent perspectives on both present and past. Here her invocation of the imagery of the garden doesn't assume unity of perspective but reflects more deeply on the passage of time and on the complex and contingent character of human perception.

Although the representation of gardens offers Groarke an opportunity to engage with the non-human habitat, in these poems she is concerned with forms of understanding that encompass contextualized human 
relationships too. Breath is a recurring trope in these poems, obliquely considering the different relationships between human and plant life. It appears first in the opening text: 'Only a roofline tin whistle / practising "The Parting Glass" / construes the gap / between lupin and rose / as possible held breath' $\left(X_{4} \mathrm{I}\right)$. Here the interaction between human sound and plant life sets the tone for the oblique and fleeting contact that the sequence will explore. The shape of the stanza - which is without punctuation - is itself that of the held breath, and the subject of the barely heard song is of closure. ${ }^{16}$ This draws attention to the poet's choice of the sequence mode, ${ }^{17}$ as well as to the ways in which they revisit earlier themes and images in her work.

From this opening poem, Groarke acknowledges the pivotal role of the poetic imagination in interpreting these plants, but in noting its deliberate character she also confirms the power of symbolic meaning and its significance for how we read the world. The poem she places second in the sequence, 'The Garden in Hindsight', carries this idea over to a direct exploration of past and present. Imagining a garden that belonged to her years before, the speaker frames this memory in a particularized present. The poem recalls an earlier theme of Groarke's - that of a visit to a previous home - encountered in such poems as 'Other People's Houses' (OPH 52-3) and 'The Return' (JS 26). In contrast to those poems, however, 'The Garden in Hindsight' is not a poem of intimacy. Rather, it invokes a refusal to connect with the world; the black tulips are remembered as 'close in themselves', they 'turn embittered / hearts against all possible sky' $\left(X_{42}\right)$. Yet these are balanced by more recently planted bulbs that 'yield / as to remembered light', suggesting an inherent desire to bloom $\left(X_{42}\right)$. The tension here between a dark inwardness and a disposition open to growth and change shadows a number of poems in this sequence. This capacity to look in two directions - towards the past and the future - is a distinctive feature of this collection, helping both to connect it to her previous work and to suggest new aesthetic departures.

The metaphorical power of garden imagery reinforces the concept of unity in this group of poems. In 'The Garden as Event' we pick up echoes of W. B. Yeats's root, blossom and bole in the relationship Groarke traces between skyline and sky, between branch and cherry tree. ${ }^{18}$ The dynamics of part and whole are important both in the sequence and in individual poems, and have spatial and temporal resonance too: as all these poems indicate, time can be both fleeting and expansive. In the unchanging kitchen scene of 'The Garden as Event', with its barely moving square of light, we see reflections of poems from 
Spindrift (2009) - 'The hours stack up like saucers. The knives / are resting on their polished sides. A widening stream / from the back-door light is the last thing sure of itself' ('Beyond Me', SD 43). Now the act of making becomes even more deliberate than in earlier poems, so that just as the 'fruit in the fruitbowl glosses / a composed version of itself' $(X$ 46), elsewhere too there is a concern for the realistic detail that alludes to artful creation. Groarke has acknowledged the challenge of negotiating 'between the life one lives and the life one writes', and in the garden poems the subtleties of this relationship are probed in images that emerge from earlier texts: the cowslips in 'their borrowed pot' grow from the convergence of life and art in Spindrift's 'Cowslips', and take up the strands of its discussion (S 6I).

'The Garden, Over Time' reflects on the transitory nature of belonging, balancing the contingencies of human existence against the unhurried pace of nature. Time is not marked conventionally by the passage of the seasons here, but rather by the erratic involvement of the human in nature's rhythms, suggesting that we are both part of and other to this non-human world. The tree that would not thrive finds its analogue in the false starts of independent life before a new pattern of existence can be established; trial and error is the process foremost here. This sense of learning anew is also a way of refiguring the past to create meaningful connections to the present - even if these connections may conversely mark a decisive break in understanding. This disruption is expressive too: the barren winter halted language - the 'bones of winter [...] ring hollow as words / / I would just as soon / shroud in darkness / as bring to / open light' $(X 58)$. Yet though the speaker seems to treat the future casually (the early arrival of summer is 'fine by me'), she is not careless of the fragility of hope; reflecting on the speed of time's passing she concludes:

\section{Left}

to my own devices,

I would spend it, surely,

cradling the only

fact of winter

coming in early,

yes, this year.

( $X$ 59)

Three-beat lines expand slightly to accommodate the disyllabic opening words 'cradling' and 'coming', creating the sensation of a shallow breath - a delicate pulse of life for which the poet is grateful. 
The evolution of Groarke's response to the materiality of the past - and what it means for the future - has been considerable. Closely observed detail remains important in this work, but temporal continuities have given way to an acceptance of change. Since Spindrift, the uncertainties of history have been actualized in the domestic life of the poems and it is in this space that the growth of understanding must, and does, take place. The thematic unities of Groarke's work yield to an understanding of the past made complex both through suffering and through aesthetic refinement. So it is that the evolving precision of the poet's language leads to greater insight into our relationship with the past.

\section{Notes}

I The relationship between public and private readings of Groarke's work is a contested one. John Redmond argues that it is almost possible to supply a publicly oriented reading for the poems in Other People's Houses: 'The way in which Groarke allows her poems to brush against seemingly relevant public narratives gives them a necessary, extra charge.' Poetry and Privacy: Questioning Public Interpretations of Contemporary British and Irish Poetry (Bridgend: Seren, 20I3), p. I66. See also Selina Guinness, "'The Annotated House”: Feminism and Form', in Justin Quinn (ed.), Irish Poetry After Feminism (Gerrards Cross: Colin Smythe, 2008), pp. 69-79.

2 Catriona Clutterbuck, 'New Irish Women Poets: The Evolution of (In)determinacy in Vona Groarke', in Fran Brearton and Alan Gillis (eds), The Oxford Handbook of Modern Irish Poetry (Oxford: Oxford University Press, 20I2), p. 66I.

3 Lord Louis Mountbatten was a British naval officer, the second cousin of Queen Elizabeth II. He was Supreme Allied Commander in South-east Asia during the Second World War and the last Viceroy of India. In 1979, he was killed by an IRA bomb at Mullaghmore, County Sligo. See Bew and Gillespie, Northern Ireland: A Chronology of the Troubles.

4 The Ritz Cinema in Athlone was built in 1939 and was designed by Bill O'Dwyer from the office of Michael Scott, the renowned Irish architect. Extensive glazing and white plasterwork, together with portholes and flat roofs suggested a maritime theme. After years of disuse, the building was finally demolished in the I990s. 'I938 - Ritz Cinema, Athlone, Co. Westmeath', http://archiseek. com/2009/1938-ritz-cinema-athlone/.

5 Gandhi is a biographical film directed by Richard Attenborough. It dramatizes the life of Mohandas Gandhi, the leader of India's non-violent independence movement. It was released in Ireland on April 22, 1983, www.imdb.com/title/ ttoo83987/.

6 Heat and Dust, a novel by Ruth Prawer Jhabvala, was published in 1975 and won the Booker Prize in the same year. In 1983 , it was made into a film from Merchant Ivory productions (www.imdb.com/title/ttoo84058/).

7 Richard Rorty, Contingency, Irony and Solidarity (Cambridge: Cambridge University Press, 1989), p. 4I.

8 'Paddle-boat / and tin canoe' evoke the culture of Mark Twain's Adventures of 
Huckleberry Finn (London: Penguin, 20I2), the quintessential text of American coming of age.

9 Poetic precursors include Wordsworth, terrified by cliffs in his stolen canoe (The Prelude, Book I). In the Irish context, further resonances can be noted: Thomas Kinsella's 'Wyncote, Pennsylvania: a gloss' was first published in New Poems (1973), shortly after he had moved to America. It includes a sensitive description of a mocking-bird in this new environment. Bernard O'Donoghue's 'The Nuthatch' draws parallels between bird and observing poet, noting that the bird 'didn't / Lift his head as he pored over his wood-text'. See Bernard O'Donoghue, Selected Poems (London: Faber \& Faber, 2008), p. I7.

Io Rorty, Contingency, Irony and Solidarity, p. 47.

II Julia Kristeva, Strangers to Ourselves, trans. Leon S. Roudiez (New York: Columbia University Press, I99I), p. Io.

I2 John McAuliffe, ' $X$ marks a new place for Vona Groarke, and for Irish writing'. Review of $X$ by Vona Groarke, Irish Times, March 15, 2014, p. I3.

I3 Jay Winter, 'Sites of Memory and the Shadow of War', in Erll and Nünning, Cultural Memory Studies, p. 72.

I4 Turkle discusses the work of Bruno Latour in Sherry Turkle (ed.), Evocative Objects: Things We Think With (Cambridge, MA: MIT Press, 2007), loc. 2449 [kindle edition].

Is Hedwig Schwall, 'How Do you Make a Teapot Be Intellectually Interesting? An Interview with Vona Groarke', Irish University Review 43.2 (Autumn/Winter 20I3), pp. 288-306.

I6 'Oh all the money that e'er I had, I spent it in good company / And all the harm that e'er I've done, alas, it was to none but me / And all I've done for want of wit to memory now I can't recall / So fill to me the parting glass, good night and joy be with you all' ('The Parting Glass'). See Colm Ó Lochlainn, Irish Street Ballads (London: Pan, 1978).

I7 Four of these poems were printed in Irish University Review 43.2 (Autumn/Winter 2013), in the following order: 'The Garden from Above', 'The Garden in Hindsight', 'The Garden as Event' and 'The Garden as an Island Approached by a Tidal Causeway'.

I8 'O chestnut tree, great rooted blossomer, / Are you the leaf, the blossom or the bole? / O body swayed to music, O brightening glance, / How can we know the dancer from the dance?'. W. B. Yeats, 'Among School Children', The Collected Works of W. B. Yeats, vol. I, The Poems (London: Simon \& Schuster, 2010), p. 219. Groarke herself has commented on the importance of Yeats to her as a practising poet: 'he's a great technician, he has great mastery of metre and music within a line ... he also has real intellectual ballast in the poems'. Schwall, 'How Do you Make a Teapot?', p. 290. 


\title{
Conclusion
}

\author{
Memories of the Future
}

The many ways in which contemporary Irish women poets respond to the past is evidence of the significance of this negotiation for generations of writers, and its vital intersection with a range of themes and practices. All the poets featured in this study engage with different dimensions of memory, from explorations of key historical events to the recollection of the turbulent personal past; from shared networks of tradition to textual resonances from their own earlier work. Some of these poets first became established in the r960s and 1970s, when feminist debates inflected how their work was read and received. The development of their poetry, politically and aesthetically, has not only helped to keep poetry written by women to the forefront of the Irish poetry scene but has also highlighted the significance of reflecting on this process of evolution within creative practice itself.

All acts of reading and criticism take place in time and they too must reflect upon the trajectories of such commentary. In this sense, we remember past reading experiences - poetic and critical - and bring these memories to our analysis of the texts we encounter. Eavan Boland's ongoing interrogation of silenced voices in narrative history has created an awareness of the partial nature of the official past; yet it has also highlighted the strategic character of some memory practices. In the presence of this repeated engagement, other women have traced oblique routes through personal and political histories, using the dynamics of place and belonging as a counterpoint. For poets such as Paula Meehan, Mary O'Malley and Eva Bourke, responses to the past - and the formal mechanisms deployed to explore them - are shaped by the landscapes and streetscapes of experience. The enduring links between temporal and spatial imagination for these poets has not limited their aesthetic 
development, instead it has emphasized their creative process as one of constant renewal.

The rich variety of work produced by women during this period emphasizes the interconnected nature of these voices. As some of these poets write out of a specifically Irish present, others move abroad to articulate an Irish experience that may be in the past, yet remains an important dimension of their identity. Mairéad Byrne and Catherine Walsh have demonstrated that unfixed perspectives can be productive of formally innovative poems that extend the boundaries of form and tradition. Though these texts create very different reading experiences, they contribute to a larger network of meaning and representation that encompasses stylistically various texts. This has the important effect of making these texts 'present' to one another, existing in the same critical space and therefore demonstrating an awareness that the poetic practice of others is a vital part of each woman's own writing process.

The generational differences encompassed by this study reflect the overlapping nature of present and past in important ways. The women represented here are born between 1942 and 1983 and represent three generations of creative life. By bringing these poets together, this book draws attention to their evolving styles and preoccupations, yet also shows how key concerns with personal, social and political histories remain strong. Though the younger poets represented here do not identify with feminism, their mediation of the past shows an awareness that such an inheritance spans ideological and personal realms.

Within these patterns of connection, personal relationships remain an important determinant of identity and a means of exploring one's place in the world. A number of poets from the younger generation explore their relationship to time through inter-generational reflection - by reflecting upon their bonds to parents and grandparents, and with their own young children. Sinéad Morrissey's Parallax is a volume that brings past and future into alignment in this way. 'The House of Osiris in the Field of Reeds' records the inexorable process of leaving youth behind:

All through last winter, each day

made to bear the pressure of impending loss.

Soon it will no longer be like this. The lean girls

picnicking in the park, their haul of charity-shop

dresses at their feet

$(P X 57)$

The collection as a whole contemplates how the past can be recorded; its particular histories are read through photography and text. Birth-giving 
offers a counterpoint to these explorations, combining memory and futurity in the single unit of the poem.

'A Matter of Life and Death' is particularly significant in this respect. It subtly binds together the process of childbirth with the death of a grandmother, balancing the optimism regarding new life with the loss of the old: 'making room as she herself predicted' ( $P X_{4 \mathrm{I}}$ ). This poem of long lines and tercets negotiates the escalating pain of labour through its intensification and release, both mind and body concentrating on the event to come. To pass the time, the speaker watches 'A Matter of Life and Death', a Powell and Pressburger film made in 1946. The film, a fantasy featuring David Niven as a Second World War pilot, plays with the relationship between this world and the next. Our first glimpse of the action interweaves Niven's decision to bale out of a burning plane with a heightening of labour pain from which no escape is possible. At this point in the poem (much as in the film) present and future become confused: references to pethidine and epidurals are followed by a vision of the speaker walking 'the sunny verges / / of our cul-de-sac like a wind-up, fat-man toy' ( $\left.P X_{4} \mathrm{I}\right)$. Soon the film reveals the monochrome of the afterlife, ${ }^{1}$ where the vision of death is one of orderly exchange a balancing of the books between life and death. This image presages the equilibrium of the poem itself, balanced between the death of the grandmother and the expectation of new life. The film plays a dual role in furthering this theme: it not only suggests the coexistence of worlds but also evokes a period when the speaker's grandmother was young and herself giving birth. This female lineage is an important one, creating a vital link between generations of women that is deeply embedded in the contexts of writing.

The disruption of time is an important way in which the poem unites theme and form, destabilizing our sense of clear progression. Morrissey's focus shifts between present physicality, personal memory and imaginative creation, affirming the mind's tendency to move swiftly across time, to gather and connect disparate elements at first unconsciously and then with more deliberation. At the close of the poem, the grandmother enters the film world - 'young, glamorous, childless, free, in her I940s' shoes and sticky lipstick' (PX 43) - to become twice imagined: first by the speaker's remembrance, then by the cinematic construct. Morrissey's layering of memory and imagination here shows how the poetic text can realize discursive tensions in its own formal techniques.

Morrissey's 'Home Birth' and Leanne O'Sullivan's 'You Were Born 
at Mealtime' both explore how the moment of birth changes the space of the family, displacing existing positions to make room for new relationships. Morrissey's use of the sonnet overturns the expected dynamics of arrival: here it is the sick older sibling who goes to hospital, the newborn who emerges at home - 'You came back days later, pale and feverish, / and visited us in the bedroom in your father's arms. / You turned your head to take her in: this black-haired, / tiny yellow person who'd happened while you slept' ( $P X$ I8). O'Sullivan's poem is more oblique, imagining birth within a space of memory: 'The empty kitchen hummed when I came home / like a swollen river with the swelling gone' (MR I4). The delicate balance here of recall and expectation is reflected in the whole volume: The Mining Road is preoccupied with the process of recollection, from the 'Old homes and a half remembered word of mouth' in the opening poem $(M R$ 13) to the repeated entreaty to the beloved in 'Valentine' - 'remember / / how at night you bring your face to mine' (MR 52). The volume resonates with the landscape of West Cork, revealing the ways in which the past is embedded in place and community.

Sara Berkeley's landscapes are distinct from this: her last two collections, Strawberry Thief (2005) and The View from Here (2010) are largely set on the west coast of America, where Berkeley now lives. The earliest of these poems celebrate birth: the title poem from Strawberry Thief speaks to Anne Sexton's poem to her daughter 'Little Girl, My String Bean, My Lovely Woman' in its use of plant imagery: 'Bean seedling, starting with that soft, divided green, / already you are wild thyme, climbing rose, strawberry thief' (ST I5). ${ }^{2}$ These poems embrace the present moment in celebrating the newness of the child's life but are also aware of the fleeting nature of this intense experience - 'I touch her tiny shoulder blades as a gentle reminder - / she'll be my flown one' ('The Call', ST I3). Within these meditations on happiness and completion, more troubled memories are to be found, reminding the reader of the experiences that have led to this moment, and those that may follow in time. Fittingly, The View from Here records the need to look to both the past and the future: 'And though the past / is a dress I'll always wear / I am putting on a new one' ('Carrying', $V H$ is). Many of these poems are preoccupied with loss: 'Meal for Friends' addresses this process unflinchingly. A four-stanza poem, it begins by juxtaposing birth and death: the 'white curtain blowing in the breeze' set against the house with blinds drawn. Yet the poem is a meditation on memory and forgetting: 
Everything I needed to remember

has been remembered; everything I yearned to forget

is lost. Who knows what future, who cares what past,

the night sky is no longer far away

Again the poem holds us in the present, but this time not to celebrate the joy of young life but to take stock of the moment that has been reached through years of both suffering and delight. Here the relationship between past and present is vital, even as it is discarded, the poem's stanzas marking the cardinal points by which we must get our bearings - the intimacy of friendships, the broad and ever-changing sweep of our thoughts and feelings.

Leontia Flynn's collection Drives also negotiates between the experiences of generations, and in a book of journeys the poems remain grounded in the lives of writers, among them Charles Baudelaire, Elizabeth Bishop, Sylvia Plath. The act of driving is one that at once invokes the past and seeks to leave it behind, as the poem 'Dungeness' reveals:

Here were the cottage and lighthouse. You wanted to cut ties so came to this coast away from 'You know ...' Now I look behind me and there is our youth among the shingled waste that recedes before my eyes like the angel of history ${ }^{3}$

The decision to move away from the past prompts reflection on this relationship; the hidden knowledge of the elliptical explanation suggests an apocalyptic landscape, yet one, it seems, that can be escaped.

One of the most resonant poems in this collection reads the landscape as a means to explore the difficult relationship between remembering and forgetting. 'Drive' situates the speaker's mother and father in a landscape that remains meaningful to one, but not to the other. For her father, suffering from Alzheimer's Disease, road signs become words more useful for their musical resonance than for the directions they offer:

They drive along the old road and the new road my father, in beside her, reads the signs

as they escape him - for now they are empty signs, now one name means as little as another; the roads they drive along are fading roads. 
- 'Dromore', 'Banbridge' (my father's going to drive

my mother to distraction). 'In Banbridge town ...', he sings.

Retracing their shared life through the form of an imperfect sestina, Flynn suggests the change within sameness; the process of recurrence that may bring new meaning or no meaning at all. The difference in perspective between husband and wife is delicately handled - inverted commas appearing around the place names her father reads. The landscape the mother traverses suggests her adventurous younger self, but behind this 'indefatigable drive' is the clock that ticks - heard first in the sound of the cricket, then reappearing in the clock the mother turns back to recapture her early married life when her grown children were still young. This reminds us that memory will deteriorate, and that shared time, when familial care will still be possible, is short. Flynn's choice of the sestina in which to interweave past and present, connection and detachment, movingly expresses the need for structure to bind us to one another and to the places that are meaningful to us.

In this book of memory and forgetting, Flynn summons key dilemmas for the younger Irish poet: the inescapable facts of geography and history that can be altered at will, or through a twist of fate; painful experience can be shaped by wit. The radical instability of memory, glimpsed in the work of the older generation, is more profoundly expressed by the women growing to adulthood in the I990s. The personal independence that was the hallmark of this generation profoundly altered their relationship to forms of authority, yet the question of subjectivity remains an enduring preoccupation in their work. In this coming together of private and public, of difficult circumstances and control in their expression, the dynamics of memory and estrangement are aptly expressed. It is this rich and challenging juncture that remains as critically compelling as ever for readers of poetry in Ireland today.

\section{Notes}

I The film was shot in Technicolor, but for the afterlife scenes the colour was not fully developed, giving a pearly monochrome to the scenes. See www.powell-pressburger. org.

2 Sexton's poem, addressed to her elder daughter when aged II, was first published in Live or Die (New York: Houghton Mifflin, 1966).

3 'This is how one pictures the angel of history. His face is turned toward the past. 


\section{CONTEMPORARY IRISH WOMEN POETS}

Where we perceive a chain of events, he sees one single catastrophe which keeps piling wreckage upon wreckage and hurls it in front of his feet'. Walter Benjamin,

'Theses on the Philosophy of History', Illuminations, ed. Hannah Arendt, trans. Harry Zohn (London: Fontana, 1992), p. 249. 


\section{Bibliography}

\section{Texts by Irish Women Poets}

Berkeley, Sara, Strawberry Thief (Oldcastle, Co. Meath: Gallery Press, 2005).

- The View from Here (Oldcastle, Co. Meath: Gallery Press, 20I0).

Boland, Eavan, Collected Poems (Manchester: Carcanet, 1995).

- In a Time of Violence (Manchester: Carcanet, 1994).

- The Journey and Other Poems (Galway: Arlen House, 1986; Manchester: Carcanet, 1987).

- The Lost Land (Manchester: Carcanet, 1998).

- Outside History (Manchester: Carcanet, 1990).

- Woman without a Country (Manchester: Carcanet, 20I4).

Bourke, Eva, Piano (Dublin: Dedalus Press, 20II).

- Travels with Gandolpho (Dublin: Dedalus Press, 200o).

Bryce, Colette, The Full Indian Rope Trick (London: Picador, 2005).

- The Heel of Bernadette (London: Picador, 2000).

- Self-Portrait in the Dark (London: Picador, 2008).

- The Whole and Rain-domed Universe (London: Picador, 20I4).

Byrne, Mairéad, The Best of (What's Left of) Heaven (Baltimore, MD:

Publishing Genius, 20IO).

- Nelson and the Huruburu Bird (Bray, Co. Wicklow: Wild Honey Press, 2003).

- Talk Poetry (Oxford, OH: Miami University Press, 2007).

Dorcey, Mary, Moving into the Space Cleared by Our Mothers (Galway:

Salmon Press, 199I).

Flynn, Leontia, Drives (London: Jonathan Cape, 2008).

Groarke, Vona, Flight (Oldcastle, Co. Meath: Gallery Press, 2002).

- Juniper Street (Oldcastle, Co. Meath: Gallery Press, 2006).

- Other People's Houses (Oldcastle, Co. Meath: Gallery Press, 1999).

- Shale (Oldcastle, Co. Meath: Gallery Press, 1994).

- Spindrift (Oldcastle, Co. Meath: Gallery Press, 2009).

—X (Oldcastle, Co. Meath: Gallery Press, 20I4). 
Hardie, Kerry, A Furious Place (Oldcastle, Co. Meath: Gallery Press, 1996). McGuckian, Medbh, The Book of the Angel (Oldcastle, Co. Meath: Gallery Press, 2004).

- Captain Lavender (Oldcastle, Co. Meath: Gallery Press, 1995).

- The Face of the Earth (Oldcastle, Co. Meath: Gallery Press, 2002).

- The Flower Master (Oxford: Oxford University Press, 1982; Oldcastle, Co. Meath: Gallery Press, 1993).

- Had I a Thousand Lives (Oldcastle, Co. Meath: Gallery Press, 2002).

- On Ballycastle Beach (Oxford: Oxford University Press, I988).

- Portrait of Joanna (Belfast: Ulsterman Publications, 1980).

- Shelmalier (Oldcastle, Co. Meath: Gallery Press, 1998).

- Single Ladies: Sixteen Poems (Devon: Interim Press, I980).

- Venus and the Rain (Oxford: Oxford University Press, 1984; Oldcastle, Co. Meath: Gallery Press, 1994).

Meehan, Paula, Dharmakaya (Manchester: Carcanet, 200o).

- The Man Who Was Marked by Winter (Oldcastle, Co. Meath: Gallery Press, I99I).

- Painting Rain (Manchester: Carcanet, 2009).

- Pillow Talk (Oldcastle, Co. Meath: Gallery Press, 1994).

Morrissey, Sinéad, Between Here and There (Manchester: Carcanet, 2002).

- Parallax (Manchester: Carcanet, 2013).

- There was Fire in Vancouver (Manchester: Carcanet, 1996).

Ní Chuilleanáin, Eiléan, The Brazen Serpent (Oldcastle, Co. Meath: Gallery Press, 1994).

- The Girl Who Married the Reindeer (Oldcastle, Co. Meath: Gallery Press, 200I).

- The Magdalene Sermon (Oldcastle, Co. Meath: Gallery Press, 1989).

- The Second Voyage (Dublin: Gallery Press, 1986).

- The Sun Fish (Oldcastle, Co. Meath: Gallery Press, 2009).

O'Malley, Mary, The Boning Hall: New and Selected Poems (Manchester: Carcanet, 2002).

- The Knife in the Wave (Galway: Salmon Press, 1997).

- Valparaiso (Manchester: Carcanet, 2012).

O'Sullivan, Leanne, The Mining Road (Tarset, Northumberland: Bloodaxe Books, 20I3).

Walsh, Catherine, City West (Exeter: Shearsman, 2005).

- Idir Eatortha and Making Tents (London: Invisible Books, 1996).

\section{Other Primary Sources}

Bourke, Angela, et al., The Field Day Anthology of Irish Women's Writing and Traditions, 2 vols (Cork: Cork University Press, 200I).

Bourke, Eva, and Borbála Faragó (eds), Landing Places: Immigrant Poets in Ireland (Dublin: Dedalus Press, 20IO). 
Bushe, Paddy (ed.), Voices at the World's Edge: Irish Poets on Skellig Michael (Dublin: Dedalus Press, 20Io).

Claire, Paula, 'The Paula Claire Archive of Sound and Visual Poetry', accessed May I2, 20I4, www.paulaclaire.com.

De Angelis, Irene, and Joseph Woods (eds), Our Shared Japan: An Anthology of Contemporary Irish Poetry (Dublin: Dedalus, 2007).

Deane, Seamus, Andrew Carpenter and Jonathan Williams (eds), The Field Day Anthology of Irish Writing, 3 vols (Derry: Field Day Publications, I99I).

Eliot, T. S., Collected Poems, I909-1962 (London: Faber \& Faber, 1963).

Hartnett, Michael, Ó Bruadair: Selected Poems of Dáibhi Ó Bruadair

(Oldcastle, Co. Meath: Gallery Press, 1985).

Heaney, Seamus, Death of a Naturalist (London: Faber \& Faber, 1966).

- New Selected Poems: 1966-1987 (London: Faber \& Faber, 1990).

- Opened Ground: Poems I966-1996 (London: Faber \& Faber, 1998).

Howe, Susan, 'Susan Howe at the Poetry Foundation', accessed May I2, 20I4, www.poetryfoundation.org/bio/susan-howe\#about.

Joyce, James, Finnegans Wake (London: Faber, 1939).

- Ulysses (Paris: Sylvia Beach, 1922).

Kiberd, Declan, and Gabriel Fitzmaurice (eds), An Crann Faoi Bláth/The Flowering Tree (Dublin: Wolfhound Press, I99I).

Kinsella, Thomas, Another September (Dublin: Dolmen Press; Oxford: Oxford University Press, 1962).

- New Poems (Dublin: Dolmen Press, 1973).

- Nightwalker and Other Poems (Dublin: Dolmen Press, I967).

- Poems from Centre City (Dublin: Peppercanister, 1990).

MacNeice, Louis, Collected Poems (London: Faber \& Faber, 1979).

Ó Lochlainn, Colm, Irish Street Ballads (London: Pan, 1978).

O’Donoghue, Bernard, Selected Poems (London: Faber \& Faber, 2008).

Plath, Sylvia, Ariel: The Restored Edition (London: Faber \& Faber, 2004).

Rich, Adrienne, The Fact of a Doorframe: Selected Poems I950-200I (New

York: W.W. Norton, 2002).

Sexton, Anne, Live or Die (New York: Houghton Mifflin, 1966).

Twain, Mark, Adventures of Huckleberry Finn (London: Penguin, 20I2).

Wordsworth, William, The Prelude: The Four Texts (I798, I799, I805, I850) (Harmondsworth: Penguin, 1996).

Yeats, W. B., The Collected Works of W. B. Yeats, vol. I, The Poems (London: Simon \& Schuster, 20I0).

\section{Secondary Sources}

'1938 Ritz Cinema, Athlone, Co. Westmeath', http://archiseek. com/2009/1938-ritz-cinema-athlone/.

Ahmed, Sara, 'Who Knows? Knowing Strangers and Strangerness', Australian Feminist Studies I5.3I (2000), pp. 49-68. 
Allen, Nicholas, “"Each Page Lies Open to the Version of Every Other”: History in the Poetry of Eiléan Ní Chuilleanáin', Irish University Review 37.I (Spring/Summer 2007), pp. 22-35.

Andrews, Elmer, "Some Sweet Disorder" - The Poetry of Subversion: Paul Muldoon, Tom Paulin and Medbh McGuckian', in Gary Day and Brian Docherty (eds), British Poetry from the I950s to the Iggos: Politics and Art (Basingstoke and New York: Macmillan/St Martin's Press, 1997), pp. II8-42.

'Ann Lovett: The Story that Wouldn't Remain Local', Scannal, RTÉ I television documentary, produced by Sarah Ryder, 2004.

Archer, Nuala, 'Nuala Archer on Blue Farm', Two Women, Two Shores: Poems by Medbh McGuckian and Nuala Archer (Baltimore, MD: New Poets Series; Galway: Salmon Press, 1989).

Armstrong, Charles, I., Figures of Memory: Poetry, Space, and the Past (Basingstoke: Palgrave Macmillan, 2009).

Assmann, Aleida, and Linda Shortt (eds), Memory and Political Change (Basingstoke: Palgrave Macmillan, 20I2).

Bachelard, Gaston, The Poetics of Space (Boston, MA: Beacon Press, 1994). Bainbridge, Charles, 'The Great Escape'. Review of The Full Indian Rope Trick by Colette Bryce, Guardian, January 29, 2005, accessed November 23, 20I4, www.theguardian.com/books/2005/jan/29/featuresreviews. guardianreviewi2.

Bal, Mieke, Travelling Concepts in the Humanities (Toronto: University of Toronto Press, 2002).

Bal, Mieke, Jonathan Crewe and Leo Spitzer (eds), Acts of Memory: Cultural Recall in the Present (Hanover, NH: University Press of New England, I999).

Barnett, Clive, 'Ways of Relating: Hospitality and the Acknowledgement of Otherness', Progress in Human Geography 29.I (2005), pp. 5-2I.

Baronian, Marie-Aude, Stephan Besser and Yolande Jansen (eds), Diaspora and Memory: Figures of Displacement in Contemporary Literature, Arts and Politics (Amsterdam: Rodopi, 2006).

Barthes, Roland, 'Semiology and the Urban', in Mark Gottdreiner and Alexandros P. Logapoulous (eds), The City and the Sign: An Introduction to Urban Semiotics (New York: Columbia University Press, 1986), pp. $87-98$.

Bartlett, Frederic, Remembering: A Study in Experimental and Social Psychology (Cambridge: Cambridge University Press, I954 [1932]).

Batten, Guinn, 'Boland, McGuckian, Ní Chuilleanáin and the Body of the Nation', in Matthew Campbell (ed.), The Cambridge Companion to Contemporary Irish Poetry (Cambridge: Cambridge University Press, 2003), pp. 169-88.

— “The World Not Dead After All”: Eiléan Ní Chuilleanáin's Work of Revival', Irish University Review 37.I (Spring/Summer 2007), pp. I-2I. 
Bear, Bethany, 'Writing within a Zone of Grace: Eavan Boland, Sacred Space, and the Redemption of Representation', Contemporary Literature 54. I (Spring 2013), pp. 77-IO8.

Beer, Ann, 'Medbh McGuckian's Poetry: Maternal Thinking and a Politics of Peace', Canadian Journal of Irish Studies I8.I (July 1992), pp. 192-203.

Begnal, Michael, Review of Catherine Walsh's City West, B'Fhiu an Braon Fola (June 2006), accessed February 7, 20I2, www.mikebegnalblogspot.ie.

Beiner, Guy, 'Between Trauma and Triumphalism: The Easter Rising, the Somme, and the Crux of Deep Memory in Modern Ireland', Journal of British Studies 46.2 (April 2007), pp. 366-89.

- 'Commemorative Heritage and the Dialectics of Memory', in Mark McCarthy (ed.), Ireland's Heritages: Critical Perspectives on Memory and Identity (London: Ashgate, 2005), pp. 55-69.

- 'Modes of Memory: Remembering and Forgetting the Irish Rebellion of I798', in Oona Frawley (ed.), Memory Ireland, vol. I, History and Modernity (Syracuse, NY: Syracuse University Press, 20II), pp. 66-82.

- 'Recycling the Dustbin of Irish History: The Radical Challenge of "Folk Memory", History Ireland I4. I (January/February 2006), pp. $42-7$.

Benjamin, Walter, 'Theses on the Philosophy of History', in Hannah Arendt (ed.), Illuminations, trans. Harry Zohn (London: Fontana, 1992).

Bergvall, Caroline, 'No Margins to this Page: Female Experimental Poets and the Legacy of Modernism', Fragmente 5 (1993), pp. 30-8.

Bew, Paul, and Gordon Gillespie (eds), Northern Ireland: A Chronology of the Troubles, 1968-99 (Dublin: Gill \& Macmillan, 1999).

Blakeman, Helen, "I am listening in black and white to what speaks to me in blue": Medbh McGuckian, interviewed by Helen Blakeman', Irish Studies Review II.I (2003), pp. 6I-9.

Blau DuPlessis, Rachel, 'Considering the Long Poem: Genre Problems', Readings: Response and Reactions to Poetries, 4 (2008), accessed February 17, 20I2, www.bbk.ac.uk/readings/issues/issue4/ duplessis_on_Consideringthelongpoemgenreproblems.

Boland, Eavan, 'Daughters of Colony: A Personal Interpretation of the Place of Gender Issues in the Postcolonial Interpretation of Irish Literature', Eire-Ireland: A Journal of Irish Studies 32.2/3 (Summer/Autumn 1997), pp. 9-20.

- A Journey with Two Maps: Becoming a Woman Poet (Manchester: Carcanet, 20II).

- A Kind of Scar: The Woman Poet in a National Tradition (Dublin: Attic Press, 1989).

- Object Lessons: The Life of the Woman and the Poet in Our Time (London: Vintage, I995).

- 'A Woman Without a Country: A Detail', PN Review 4I.2 (November/ December 20I4), p. 49. 
Bort, Eberhard (ed.), Commemorating Ireland: History, Politics, Culture (Dublin: Irish Academic Press, 2004).

Bourke, Angela, et al., The Field Day Anthology of Irish Writing, vols 4 and 5, Irish Women's Writing and Traditions (Cork: Cork University Press, 2002).

Brearton, Fran, Review of Parallax, Guardian, September 6, 2013, accessed January 25, 20I4, www.theguardian.com/books/20I3/sep/o6/ parallax-sinead-morrissey-review.

Broom, Sarah, Contemporary British and Irish Poetry: An Introduction (Basingstoke and New York: Macmillan, 2006).

- 'McGuckian's Conversations with Rilke in Marconi's Cottage', Irish University Review 28.I (Spring/Summer 1998), pp. 33-50.

Burgess, Glyn S., and Clara Strijbosch, The Legend of St Brendan: A Critical Bibliography (Dublin: Royal Irish Academy, 200o).

Caruth, Cathy, Unclaimed Experience: Trauma, Narrative, and History (Baltimore, MD and London: Johns Hopkins University Press, 1996).

Carville, Conor, 'Warding off an Epitaph': Had I a Thousand Lives, in Shane Alcobia-Murphy and Richard Kirkland (eds), The Poetry of Medbh McGuckian: The Interior of Words (Cork: Cork University Press, 2010), pp. II7-29.

Clutterbuck, Catriona, 'The Artistry of Freefall'. Review of Dharmakaya, Metre io (Autumn 200I), pp. IIO-I4.

- 'A Gibbous Voice: The Poetics of Subjectivity in the Early Poetry of Medbh McGuckian', in Shane Alcobia-Murphy and Richard Kirkland (eds), The Poetry of Medbh McGuckian: The Interior of Words (Cork: Cork University Press, 20I0), pp. 4I-67.

- 'Irish Critical Responses to Self-Representation in Eavan Boland, I987-1995', Colby Quarterly 35.4 (1999), pp. 275-87.

- 'New Irish Women Poets: The Evolution of (In)determinacy in Vona Groarke', in Fran Brearton and Alan Gillis (eds), The Oxford Handbook of Modern Irish Poetry (Oxford: Oxford University Press, 20I2), pp. 65I-67.

Collins, Lucy, 'Architectural Metaphors: Representation of the House in the Poetry of Eiléan Ní Chuilleanáin and Vona Groarke', in Scott Brewster and Michael Parker (eds), Irish Literature since I9oo: Diverse Voices (Manchester: Manchester University Press, 2008), pp. I42-59.

- 'Being in Span: The Space of the Subject in Catherine Walsh's City West', Journal of British and Irish Innovative Poetry 5.2 (20I4), pp. 3I-46.

- 'Emergent Ground: Four Poems by Vona Groarke', Irish University Review 43.2 (Autumn/Winter 2013).

- 'Joyful Mysteries: Language and Spirituality in Medbh McGuckian's Recent Poetry', in Elke d'Hoker, Raphaël Ingelbien and Hedwig Schwall (eds), Irish Women's Writing (Berne: Peter Lang, 2010), pp. 4I-56.

- 'A Way of Going Back: Memory and Estrangement in the Poetry of Paula Meehan', An Sionnach: A Journal of Literature, Culture and the Arts 5.I-2 (Spring/Fall 2009), pp. I27-39. 
- 'What She Lost and How: Eavan Boland's London Childhood', in Thomas Herron (ed.), Irish Writing London, vol. 2, Post-War to the Present (London: Continuum, 20I2), pp. 33-46.

Colman, Anne Ulry, 'Far from Silent: Nineteenth-Century Irish Women Writers', in Margaret Kelleher and James H. Murphy (eds), Gender Perspectives in Nineteenth-Century Ireland: Public and Private Spheres (Dublin: Irish Academic Press, I997), pp. 203-II.

Conboy, Katie, 'Lays of the Land'. Review of The Lost Land by Eavan Boland, and Meadowlands by Louise Gluck, Poetry Ireland Review 6o (Spring 1999), pp. 96-9.

Conlon, James, 'Cities and the Place of Philosophy', in Sharon M. Meagher (ed.), Philosophy and the City: Classic to Contemporary Writings (New York: State University of New York Press, 1999), pp. 199-209.

Connerton, Paul, How Societies Remember (Cambridge: Cambridge University Press, 1989).

Consalvo, Deborah McWilliams, 'An Interview with Eavan Boland', Studies: An Irish Quarterly Review 8I.32I (Spring 1992), pp. 89-100.

- 'An Interview with Eiléan Ní Chuilleanáin', Irish Literary Supplement I2.I (1993), pp. I5-I7.

Critchley, Simon, Ethics-Politics-Subjectivity: Essays on Derrida, Levinas and Contemporary French Thought (London and New York: Verso, 1999).

Cubitt, Geoffrey, History and Memory (Manchester: Manchester University Press, I98I).

Davidson, Ian, Ideas of Space in Contemporary Poetry (London: Palgrave Macmillan, 2007).

Davies, Alistair, and Alan Sinfield (eds), British Culture of the Postwar: An Introduction to Literature and Society, 1945-1999 (London: Routledge, 2000).

Davis, Alex, 'Deferred Action: Irish Neo-Avant-Garde Poetry', Angelaki 5.I (2000), pp. 8I-93.

Dawe, Gerald, 'Poetry as Commemoration', in Eberhard Bort (ed.),

Commemorating Ireland: History, Politics, Culture (Dublin: Irish Academic Press, 2004), pp. 213-22.

De Angelis, Irene, The Japanese Effect in Contemporary Irish Poetry (London: Palgrave Macmillan, 20I2).

- 'Sinéad Morrissey: Between Northern Ireland and Japan', Journal of Irish Studies 20 (2005), accessed March IO, 2012, www.carcanet.co.uk.

Deane, Seamus (ed.), The Field Day Anthology of Irish Writing, vols I-3 (Derry: Field Day Publications, 199I).

- 'Wherever Green is Read', in Máirín Ní Dhonnchadha and Theo Dorgan (eds), Revising the Rising (Derry: Field Day, 199I), pp. 9I-IO5.

Denman, Peter, 'Contexts of Irish Writing', Irish University Review 2I.I (Spring/Summer 199I), pp. I-2. 
Derrida, Jacques, Archive Fever: A Freudian Impression (Chicago: University of Chicago Press, 1998).

- Of Hospitality, trans. Rachel Bowlby (Stanford, CA: Stanford University Press, 1997).

Docherty, Thomas, 'Initiations, Tempers, Seductions: Postmodern McGuckian', in Neil Corcoran (ed.), The Chosen Ground: Essays on the Contemporary Poetry of Northern Ireland (Brigend: Seren, 1992), pp. 192-210.

Edkins, Jenny, Trauma and the Memory of Politics (Cambridge: Cambridge University Press, 2003).

Elliott, Marianne, Robert Emmet: The Making of a Legend (London: Profile Books, 2003).

Ellmann, Maud, The Hunger Artists: Starving, Writing and Imprisonment (London: Virago Pres, 1992).

Erll, Astrid, and Ansgar Nünning (eds), Cultural Memory Studies: An International and Interdisciplinary Handbook (New York and Berlin: Walter de Gruyter, 2008).

Falci, Eric, Continuity and Change in Irish Poetry, I966-20Io (Cambridge: Cambridge University Press, 2012).

Faragó, Borbála, “'The Informant”, Eiléan Ní Chuilleanáin', Irish University Review 39.2 (Autumn/Winter 2009), pp. 30I-9.

- Medbh McGuckian (Lewisburg, PA: Bucknell University Press; Cork: Cork University Press, 20I4).

- 'Medbh McGuckian: The Angel in Two Parts', European English Messenger I3.2 (Autumn 2004), pp. 47-54.

Finch, Annie, 'Coherent Decentering: Toward a New Model of the Poetic Self', in Kate Sontag and David Graham (eds), After Confession: Poetry as Autobiography (Saint Paul, MN: Graywolf Press, 200I), pp. 137-43.

Flynn, Leontia, Reading Medbh McGuckian (Dublin: Irish Academic Press, 20I4).

Fogarty, Anne, "I was a voice": Orality and Silence in the Poetry of Eavan Boland', in Elke D'hoker, Raphaël Ingelbien and Hedwig Schwall (eds), Irish Women Writers: New Critical Perspectives (Berne: Peter Lang, 20II), pp. 7-24.

Frawley, Oona, Memory Ireland, vol. I, History and Modernity (Syracuse, NY: Syracuse University Press, 20II).

- Memory Ireland, vol. 2, Diaspora and Memory Practices (Syracuse, NY: Syracuse University Press, 2012).

- Memory Ireland, vol. 3, The Famine and the Troubles (Syracuse, NY: Syracuse University Press, 20I4).

Freud, Sigmund, The Uncanny, trans. David McLintock (London: Penguin, 2003).

Gibbons, Luke, “'Where Wolfe Tone's Statue Was Not”: Joyce, Monuments and Memory', in Ian McBride (ed.), History and Memory in Modern Ireland (Cambridge: Cambridge University Press, 200I), pp. 139-59. 
Gillis, John R., 'Memory and Identity: The History of a Relationship', in John R. Gillis (ed.), Commemorations: The Politics of National Identity (Princeton, NJ: Princeton University Press, I994), pp. 3-24.

Gilroy, Paul, 'Diaspora and the Detours of Identity', in Kay Woodward (ed.), Identity and Difference (London: Sage, 1997), pp. 299-343.

González-Arias, Luz Mar, 'In Dublin's Fair City: Citified Embodiments in Paula Meehan's Urban Landscapes', An Sionnach: A Journal of Literature, Culture and the Arts 5.I-2 (Spring/Fall 2009), pp. 34-49.

Goodby, John, Irish Poetry since I950: From Stillness into History (Manchester: Manchester University Press, 2000).

Gottdreiner, Mark and Alexandros P. Logapoulous (eds), The City and the Sign (New York: Columbia University Press, 1986).

Grennan, Eamon, 'Mazing McGuckian', Facing the Music: Irish Poetry in the Twentieth Century (Omaha, NE: Creighton University Press, I999), pp. 35I-6o.

- 'Real Things: The Work of Eiléan Ní Chuilleanáin', Facing the Music: Irish Poetry in the Twentieth Century (Omaha, NE: Creighton University Press, 1999), pp. 283-95.

Grubgeld, Elizabeth, 'Topography, Memory, and John Montague's “The Rough Field”, Canadian Journal of Irish Studies I4.2 (January 1989), pp. 25-36.

Gubbins, Martin, 'Time and Visual Poetry', PORES 3, accessed February I2, 20I2, www.pores.bbk.ac.uk/3/gubbins.html.

Guinness, Selina, “'The Annotated House”: Feminism and Form' in Justin Quinn (ed.), Irish Poetry After Feminism (Gerrards Cross: Colin Smythe, 2008), pp. 69-79.

Haberstroh, Patricia Boyle, The Female Figure in Eiléan Ni Chuilleanáin's Poetry (Cork: Cork University Press, 2013).

- 'Interview with Eiléan Ní Chuilleanáin', Canadian Journal of Irish Studies 20.2 (December 1994), pp. 63-74.

- 'Interview with Eiléan Ní Chuilleanáin', Irish University Review 37.I (Spring/Summer 2007), pp. 36-49.

- (ed.), My Self, My Muse: Irish Women Poets Reflect on Life and Art (Syracuse, NY: Syracuse University Press, 200I).

Halbwachs, Maurice, The Collective Memory, trans. Francis J. Ditter and Vida Yazdi Ditter (New York: Harper Colophon Books, 1980).

Heaney, Seamus, 'The Poet Who Came Back', Belfast Telegraph, November 23, I97I.

Hess, Lawrence, 'St Margaret of Cortona', The Catholic Encyclopaedia, vol. 9 (New York: Robert Appleton Company, I9IO).

Hewison, Robert, In Anger: Culture in the Cold War 1945-60 (London: Methuen, 1988).

Hipp, Shannon, “'Things of the Same Kind are Separated Only by Time”: Reading the Notebooks of Medbh McGuckian', Irish University Review 39.I (Spring/Summer 2009), pp. 130-48. 
Hirsch, Marianne, and Valerie Smith, 'Feminism and Cultural Memory: An Introduction', Signs: Journal of Women in Culture and Society 28.I (2002), pp. 3-I2.

Hobsbawm, Eric, and Terence Ranger (eds), The Invention of Tradition (Cambridge: Cambridge University Press, 1983).

Johnson, Kent, 'Poetic Comedy, September II, Truth, the Lyric, Mississippi, the Persecution of Gabe Gudding by Trent Lott Radio, the Cohabitation of Poets, and Prison Teaching: An Interview with Mairéad Byrne and Gabriel Gudding', VeRT 6, accessed February I2, 20I4, http//:epc.buffalo. edu/mags/vert/index2.html.

Johnston, Dillon, “'Hundred-Pocketed Time”: Ní Chuilleanáin's Baroque Spaces', Irish University Review 37.I (Spring/Summer 2007), pp. 53-67.

— "'Our Bodies' Eyes and Writing Hands": Secrecy and Sensuality in Ní Chuilleanáin's Baroque Art', in Anthony Bradley and Maryann Gialanella Valiulis (eds), Gender and Sexuality in Modern Ireland (Amherst, MA: University of Massachusetts Press, 1997), pp. I87-2II. Jones, Andrew, Memory and Material Culture (Cambridge: Cambridge University Press).

Kansteiner, Wulf, 'Finding Meaning in Memory: A Methodological Critique of Collective Memory Studies', History and Theory 4I.2 (December 2002), pp. I79-97.

Kant, Immanuel, 'Towards Perpetual Peace' and Other Writings on Politics, Peace and History, trans. D. L. Colclasure (New Haven, CT and London: Yale University Press, 2006).

Kearney, Richard, 'Strangers and Others: From Deconstruction to Hermeneutics', Critical Horizons 3.I (2002), pp. 7-36.

- Strangers, Gods and Monsters: Interpreting Otherness (London: Routledge, 2002).

Kelleher, Margaret, 'Commemorating the Great Irish Famine: I840s-I990s', in Oona Frawley (eds), Memory Ireland, vol. 3, The Famine and the Troubles (Syracuse, NY: Syracuse University Press, 20I4), pp. 9I-I2O.

Keller, Lynn, and Cristanne Miller (eds), Feminist Measures: Soundings in Poetry and Theory (Ann Arbor, MI: University of Michigan Press, 1994).

Kennedy-Andrews, Elmer, 'The Language of Memory: Translation, Transgression, Transcendence', in Oona Frawley (ed.), Memory Ireland, vol. 3, The Famine and the Troubles (Syracuse, NY: Syracuse University Press, 20I4), pp. 247-7I.

Kerrigan, John, 'Hidden Ireland: Eiléan Ní Chuilleanáin and Munster Poetry', Critical Quarterly 40.4 (Winter 1998), pp. 76-100.

Kilcoyne, Catherine, 'Eavan Boland and Strategic Memory', Nordic Irish Studies 6 (2007), pp. 89-IO2.

King, Russell, John Connell and Paul White (eds), Writing Across Worlds: Literature and Migration (London: Routledge, 1995). 
Kinnahan, Linda, 'An Interview with Caroline Bergvall', Contemporary Women's Writing 5:3 (November 20II), accessed May 2, 20I2, www. carolinebergvall.com/content/text/Kinnahan\%2ointerview.pdf.

Kinsella, Thomas, The Dual Tradition: An Essay on Politics and Poetry in Ireland (Manchester: Carcanet, I995).

Kirkpatrick, Kathryn, “Between Breath and No Breath”: Witnessing Class Trauma in Paula Meehan's Dharmakaya', An Sionnach: A Journal of Literature, Culture and the Arts I.2 (Fall 2005), pp. 47-64.

- 'Between Country and City: Paula Meehan's Eco-Feminist Poetics', in Christine Cusick (ed.), Out of the Earth: Eco-Critical Readings of Irish Texts (Cork: Cork University Press, 2009), pp. I08-26.

Krell, David Farrell, Of Memory, Reminiscence, and Writing: On the Verge (Bloomington, IN: Indiana University Press, 1990).

Kristeva, Julia, In the Beginning Was Love: Psychoanalysis and Faith (New York: Columbia University Press, 1987).

- 'Stabat Mater', in Toril Moi (ed.), The Kristeva Reader (London: Blackwell, 1986), pp. I6o-86.

- Strangers to Ourselves, trans. Leon S. Roudiez (New York: Columbia University Press, 199i).

LaCapra, Dominick, History in Transit: Experience, Identity, Critical Theory (Ithaca, NY and London: Cornell University Press, 2004).

- Writing History, Writing Trauma (Baltimore, MD and London: Johns Hopkins University Press, 200I) [Kindle edition].

Lachmann, Renate, 'Mnemonic and Intertextual Aspects of Literature', in Astrid Erll and Ansgar Nünning (eds), Cultural Memory Studies: An International and Interdisciplinary Handbook (New York and Berlin: Walter de Gruyter, 2008), pp. 30I-IO.

Lefebvre, Henri, The Production of Space (Oxford: Blackwell, 199I).

- State, Space, World: Selected Essays, ed. Neil Brenner and Stuart Elden, trans. Gerald Moore, Neil. Brenner and Stuart Elden (Minneapolis, MN: University of Minnesota Press, 2009).

Lenihan, Pádraig, I69o: The Battle of the Boyne (London: The History Press, 2003).

Lloyd, David, 'The Indigent Sublime: Specters of Irish Hunger', in Oona Frawley (eds), Memory Ireland, vol. 3, The Famine and the Troubles (Syracuse, NY: Syracuse University Press, 20I4), pp. I7-58.

Lorenzo-Modia, María Jesús, and Cristina Fernández-Méndez, “'Longer and Longer Sentences Prove Me Wholly Female”: Medbh McGuckian and Feminism(s)', in Manuela Palacios and Laura Lojo (eds), Writing Bonds: Irish and Galician Contemporary Women Poets (Berne: Peter Lang, 2009), pp. 33-56.

Lysaght, Patricia, 'Perspectives on Women during the Great Irish Famine', Bealoideas 64/5 (1996-7), pp. 63-130. 
McAuliffe, John, ' $X$ marks a new place for Vona Groarke, and for Irish writing', Review of $X$ by Vona Groarke, Irish Times, March 15, 2014, p. I3.

McBride, Ian, 'Memory and National Identity in Modern Ireland', in Ian McBride (ed.), History and Memory in Modern Ireland (Cambridge: Cambridge University Press, 200I), pp. I-42.

McCracken, Kathleen, 'An Attitude of Compassion: Q \& A with Medbh McGuckian', Irish Literary Supplement 9.2 (Fall 1990), pp. 20-I.

McLennan, Rob, 'I2 or 20 Questions: with Mairéad Byrne' (November 2007), accessed February I2, 20I4, http://I2or2oquestions.blogspot.ie/.

Maier, Charles, 'A Surfeit of Memory: Reflections on History, Melancholy and Denial', History and Memory 5.2 (1993), pp. 136-52.

Massey, Doreen, For Space (London: Sage, 2005).

Marangoly George, Rosemary, The Politics of Home: Postcolonial Relocations and Twentieth-century Fiction (Oakland, CA: University of California Press, 1999).

Meaney, Gerardine, (Un)like Subjects: Women, Theory, Fiction (London: Routledge, 1993).

Misztal, Barbara A., 'Memory and History', in Oona Frawley (ed.), Memory Ireland, vol. I, History and Modernity (Syracuse, NY: Syracuse University Press, 20IO), pp. 3-I7.

Mohanty, Chandra Talpade (with Biddy Martin), 'What's Home Got to Do with It?', Feminism Without Borders: Decolonising Theory, Practicing Solidarity (Durham, NC and London: Duke University Press, 2003), pp. 85-105.

Morash, Christopher, A History of the Media in Ireland (Cambridge: Cambridge University Press, 2010).

Mulhall, Anne, 'Memory, Poetry and Recovery: Paula Meehan's Transformational Aesthetics', An Sionnach: A Journal of Literature, Culture and the Arts 5.I-2 (Spring/Fall 2009), pp. I42-55.

Murphy, Shane, 'Intertextual Relations in the Poetry of Medbh McGuckian', in Patricia A. Lynch, Joachim Fischer and Brian Coates (eds), Back to the Present, Forward to the Past: Irish Writing and History Since 1798, vol. 2 (Amsterdam: Rodopi, 2006), pp. 27I-85.

- 'Obliquity in the Poetry of Paul Muldoon and Medbh McGuckian', Eire-Ireland: A Journal of Irish Studies 31.3-4 (Fall/Winter 1996), pp. 76-IOI.

— 'Roaming Root of Multiple Meanings: Intertextual Relations in Medbh McGuckian's Poetry', Metre 4 (Winter 1998), pp. 99-I09.

- 'Sonnets, Centos and Long Lines: Muldoon, Paulin, McGuckian and Carson', in Matthew Campbell (ed.), The Cambridge Companion to Contemporary Irish Poetry (Cambridge: Cambridge University Press, 2003), pp. 189-208.

— "'You Took Away My Biography": The Poetry of Medbh McGuckian', Irish University Review 28.I (Spring/Summer 1998), pp. IIO-32. 
Ní Chuilleanáin, Eiléan, 'Acts and Monuments of an Unelected Nation: The Cailleach Writes about the Renaissance', Southern Review 3I.3 (I995), pp. 570-80.

- 'In Conversation with Eileen Battersby', 'Celebrating Women's Writing', WERRC Conference, May 1999 (unpublished).

- (ed.), Irish Women: Image and Achievement (Dublin: Arlen House, 1985).

- 'Nuns: A Subject for a Woman Writer', in Patricia Boyle Haberstroh (ed.), My Self, My Muse: Irish Women Poets Reflect on Life and Art (Syracuse, NY: Syracuse University Press, 200I), p. I8-3I.

Nora, Pierre, 'Between Memory and History: Les Lieux de Mémoire', Representations 26 (Spring 1989), pp. 7-24.

Nordin, Irene Gilsenan, “'And / A Green Leaf of Language Comes Twisting Out of Her Mouth": Eiléan Ní Chuilleanáin and the Quest Theme', Irish University Review 31.2 (Autumn/Winter 200I), pp. 420-30.

— " "Betwixt and Between": The Body as Liminal Threshold in the Poetry of Eiléan Ní Chuilleanáin', in Irene Gilsenan Nordin (ed.), The Body and Desire in Contemporary Irish Poetry (Dublin: Irish Academic Press, 2006), pp. 226-43.

- Reading Eiléan Ni Chuilleanáin: A Contemporary Irish Poet (Lewiston, NY: Edwin Mellen Press, 2008).

Ó Ciosáin, Niall, 'Famine Memory and the Popular Representation of Scarcity', in Ian McBride (ed.), History and Memory in Modern Ireland (Cambridge: Cambridge University Press, 200I), pp. 95-II7.

O'Connor, Laura, 'Comhrá: Conversation between Medbh McGuckian and Nuala Ní Dhomhnaill, Southern Review 28.i (I995), pp. 58I-6I4.

O'Halloran, Eileen, and Kelli Maloy, 'An Interview with Paula Meehan', Contemporary Literature 43.I (Spring 2002), pp. I-27.

Olick, Jeffrey K., The Politics of Regret: On Collective Memory and Historical Responsibility (London: Routledge, 2007).

O'Malley, Mary, 'Between the Snow and the Huge Roses', in Patricia Boyle Haberstroh (ed.), My Self, My Muse: Irish Women Poets Reflect on Life and Art (Syracuse, NY: Syracuse University Press, 2000), pp. 34-45.

Owens Weekes, Ann, Unveiling Treasures: The Attic Guide to Published Works of Irish Women Literary Writers (Dublin: Attic Press, 1993).

Perloff, Marjorie, Radical Artifice: Writing Poetry in the Age of Media (Chicago: Chicago University Press, 1991).

Pine, Emilie, The Politics of Irish Memory: Performing Remembrance in Contemporary Irish Culture (Basingstoke: Palgrave Macmillan, 20II).

Queyras, Sina, 'A Few Words and Poems: Mairéad Byrne', Harriet, April 30, 20IO, accessed January 28, 20I4, www.poetryfoundation.org/ harriet/20Io/o4/a-few-words-and-poems-mairead-byrne/.

Quinn, Justin, 'Introduction', Metre 3 (Autumn 1997).

Ralph, David, and Lynn A. Staeheli, 'Home and Migration: Mobilities, Belongings and Identities', Geography Compass 5.7 (July 20II), pp. 517-30. 
Randolph, Jody Allen, Eavan Boland (Lewisburg, PA: Bucknell University Press; Cork: Cork University Press, 20I4).

- 'Interview with Eavan Boland', Irish University Review, 23.I (Spring/ Summer, 1993), pp. II7-30.

Ray, Kevin, 'Interview with Eiléan Ní Chuilleanáin', Eire-Ireland: A Journal of Irish Studies 3I.I-2 (Spring/Summer 1996), pp. 62-73.

Redmond, John, Poetry and Privacy: Questioning Public Interpretations of Contemporary British and Irish Poetry (Bridgend: Seren, 20I3).

Rees-Jones, Deryn, 'Motherlands and Mothertongues: Writing the Poetry of Nation', Consorting with Angels: Essays on Modern Women Poets

(Newcastle upon Tyne: Bloodaxe Books, 2005), pp. I74-2I4.

Rigney, Ann, 'Plenitude, Scarcity and the Circulation of Cultural Memory', Journal of European Studies 35.I/2 (2005), pp. 209-26.

Rorty, Richard, Contingency, Irony and Solidarity (Cambridge: Cambridge University Press, 1989).

Rossington, Michael, 'Introduction: Collective Memory', in Michael Rossington and Anne Whitehead (eds), Theories of Memory: A Reader (Edinburgh: Edinburgh University Press), pp. 134-8.

Rushdie, Salman, Imaginary Homelands: Essays and Criticism, I98I-I99I (Harmondsworth: Penguin, 1992).

Scarry, Elaine, The Body in Pain: The Making and Unmaking of the World (Oxford: Oxford University Press, 1987).

Schulte, Joachim, “'The Life of the Sign”: Wittgenstein on Reading a Poem', in John Gibson and Wolfgang Huemer (eds), The Literary Wittgenstein (London: Routledge, 2004), pp. I46-64.

Schwab, Gabriele, Haunting Legacies: Violent Histories and Transgenerational Trauma (New York: Columbia University Press, 20Io).

Schwall, Hedwig, 'How Do you Make a Teapot Intellectually Interesting? An Interview with Vona Groarke', Irish University Review 43.2 (Autumn/ Winter 2013), pp. 288-306.

Seiferle, Rebecca, 'An Interview with Mairéad Byrne', The Drunken Boat 5.3/4 (Spring/Summer 2005), accessed February 24, 20I4, www.thedrunkenboat. com/byrne.html.

Sered, Danielle, "By Escaping and [Leaving] a Mark": Authority and the Writing Subject of the Poetry of Medbh McGuckian', Irish University Review 32.2 (Autumn/Winter 2002), pp. 273-85.

Setti, Nadia, 'Migrants' Art and Writing: Figures of Precarious Hospitality', European Journal of Women's Studies I6.4 (2009), pp. 325-35.

Shils, Edward, Tradition (Chicago: Chicago University Press, 198I). Shukla, Sheobhushan, and Anu Shukla, Migrant Voices in Literatures in English (New Delhi: Sarup, 2006).

Simmons, James, 'A Literary Legpull?' Review of Venus and the Rain by Medbh McGuckian, Belfast Review, August i984, p. 27.

Somerville-Arjat, Gillean, and Rebecca E. Wilson (eds), Sleeping with 
Monsters: Conversations with Scottish and Irish Women Poets (Dublin: Wolfhound Press, 1990).

Sontag, Susan, AIDS and its Metaphors (New York: Farrar, Straus and Giroux, 1989).

- Illness as Metaphor (New York: Farrar, Straus and Giroux, 1978).

Spencer, Graham (ed.), Forgiving and Remembering in Northern Ireland: Approaches to Conflict Resolution (London: Continuum, 20II).

Steinberg, Michael P., 'Mendelssohn and Judaism', in Peter Mercer-Taylor (ed.), The Cambridge Companion to Mendelssohn (Cambridge: Cambridge University Press, 2004), pp. 26-4I.

Steiner, George, After Babel: Aspects of Language and Translation (Oxford: Oxford University Press, 1998).

Sullivan, Moynagh, 'Dreamin' My Dreams With You: Medbh McGuckian and the Theatre of Dreams', Metre I7 (Spring 2005), pp. IOo-II.

- 'The In-formal Poetics of Medbh McGuckian', Nordic Irish Studies 3 (2004), pp. 75-92.

Tarlo, Harriet, 'Provisional Pleasures: The Challenge of Contemporary Experimental Women Poets', Feminist Review 62 (Summer 1999), pp. 94-II2.

Terdiman, Richard, Present Past: Modernity and the Memory Crisis (Ithaca, NY and London: Cornell University Press, 1993).

'To the Island: Mary O’Malley in Inishmore', RTÉ Radio I documentary, produced by Lorelei Harris, I994.

Turkle, Sherry (ed.), Evocative Objects: Things We Think With (Cambridge, MA: MIT Press, 2007).

Van Alphen, Ernst, 'Symptoms of Discursivity: Experience, Memory and Trauma', in Mieke Bal, Jonathan Crewe and Leo Spitzer (eds), Acts of Memory: Cultural Recall in the Present (Hanover, NH: University Press of New England, 1999), pp. 24-38.

Wall, Eamonn, 'Tracing the Poetry of Mary O'Malley', Writing the Irish West: Ecologies and Traditions (Notre Dame, IN: University of Notre Dame Press, 20II), pp. 7I-86.

Walter, Katharina, 'The Maternal Muse in Medbh McGuckian's Poetry', in Tina-Karen Pusse and Katharina Walter (eds), Precarious Parenthood: Doing Family in Literature and Film (Vienna and London: LIT, 20I3), pp. 85-roo.

Watten, Barrett, 'The Turn to Language and the I960s', Critical Inquiry 29.I (Autumn 2002), pp. 139-83.

Whelan, Yvonne, Reinventing Modern Dublin: Streetscape, Iconography and the Politics of Identity (Dublin: UCD Press, 2003).

Whitehead, Anne, Memory (London and New York: Routledge, 2009)

[Kindle edition].

Williams, Leslie, “"The Stone Recalls its Quarry”: An Interview with Eiléan Ní Chuilleanáin', in Susan Shaw Sailer (ed.), Representing Ireland: 
Gender, Class, Nationality (Gainsville, FL: University Press of Florida, 1997), pp. 29-44.

Williams, Patrick, 'Spare that Tree!' Review of On Ballycastle Beach by Medbh McGuckian, Honest Ulsterman 86 (I989), pp. 49-52.

Wills, Clair, 'Contemporary Women's Poetry: Experimentalism and the Expressive Voice', Critical Quarterly 36.3 (September 1994), pp. 34-52.

- Improprieties: Politics and Sexuality in Northern Irish Poetry (Oxford: Oxford University Press, 1993).

- 'Voices from the Nursery: Medbh McGuckian's Plantation', in Michael Kenneally (ed.), Poetry in Contemporary Irish Literature (Gerrards Cross: Colin Smythe, 1995), pp. 373-99.

Wineburg, Sam, Historical Thinking and Other Unnatural Acts: Charting the Future of Teaching the Past (Philadelphia PA: Temple University Press, 200I). 


\section{Index}

Ahmed, Sara 83

Allen, Nicholas I36nI

Archer, Nuala I40

Assmann, Aleida 64

Bachelard, Gaston 50, 130

Bainbridge, Charles Iosni3

Bal, Mieke 3

Barcelona 80, 179-80

Barnett, Clive 32, 46ni6

Bartlett, Frederic II2

Baronian, Marie-Aude 52

Barthes, Roland 26

Batten, Guinn 8, I05n2O, II4, I27, I54

Baudelaire, Charles 222

Beckett, Samuel 49, 68

Begnal, Michael 169

Beiner, Guy 8, I2, I7n 4

Belfast 4, 6I-5, 99, I5I, I6I

Benjamin, Walter 68, 223n3

Bergvall, Caroline 171, I93n7

Berkeley, Sara IO5n7, 22I-2

'Call, The' 22I

'Carrying' 22I

'Meal for Friends' 22I

'Strawberry Thief' 22I

Strawberry Thief 22I

View from Here, The 22I-2

Berlin 70, 73

Berryman, John I5

Besser, Stephan 75ni7 bilingualism 75n23, 95, I3I-2, 139

Bishop, Elizabeth I5, 206, 222

Blakeman, Helen 153

Blau DuPlessis, Rachel I89

Boland, Eavan 3-4, 5, 8-9, IO-I2, I4, I5, I7nI3, 23-48, 68, 94, IO5n2O, IO6n37, II3, II4-I5, I46, I66ni9, I70, I83, 218

'Art of Empire' 45

'Briar Rose, The' 3I-2

'City of Shadows 43

'Colonists, The' 43

'Daughters of Colony' 43

'Fond Memory' 38

'Game, The' 34-5

'Habitable Grief, A' 4I-2

'Harbour, The' 42

In a Time of Violence I2, 33-4

'In Which the Ancient History I

Learn is Not My Own' 33-4

'I Remember' 29-30

'Irish Childhood: 195I, An' 36-7

Journey, The 29-32, 36-8, 48n 43

'Lava Cameo' I2

Lost Land, The 39-43

'Mise Eire' 48n 43

Object Lessons 17ni3, 27-8, 36, 39, 40, 43, 47n21, 47n28

Outside History 34-5

'Scar, The' 43

'Sea Change' 44

'Source, The' 30-I 
'Unheroic' 43

'Watching Old Movies As If They Were New' 40

'Witness' 42

'Woman Without a Country, A' (sequence) 44-5

Woman Without a Country, A 44-5

Bort, Eberhard 7

Bourke, Eva 6, 68-74, 74nI, 82, 218

'Amber' 7I

'Berlin Notebook' (sequence) 68-7I

'Bunkers' 69-70

'Fatherland' 69

'Graves' 69

'Kreuzberg Nuptials' 70

'Nightingale' 70-I

'Nightsinger, The' 7I

'Notes from Henry Street' 73-4

Piano 7I-4

Travels with Gandolpho 68-7I

'View of Berlin, A' 7I-2

Brearton, Fran $76 \mathrm{n}_{32}$

British Army 7, I37n20

Broom, Sarah 148

Bryce, Colette 7, 9, 79-IO7 passim

'Derry' 99

'Epilogue' 82

Full Indian Rope Trick, The 82

Heel of Bernadette, The 82

'little girl I knew when she was my mother, A' 88-9

'Re-entering the Egg' 85-6

'Riddle' 82

'Self-Portrait in the Dark (with Cigarette)' 92

Self-Portrait in the Dark 80

'Twelve' 80-I

Whole and Rain-Domed Universe, The 88-9, 99-I00

Buddhism 66, I03

Bushe, Paddy I33, I38n37

Byrne, Mairéad 5, 50, 51, 53-60, $75 \mathrm{n} 20,76 \mathrm{n} 28,2 \mathrm{I} 9$
'After Valentine's Day' 6o

Best of (What's Left of) Heaven, The 59

'Commercial Street' 58

'Cycling to Marino' 53-4

'Hive of Home, A' 59-60

'Irish Discover America, The' 56-7

Nelson and the Huruburu Bird $53-8,60$

'Pillar, The' 54-5

'Reflex' 57-8

Talk Poetry 59-60

Caruth, Cathy I2, 64

Carville, Conor 158

Catholicism 9, 64, 77n39, IO2, Io6n35, I19-22, I25-7, I28-9, I32-5, I6I

Celtic Tiger I94nI7

childhood 5, 7, II, I3, I7n4, 22-45, $48 \mathrm{n} 42,53-4,6 \mathrm{I}, 86-90,93,96-7$, 99-IO3, II8, I2O, I27, I36n4, I43-7, I60, I63, I8I, I97, I99-200, 203, 207, 219-2I, 223

city spaces 24-33 passim, 43-4, 46n5, 47n28, 54-8, 6I-4, 68, 69-74, 79, 92, 97-9, I76, I79, I80, I8I, I82-92, I94nI7, I94n23, 2I2

Claire, Paula I72, I93nII

clerical abuse I7n 4

Clutterbuck, Catriona 36, 86, I50, I97

Colman, Anne Ulry I5

Conboy, Katie 39

Conlon, James 25

Connerton, Paul I5, I3I, I37nI7

Consalvo, Deborah McWilliams I83

Cork II2, I36n4, 22I

Correggio, Antonio da 126

creative process $16,35-6,38-9,40$, 48n34, 50, 59, 62, 8I, II3-I4, I39-4I, I5O-I, I54, I56, I59-6I, I65n6, I77-8, I90-I, 204-5, 219 
Critchley, Simon 46nIs

Cubitt, Geoffrey 3

Davidson, Ian 187

Davis, Alex I83

Dawe, Gerald 6I

Deane, Seamus 8

De Angelis, Irene 76n34

De Fréine, Celia 6, 51

Derrida, Jacques II, I6n2, 26, 32, 36, 46ni6, 80

Derry 79, 99-I00

Docherty, Thomas I52, I59

Dorcey, Mary I3

Dublin 4, 5, 24, 29-3I, 37, 42-3, 53, 54-5, 75n22, 79, 97-9, II9, I25, I80, I82-92, 194

Easter Rising I9I6 8

Edkins, Jenny 99, Io5n3

Eliot, T. S. I87

Ellmann, Maud I3

Emmet, Robert I67n4I

Erll, Astrid 63, 77n37, 78

Esposito, Elena 156

experimental poetry $170-3$

Falci, Eric I40, I52, I53-4, I67n33, I7I, I72, I75

Faragó, Borbála 74ni, II8, I40, I53, I6I, I65n6

Fernández-Méndez, Cristina 139, I5I, 153

Field Day Anthology of Irish Writing, The 5, i7nio

Finch, Annie 8I

Flynn, Leontia I44, I5I, I67n29, 222-3

Drives 222-3

'Drive' 223

'Dungeness' 222

Fogarty, Anne 36

folklore 6, II-I2, I8n34, 82, IOO, II2, II7, I24, I37n28
Frawley, Oona 2, I7n4, I36n3

Freud, Sigmund 28, 83

Friel, Brian $165 \mathrm{n} 3$

Galway 4, 73

George, Rosemary Marangoly 74n6

Germany 6, 68-73, 82

Gibbons, Luke 155

Gillis, John R. II2

Gilroy, Paul 52

González-Arias, Luz Mar 97

Good Friday Agreement 77n38

Goodby, John I73

Granard, County Longford IO2-3

Great Famine I8n33-4, IO3

Grennan, Eamon I2I

Groake, Vona 5, 6, 50, I05n7, I95-217

'3' 2II

'Away' 207-8

'Beyond Me' 209-IO

'Box, The' 209

'Fate' 2II

Flight 195

'Garden as Event' 214-I5

'Garden in Hindsight' 2I4

'Garden over Time' 2I5

'Garden Sequence' 213-I5

'Ghost on the Road, The' 213

'Ghost Poem' 213

'Jetty, The' 204

'Juniper Street' 196-7

Juniper Street 196-20I

'Local Accent, The' 200-I

'Midsummer' 2II

'Orange' 208

Other People's Houses 196, 198

'Pocket Mirror, A' 2II

'Return, The' I98-9

'Some Weather' 204

'Spindrift' 202-4

Spindrift 202-10

'Stairwell, The' 208-9

'Sunday's Well' 206 
'To Smithereens' 199-200

'Trapdoor, The' 205-6

'Where She Imagines the Want of

Being Alone' 2II

'White Year, The' $2 \mathrm{I2}$

'X' 2II

$X$ 2II-I5

Grubgeld, Elizabeth I7n9

Gubbins, Martin I89

Guinness, Selina 216nI

Guinness's Brewery I80

Haberstroh, Patricia Boyle II4, I36nI5, I37n24

Halbwachs, Maurice 4, IO, 33, 78, 83, IO4nI

Hardie, Kerry I4

Hartnett, Michael 48n44

Heaney, Seamus 133

Heidegger, Martin 50

Hipp, Shannon I65n8

Hirsch, Marianne 23

history 2, 3, 6-9, I3, 16, 23, 27, 29,

33-4, 36, 38-45 passim, 47n27, 54,

$57,62-4,68-73,77 \mathrm{n} 37, \mathrm{II} 2-\mathrm{I} 3$,

79, 88, 97, IOO, IO4, IO5n3, III,

II2-I4, II6, II8-20, I23, I3I,

I33-5, I5I-4, I55, I58, I80, I93nII, I95, 199, 2I2, 2I6, 2I8, 223

Hobsbawm, Eric 8

Hoffmann, E. T. A. 69, 77n 43

home 6, 24-9 passim, 34-6, 44, 49-52, 58-60, 63, 66-7, 74n2, 74n6, 75n8, 75n9, 79-82, 87, 90, 97, I00, I13, I30, 176, I77, I96-216 passim, 220-I

Hood, Thomas 47n2I

Howe, Susan I72, I93nII

humour 56

illness I4, 94-5, I24-5, I80, 222-3

Irish Memory Studies Network 2

IRA 55, 77n38, I06n35

Italy 5, I25, I26
Japan 6, 6I-2, 65-8, 76n34

Johnson, Kent 76n25

Johnston, Dillon I27, I37n24

Joyce, James 49, 85n22, 191, I94n23, I94n73

Jones, Andrew I37ni8

Kansteiner, Wulf io

Kant, Immanuel I6n2, 26

Kavanagh, Patrick 76n28

Kearney, Richard I6n2, 80

Kelleher, Margaret I8n33

Kelly, Frances 47n2o

Kennedy-Andrews, Elmer 17n4, I65n3, I67n33

Kilcoyne, Catherine 23, 46n9, 47n22

Kinnahan, Linda $193 n 7$

Kinsella, Thomas 15, 50, 180, 194n22, I94n28, 217ng

Kirkpatrick, Kathryn I03

Krell, David Farrell I2

Kristeva, Julia 2, I6n2, 28, 82-3, I23, I60, 207

LaCapra, Dominick I2, 84

Lachmann, Renate 16

landscape $37-8,44,67-8,82,84$, $85,96-7,99$, IOO, I02, I23, I25, I40, I45, I47, I56, I73-4, I76, I87, I94 $\mathrm{nI} 7,195-6,203,205,2 \mathrm{II}, 2 \mathrm{I3}$, 2I8, 22I-2, 223

Larkin, Philip 47n2I

Lefebvre, Henri I70, I93n6

Levinas, Immanuel I6n2, 26, 27, 32, 80

literary precursors I, I3, I5, 94-5, I4I, 217ng

Lloyd, David I7n4, I8n33

London 5, 24-38, 46n5, 48n42, $77 \mathrm{n} 38,80$, Io6n35

Lorenzo-Modia, María Jesús I65n2

Lovett, Ann 102-3, IO6n39

lyric poetry 56, I69-70

Lysaght, Patricia II 
McAuliffe, John 2 IO

McBride, Ian 8

McCracken, Kathleen I66n24

McGuckian, Medbh 7

'Angel in Two Parts' I6I-2

'Albert Chain, The' I5I-2

Book of the Angel, The 159-64

Captain Lavender I5I-2

'Chamomile Lawn, The' 156

'Charcoal Angel' I64

'Chrisom Child, A' I63

'Cleaning out the Workhouse' I54-5

'Confinement' I45

'Eavesdropper' I44

'Feastday of Peace, The' I54

'Flitting, The' I45-7

Flower Master, The I42-4, I45-9

'Green Crucifix' I55

Had I a Thousand Lives I56-8

'Mazurka' I42

'Petit Bleu' I57-8

'Religion of Writing, A' 158

'River of January' 156

'Script for an Unchanging Voice' I54

'Seed-Picture, The' I47-8

Shelmalier I53-5

'Shoulder-Length, Caged-Parrot Earrings' I55

'Sitting, The' I48-9

'Sofa in the Window with Trees

Outside, The' I54

'Studies for a Running Angel' I63

'That Year' I43-4

Venus and the Rain I42, I45, I48-50

'Venus and the Rain' I5O

'Venus and the Sun' I49

McLennan, Rob 5I

MacNeice, Louis I5, 99

Magdalene Laundries I7ni6

Mahler, Gustav 90

Maier, Charles 3
Maloy, Kelli Iosn4

Massey, Doreen I7I

Meaney, Gerardine 9

Meehan, Paula I3, 78-IO7 passim, I85, 218

Child's Map of Dublin, A 97-8

'Dharmakaya' I03

Dharmakaya 86, 93, 96, I03

'Full Moon' 98-9

'Hearth' 98

'Man Sleeping' 98

Man Who Was Marked By Winter, The 86-88, IO2-3

'Night Walk' 98

" Not alone the rue in my herb garden..." 9I-2

Painting Rain 79-80, 84-5, 9I-2, 96-9

'Pattern, The' 87-8

'Remembrance of My Grandfather, Wattie, Who Taught Me to Read and Write, A' 96-7

'Return and No Blame' 86-7

'Statue of the Virgin at Granard Speaks, The' IO2-3

'Swallows and Willows' 96

'This is Not a Confessional Poem' $84-5$

media $76 \mathrm{n} 26$

memory

collective memory IO, 33, IO4nI

commemoration 8, I8ni9, 24, I45, I5O-8 passim, I64

cultural memory IO-I2

definitions of memory 3

private memory $4,5-6,16,23$,

78-107 passim, 169-70

traumatic memory I2-I4, 90-5

migration $24-38$ passim, 49-77, 79,

$80,82,103,196-9$

Miller, Cristanne i9n 46

Misztal, Barbara A. 2, I7n 4

modernization 9, 37, I29

Mohanty, Chandra Talpade 52 
Montale, Eugenio 73-4

Moore, Thomas 38

Morash, Christopher 76n26

Morrissey, Sinéad 5, 6, 7, 6I-8, 219-20

Between Here and There 6I-8

'House of Osiris in the Field of Reeds, The' 219

'Goldfish' 65-7

'Home Birth' 22I

'In Belfast' 62-3

'Matter of Life and Death, A' 220

'Night Drive in Four Metaphors' 67-8

Parallax 6I, 219-2I

There Was Fire in Vancouver 6I

'Tourism' 63-5

mothers / motherhood 87-90

Mountbatten, Lord 216n3

Mulhall, Anne Iosns

Murphy, Shane I40, I4I, I52, I65n8, music 58, 66, 69, 72-3, 77n 43, I0o, I28, I3I-2, I8I, I93nII, 2I7nI8, 222

Nelson, Horatio 54-5

New York 5, 24, 5 I

Ní Chuilleanáin, Eiléan 5, 9, I0, III-38, I4I, I80

'Angel in the Stone, The' I29-30

'Architectural Metaphor, The' I2I

Brazen Serpent, The II9-26

'Chestnut Choir, The' I28

'Cloister of Bones, The' I28-9

'Consolation' II7

'Fireman's Lift' I25-6

'Gentleman's Bedroom, A' IIs

Girl Who Married a Reindeer, The I28-32

'Gloss / Clós / Glas' I3I-2

'Hand, A Wood, A' I24-5

'In Her Other House' I3O-I

'In Her Other Ireland' I30

'Indoors' I33-4

'Informant, The' II7-I8
'Lady's Tower, The' IIs

'Litany, The' I33

'Liturgy, The' II5-I6

'Macmoransbridge' II6

Magdalene Sermon, The II5-I8

'Outdoors' I34-5

'Passing Over in Silence' I23-4

'Pastoral Life, The' I24

'Real Thing, The' I2O-I

'Saint Margaret of Cortona'

II9-20

Second Voyage, The IIs

'Secret, The' II6, I37n27

'Storm, The' I33-4

Sun Fish, The 132-3

'Sunday' I28

'That Summer' I24

'Vertigo' I35

'Witness, A' II9

Ní Dhomhnaill, Nuala 6, II

Nora, Pierre 4, 6, 33

Nordin, Irene Gilsenan I2I

Northern Ireland 7, 6I-5, 79, 99-IOO, IO6n35, I5O-3

Troubles 7, 6I-5, 79, 99-IOo, Io6n35, I37n20, I5O-7 passim, 199-200

Nünning, Ansgar 63, 77n37

Ó Bruadair, Dáibhi 48n44

Ó Ciosáin, Niall I8n34

O'Donoghue, Bernard 205, 2I7ng

Ó Gráda, Cormac I2

O’Halloran, Eileen I05n4

Olick, Jeffrey K. I, I68n52

Ó Lochlainn, Colm 2I7nı6

O’Malley, Mary II, I3, 5I, 78-IO7 passim, I25, 218

'Abandoned Child, The' Ior

'Boning Hall, The' I03-4

Boning Hall, The 89-9I, IOI, IO3-4

'Journey, The' 8I

'Ice Age, The' 90-I

Knife on the Wave, The 94-5 
'Maighdean Mhara, The' II, Ioo

'Miss Panacea Regrets' 94-5

'Otter Woman, The' Ioo

'Poem for My Birthday' 89-90

'Question of Travel, A' 8I

'Resident at Sea' 8I

'Seascape, Errislanaan' IOI

'Song of the Wise Woman' II

Valparaiso 8I

O'Sullivan, Leanne 9, 220-2

Mining Road, The 22I-2

'Townland' 22I

'Valentine' 22I

'You Were Born at Mealtime' 22I-2

pain $\mathrm{I3}-\mathrm{I4}, 4 \mathrm{I}, 83,87,90,93-5$, IO6n27, I24, I25, I57, I63, 220, 223

painting 29, I25-7, I46-9, I5I, I63, I66ni8, I66ni9

Perloff, Marjorie I70, I93n4

Pine, Emilie 2, I7n 4

Plath, Sylvia I5, 96, 222

Pratt, Minnie Bruce 66

Poetry Ireland Review 39

post-colonialism 27

Queyras, Sina 56, 59

Quinn, Justin 5

Ralph, David 75n9

Randolph, Jody Allen 45nI, 46n5, $48 \mathrm{n} 44,48 \mathrm{n} 45$

Ranger, Terence 8

Ray, Kevin I36nI4

Redmond, John 2I9nI

Rees-Jones, Deryn I4I

Renan, Ernest 8

Rich, Adrienne IO4

Rigney, Ann I7n6

Rorty, Richard 202

Rushdie, Salman 52

Russia I67n29
Saint Brendan 56-7, 76n27

Scarry, Elaine i9n 43

Schulte, Joachim I68n5I

Schwab, Gabriele Io6n23

Schwall, Hedwig 2I7nI5

Scully, Maurice I7I, I82

seascape II, 42-4 passim, 62, 76n27,

8I, IOO-I, IO4, II7, I33-4, I5I, I56, I78-9, I8I, I99, 203

Seiferle, Rebecca 56

Sered, Danielle io5n8

Setti, Nadia 74n2

Sexton, Anne 22I

Shils, Edward Io

Shaw, George Bernard i8ni9

Simmons, James I65nI

Skellig Michael I33, I38n37

Smith, Valerie 23

Somerville-Arjat, Gillean I8n23, I9n 45, I67n26, I67n28

Sontag, Susan I9n44

Spain I8I-2

Steinbeck, John 5I

Strong, Eithne I3

Sullivan, Moynagh I44

Tarlo, Harriet I83

technology 59

Terdiman, Richard 46n8, 75nig

translation 48n44, I3I, I65n3, I8o

Truth and Reconciliation

Commission 7

Turkle, Sherry 2I2

Twain, Mark 2I7n8

United Irishmen 153

United States of America 5, 50, 5I, $53,56-60,104,182$

Van Alphen, Ernst 84, 86

violence $7,14,61,63-5,79,80,93-4$, 99, IOO, IO2, II8-I9, I20, I23, I25, I37n2O, I43, I5O-7 passim, 199-200 


\section{CONTEMPORARY IRISH WOMEN POETS}

Wall, Eamonn ioo

Walsh, Catherine 5, 6, IO, I4I, I69-94, 219

City West $\mathrm{I} 82-92$

'Idir Eatortha' I75-82

'Making Tents' I73-5

Pitch I87

Walsh, Paul 63

War 30, 64, 69, 74n2, 77n37, IOI, I5I-3

Cold War 2, 46n4, 72-3

First World War 69, 99

Second World War 24, 38, 46n4, 7I-3, 2I6n3, 220

War of Independence I7n 4 I36n4
Watten, Barrett I83

Whelan, Yvonne 75n22

White, Paul 74n3

Whitehead, Anne I8ni9, I8n29

Williams, Patrick I65nI

Wills, Clair I6, 39, I48

Wilson, Rebecca E. I8n23, I9n45, I67n26, I67n28

Wineburg, Sam 47n27

Winter, Jay 2II

Woolf, Virginia I75

Wordsworth, William 2I7ng

Yeats, W. B. I5, 53-4, I54-5, 2I4, 2I7nI8 

